\title{
GEOCHEMISTRY OF GROUND WATER IN THE GULF COAST AQUIFER SYSTEMS, SOUTH-CENTRAL UNITED STATES
}

UNITED STATES GEOLOGICAL SURVEY

Water-Resources Investigations Report 96-4107

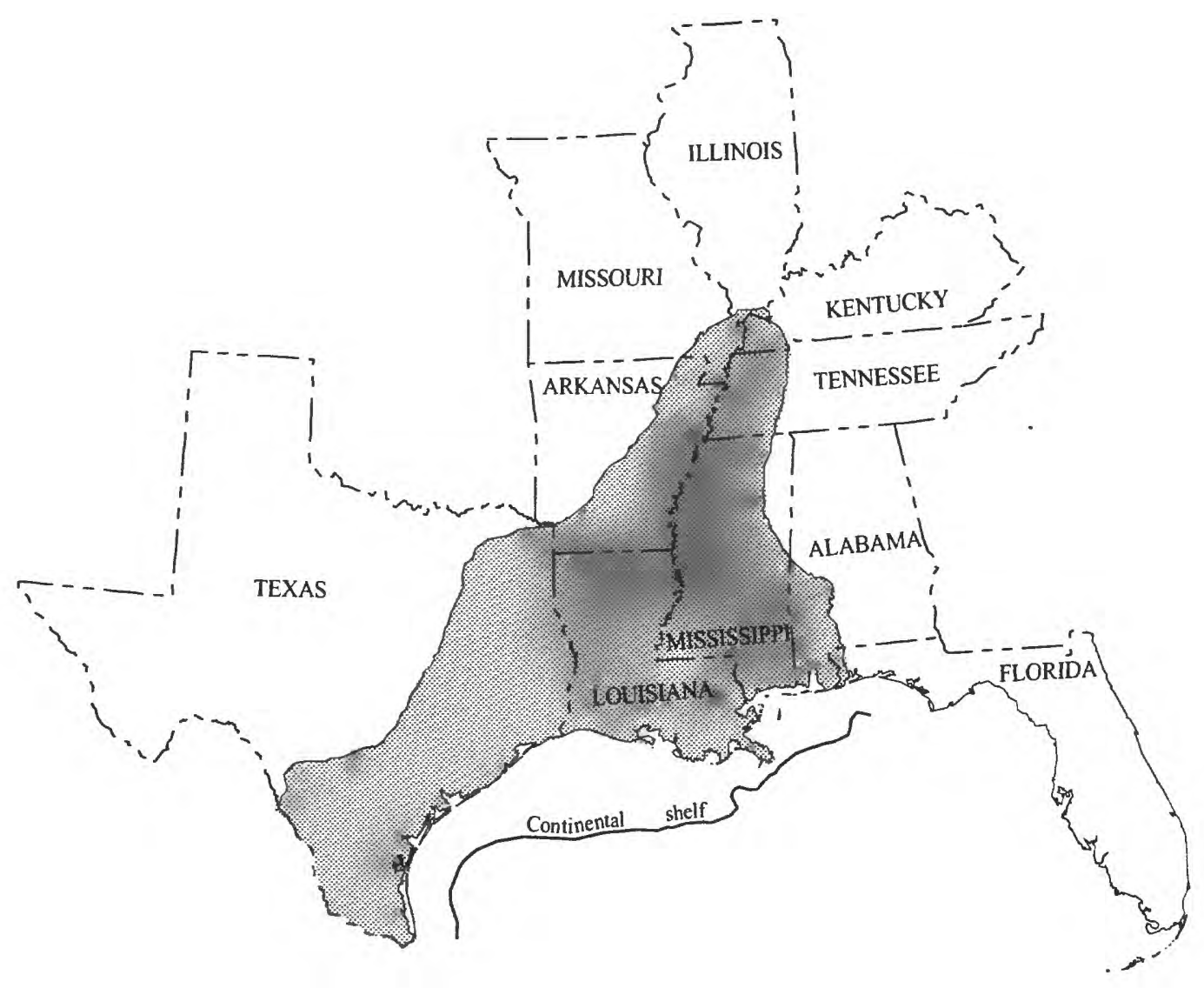




\section{GEOCHEMISTRY OF GROUND WATER IN THE GULF COAST AQUIFER SYSTEMS, SOUTH-CENTRAL UNITED STATES By Robert A. Pettijohn}

U.S. GEOLOGICAL SURVEY

Water-Resources Investigations Report 96-4107

A Contribution of the

Regional Aquifer-System Analysis

Program

Austin, Texas

1996 


\title{
U.S. DEPARTMENT OF THE INTERIOR \\ BRUCE BABBITT, Secretary
}

\author{
U.S. GEOLOGICAL SURVEY \\ Gordon P. Eaton, Director
}

\begin{abstract}
Any use of trade, product, or firm names in this publication is for descriptive purposes only and does not imply endorsement by the U.S. Government
\end{abstract}

For additional information write to:

District Chief U.S. Geological Survey, WRD 8011 Cameron Road Austin, Texas 78754
Copies of this report can be purchased from:

U.S. Geological Survey Branch of Information Services Federal Center

Box 25286

Denver, CO 80225-0286 


\section{CONTENTS}

Introduction

Purpose and scope

Previous hydrologic studies

Approach to study

Physiography.

Geohydrology

Chemical processes and mechanisms

Chemical character of ground water

Mississippi River Valley alluvial aquifer and permeable zone A

(Holocene-upper Pleistocene deposits)

Dissolved-solids concentrations

Primary water types

Ground-water chemistry within subareas

Correlation among chemical constituents and properties of ground water within subareas...............

Alluvial aquifer

Permeable zone A

Relation of ground-water chemistry to chemical and physical processes.

Alluvial aquifer

Permeable zone A

Permeable zone B (lower Pleistocene-upper Pliocene deposits)

Dissolved-solids concentrations.

Primary water types

Ground-water chemistry within subareas

Correlation among chemical constituents and properties of ground water within subareas....

Relation of ground-water chemistry to chemical and physical processes

Permeable zone C (lower Pliocene-upper Miocene deposits

Dissolved-solids concentrations.

Primary water types

Ground-water chemistry within subareas

Correlation among chemical constituents and properties of ground water within subareas............

Relation of ground-water chemistry to chemical and physical processes

Permeable zone D (middle Miocene deposits)

Dissolved-solids concentrations.

Primary water types

Ground-water chemistry within subareas

Correlation among chemical constituents and properties of ground water within subareas.......

Relation of ground-water chemistry to chemical and physical processes

Permeable zone E (lower Miocene-upper Oligocene deposits)

Dissolved-solids concentrations

Primary water types

Ground-water chemistry within subareas

Correlation among chemical constituents and properties of ground water within subareas.......

Relation of ground-water chemistry to chemical and physical processes

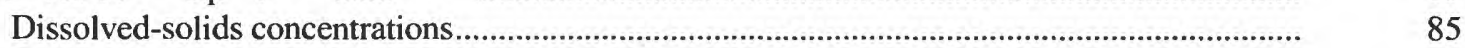

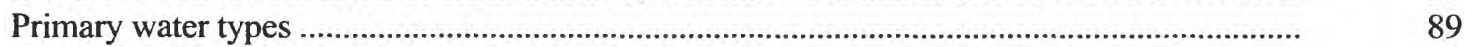

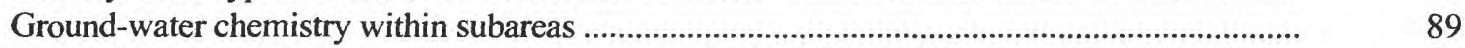

Correlation among chemical constituents and properties of ground water within subareas....... $\quad 93$

Relation of ground-water chemistry to chemical and physical processes.................................... 


\section{CONTENTS--Continued}

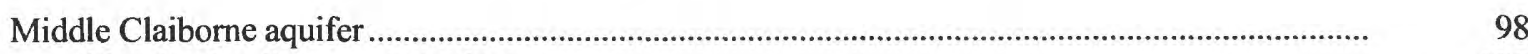

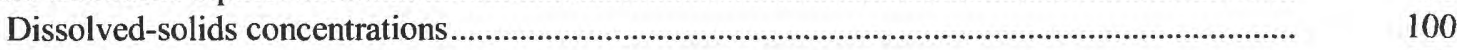

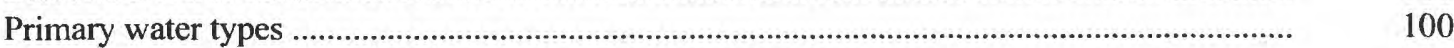

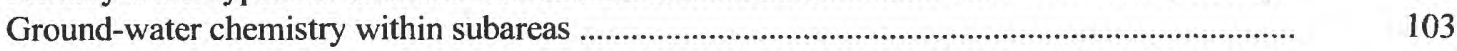

Correlation among chemical constituents and properties of ground water within subareas....... $\quad 103$

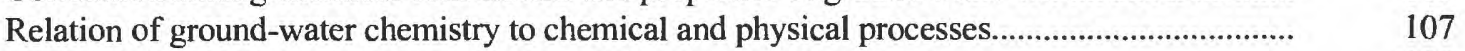

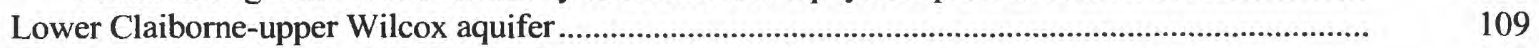

Dissolved-solids concentrations............................................................................................ $\quad 110$

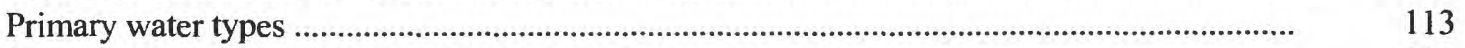

Ground-water chemistry within subareas ................................................................................. 113

Correlation among chemical constituents and properties of ground-water within subareas ...... $\quad 116$

Relation of ground-water chemistry to chemical and physical processes.................................... 117

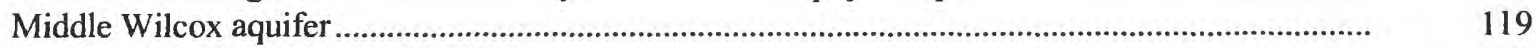

Dissolved-solids concentrations.............................................................................................. $\quad 119$

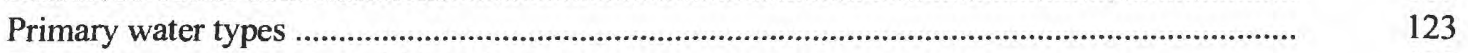

Ground-water chemistry within subareas ........................................................................... 123

Correlation among chemical constituents and properties of ground water within subareas....... $\quad 126$

Relation of ground-water chemistry to chemical and physical processes........................................ 128

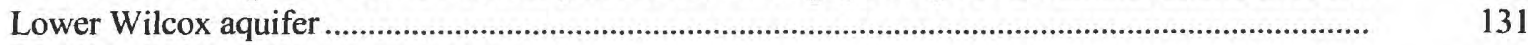

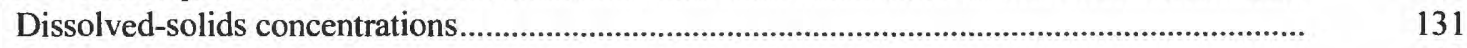

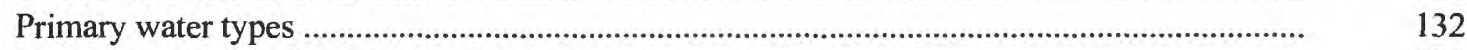

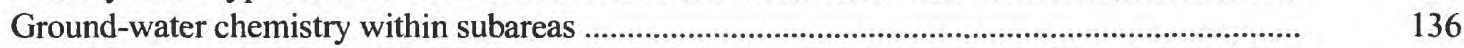

Correlation among chemical constituents and properties of ground-water within subareas ....... 136

Relation of ground-water chemistry to chemical and physical processes.................................... 138

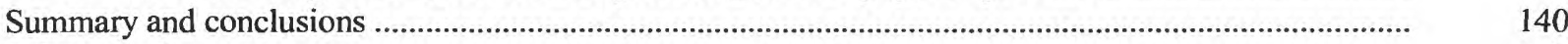

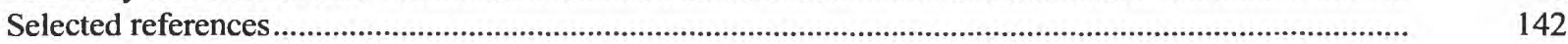

\section{ILLUSTRATIONS}

Figures 1-13.

1.Map showing location of Gulf Coast Regional Aquifer-System Analysis study area and adjacent

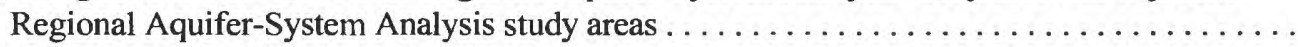

2. Schematic diagram showing the order of study of chemistry of water in the gulf coast aquifer systems

3.Diagrammatic section from northern edge of study area to edge of Continental Shelf

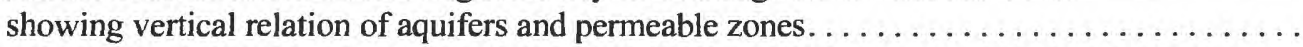

4-7. Maps of permeable zone A (Holocene-upper Pleistocene deposits) and the Mississippi River

Valley alluvial aquifer showing:

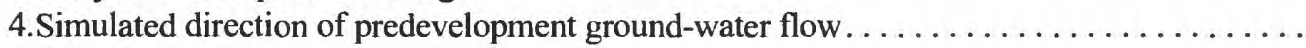

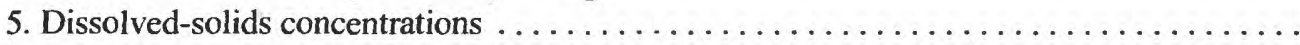

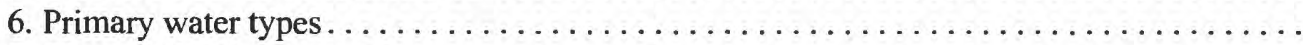

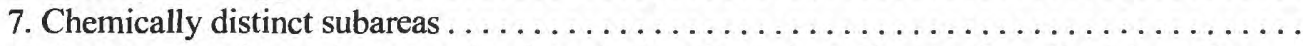

8. Diagram showing the change in water chemistry in the Mississippi River Valley alluvial aquifer

from subarea to subarea based on three representative samples. ................. 25

9. Diagram showing the change in water chemistry in permeable zone A (Holocene-upper

Pleistocene deposits) from subarea to subarea based on three representative samples....... $\quad 26$

10-13. Maps of permeable zone B (lower Pleistocene-upper Pliocene deposits) showing:

10. Simulated direction of predevelopment ground-water flow $\ldots \ldots \ldots \ldots \ldots \ldots \ldots$

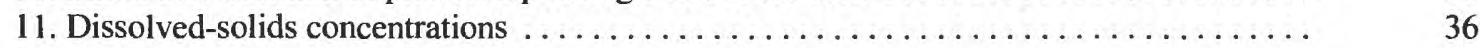

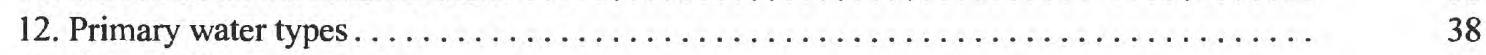

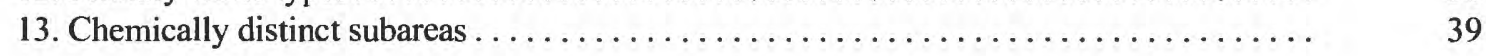




\section{ILLUSTRATIONS--Continued}

Figures 14-49.

14. Diagram showing the change in water chemistry in permeable zone B (lower Pleistocene-

upper Pliocene deposits) from subarea to subarea based on three representative samples....

15-18. Maps of permeable zone C (lower Pliocene-upper Miocene deposits) showing:

15. Simulated direction of predevelopment ground-water flow $\ldots \ldots \ldots \ldots \ldots \ldots \ldots$

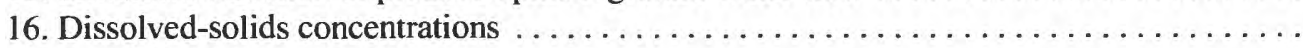

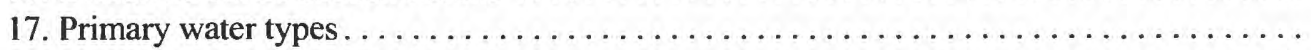

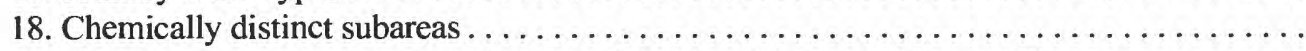

19. Diagram showing the change in water chemistry in permeable zone $C$ (lower Pliocene-

upper Miocene deposits) from subarea to subarea based on three representative samples.....

20-23. Maps of permeable zone D (middle Miocene deposits) showing:

20. Simulated direction of predevelopment ground-water flow $\ldots \ldots \ldots \ldots \ldots \ldots \ldots \ldots$

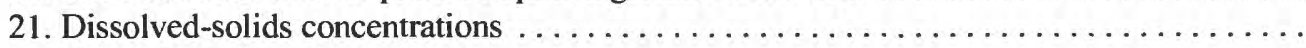

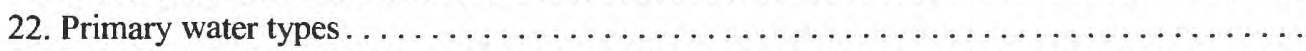

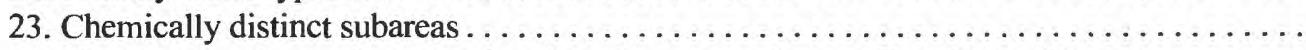

24. Diagram showing the change in water chemistry in permeable zone $\mathrm{D}$ (middle Miocene deposits) from subarea to subarea based on three representative samples .............

25-28. Maps of permeable zone E (lower Miocene-upper Oligocene deposits) showing:

25 . Simulated direction of predevelopment ground-water flow $\ldots \ldots \ldots \ldots \ldots \ldots \ldots$

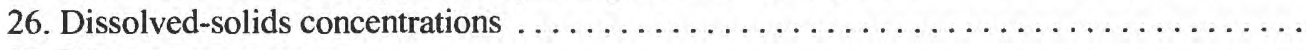

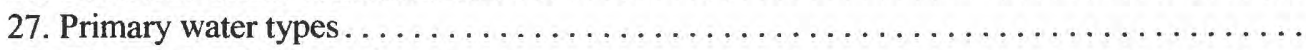

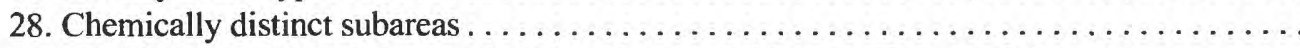

29. Diagram showing the change in water chemistry in permeable zone E (lower Mioceneupper Oligocene deposits) from subarea to subarea based on three representative samples. ...

30-33. Maps of the upper Claiborne aquifer showing:

30. Simulated direction of predevelopment ground-water flow $\ldots \ldots \ldots \ldots \ldots \ldots \ldots$

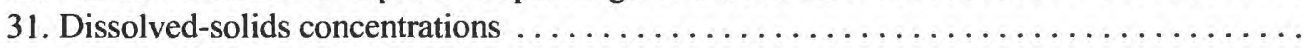

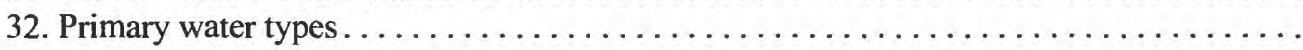

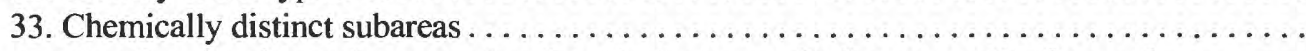

34. Diagram showing the change in water chemistry in the upper Claiborne aquifer from subarea

to subarea based on three representative samples . . . . . . . . . . . . . . . . . . . .

35-38. Maps of the middle Claiborne aquifer showing:

35. Simulated direction of predevelopment ground-water flow $\ldots \ldots \ldots \ldots \ldots \ldots \ldots$

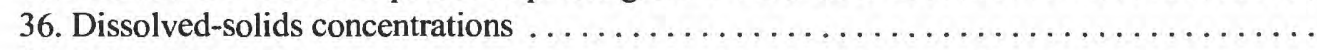

37. Primary water types. . . . . . . . . . . . . . . . . . . . . . . . . . .

38. Chemically distinct subareas . . . . . . . . . . . . . . . . . . . . . . .

39. Diagram showing the change in water chemistry in the middle Claiborne aquifer from subarea to subarea based on three representative samples . . . . . . . . . . . . . . . . . .

40-43. Maps of the lower Claiborne-upper Wilcox aquifer showing:

40. Simulated direction of predevelopment ground-water flow $\ldots \ldots \ldots \ldots \ldots \ldots \ldots$

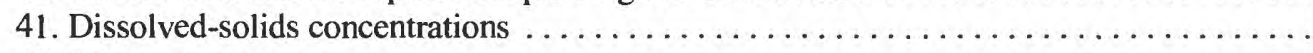

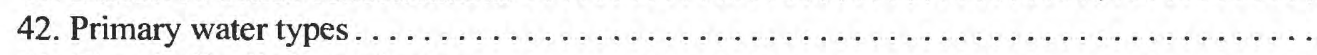

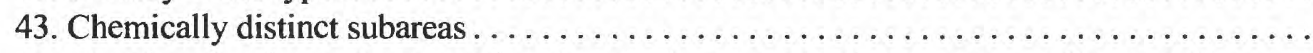

44. Diagram showing the change in water chemistry in the lower Claiborne-upper Wilcox aquifer

from subarea to subarea based on three representative samples . . . . . . . . . . . . . .

45-48. Maps of the middle Wilcox aquifer showing:

45. Simulated direction of predevelopment ground-water flow $\ldots \ldots \ldots \ldots \ldots \ldots \ldots$

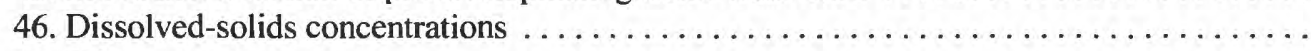

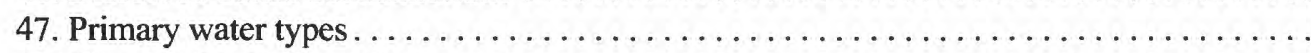

48. Chemically distinct subareas . . . . . . . . . . . . . . . . . . . . . .

49. Diagram showing the change in water chemistry in the middle Wilcox aquifer from subarea

to subarea based on three representative samples $\ldots \ldots \ldots \ldots \ldots \ldots \ldots \ldots \ldots \ldots \ldots \ldots$ 


\section{ILLUSTRATIONS--Continued}

Figures 50-54.

50-53. Maps of the lower Wilcox aquifer showing:

50. Simulated direction of predevelopment ground-water flow $\ldots \ldots \ldots \ldots \ldots \ldots \ldots$

51. Dissolved-solids concentrations . . . . . . . . . . . . . . . . . . . . . .

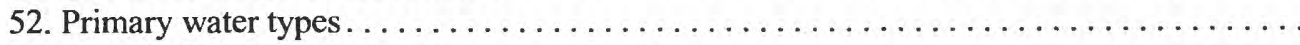

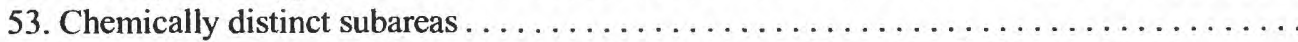

54.Diagram showing the change in water chemistry in the lower Wilcox aquifer from subarea

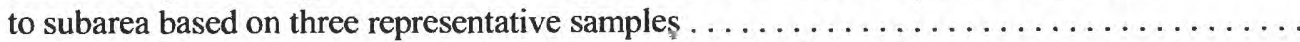

\section{TABLES}

TABLE 1. Variation in concentration of chemical constituents of ground water attributed to

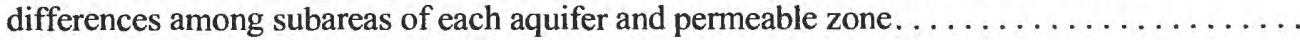

2. Geologic units and geohydrologic units of the gulf coast aquifer systems. . . . . . . . . . . .

3. Estimates of hydraulic conductivity by aquifer or permeable zone in the gulf coast aquifer systems .

4. Probable mechanisms and chemical processes in the gulf coast aquifer systems and their effect

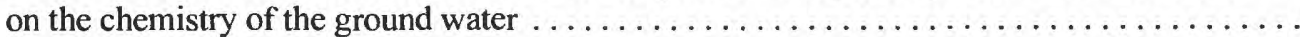

5. Median value of selected chemical constituents and properties of water, median sampling depth, water types, and number of analyses for each subarea of the Mississippi River Valley alluvial aquifer and permeable zone A (Holocene- upper Pleistocene deposits) ..........

6. Factor loading and percent communalities for water chemistry in each subarea of the Mississippi River Valley alluvial aquifer . . . . . . . . . . . . . . . . . . .

7. Factor loading and percent communalities for water chemistry in each subarea of permeable zone A (Holocene-upper Pleistocene deposits) . . . . . . . . . . . . . . . . . .

8. Median value of selected chemical constituents and properties of water, median sampling depth, water types, and number of analyses for each subarea of permeable zone B (lower

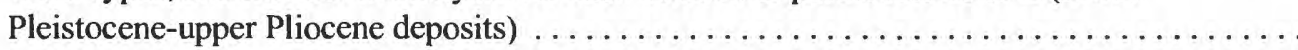

9. Factor loading and percent communalities for water chemistry in each subarea of permeable zone B (lower Pleistocene-upper Pliocene deposits) . . . . . . . . . . . . . . . .

10. Median value of selected chemical constituents and properties of water, median sampling depth, water types, and number of analyses for each subarea of permeable zone $\mathrm{C}$

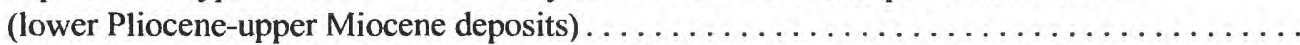

11. Factor loading and percent communalities for water chemistry in each subarea of permeable zone $\mathrm{C}$ (lower Pliocene-upper Miocene deposits) . . . . . . . . . . . . . .

12. Median value of selected chemical constituents and properties of water, median sampling depth, water types, and number of analyses for each subarea of permeable zone D

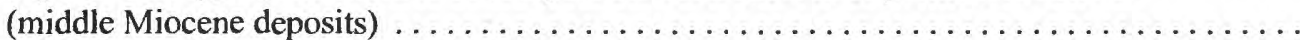

13. Factor loading and percent communalities for water chemistry in each subarea of

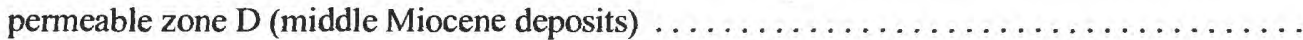

14. Median value of selected chemical constituents and properties of water, median sampling depth, water types, and number of analyses for each subarea of permeable zone $E$ (lower

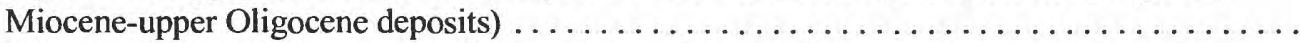

15. Factor loading and percent communalities for water chemistry in each subarea of permeable zone E (lower Miocene-upper Oligocene deposits). . . . . . . . . . . . . . . . .

16. Median value of selected chemical constituents and properties of water, median sampling depth, water types, and number of analyses for each subarea of the upper Claiborne aquifer.

17. Factor loading and percent communalities for water chemistry in each subarea of the upper Claiborne aquifer . 
18. Median value of selected chemical constituents and propertiesof water, median sampling depth, water types, and number of analyses for each subarea of the middle Claiborne

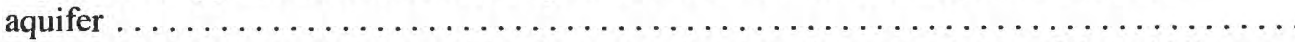

19. Factor loading and percent communalities for water chemistry in each subarea of the middle

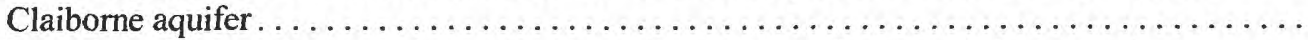

20. Median value of selected chemical constituents and properties of water, median sampling depth, water types, and number of analyses for each subarea of the lower Claiborneupper Wilcox aquifer.

21. Factor loading and percent communalities for water chemistry in each subarea of the lower Claiborne-upper Wilcox aquifer . . . . . . . . . . . . . . . . . . . .

22. Median value of selected chemical constituents and properties of water, median sampling depth, water types, and number of analyses for each subarea of the middle Wilcox aquifer ...

23. Factor loading and percent communalities for water chemistry in each subarea of the middle

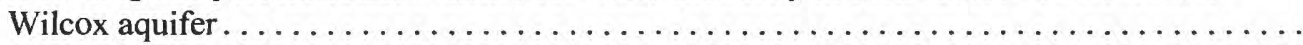

24. Median value of selected chemical constituents and properties of water, median sampling depth, water types, and number of analyses for each subarea of the lower Wilcox aquifer....

25. Factor loading and percent communalities for water chemistry in subarea 1 of the lower

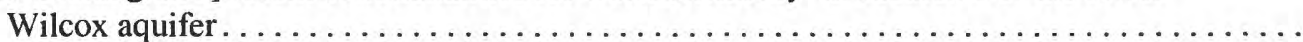

26. Analysis of water from each subarea of an aquifer or permeable zone in the gulf coast

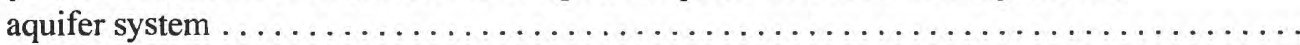

\section{CONVERSION FACTORS, VERTICAL DATUM, AND ABBREVIATED WATER-QUALITY UNITS}

\begin{tabular}{ccl}
\hline Multiply & By & To obtain \\
\hline $\begin{array}{c}\text { foot (ft) } \\
\text { foot per day (ft/d) }\end{array}$ & 0.3048 & meter \\
mile (mi) & 1.609 & meter per day \\
$\begin{array}{c}\text { square mile (mi }{ }^{2} \text { ) } \\
\text { billion gallons } \\
\text { per day (Ggal/d) }\end{array}$ & 2.590 & square kilometer \\
\end{tabular}

Sea level: In this report, "sea level" refers to the National Geodetic Vertical Datum of 1929--a geodetic datum derived from a general adjustment of the first-order level nets of the United States and Canada, formerly called Sea Level Datum of 1929. Chemical concentration in water is expressed in milligrams per liter $(\mathrm{mg} / \mathrm{L})$ or micrograms per liter (ug/L). Cation exchange capacity is expressed as milliequivalents per liter (meq/L).

Water temperature is given in degree Celsius $\left({ }^{\circ} \mathrm{C}\right)$, which can be converted to degrees Fahrenheit $\left({ }^{\circ} \mathrm{F}\right)$ by the following equation: ${ }^{\circ} \mathrm{F}=1.8\left({ }^{\circ} \mathrm{C}\right)+32$ 


\title{
GEOCHEMISTRY OF GROUND WATER IN THE GULF COAST AQUIFER SYSTEMS, SOUTH CENTRAL UNITED STATES
}

\author{
By ROBERT A. PETTIJOHN
}

\begin{abstract}
The ground-water chemistry of the aquifers and permeable zones composing the gulf coast aquifer systems in south-central United States is characterized and the geochemical and hydrologic processes are postulated using water-chemistry data consisting of 95,600 chemical analyses from both the freshwater and salt-water part of the study area that comprises 290,000 square miles. The gulf coast aquifer systems, which have been divided into six aquifers and five permeable zones, are composed of sediments of both marine and nonmarine origin that were deposited during Tertiary and Quaternary time, creating vast layers of sand and clay. The minerals contained in the sand and clay layers react with moving ground water to produce a water chemistry that is characterized by the concentration of dissolved solids and the primary water types. The concentration of dissolved solids is based on the median value of all samples from each 100-square-mile area. Primary water type is based on the most frequently observed type (mode) in each 100-square-mile area.
\end{abstract}

The median concentration of dissolved solids generally is less than $500 \mathrm{mg} / \mathrm{L}$ in water from the outcrop and subcrop areas of all the aquifers and permeable zones and from most of the alluvial aquifer that is part of the uppermost aquifer and permeable zone. Areas with ground water having median concentrations of dissolved solids of 500 to $1,000 \mathrm{mg} / \mathrm{L}$ are in bands parallel to and generally downdip from the outcrop. These bands vary in width from several miles to several hundred miles. Downdip from the 500 to $1,000 \mathrm{mg} / \mathrm{L}$ band are transition zones where the median concentration of dissolved solids increases $1,000 \mathrm{mg} / \mathrm{L}$ in a short distance. These transition zones, which are narrow areas parallel to and downdip from the outcrop, show changes in water chemistry from slightly saline to saline and from saline to brine. Moving downdip in the aquifer or permeable zone from these transition zones, the concentration of dissolved solids increases to more than $150,000 \mathrm{mg} / \mathrm{L}$ at the downdip limit.

The primary water type varies from a fresh calcium-sodium-bicarbonate type along the outcrop and in areas of less than $1,000 \mathrm{mg} / \mathrm{L}$ median concentration of dissolved solids to a saline sodium-bicarbonate-chloride type in areas of 1,000 to $10,000 \mathrm{mg} / \mathrm{L}$ median concentration. Further downdip the water type changes to sodium-chloride type brine as the concentration of dissolved solids increases to $150,000 \mathrm{mg} / \mathrm{L}$ or more.

The major geochemical and hydrologic processes postulated to be controlling the chemistry of the ground water from updip (subareas 1) to downdip (subareas 5) in most aquifers or permeable zones are: in subareas 1, alteration of silicate minerals and leaching of soluble salts from the unsaturated zone; in subareas 2, upward leakage of water from underlying deposits and alteration of silicate minerals; in subareas 3, upward leakage of water from underlying deposits and some dissolution of evaporite minerals and alteration of silicate minerals; and in subareas 4 and 5 , dissolution of evaporite minerals in salt domes and caprock and some upward leakage. Other processes affecting the chemistry of the ground water are exchange reactions, oxidation-reduction reactions, precipitation of minerals, and alteration of secondary minerals.

\section{INTRODUCTION}

The Gulf Coast Regional Aquifer System Analysis (Gulf Coast RASA) is one of many hydrologic investigations conducted under the U.S. Geological Survey's Regional Aquifer-System Analysis Program. The overall objective of the program is to assemble hydrologic information and create predictive capabilities necessary for effective management of the Nation's ground water on a regional scale (Bennett, 1979). 
The Gulf Coast RASA study area encompasses most of the Gulf Coastal Plain and extends from the Rio Grande on the southwest to the Ohio River on the northeast and the Escambia River in Florida on the southeast. The study area covers about $230,000 \mathrm{mi}^{2}$ onshore in parts of Alabama, Arkansas, Florida, Illinois, Kentucky, Mississippi, Missouri, Tennessee, Texas, and all of Louisiana (Grubb, 1984). The study area also includes about $60,000 \mathrm{mi}^{2}$ on the Continental Shelf (fig. 1).

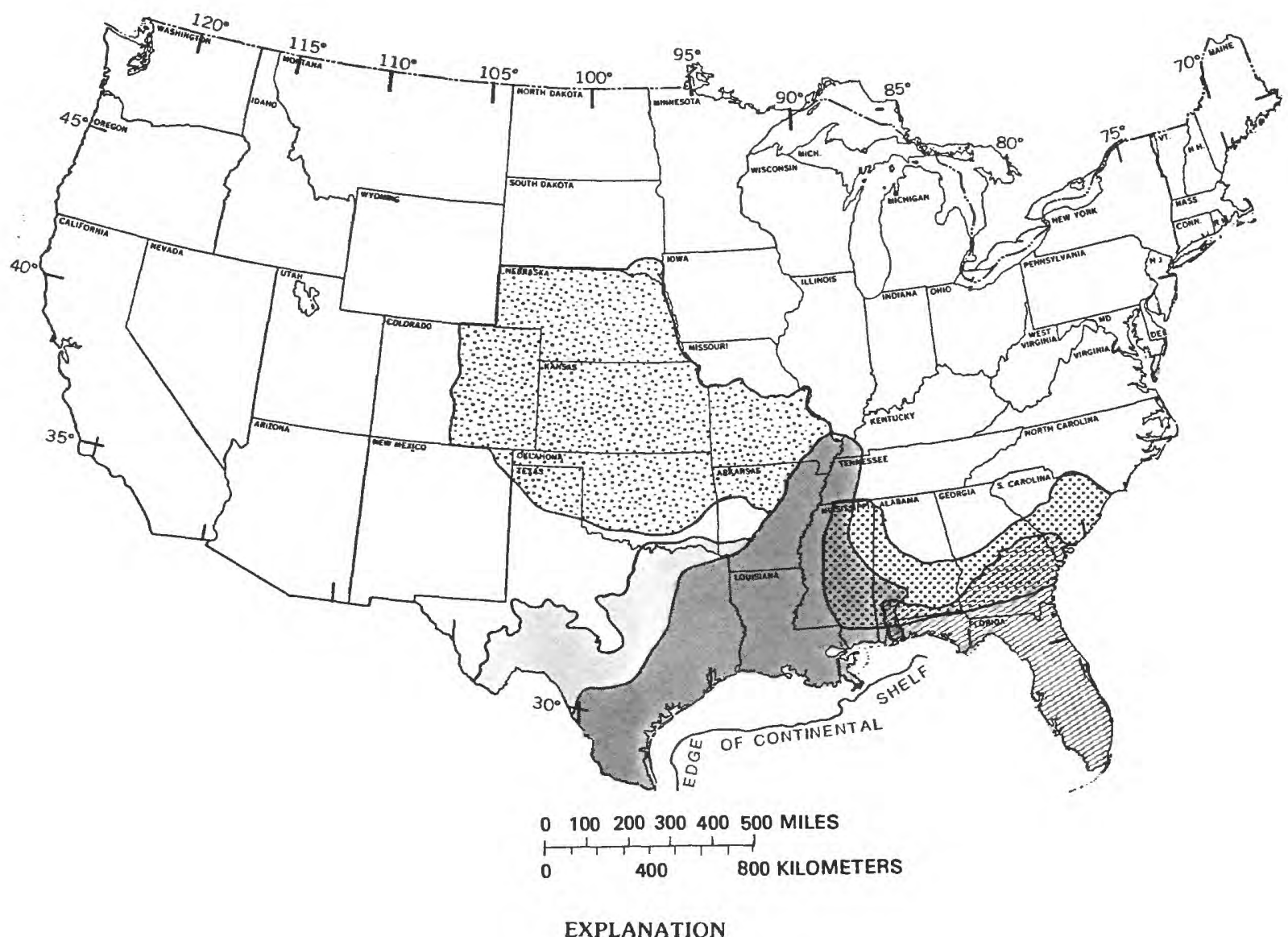

REGIONAL AQUIFER-SYSTEM ANALYSIS (RASA) STUDY AREAS

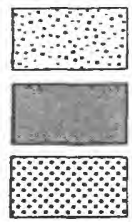

CENTRAL MIDWEST

GULF COAST

SOUTHEASTERN COASTAL PLAIN
FLORIDAN AQUIFER SYSTEM

EDWARDS-TRINITY AQUIFER SYSTEM

Figure 1.--Location of Gulf Coast Regional Aquifer-System Analysis study area and adjacent Regional Aquifer-System Analysis study areas.

The economy of the area is dependent on agriculture, development of energy supplies, industrial production, and trading centers. These enterprises, which are important to the overall economy of the United States, require large volumes of good-quality water. The following section discusses the increasing use of ground water in the study area and compares that increase with that of the continental United States. 
Water withdrawn from ground-water supplies in the United States increased from an estimated $50 \mathrm{Ggal} / \mathrm{d}$ in 1960 (Murray and Reeves, 1977) to an estimated $89 \mathrm{Ggal} / \mathrm{d}$ in 1980 (Solley and others, 1983). During the same period water withdrawn from ground-water supplies in the Gulf Coast RASA study area increased from an estimated $3.8 \mathrm{Ggal} / \mathrm{d}$ in 1960 to an estimated $9.5 \mathrm{Ggal} / \mathrm{d}$ in 1980 (Mesko and others, 1990). These estimates indicate that water withdrawn from ground-water supplies in the United States increased 78 percent between 1960 and 1980; however, during the same period water withdrawn from ground-water supplies in the Gulf Coast RASA study area increased 168 percent. These figures further indicate that the use of ground water is increasing at a greater rate in the gulf coast study area than the national average rate. Consequently, it is important to know not only where the largest ground-water supplies are located in the gulf coast area but also the quality of the water, because 98.8 percent of the ground water used is freshwater (Solley and others, 1983).

\section{PURPOSE AND SCOPE}

This report describes the chemistry of the water in six aquifers and five permeable zones (Grubb, 1987, p. 105) composing the gulf coast aquifer systems. The objectives of the report are to show for each of the aquifers or permeable zones the following: (1) The distribution of dissolved-solids concentrations and water types, (2) the distribution of ground-water subareas that have different geochemical attributes, (3) the change in water chemistry from subarea to subarea using trilinear diagrams, and (4) the correlations among major constituents that characterize ground-water chemistry and to relate that information to water origin, flow patterns, and probable chemical processes active in each subarea.

Data used are from analyses of ground water in the study area and were obtained from the water-quality files of the U.S. Geological Survey's National Water Data Storage and Retrieval System (WATSTORE); the brine tape file, compiled by Taylor (1975) from data supplied by the petroleum industry; and the Texas tape file, compiled by the Texas Department of Water Resources (TDWR).

Companion reports (Hosman and Weiss, 1991; Weiss, 1992; Williamson and others, 1990) present the geohydrologic framework and the ground-water flow patterns within the aquifer systems. This report can be used in conjunction with these and the 12 reports on water quality from the Gulf Coast RASA (listed in the "Selected References" section of this report) to better understand the quantity and quality of water available from the gulf coast aquifer systems.

\section{PREVIOUS HYDROLOGIC STUDIES}

Previous investigations of the chemistry of ground water in the Gulf Coastal Plain area generally have been made on a county basis. Results from most of these investigations are presented in county reports in conjunction with results from the study of ground-water quantity and availability. Although reports from county studies provide a wealth of information, they lack the continuity across political boundaries that is needed by planners as they anticipate increased withdrawals of ground water and the effect of those withdrawals on the quantity and quality of the water resource.

Investigations that are regional in scope have been made in recent years. Those that include water quality are the "Summary appraisals of the Nation's ground-water resources" series (Baker and Wall, 1976; Bedinger and Sniegocki, 1976; Zurawski, 1978; Cederstrom and others, 1979; Terry and others, 1979). This series includes reports on five water-resources regions that are all or partly in the Gulf Coastal Plain. Other regional investigations that contain information on water quality are the Mississippi Embayment studies (Hosman and others, 1968; Boswell and others, 1968; Cushing and others, 1970), the gulf-coast studies (Payne, 1968, 1970, 1972, and 1975), and the Lower Mississippi Region Comprehensive study (Mississippi River Commission, 1974). 


\section{APPROACH TO STUDY}

Considering that the gulf coast aquifer systems contain numerous types of strata arranged in an almost limitless variety of geometric configurations, it is reasonable to expect that in many areas the ground-water chemistry shows spatial patterns that are difficult to interpret, even where good stratigraphic and hydraulic-head information is available. It is because of this complex system, the limited type and distribution of chemical data, and the near absence of solid phase data that the particular graphical and statistical methods were selected to analyze and interpret the waterchemistry data in this study.

Because of the size of the study area--290,000 $\mathrm{mi}^{2}$--and the large amount of data--95,600 chemical analyses--it was necessary to rely primarily on the digital computer and associated software to process and synthesize the data. Statistical software programs were the analytical tools used to make maps, graphical representations, and statistical tables and to interpret the data used in postulating the most important chemical processes.

The procedure for processing the 95,600 chemical analyses of ground-water samples is described by Pettijohn (1986). The computer programs used to calculate various statistics and to make summary tables are from P-STAT Inc. (1985). The computer programs used to plot data points and post and contour data values onto maps are from Surface II Graphic System (Sampson, 1978, 1988). The computer program used in compiling the trilinear diagrams was obtained from the Kansas District, Water Resources Division (WRD), U.S. Geological Survey (R.B. Leonard, written commun., 1985).

The order of study of the chemistry of water in the gulf coast aquifer systems (fig. 2) was as follows:

1. A large data base of water analyses containing physical and chemical properties of water and concentrations of dissolved constituents was obtained from the U.S. Geological Survey's water-quality and brine file, and the Texas Department of Water Resources' data base (Pettijohn, 1986). Outliers were noted during the mapping of dissolved-solids concentration, and data anomalies that could not be explained were deleted from the map and data base. Although well depths reached $20,000 \mathrm{ft}$ in the gulf coast aquifer systems, 80 percent of these analyses are of water samples from wells constructed at depths of less than $1,100 \mathrm{ft}$.

2. Maps were prepared showing the distribution of dissolved-solids concentrations based on median values of all samples in each 100-square-mile area (Pettijohn and others, 1988) and primary water types based on the most frequently observed type (mode) in each 100-square-mile area for each aquifer and permeable zone. The median and mode values per 100-square-mile area were selected due to the variability in dissolved-solids concentration and the high density of point data within small areas. Because of the small amount of data from water analyses in downdip areas where the dissolved-solids concentrations exceeded $10,000 \mathrm{mg} / \mathrm{L}$, it was necessary to compute dissolved solids from electric logs. A discussion of the method was presented by Weiss (1987).

The concentrations of dissolved solids, major ions, $\mathrm{pH}$, and temperature vary with depth within aquifers and permeable zones. Point values can be smaller or larger than the values shown on the map, depending on whether the point is at the top or bottom of the aquifer or permeable zone. Thus some of the variability in data shown in this report may be due to a difference in depths from which water samples were collected. However, it is believed that regional trends are correctly portrayed.

The primary water type was computed from the cation and the anion that composed the largest percentage of milliequivalents per liter of the dissolved solids in a ground-water sample. The secondary water type was computed from the cation and anion that composed the second largest percentage. Although water types were computed for each sampling site, only the most frequently observed water types in each 100-square-mile area are shown in the table and on the map for each aquifer and permeable zone. More detailed discussions of how the data were analyzed, processed, and mapped are given by Pettijohn $(1986,1988)$, Weiss (1987), and Pettijohn and others (1988). Maps showing direction of predevelopment ground-water flow and leakage were obtained from ground-water flow maps from the Gulf Coast RASA similar to those in Williamson (in press). 
Water Chemistry Files

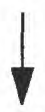

Compile and Process Selected Water-Chemistry Data

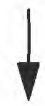

Construct Dissolved-Solids Concentration and Water Type Maps

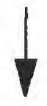

Compile List of Probable Chemical Processes and Mechanisms Occurring in Study Area

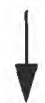

Divide Aquifers and Permeable Zones into Subareas based on Mapped Chemical, Hydrologic, and Geomorphic Data

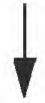

Test Relatedness of Data Within and Between Subareas by Linear Discriminant-Function Analysis<smiles>[C+]1CC1</smiles>

Compile Median or Mode Values for Selected Parameters by Subarea

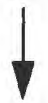

Determine Water Type in each Subarea by Trilinear-Diagram Analysis<smiles>C[13CH3]</smiles>

Postulate Chemical Processes and Mechanisms Occurring in each Subarea by Factor Analysis<smiles>[3H][13CH3]</smiles>

Select Most Likely Chemical Processes or Mechanisms Occurring in each Subarea on basis of Mapped Data, Statistical Analysis, and Published Information

Figure 2.--The order of study of chemistry of water in the gulf coast aquifer systems.

3. Each aquifer and permeable zone was initially divided into chemically distinct subareas based on maps showing delimited areas of median dissolved-solids concentration. Five ranges, each range including one or more delimited areas of dissolved-solids concentrations, were selected, resulting in five subareas. The subareas were numbered sequentially from one to five, with one having the smallest concentration of dissolved solids and five having the largest concentration of dissolved solids. The boundaries of the subareas were modified from maps of primary water type, potentiometric surfaces, distribution of selected constituents, or geomorphic units if the respective mapped data were shown to increase the uniqueness of the chemical characteristics of the ground water in that subarea. Subareas are represented on maps by discrete squares representing 100-square-mile areas. Where chemical data are sparse, subarea boundaries were not extrapolated based solely on concentration of dissolved solids. The number of subareas into which an aquifer or permeable zone was divided was reduced to less than five by merging ranges if the number of analyses in a selected range were small. 
4. Selected water-chemistry data from each subarea were logarithmically transformed. This procedure was done because exploratory data analysis showed that the water-chemistry data were not normally distributed, an assumption that must be satisfied to use the parametric statistical methods (Davis, 1986). By using the logarithmic transformation, the data are transformed to nearly normal distribution.

5. Linear discriminant function analysis, which differentiates on the basis of the amount of variation in data (Davis, 1986) was used to test the chemical analyses for uniqueness to a specific subarea. To determine which chemical constituents would be best for the discriminant analysis, an analysis of variance was made of major chemical constituents that would show the largest amount of variation among those constituents associated with different subareas. The constituents selected for the analysis were calcium, magnesium, sodium, potassium, chloride, bicarbonate, sulfate, silica, manganese, and iron. The results of the analysis of variance are shown in table 1. The first seven constituents in the table showed the most variation and the last three the least.

TABLE 1.-- Variation in concentration of chemical constituents of ground water attributed to differences among subareas of each aquifer and permeable zone

[Values are in percent; $<$, less than; ----, no data]

\begin{tabular}{|c|c|c|c|c|c|c|c|c|c|c|c|}
\hline \multirow[t]{2}{*}{ Constituent } & \multirow[t]{2}{*}{$\begin{array}{c}\text { Alluvial } \\
\text { aquifer }\end{array}$} & \multicolumn{5}{|c|}{ Permeable zone } & \multirow[t]{2}{*}{$\begin{array}{c}\text { Upper } \\
\text { Claiborne }\end{array}$} & \multirow[t]{2}{*}{$\begin{array}{c}\text { Middle } \\
\text { Claiborne }\end{array}$} & \multirow{2}{*}{$\begin{array}{c}\text { Lower } \\
\text { Claiborne } \\
\text {-upper } \\
\text { Wilcox }\end{array}$} & \multirow[t]{2}{*}{$\begin{array}{l}\text { Middle } \\
\text { Wilcox }\end{array}$} & \multirow[t]{2}{*}{$\begin{array}{l}\text { Lower } \\
\text { Wilcox }\end{array}$} \\
\hline & & A & B & $\mathrm{C}$ & $\mathrm{D}$ & $\mathrm{E}$ & & & & & \\
\hline Calcium & 32.2 & 64.4 & 64.5 & 27.4 & 12.8 & 45.6 & 46.9 & 56.5 & 31.2 & 40.1 & 95.7 \\
\hline Magnesium & 29.6 & 63.9 & 77.0 & 57.2 & 53.8 & 34.2 & 53.5 & 45.3 & 56.2 & 34.6 & 91.7 \\
\hline Sodium & 24.0 & 69.9 & 86.5 & 75.3 & 84.4 & 80.3 & 86.5 & 89.1 & 98.9 & 79.5 & 98.4 \\
\hline Potassium & 4.0 & 62.6 & 81.3 & 2.1 & 87.4 & 12.3 & 56.7 & 70.2 & 64.3 & 10.3 & 75.1 \\
\hline Chloride & 22.0 & 68.2 & 88.8 & 77.0 & 83.6 & 79.9 & 84.9 & 92.2 & 99.5 & 76.4 & 98.5 \\
\hline Bicarbonate & 29.3 & 20.0 & 35.3 & 20.0 & 25.6 & 18.3 & 47.2 & 44.0 & 37.9 & 38.6 & .1 \\
\hline Sulfate & 6.6 & 78.9 & 22.4 & 16.0 & 15.2 & 11.6 & 16.8 & 24.7 & 31.4 & 2.1 & $\ldots$ \\
\hline Silica & 0.3 & 9.8 & 3.9 & 2.7 & 8.4 & 7.9 & .2 & 2.4 & 1.7 & 4.4 & 25.4 \\
\hline Manganese & $<.1$ & 8.3 & 46.3 & 2.3 & 20.9 & 47.6 & 6.2 & 2.7 & 1.3 & 10.9 & 36.2 \\
\hline Iron & 2.6 & 56.2 & 2.8 & .7 & .9 & 24.3 & 3 & .8 & 4.2 & 11.2 & 58.2 \\
\hline
\end{tabular}

Discriminant function analysis requires that all chemical analyses have complete data on each of the selected constituents. Because some chemical analyses had missing values for the selected constituent, the following procedure was used to maximize the number of analyses from each subarea. If the analysis contained no missing values for at least 10 of the 13 selected constituents or properties, the analysis was retained. The missing values were then replaced with the median value of the respective constituent for that subarea. However, if the analysis had four or more missing values it was not included in the discriminant function analysis test. If the test of data by discriminant analysis indicated that dissimilar data were included in a subarea, the boundaries of the subarea were changed in order to obtain subareas that contain water of similar chemistry. The differences between subareas reflect different controls on water chemistry.

6. Following discriminant function analysis, the median concentration or value of each selected constituent or property was determined statistically for each subarea of the aquifer or permeable zone. Next the prevalent chemical character (water type) of ground water in each of the subareas was plotted on the trilinear diagram of Hill and Piper (Hem, 1985). This diagram permits the major cation and anion composition of many samples to be represented on a single graph in which major groupings or trends in the data can be discerned visually. In this study three analyses, which were representative of the median value of each major constituent in each subarea of an aquifer or permeable zone, were plotted on the trilinear diagram. A selection of three was made to avoid the clutter of hundreds of analyses on the diagram, which would tend to obscure any trend from subarea to subarea. 
Thus the concentration of major ions from 15 analyses, 3 for each subarea, were plotted on the trilinear diagram, assuming the aquifer or permeable zone was divided into 5 subareas. The three representative analyses of water from each subarea of an aquifer or permeable zone are placed in a table at the end of the report (table 26). By portraying the major cation and anion in each subarea based on analyses representing the median concentration of those ions, the water was classified as to water type for that subarea.

By expressing the water analysis in this manner, the relation of water composition to the solid-mineral composition was studied. This relation was studied primarily by observing the change in the chemical character of the ground water as portrayed by the trilinear diagram from subarea to subarea. The change observed is generally a reflection of the complex interaction of many factors such as (1) flow direction, (2) residence time of the ground water, (3) the physical and chemical composition of the source aquifers, and (4) the ability of the waters to dissolve and chemically alter the different minerals. Thus, the trilinear diagrams are used not only to visually describe change in major-ion chemistry but also to determine if water from wells successively downdip from each other show directional trends and other relations that can be interpreted geochemically.

7. The relation among the constituents and other properties that characterizes the ground-water chemistry in each subarea was shown by factor analysis, a statistical method described by Davis (1986), Hair and others (1979), and Joreskog and others (1976). Factor analysis uses a correlation matrix of selected constituents, which are listed in paragraph 5 above, plus $\mathrm{pH}$, dissolved solids, and depth. Horizontal flow and vertical leakage of ground water from one aquifer to another were not included in the analysis because the magnitude of the flow or leakage was not measured. The statistical procedure creates a matrix of factors that include all the constituents and properties and arranges them according to their correlation (factor loading) for each subarea. Factors represent the underlying dimensions that account for the original set of observed values. Factor loadings indicate what percentage of the variance in an original variable is explained by a factor. The number of factors produced in the factor analysis for each subarea is based on the square root of the computed eigenvalues, which were extracted from a matrix of the cross product of a data set (Davis, 1986). If the square-root value was about one or greater it was considered significant. The matrix of significant factors show the constituents that are highly correlated (highly significant factor loading), those that are slightly correlated (significant factor loading), and those that appear not to be correlated (nonsignificant factor loading) or related at all in the respective subareas. Significant positive loading on a factor was interpreted as indicating an increase in that constituent or property, whereas a significant negative loading was interpreted as indicating a decrease in that constituent or property. The criteria for the significance of factor loading was guided by the goal to elucidate only major processes or mechanisms in the ground-water system. Therefore significant loading was set at +0.50 or greater, which is generally considered very significant (Hair and others, 1979, p. 234). After studying the pattern of all significant variable loading on the respective factors, the probable chemical processes or mechanisms responsible for the observed water chemistry were postulated. The processes or mechanisms postulated are either retained, or another is selected based on the results from the trilinear diagram plots, properties and constituents that characterize the ground water, mapped ground-water flow, and published and unpublished information. The published and unpublished information include water-rock interactions, mineral content of the aquifer sediments, and aquifer depth.

\section{PHYSIOGRAPHY}

The Gulf Coastal Plain emerged from beneath the sea due to eustatic sea-level changes. It formed on the shallow marine continental shelf by accumulating layers of sediments eroded from the land and distributed by marine currents. The emerged coastal plain developed a series of streams and topographic features due to differential weathering and uplifting of strata.

Within the study area the Gulf Coastal Plain was divided into three sections by Fenneman (1938): (1) The Mississippi Alluvial Plain, which is flat and extends from the mouth of the Ohio River to the Gulf of Mexico; (2) the East Gulf Coastal Plain, which features broad low hills and extends from beyond the eastern boundary of the study area westward through Alabama, Mississippi, and eastern Louisiana, and then northward through western Tennessee and Kentucky to the abrupt change in topography that marks the eastern limit of the Mississippi Alluvial Plain; and 
(3) the West Gulf Coastal Plain, which features broad low hills that reach altitudes as much as $300 \mathrm{ft}$ higher than those in the East Gulf Coastal Plain and extends from the Mississippi Alluvial Plain through southwestern Arkansas, western Louisiana, and all of Texas within the study area. Consequently, the topography ranges from flat areas along the coast and alluvial valleys to gently rolling plains and hilly terrain elsewhere.

The altitude of the Gulf Coastal Plain rises from sea level at the coastline to more than $900 \mathrm{ft}$ in the West Gulf Coastal Plain in Webb and Zavala Counties, Texas. The series of streams that developed across the coastal plain are relatively normal to the coastline except for tributaries to the Mississippi River. Major streams in Texas are the Sabine River, the Neches River, the Trinity River, the Brazos River, the Colorado River, the Guadalupe River, the San Antonio River, the Nueces River, and the Rio Grande. Major streams that are tributaries to the Mississippi River are the White River, the Arkansas River, the Ouachita River, the Red River, the Yazoo River, and the Big Black River. Other major streams that flow directly into the Gulf of Mexico are the Pearl and Pascagoula Rivers in Mississippi and the Tombigbee River in Alabama.

The climate of the Gulf Coastal Plain varies from dry semiarid in southwest Texas to humid semitropical in southeast Louisiana. The possible sunshine ranges from around 60 percent in the eastern part to near 70 percent in the western part of the study area. Mean annual temperatures range from about $58^{\circ} \mathrm{F}$ near the southern tip of Illinois to $74^{\circ} \mathrm{F}$ at the southernmost part of Texas. Both the dry and humid climates have large daily and seasonal extremes in temperatures. Daily temperatures may vary as much as $30^{\circ} \mathrm{F}$, whereas the seasonal extremes may be as much as $100^{\circ}$ Fahrenheit. The amount of discomfort to people and livestock and damage to crops from the extreme temperatures are heightened with increasing relative humidity and wind velocity.

Relative humidity range from highs of 90 percent at early morning to 50 percent at midday in Texas and western Louisiana. Relative humidity is lower in the western part of Texas due to lower annual precipitation and higher average wind velocity.

Mean annual precipitation ranges from 18 in. near the Rio Grande in southwest Texas to 66 in. in southeastern Louisiana. Seasonal maximums vary across the study area. For example, in the western part of the study area the maximum precipitation is in the spring and fall, in the southwest part of the study area it is in the spring and summer, and in northeast Texas it is in the winter and spring. In the Mississippi embayment area, maximum precipitation generally occurs in the winter and spring in the northern part of the embayment (Boswell and others, 1968) and in spring and summer in the southern part (Terry and others, 1979).

\section{GEOHYDROLOGY}

There are three regional aquifer systems in the study area: The Mississippi embayment aquifer system, the Texas coastal uplands aquifer system, and the coastal lowlands aquifer system. They consist mainly of sediments of Tertiary and Quaternary age (table 2).

The gulf coast aquifer systems were subdivided into aquifers, permeable zones, and confining units (fig. 3 ) (Hosman and Weiss, 1991; and Weiss, 1992) by the following approaches: (1) Identifying areally extensive, lowpermeability formations as regional confining units, (2) identifying large hydraulic-conductivity contrasts between adjacent aquifers not separated by regional confining units, (3) identifying variations of hydraulic-head between permeable zones with depth, and (4) extending the subdivisions, determined by approach 1,2 , or 3 , as a constant proportion of the total thickness through areas where approaches 1, 2, or 3 could not be applied (Weiss and Williamson, 1985). The outcrop and subcrop area for each of the aquifers is shown on respective maps. The aquifers and confining units that compose the Mississippi embayment aquifer system are laterally equivalent to those of the Texas coastal uplands aquifer system, except that the lower Wilcox aquifer and the Mississippi River Valley alluvial aquifer are not present in Texas. In descending order the aquifers and permeable zones are briefly described in the following paragraphs in regard to their arrangement of strata, rock type, and mineral composition. The hydraulic conductivity values for the aquifers and permeable zones (table 3 ) are the geometric means from a report by Prudic (1990). 
TABLE 2.--Geologic units and geohydrologic units of the gulf coast aquifer systems

[From Williamson and others (1990), table 2. Correlations are generalized; exact relations vary widely from place to place]

\begin{tabular}{|c|c|c|c|c|c|}
\hline \multicolumn{3}{|c|}{ Geologic Unit } & \multirow{2}{*}{$\begin{array}{l}\text { Geohydrologic units } \\
\text { defined by } \\
\text { previous studies }\end{array}$} & \multicolumn{2}{|c|}{ Gulf Coast Regional Aquifer-system Analysis } \\
\hline System & Series & Group & & $\begin{array}{c}\text { Assigned } \\
\text { number on } \\
\text { figure } 3\end{array}$ & Geohydrologic units \\
\hline 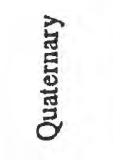 & 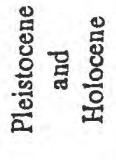 & & $\begin{array}{l}\text { Mississippi River Valley } \\
\text { alluvial aquifer (Boswell } \\
\text { and others, 1968) }\end{array}$ & 11 & $\begin{array}{l}\text { Mississippi River Valley } \\
\text { alluvial aquifer }\end{array}$ \\
\hline \multirow{11}{*}{ 莺 } & 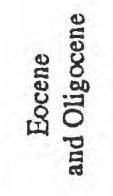 & 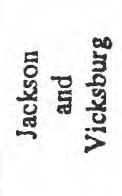 & $\begin{array}{l}\text { Jackson and } \\
\text { Vicksburg Groups }\end{array}$ & 15 & $\begin{array}{l}\text { Vicksburg-Jackson } \\
\text { Confining unit }\end{array}$ \\
\hline & \multirow{9}{*}{ 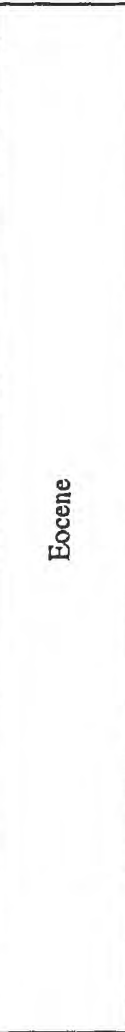 } & \multirow{7}{*}{ 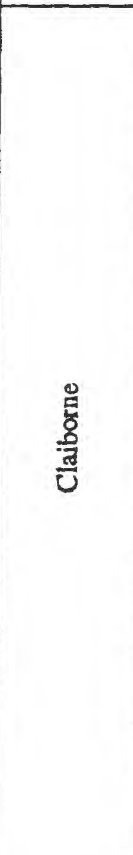 } & $\begin{array}{l}\text { Cockfield aquifer system } \\
\text { (Payne, 1970) } \\
\text { Cockfield Formation } \\
\text { (Hosman and others, 1968) }\end{array}$ & 6 & Upper Claiborne aquifer \\
\hline & & & Cook Mountain Formation & 14 & $\begin{array}{l}\text { Middle Claiborne } \\
\text { confining unit }\end{array}$ \\
\hline & & & $\begin{array}{l}\text { Sparta hydraulic system } \\
\text { (Payne, 1968) }\end{array}$ & \multirow{3}{*}{5} & \multirow{3}{*}{ Middle Claiborne aquifer } \\
\hline & & & $\begin{array}{l}\text { Sparta Sand (Hosman and } \\
\text { others, 1968) }\end{array}$ & & \\
\hline & & & $\begin{array}{l}\text { Memphis aquifer (Hosman } \\
\text { and others, 1968) } \\
\text { (layers } 4 \text { and 5) }\end{array}$ & & \\
\hline & & & Cane River Formation ${ }^{3}$ & 13 & $\begin{array}{l}\text { Lower Claiborne } \\
\text { confining unit }\end{array}$ \\
\hline & & & $\begin{array}{l}\text { Carrizo and Meridian Sand } \\
\text { Aquifer (Payne, 1975) } \\
\text { Carrizo Sand and Meridian } \\
\text { upper Wilcox aquifer } \\
\text { (Hosman and others, 1968) }\end{array}$ & 4 & $\begin{array}{l}\text { Lower Claiborne- } \\
\text { upper Wilcox aquifer }\end{array}$ \\
\hline & & \multirow{2}{*}{$\stackrel{0}{0}$} & $\begin{array}{l}\text { Wilcox Group (Hosman } \\
\text { and others, 1968) }\end{array}$ & 3 & Middle Wilcox aquifer \\
\hline & & & $\begin{array}{l}\text { Lower Wilcox aquifer } \\
\text { (Hosman and others, 1968) }\end{array}$ & 2 & Lower Wilcox aquifer ${ }^{1}$ \\
\hline & 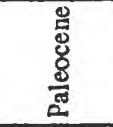 & 效 & Midway Group & 12 & Midway confining unit ${ }^{2}$ \\
\hline
\end{tabular}


TABLE 2.--Geologic units and geohydrologic units of the gulf coast aquifer systems--Continued

\begin{tabular}{|c|c|c|c|c|c|}
\hline \multicolumn{3}{|c|}{ Geologic Unit } & \multirow{2}{*}{$\begin{array}{l}\text { Geohydrologic units } \\
\text { defined by } \\
\text { previous studies }\end{array}$} & \multicolumn{2}{|c|}{ Gulf Coast Regional Aquifer-system Analysis } \\
\hline System & Series & Group & & $\begin{array}{c}\text { Assigned } \\
\text { number on } \\
\text { figure } 3\end{array}$ & Geohydrologic units \\
\hline $\begin{array}{l}\text { 曾 } \\
\text { 总 }\end{array}$ & 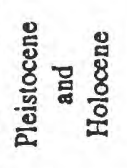 & & $\begin{array}{l}\text { Upper Chicot aquifer } \\
\text { (Jorgensen, } 1975 \\
\text { Chicot aquifer (Meyer and } \\
\text { Carr, 1979) }\end{array}$ & 11 & $\begin{array}{l}\text { Permeable zone A } \\
\text { (Holocene-upper } \\
\text { Pleistocene deposits) }\end{array}$ \\
\hline \multirow{7}{*}{ 䔍 } & 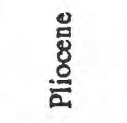 & & $\begin{array}{l}\text { Evangeline aquifer } \\
\text { (Whitefield, 1975; } \\
\text { Meyer \& Car, 1979) }\end{array}$ & 10 & $\begin{array}{l}\text { Permeable zone B } \\
\text { (Lower Pleistocene- } \\
\text { upper Pliocene deposits) }\end{array}$ \\
\hline & \multirow{4}{*}{$\begin{array}{l}\stackrel{0}{0} \\
\stackrel{8}{2}\end{array}$} & & \multirow{4}{*}{$\begin{array}{l}\text { '2,000-foot' sand of } \\
\text { the Baton Rouge area } \\
\text { (Torak and Whiteman, } \\
\text { 1982) } \\
\text { Jasper aquifer } \\
\text { (Whitfield, 1975) }\end{array}$} & 9 & $\begin{array}{l}\text { Permeable zone C } \\
\text { (Lower Pliocene- } \\
\text { upper Miocene deposits }\end{array}$ \\
\hline & & & & 17 & Zone $\mathrm{D}$ confining unit \\
\hline & & & & 8 & $\begin{array}{l}\text { Permeable zone D } \\
\text { (Middle Miocene deposits) }\end{array}$ \\
\hline & & & & 16 & Zone E confining unit \\
\hline & \multirow{2}{*}{ 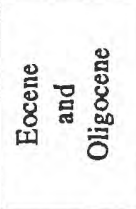 } & \multirow{2}{*}{ 总 } & & 7 & $\begin{array}{l}\text { Permeable zone E } \\
\text { (Lower Miocene- } \\
\text { upper Oligocene deposits) }\end{array}$ \\
\hline & & & & 15 & $\begin{array}{l}\text { Vicksburg-Jackson } \\
\text { confining unit }{ }^{2}\end{array}$ \\
\hline
\end{tabular}

\footnotetext{
${ }^{1}$ Not present in the Texas coastal uplands aquifer system.

${ }^{2}$ The Midway confining unit was referred to as the coastal uplands confining unit, and the Vicksburg-Jackson confining unit was referred to as the coastal lowlands confining unit by Grubb, (1984, p. 11).

${ }^{3}$ Not present north of latitude $35^{\circ}$.
}

The Mississippi River Valley alluvial aquifer is laterally continuous with permeable zone A across the Vicksburg Group subcrop area in northeastern Louisiana. The aquifer consists of gravel and coarse sand at the base and grades upward to fine sand with a cover of silt and clay at the surface. The mineral composition of clay lenses in the aquifer, as indicated by an analyzed sample, consists of quartz, montmorillonite, feldspar with orthoclase more abundant then plagioclase, and smaller amounts of illite, kaolinite, and calcite (Sniegocki, 1964). The gravelly zone at the base of the aquifer consists of chert and other chalcedonic rocks, orthoquartzite, metaquartzite, quartz, and feldspathic igneous rocks (Sniegocki, 1964).

Permeable zone A is composed mostly of Holocene-upper Pleistocene deposits and is equivalent to the upper part of the Chicot aquifer in Texas and southwestern Louisiana. The upper part of the zone includes alluvial and terrace deposits locally and may be covered by loess in upland areas. The zone typically is sand, gravel, and clay, and generally grades from coarse sand or gravel at the base to fine material at the top. Some gravel beds are cemented by caliche (Plummer, 1932). The mineral composition of a sample from near the base of the terrace and alluvial deposits consists of quartz, clay, chert, chalcedony, feldspar, and limonite, and traces of ilmenite, magnetite, hematite, epidote, tourmaline, and zircon (Plummer, 1932). The boundary between permeable zone A and the underlying permeable zone B was determined by discontinuities in hydraulic-head profile (Weiss, 1992). 


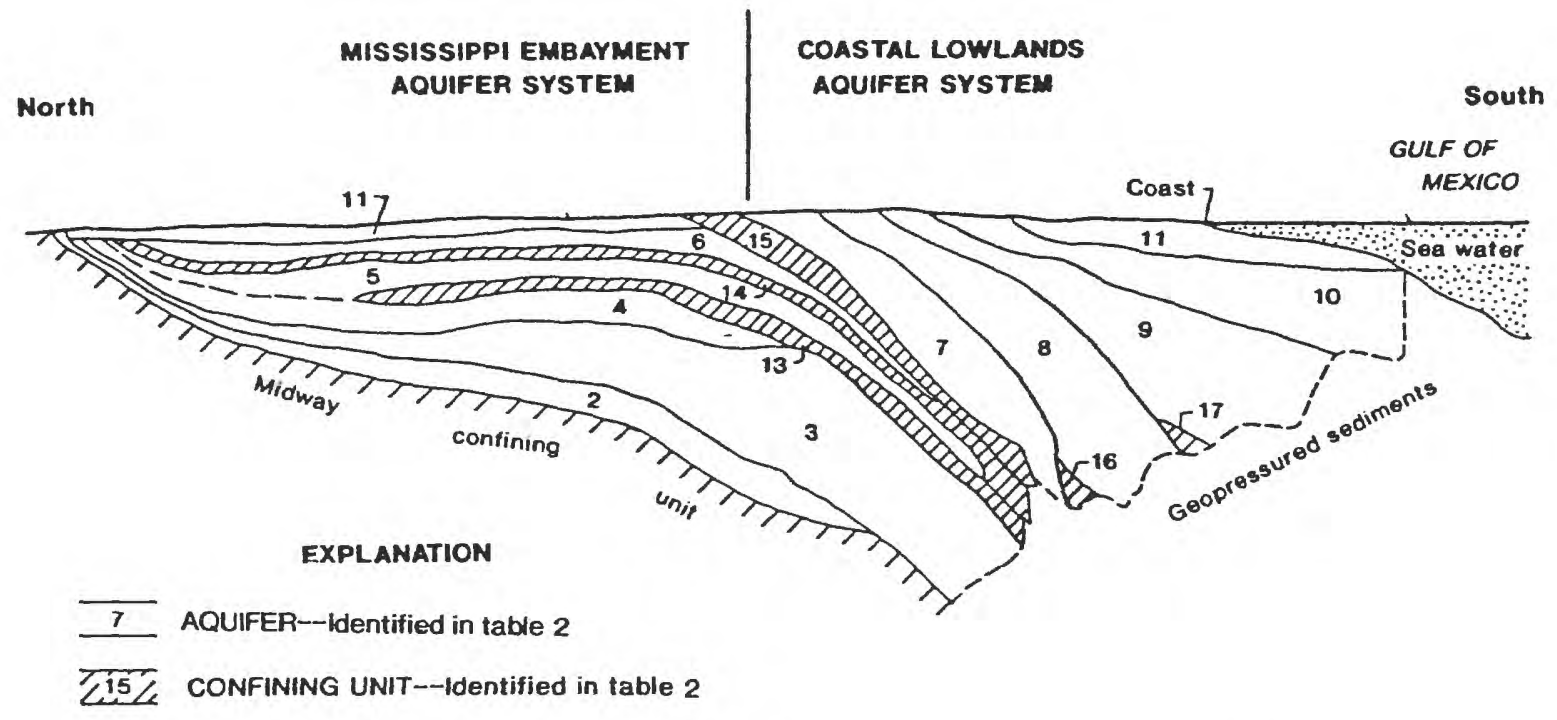

Figure 3.--Diagrammatic section from northern edge of study area to edge of Continental Shelf showing vertical relation of aquifers and permeable zones.

Permeable zone B is composed mostly of lower Pleistocene-upper Pliocene deposits and contains the upper part of the Goliad Sand in Texas and the lower part of the Citronelle Formation in Louisiana and Mississippi. It typically is composed of quartz sand, chert, gravel, and lenses and layers of clay. The mineral composition, as indicated by a sample of conglomerate, consists of clay (caliche in part), quartz, feldspar, pegmatite, chert, limonite, and traces of cassiterite, epidote, hematite, ilmenite, magnetite, muscovite, titanite, tourmaline, and zircon (Plummer, 1932).

TABLE 3.--Estimates of hydraulic conductivity by aquifer or permeable zone in the gulf coast aquifer systems

[Values are from aquifer-test analyses and specific-capacity data. Modified from Prudic, 1991.]

\begin{tabular}{lcc}
\hline \multicolumn{1}{c}{ Aquifer or permeable zone } & $\begin{array}{c}\text { Number of } \\
\text { values }\end{array}$ & $\begin{array}{c}\text { Geometric mean } \\
\text { (feet per day) }\end{array}$ \\
\hline Lower Wilcox & 136 & 76 \\
Middle Wilcox & 782 & 20 \\
Lower Claiborne-upper Wilcox & 255 & 43 \\
Middle Claiborne & 776 & 57 \\
Upper Claiborne & 331 & 52 \\
& & \\
Zone E & 432 & 59 \\
Zone D & 554 & 66 \\
Zone C & 722 & 50 \\
Zone B & 870 & 51 \\
Zone A* & 1.745 & 156 \\
Mississippi River Valley alluvial & 374 & 316 \\
\hline
\end{tabular}

*Includes values for Mississippi River Valley alluvial aquifer 
Permeable zone $\mathrm{C}$ comprises mostly lower Pliocene-upper Miocene deposits and contains the lower part of the Goliad Sand in Texas, the upper part of the Fleming Formation in Texas and Louisiana, and the Pascagoula Formation in Mississippi. Zone $\mathrm{C}$ is equivalent to the lower half of the Evangeline aquifer in Texas and southwestern Louisiana. It typically is composed of coarse to medium sands with gravel and clay balls. The sands and gravel are cemented by calcium carbonate to produce silty sandstone in some places. The mineral composition, as indicated by a sample of sandstone, consists of quartz, feldspar, calcite, chert, clay, shell fragments, and traces of apatite, barite, biotite, chalcedony, chlorite, diopside, dolomite, epidote, fluorite, garnet, glauconite, gypsum, hematite, hornblende, ilmenite, limonite, magnetite, monazite, muscovite, opal, pyrite, rutile, staurolite, strontianite, titanite, tourmaline, zircon, and zoisite (Plummer, 1932).

Permeable zone D consists mostly of middle Miocene deposits and encompasses the lower part of the Oakville Sandstone in Texas, the lower part of the Fleming Formation in Louisiana, and the Hattiesburg Formation in Mississippi. The zone is equivalent to the lower part of the Jasper aquifer in Texas and Louisiana. It is composed of medium-grained, crossbedded sand, sandy and ashy clay, marl, and some gravel and redeposited shells of Cretaceous age. The mineral composition, based on an analyzed sample, consists of quartz, calcite (largely cement), chert, orthoclase, plagioclase, shell fragments, and traces of microcline, biotite, magnetite, limonite, zircon, barite, and chalcedony (Plummer, 1932).

Permeable zone E consists mostly of lower Miocene-upper Oligocene deposits of the lower part of the Catahoula Sandstone and is mostly coincident with the "Frio" Formation downdip in Texas. It is composed of interbedded and interlensing medium to fine quartz sand, montmorillonite and illite clays, and organic materials. Minerals found in analyzed samples are quartz, plagioclase, chert, opal, orthoclase, microcline, pyrite, and limonite, and traces of magnetite, biotite, muscovite, zircon, and tourmaline (Plummer, 1932).

The upper Claiborne aquifer consists mostly of the Yegua Formation in Texas and its equivalent, the Cockfield Formation elsewhere. It is composed of interfingering sands, silts, and shales and minor amounts of lignite, bentonite, gypsum, and limestone. The sands are fine to medium-size quartz grains (Payne, 1970). The sand grains contained muscovite and traces of leucoxene, ilmenite, tourmaline, zircon, cyanite, staurolite, rulite, and limonite (Plummer, 1932). Overlying the upper Claiborne aquifer is a thick confining unit of predominantly clay and marl of the Jackson Group and Vicksburg Group. This confining unit separates the underlying Mississippi embayment and Texas coastal uplands aquifer systems from the coastal lowlands aquifer system.

The middle Claiborne aquifer consists primarily of the Sparta Sand except in the Memphis, Tennessee, and northern Mississippi embayment area where it has been referred to as the "500-foot" sand and later named the "Memphis aquifer" (Hosman and others, 1968). It is composed of varying amounts of well-sorted fine to medium quartz sand interstratified with silt, clay, and shale and minor amounts of lignite (Payne, 1972). Other minerals reported in this aquifer are glauconite, pyrite, mica, bornite, and minor heavy metals including ilmenite and rutile (Moore and Brown, 1969) and limonite (Plummer, 1932). Separating this aquifer from much of the upper Claiborne aquifer is a confining unit composed mostly of the Cook Mountain Formation. Underlying much of the middle Claiborne aquifer is the Cane River Formation or its equivalents, which is a confining unit.

The lower Claiborne-upper Wilcox aquifer is mostly the Carrizo Sand and its equivalent, the Meridian Sand Member of the Tallahatta Formation. It is composed predominantly of fine to coarse micaceous quartz sands with minor amounts of interbedded clays and silts and some lenses of lignite. Glauconite has been found in deeper downdip parts of the aquifer (Payne, 1975). The mineral composition of the Carrizo Sand in order of abundance is quartz, microcline, plagioclase, glauconite, leucoxene, ilmenite, magnetite, tourmaline, zircon, staurolite, rulite, and muscovite (Plummer, 1932).

The middle Wilcox aquifer is the lowermost aquifer in the gulf coast aquifer systems in Texas. It is composed mostly of thin sand beds interbedded with clays and silts (Hosman, 1988). The individual sand beds of the aquifer are not areally extensive, but collectively they are a source of water for local use for an area of several thousand square miles. These sand beds and interbedded sands and silts are composed of calcareous concretions and mineral grains of quartz, selenite, limonite, and altered mica and traces of magnetite and glauconite. Lignite is also present. Younger sediments of this aquifer contain minerals of the feldspar group and the heavy minerals leucoxene and ilmenite 
(Plummer, 1932).

The lower Wilcox aquifer is the lowermost aquifer in the gulf coast aquifer systems except in Texas where the lowermost is the middle Wilcox aquifer. The aquifer is typically a massive sand that underlies a large part of the Mississippi embayment where it is known as the Fort Pillow Sand (Hosman, 1988). It is composed of fine to medium sand. The sand is composed of glauconitic, siliceous cemented quartz with some pyrite and iron-stained chert. The sand is separated in places by micaceous clay (Moore and Brown, 1969).

At the base of the gulf coast aquifer systems is a confining unit of thick extensive clay of the Midway Group of Paleocene age. This clay layer is the Wills Point Formation in Texas and the Porters Creek clay in the remainder of the study area. The downdip limit of most aquifers and permeable zones in the systems is the geopressured sediments. The geopressured sediments are described as that part of the aquifer or aquifer system that has a fluid pressure that exceeds the hydrostatic pressure of a column of water containing $80,000-\mathrm{mg} / \mathrm{L}$ dissolved solids (Jones, 1968).

\section{CHEMICAL PROCESSES AND MECHANISMS}

The following is a brief discussion of the chemical processes and mechanisms that are operating in the aquifers and permeable zones of the Gulf Coastal Plain (table 4). For further discussion of these chemical processes and mechanisms see Drever (1982), Freeze and Cherry (1979), Grim (1968), Hem (1985), Kraushopf (1967), and Lyon and others (1953).

TABLE 4.--Probable mechanisms and chemical processes in the gulf coast aquifer systems and their effect on the chemistry of the ground water

\begin{tabular}{|c|c|}
\hline Mechanism or process & Effect on the chemistry of the ground water \\
\hline \multicolumn{2}{|l|}{ Alteration: } \\
\hline Silicate minerals & Increases $\mathrm{HCO}_{3}^{-}$and one or more major cations. \\
\hline Clay minerals & Decreases $\mathrm{H}^{+}$, increases one or more major cations. \\
\hline \multicolumn{2}{|l|}{ Dissolution: } \\
\hline Carbonate minerals & Increases $\mathrm{Ca}^{+2} \cdot \mathrm{Mg}^{+2} \cdot \mathrm{HCO}_{3}$. \\
\hline Sulfate minerals & Increases $\mathrm{Ca}^{+2} \cdot \mathrm{Mg}^{+2} \cdot \mathrm{SO}_{4}^{-2}$ \\
\hline Evaporite minerals & Increases $\mathrm{Na}^{+}, \mathrm{Cl}^{-}, \mathrm{Ca}^{+2}, \mathrm{Mg}+2, \mathrm{SO}_{4}{ }^{-2}$. \\
\hline Cementing material & Increases $\mathrm{Ca}^{+2} \cdot \mathrm{HCO}_{3}-\mathrm{Mg}^{+2} \cdot \mathrm{SO}_{4}^{-2} \cdot \mathrm{Fe}^{+2} \cdot \mathrm{SiO}_{2}$. \\
\hline \multicolumn{2}{|l|}{ Precipitation: } \\
\hline Carbonate minerals & Decreases $\mathrm{Ca}^{+2}, \mathrm{Mg}^{+2} \cdot \mathrm{HCO}_{3}^{-}$ \\
\hline Sulfate minerals & Decreases $\mathrm{Ca}^{+2}, \mathrm{Mg}^{+2}, \mathrm{SO}_{4}{ }^{-2}$. \\
\hline Crystallization of silicate minerals & Decreases silicon, $\mathrm{Al}^{+4}$, some major cations. \\
\hline \multicolumn{2}{|l|}{ Oxidation-reduction: } \\
\hline Sulfide oxidation & Increases $\mathrm{SO}_{4}^{-2}, \mathrm{H}^{+}$ \\
\hline Organic carbon oxidation & Increases $\mathrm{CO}_{2}$ (gas). $\mathrm{H}_{2} \mathrm{CO}_{3}$. \\
\hline Sulfate reduction & Decreases $\mathrm{SO}_{4}^{-2}$ : Increases $\mathrm{HCO}_{3}$. \\
\hline Organic carbon reduction & Increases $\mathrm{HCO}_{3}^{-}, \mathrm{H}^{+}$ \\
\hline Dissociation of $\mathrm{H}_{2} \mathrm{CO}_{3}$ & Increases $\mathrm{H}^{+}, \mathrm{HCO}_{3}^{-}$. \\
\hline Cation exchange and adsorption & Decreases $\mathrm{K}^{+}, \mathrm{Ca}^{+2}, \mathrm{Mg}^{+2}, \mathrm{Fe}^{+2}, \mathrm{Mn}^{+2}$. Increases $\mathrm{Na}^{+}$. \\
\hline \multicolumn{2}{|l|}{ Ground-water movement: } \\
\hline Leaching of unsaturated zone & Increases concentration of major ions. \\
\hline Vertical leakage & Increases concentration of dissolved solids. \\
\hline
\end{tabular}


The clay minerals contained in the aquifers and permeable zones are formed by alteration of aluminum silicates, both in weathering and in low-temperature hydrothermal processes. The alteration proceeds by hydrolysis, which produces hydroxide that cannot long exist in the presence of carbon dioxide and usually changes to carbonate or bicarbonate. The hydrolysis of albite in the presence of carbon dioxide proceeds as follows:

$$
\underset{\text { Albite }}{2 \mathrm{NaAlSi}_{3} \mathrm{O}_{8}}+11 \mathrm{H}_{2} \mathrm{O}+2 \mathrm{CO}_{2}=\underset{\text { Kaolinite }}{\mathrm{Al}_{2} \mathrm{Si}_{2} \mathrm{O}_{5}(\mathrm{OH})_{4}}+2 \mathrm{Na}+2 \mathrm{HCO}_{3}+4 \mathrm{H}_{4} \mathrm{SiO}_{4}
$$

$$
\text { Kaolinite }
$$

In this reaction sodium and bicarbonate ions are released to the ground water and $\mathrm{pH}$ is increased due to the consumption of hydrogen ions. The source of the carbon dioxide is the product of decay in the soil zone and from the atmosphere. Consequently, the effect of the hydrolysis of albite on the water chemistry decreases with distance from the source of carbon dioxide.

The alteration process for aluminum silicates is characterized by the release of cations of sodium, calcium, magnesium, iron, and potassium and a rise in $\mathrm{pH}$ and in bicarbonate ion concentration in the ground water. The chemical constituents that are released to the ground water in the weathering alteration process are determined by the type of aluminum silicate present, the degree of weathering, and the acidity of the weathering. For example, weathering of feldspar may proceed in a neutral or alkaline environment to montmorillonite, then to kaolinite if the environment becomes acidic. Montmorillonite may reverse to illite by adsorbing potassium ions. However, if weathering of feldspar is in an acid environment, it will proceed directly to kaolinite.

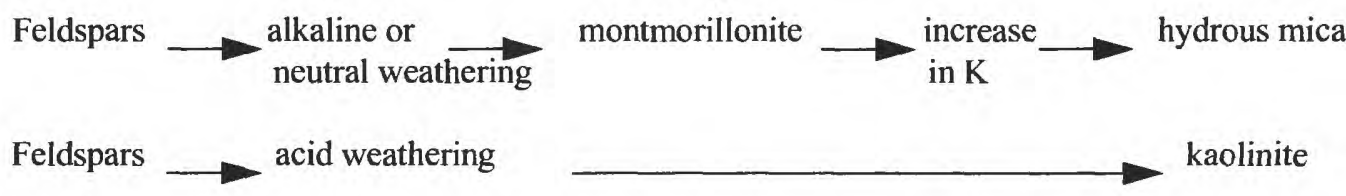

Those aluminum silicates high in potassium, such as microcline, may weather to illite, then to montmorillonite, then, if in an acid environment, to kaolinite (Lyon and others, 1953). In the alteration of alumino-silicates to illite, most of the calcium and magnesium ions are removed, and the silicon in the silica sheet is replaced by aluminum. A few of the alteration reactions that change mineral structure are: illitization, the alteration of muscovite mica to illite; albitization, the alteration of a calcium-rich plagioclase to albite, and chloritization, the alteration of biotite mica to muscovite mica releasing iron, magnesium, and silica to form chlorite (Krauskopf, 1967). Alteration reactions in which clay (secondary) minerals are formed are referred to as incongruent dissolution.

Some clay minerals are also formed from the decomposition of original minerals and the subsequent recrystallization of certain of their decomposition products. An example is the formation of kaolinite from solutions containing aluminum and silicon (Lyon and others, 1953).

The minute clay colloids, comprising the secondary minerals formed as a result of weathering, are usually negatively charged. The negative charge may be due to exposed hydroxyl groups where the hydrogen of these $\mathrm{OH}$ radicals dissociates slightly, and the colloidal surface is left with a negative charge carried by the oxygen. It may be due to ionic substitution where one 3-valent atom has substituted for a 2-valent atom within the clay lattice, resulting in an unsatisfied negative valence. Consequently, major cations in the ground water may be adsorbed on the surface of the clay colloids. Because these cations are easily replaced from the clay, they are referred to as exchangeable ions. This replacement, called cation exchange, is an important process in clay genesis and influences the chemistry of the ground water. The most common exchange reaction is calcium for sodium adsorbed on the clay colloid.

$$
\mathrm{Ca}^{2+}+2 \mathrm{Na}-\text { clay }=2 \mathrm{Na}^{+}+\mathrm{Ca}-\text { clay }
$$

The reverse effect, the exchange of sodium for calcium, can be expected but is less documented (Hem, 1985).

In nearly all sedimentary terrane, ground water is in contact with carbonate minerals during part of its flow history. If carbonate minerals, such as calcite or dolomite, and carbon dioxide gas are in contact with ground water, the mineral will begin to dissolve, releasing calcium, magnesium, and bicarbonate ions. 
$\mathrm{CaMg}\left(\mathrm{CO}_{3}\right)^{2}+2 \mathrm{H}_{2} \mathrm{CO}_{3}=\mathrm{Ca}^{2+}+\mathrm{Mg}^{2+}+4 \mathrm{HCO}_{3}^{-}$

dolomite

In regions of low rainfall the dissolved carbonates may precipitate and accumulate in concretions or as a pan in the lower part of the soil. The formation of a pan is commonly associated with an intermittent high water table. When the accumulation of bicarbonates becomes hardened, it is called caliche. Caliche generally occurs in the deeper part of soils of warm-temperate regions (U.S. Department of Agriculture, 1962). Caliche also occurs as cementing material in gravel beds and terraces (Plummer, 1932).

The dissolution of carbonate minerals may occur in a system that is either open or closed to carbon dioxide. In the open system, which occurs above the water table, the dissolved inorganic carbon is derived from carbon dioxide generated from decaying organic matter in the soil zone and from atmospheric carbon dioxide gas that is dissolved in precipitation as it recharges the ground water. In a closed system, which occurs below the water table, the dissolved inorganic carbon is derived from the dissolved carbon dioxide present in the ground water as dissolution begins and from the dissolution of calcite or dolomite in the sediments. In closed systems, carbonate minerals are less soluble than in an open system and have higher equilibrium $\mathrm{pH}$ values (Freeze and Cherry, 1979). In the alteration of silicate minerals, discussed in a previous paragraph, the carbon dioxide gas from the atmosphere and soil zone dissolved in ground water intensifies the solvent action of water and increases its power as a weathering agent.

$$
\mathrm{CO}_{2} \text { (gas) }+\mathrm{H}_{2} \mathrm{O}=\mathrm{H}_{2} \mathrm{CO}_{3} \text { (acid) }
$$

In a regional ground-water flow system, dissolution and precipitation of carbonate minerals may alternate due to change in water temperature. For example, in the recharge area the temperature may be low, increasing solubility and causing dissolution of carbonates, whereas in deeper zones having higher temperature, solubility decreases, causing precipitation of carbonates. Then as the ground water flows back to the shallower and colder zone in the discharge area, the carbonates again dissolve.

Carbonate minerals may also precipitate due to the common-ion effect. This effect may occur, for example, when ground water containing calcium and carbonate ions moves through a strata containing gypsum. The dissolution of gypsum causes the ionic strength to increase and the concentration of calcium ions to rise. In order for the groundwater solution to remain in equilibrium with respect to the carbonate mineral calcite, calcium is removed from solution by precipitation of calcite.

$$
\begin{aligned}
& \mathrm{CaSO}_{4}+\mathrm{Ca}^{2+}+2 \mathrm{HCO}_{3}^{-}=2 \mathrm{H}^{+}+\mathrm{SO}_{4}{ }^{2+}+\underset{\text { calcite }}{2 \mathrm{CaCO}_{3}} \\
& \text { calum }
\end{aligned}
$$

Other precipitation reactions that occur in the ground-water system and that are important to the water chemistry are that of magnesite, gypsum, and silica.

Evaporite sediments, primarily salt domes and accompanying caprock (Beckman and Williamson, 1990), are widely distributed in the Gulf Coast region. They occur in the Paleocene, Eocene, and up into the Miocene Series (Halbouty, 1979), which are the Series that comprise most of the gulf coast aquifer systems. The most abundant minerals in the evaporite sediments are halite, gypsum, and anhydrite. However, sylvite, carnallite, kainite, polyhalite, and kieserite are also major constituents (Krauskopf, 1967). Due to the highly soluble nature of evaporite sediments, water moving through them increases greatly in its dissolved-solids concentration (Hem, 1985). The large increase in the concentration of dissolved solids is primarily due to increases in sodium and chloride ion from dissolution of halite, the most abundant mineral in salt domes. Increases in concentration of other ions is generally due to impurities in halite.

$$
\mathrm{NaCl}+\mathrm{H}_{2} \mathrm{O} \longrightarrow \mathrm{Na}^{+}+\mathrm{Cl}^{-}+\mathrm{H}_{2} \mathrm{O}
$$

The composition of highly saline water and natural brines generally is closely related to the composition of the evaporite sediments from which they are derived. 
Oxidation-reduction reactions that occur in the ground-water environment involve the transfer of electrons between dissolved, gaseous, or solid constituents. For example, oxygen from the Earth's atmosphere, a strong oxidizing agent, is dissolved in precipitation that recharges ground water. Water that circulates through the ground-water system is generally isolated from the Earth's atmosphere, and oxygen that is consumed by hydrochemical and biochemical reactions is not replenished. Because of this process, ground-water systems tend to become more reduced with increasing depth. In order for reduction of inorganic constituents to occur, some other constituents must be oxidized. The oxidized compound is generally organic matter. The reactions are catalyzed by bacteria or isolated enzymes that derive energy by facilitating the process of electron transfer (Freeze and Cherry, 1979). An example is the oxidation of lignite by sulfate.

$$
\begin{aligned}
& 2 \mathrm{CH}_{2} \mathrm{O}+\mathrm{SO}_{4}^{2}=\mathrm{HS}^{-}+\mathrm{H}^{+}+2 \mathrm{HCO}_{3}^{-} \\
& \text {Lignite }
\end{aligned}
$$

Because the solubility of oxygen in water is low and because oxygen replenishment in the subsurface environment is limited, the oxidation of only a small amount of organic matter can result in the consumption of all the dissolved oxygen. Thus as water infiltrates through the soil zone containing organic matter, oxygen is consumed and carbon dioxide is produced. The carbon dioxide combines with water to produce carbonic acid (eq. 5) which is a major reactant in the dissolution of minerals in sedimentary rocks. Carbonic acid can dissociate and release to solution ions of hydrogen, bicarbonate, and carbonate. Dissociation lowers $\mathrm{pH}$, and the extent of the dissociation is $\mathrm{pH}$ dependent.

$$
\begin{aligned}
& \mathrm{H}_{2} \mathrm{CO}_{3}\left(\text { acid) }=\mathrm{HCO}_{3}^{-}+\mathrm{H}^{+}=\mathrm{CO}_{3}{ }^{2-}+2 \mathrm{H}^{+}\right. \\
& \text {(dissociation } \mathrm{pH} \text { ) pH } 6.4 \quad \mathrm{pH} 10.33
\end{aligned}
$$

The products from the dissociation of carbonic acid in aquifers of the Gulf Coastal Plain are bicarbonate and hydrogen ions.

Oxidation of organic matter can occur after all the oxygen has been consumed through the action of oxidizing agents such as sulfate, iron, and manganese ions. The products from these oxidizing processes are generally hydrogen and bicarbonate ions and a reduced form of the oxidizing agent. As these oxidizing agents are consumed, the groundwater environment becomes more and more reduced. If the ground-water environment becomes strongly reduced, the organic compounds may undergo anaerobic degradation. Such a process is methane fermentation, in which organic matter is converted to methane gas and ions of bicarbonate and hydrogen. The following is an example of bacterial fermentation reactions:

$$
2 \mathrm{CH}_{2} \mathrm{O}+\mathrm{H}_{2} \mathrm{O}=\mathrm{CH}_{4} \text { (gas) }+\mathrm{HCO}_{3}^{-}+\mathrm{H}^{+}
$$

A byproduct of methane fermentation is carbonic acid, which will dissolve minerals in resistates and other rocks. Such reactions increase in the ground water the concentration of the ions making up the minerals.

Iron is the second most abundant metallic element in the Earth's crust and is present in most ground-water systems. The solubility of iron depends on the oxidation intensity of the system and the $\mathrm{pH}$. When iron minerals come in contact with water, iron may be released as the ferrous or ferric ion.

$$
\begin{aligned}
& 2 \mathrm{Fe}_{2} \mathrm{O}_{3}+4 \mathrm{H}^{+}=4 \mathrm{Fe}^{2+}+2 \mathrm{H}_{2} \mathrm{O}+2 \mathrm{O}_{2} \text {, or } \\
& \mathrm{Fe}(\mathrm{OH})_{3}+3 \mathrm{H}^{+}=\mathrm{Fe}^{3+}+3 \mathrm{H}_{2} \mathrm{O}
\end{aligned}
$$

High concentrations of dissolved ferrous iron can occur in solution at sites of either reduction of ferric oxyhydroxide or oxidation of ferrous sulfide. In the latter process the sulfur is reacted with first and altered to sulfate, releasing the ferrous iron. Under reducing conditions when sulfur is available, the ferrous polysulfides such as pyrite may form, whereas when sulfur is less abundant siderite may occur (Hem, 1985). Ferric iron may occur in solution by the oxidation of a sulfide such as pyrite.

$$
\begin{aligned}
& \mathrm{FeS}_{2}+3.5 \mathrm{O}_{2}+\mathrm{H}_{2} \mathrm{O}=\mathrm{Fe}^{2+}+2 \mathrm{SO}_{4}{ }^{2-}+2 \mathrm{H}^{-} \\
& \text {pyrite }
\end{aligned}
$$




$$
\mathrm{Fe}_{2}^{+}+\mathrm{O}_{2}+4 \mathrm{H}^{+}=\mathrm{Fe}^{3+}+2 \mathrm{H}_{2} \mathrm{O}
$$

This reaction occurs in a zone of oxidation near the surface, whereas reduction commonly occurs at depth. Ferric ions adsorbed on organic matter or clay minerals may also occur in solution as a result of methane fermentation or genesis of clay minerals.

Consolidated sedimentary rocks, particularly resistates, contain cementing materials that were deposited on grain surfaces and within openings among grains making up the rock. The most common cementing materials include calcite, silica, iron oxide, gypsum, and clay minerals. The cementing materials normally are deposited from water that has moved through the rock at some time in the past and can be redissolved. Because marine sediments were deposited in seawater it is probable that sodium chloride in solution or as crystals may have been trapped in sedimentary rocks such as resistates by cementing materials; thus as the cementing materials are dissolved sodium chloride ions are released to the ground water.

Two mechanisms that are universally present in nearly all ground-water systems are leaching of soluble salts from the unsaturated zone and vertical leakage of ground water between aquifers. Leaching of soluble salts from the unsaturated zone is associated with the open system discussed above and with recharge of the aquifer by precipitation. The concentration of ions leached to the ground water generally does not increase the concentration of those ions in the ground water very much above that of rainwater. The effect of leaching on the ground-water chemistry decreases with depth from the land surface.

$$
\begin{array}{ll}
\mathrm{MgCO}_{3} \mathrm{CaCO}_{3} & \mathrm{Mg}^{2+} \mathrm{Ca}^{2+} \mathrm{HCO}_{3}^{-} \\
\mathrm{NaCl}_{\mathrm{CaSO}} \mathrm{KCl} & + \text { leaching by } \mathrm{H}_{2} \mathrm{O} \longrightarrow \\
\mathrm{Na}^{+} \mathrm{K}^{+} \mathrm{Cl}^{-} & \mathrm{SO}_{4}^{2-} \\
\text { salts in unsaturated zone } & \text { ions in ground water }
\end{array}
$$

Vertical leakage of ground water from one aquifer to another is controlled by any confining layers and by the difference in hydraulic head between the aquifer and those above or below it. Leakage to an aquifer can dramatically change the water chemistry of the receiving aquifer. Following is an example:

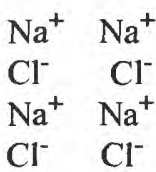

source aquifer has sodium chloride water type

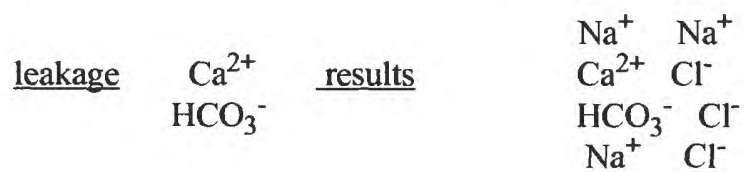

receiving aquifer changes to mixed water type.

Both leaching and leakage can be important controls in determining the chemistry of the ground water in all of the aquifers and permeable zones.

Because vertical leakage and horizontal flow can affect the chemistry of the ground water dramatically, they are included as possible mechanisms in this study. By mapping direction of flow and leakage, and the concentration of dissolved solids, and using computer-generated rates of flow, it is possible to postulate the effect of these mechanisms as significant controls on the chemistry of the ground water. However, the influence of leakage from another aquifer may not be discernible because the effect of leakage on the chemistry of the ground water from updip to downdip areas may have been accounted for when the boundaries of the subareas of the aquifer were changed as a result of testing by discriminant function analysis. 


\section{CHEMICAL CHARACTER OF GROUND WATER}

The chemical character of water is described below for each aquifer or permeable zone in terms of median dissolved-solids concentrations and primary water type. The description is preceded by a short summary of the physical aspects of the aquifer or permeable zone and highlights of the simulated ground-water flow prior to withdrawal of large quantities of water. The discussion then focuses on the chemical constituents and properties of the water within subareas, and finally the ground-water chemistry is related to chemical and physical processes.

\section{MISSISSIPPI RIVER VALLEY ALLUVIAL AQUIFER AND PERMEABLE ZONE A (HOLOCENE-UPPER PLEISTOCENE DEPOSITS)}

The Mississippi River Valley alluvial aquifer and permeable zone A (Holocene-upper Pleistocene deposits) are the uppermost units of the gulf coast aquifer systems in their respective areas of occurrence and include the youngest sediments in the Gulf Coastal Plain. They underlie about 40 percent of the onshore part of the study area and all of the Continental Shelf south of the coastline (fig. 4) and have a combined areal extent of about $150,000 \mathrm{mi}^{2}$. The Mississippi River Valley alluvial aquifer underlies an area of about 32,000 $\mathrm{mi}^{2}$ (Hosman and Weiss, 1991) and has an average thickness of $100 \mathrm{ft}$ (Ackerman, 1996). Permeable zone A underlies an area of about $117,000 \mathrm{mi}^{2}$ (Grubb, 1987) and has an average thickness of about $700 \mathrm{ft}$ (Weiss, 1992).

Median depth of water samples ranges from $47.5 \mathrm{ft}$ in the downdip areas of permeable zone A to $250 \mathrm{ft}$ in middip areas of permeable zone A (table 5). Because the alluvial aquifer and permeable zone A are the uppermost units making up the gulf coast aquifer systems, they are open to recharge from precipitation throughout their areal extent except that part of permeable zone A underlying the Continental Shelf. The two units are treated as one for the purpose of mapping median dissolved-solids concentrations, primary water type, and direction of predevelopment groundwater flow and leakage. However, because they are each a part of separate aquifer systems, they are analyzed separately both graphically and statistically.

The simulated horizontal direction of predevelopment ground-water flow and leakage to or from the base of the Mississippi River Valley alluvial aquifer and permeable zone A (Holocene-upper Pleistocene deposits) are indicated in figure 4 (Williamson, in press). Regionally, the horizontal flow in the alluvial aquifer is from the perimeter toward the center of the aquifer and then southward toward the Gulf of Mexico. Horizontal flow in permeable zone A is generally from the updip limit southward toward the coastline. Horizontal flow offshore is generally less than in most onshore areas, and direction of flow offshore is influenced by variations in water density within permeable zone A. Horizontal flows are large because the geometric mean hydraulic conductivity of the alluvial aquifer is about $316 \mathrm{ft} / \mathrm{d}$ and in permeable zone $A$ is about $156 \mathrm{ft} / \mathrm{d}$ (table 3 ).

Downward leakage of precipitation that reaches the saturated zone discharges to major streams. Leakage to the underlying permeable zone B (lower Pleistocene-upper Pliocene deposits) from permeable zone A occurs in less than 5 percent of the onshore area (fig. 4). Upward leakage of ground water from underlying deposits occurs in more than 95 percent of the onshore area underlain by the alluvial aquifer and permeable zone $\mathrm{A}$. The water leaking upward from underlying deposits generally has larger to much larger concentrations of dissolved solids than the water moving horizontally through the aquifer from outcrop areas. Thus upward leakage has the potential to affect the chemistry of the ground water in the alluvial aquifer and permeable zone A. The effects of upward leakage are discussed by subarea in the subsequent section in which the chemistry of the ground water is related to chemical and physical processes. 


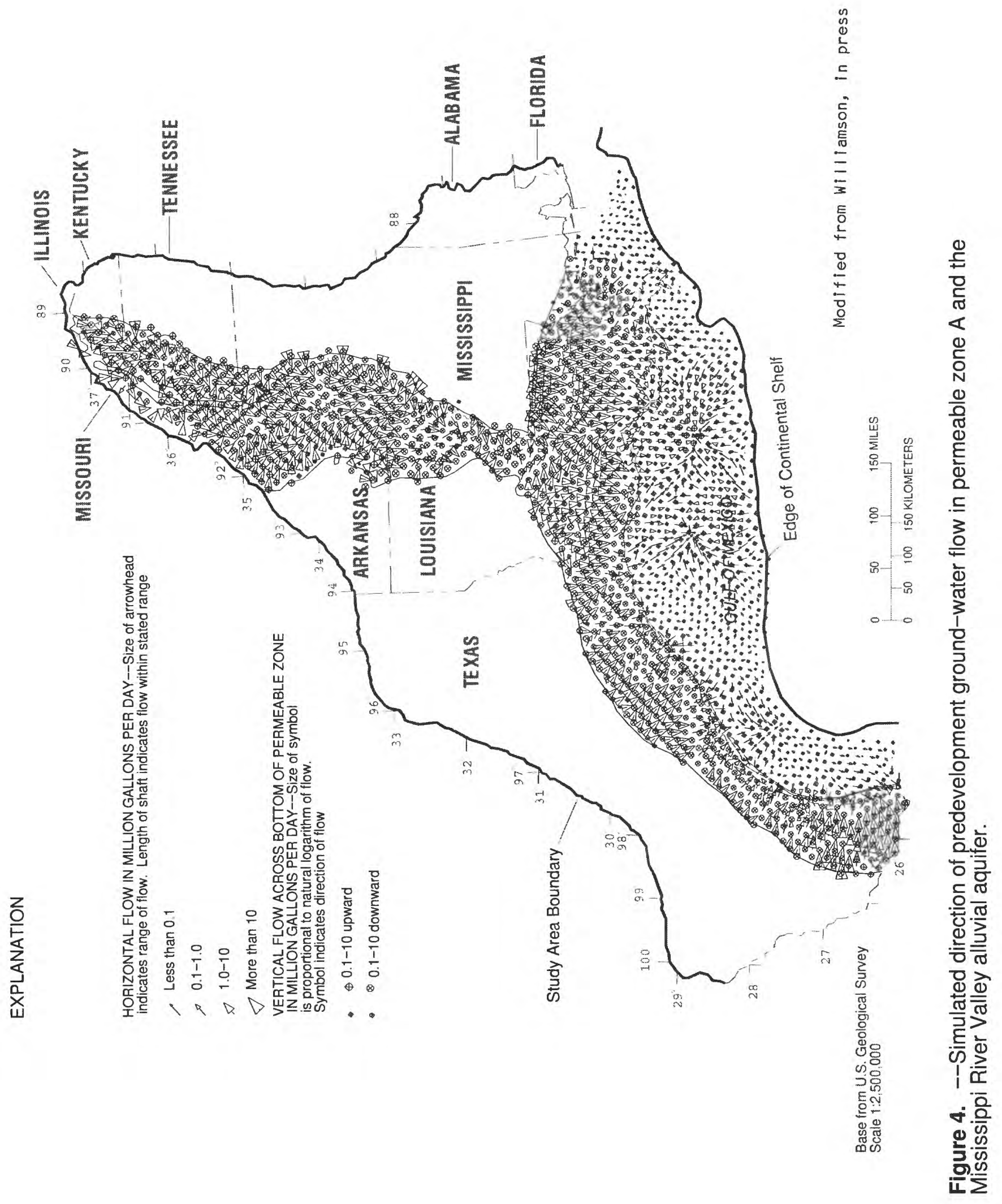


TABLE 5.--Median value of selected chemical constituents and properties of water, median sampling depth, water types, and number of analyses for each subarea of the Mississippi River Valley alluvial aquifer and permeable zone A (Holocene-upper Pleistocene deposits)

[Concentrations are in milligrams per liter, except iron and manganese, which are in micrograms per liter. Depth is in feet, $\mathrm{pH}$ is in units, and temperature is in degrees Celsius. Chemical symbols: $\mathrm{Ca}$, calcium; $\mathrm{Mg}$, magnesium; $\mathrm{Na}$, sodium; $\mathrm{K}$, potassium; $\mathrm{Fe}$, iron; $\mathrm{Mn}$, manganese; $\mathrm{HCO}_{3}$, bicarbonate; $\mathrm{SO}_{4}$, sulfate; $\mathrm{Cl}$, chloride; $\mathrm{SiO}_{2}$, silica. Water type shown is the most frequently occurring]

\begin{tabular}{|c|c|c|c|c|c|c|}
\hline \multirow{3}{*}{$\begin{array}{l}\text { Constituent or } \\
\text { property }\end{array}$} & \multicolumn{2}{|c|}{ Alluvial aquifer } & \multicolumn{4}{|c|}{ Permeable zone A } \\
\hline & \multicolumn{6}{|c|}{ Subarea } \\
\hline & 1 & 2 & 1 & 2 & 3 & $4 *$ \\
\hline $\mathrm{Ca}$ & 62 & 96 & 34 & 42 & 59 & 964 \\
\hline $\mathrm{Mg}$ & 17 & 33 & 8 & 15 & 34 & 645 \\
\hline $\mathrm{Na}$ & 13 & 73 & 37 & 183 & 620 & 5.170 \\
\hline $\mathrm{K}$ & 1.8 & 3.4 & 2.0 & 2.9 & 11 & 42 \\
\hline $\mathrm{Fe}$ & 840 & 2.200 & 845 & 340 & 185 & 140.000 \\
\hline $\mathrm{Mn}$ & 340 & 360 & 195 & 100 & 300 & 4.200 \\
\hline $\mathrm{HCO}_{3}$ & 276 & 453 & 220 & 366 & 416 & 244 \\
\hline $\mathrm{SO}_{4}$ & 8.9 & 29.5 & 3.0 & 11 & 27 & 2,500 \\
\hline $\mathrm{Cl}$ & 9 & 92 & 24 & 182 & 890 & 9.950 \\
\hline $\mathrm{SiO}_{2}$ & 31 & 30 & 35 & 25 & 23 & 34 \\
\hline Dissolved solids & 290 & 644 & 280 & 750 & 2,140 & 19,400 \\
\hline Sampling depth & 100 & 97 & 200 & 250 & 219 & 47.5 \\
\hline $\mathrm{pH}$ & 7.3 & 7.3 & 7.2 & 7.6 & 7.6 & 6.7 \\
\hline Temperature & 17.0 & 18.5 & 21.5 & 22.5 & 22.0 & 24.0 \\
\hline Primary water type & $\mathrm{CaHCO}_{3}$ & $\mathrm{CaHCO}_{3}$ & $\mathrm{CaHCO}_{3}$ & $\mathrm{NaHCO}_{3}$ & $\mathrm{NaCl}$ & $\mathrm{NaCl}$ \\
\hline Secondary water type & $\mathrm{MgCl}$ & $\mathrm{MgCl}$ & $\mathrm{CaCl}$ & $\mathrm{CaCl}$ & $\mathrm{CaHCO}_{3}$ & $\mathrm{MgSO}_{4}$ \\
\hline Number of analyses & 529 & 152 & 1.017 & 960 & 133 & 18 \\
\hline
\end{tabular}

* Areal distribution of data inadequate for mapping extent of subarea.

\section{DISSOLVED-SOLIDS CONCENTRATIONS}

The areal distribution of the median concentration of dissolved solids per 100-square-mile area in water of the Mississippi River Valley alluvial aquifer and permeable zone A (Holocene-upper Pleistocene deposits) is shown on figure 5. The delimited area of the combined alluvial aquifer and permeable zone A having median concentrations of dissolved solids of less than $500 \mathrm{mg} / \mathrm{L}$ encompasses about 80 percent of the alluvial aquifer and about 35 percent of the onshore part of permeable zone A. This delimited area includes the northern one- half of permeable zone A from central Texas to the southern border of Mississippi and for the alluvial aquifer from southern Illinois to east-central Louisiana. 


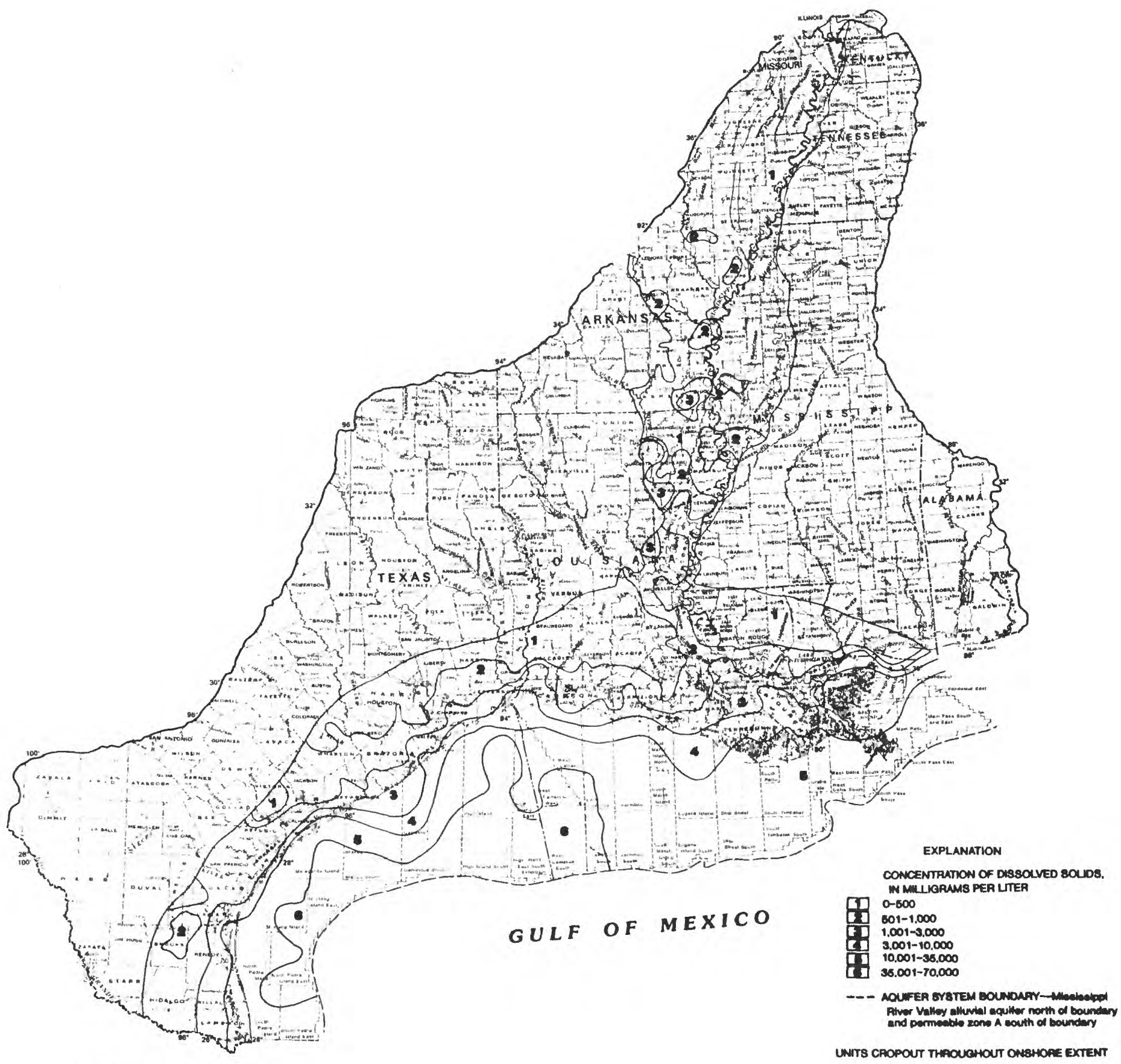

Modilied from Pettljotn and others. 1906 
The delimited area of permeable zone A having median concentrations of dissolved solids ranging from 500 to $1,000 \mathrm{mg} / \mathrm{L}$ is mostly adjacent and downdip from the less than $500 \mathrm{mg} / \mathrm{L}$ delimited area of permeable zone A. However, in the area underlain by the alluvial aquifer, the 500 to $1,000 \mathrm{mg} / \mathrm{L}$ delimited area occurs as several isolated areas surrounded by the less than $500 \mathrm{mg} / \mathrm{L}$ delimited area. The alluvial aquifer has only two small areas with median dissolved-solids concentrations ranging from 1,000 to $3,000 \mathrm{mg} / \mathrm{L}$. The delimited area of permeable zone A having median concentrations of dissolved solids ranging from 1,000 to $3,000 \mathrm{mg} / \mathrm{L}$ and 3,000 to $10,000 \mathrm{mg} / \mathrm{L}$ are mostly adjacent and downdip from the 500 to $1,000 \mathrm{mg} / \mathrm{L}$ delimited area except in southern Texas where the 1,000 to 3,000 $\mathrm{mg} / \mathrm{L}$ delimited area begins at the updip limit of permeable zone A. Both delimited areas are generally narrow in the downdip direction, indicating that they are transition zones where the ground water is changing from fresh or slightly saline to highly saline or brine. The 3,000 to $10,000 \mathrm{mg} / \mathrm{L}$ delimited area is partly on land and extends downdip to or near the shoreline except in southeast Texas and southern Louisiana where it extends offshore onto the Continental Shelf. The delimited area of permeable zone A having concentrations ranging from 10,000 to 35,000 and $35,000 \mathrm{mg} /$ L or greater are primarily on the Continental Shelf. The data used to map concentration of dissolved solids offshore primarily were from borehole geophysical logs (Weiss, 1987).

\section{PRIMARY WATER TYPES}

The primary water types are shown on figure 6 . In those areas where the median concentration of dissolved solids are less than $500 \mathrm{mg} / \mathrm{L}$ the primary water type is generally calcium bicarbonate in the area underlain by the Mississippi River Valley alluvial aquifer and sodium bicarbonate in the area underlain by permeable zone A. There are a few isolated areas underlain by the alluvial aquifer that have predominant water types other than calcium bicarbonate. These isolated areas are concentrated in northeastern Louisiana (fig. 6). In areas underlain by permeable zone A where the median concentration of dissolved solids ranges from 500 to $10,000 \mathrm{mg} / \mathrm{L}$, the primary water type is sodium bicarbonate except in southern Texas and along the gulf coast shoreline where the primary water type is sodium chloride. No water-quality data were available for mapping water type south of the shoreline on the Continental Shelf.

\section{GROUND-WATER CHEMISTRY WITHIN SUBAREAS}

The Mississippi River Valley alluvial aquifer was divided into two chemically distinct subareas as described in the "Introduction," and the boundary was adjusted using discriminant function analysis of the chemical data from the subareas. Subarea 1 (fig. 7) extends from southern Illinois to northeastern Louisiana and is about 80 percent of the area underlain by the Mississippi River Valley alluvial aquifer. Subarea 2 is primarily in the southern part of the area underlain by the aquifer and generally lies west of the Mississippi River. Chemical data are adequate to define subarea 2 throughout about $5,400 \mathrm{mi}^{2}$ of the aquifer area. The subarea is made up of three contiguous areas and many small isolated areas.

Permeable zone A (Holocene-upper Pleistocene deposits) was divided into four chemically distinct subareas, and the boundaries were adjusted using discriminant function analysis of the chemical data from the subareas. Subarea 1 (fig. 7) is underlain by that part of permeable zone A that extends from southeastern Texas along the northern boundary of permeable zone A across Louisiana to near the coast of southern Mississippi. It also extends about 80 mi northward in a narrow band 10 to $20 \mathrm{mi}$ wide along the western side of the Mississippi River in east-central Louisiana.

Subarea 2 of permeable zone A is largely adjacent and downdip from subarea 1 and extends discontinuously from southern Texas eastward across southern Louisiana to about the Pearl River. Chemical data are adequate to define subarea 3 throughout about $2,700 \mathrm{mi}^{2}$ of the permeable zone. Two small contiguous areas of subarea 3 occur in southern Texas and in southeastern Louisiana. Elsewhere subarea 3 is composed of 100 -square-mile areas that are largely adjacent to and downdip from subarea 2 and extends from near the Rio Grande eastward along the coastline to southeastern Louisiana. There are 18 analyses (table 5) of ground water from subarea 4; however, the sampled wells are clustered in three 100-square-mile areas (fig. 7) and are inadequate to define the areal extent of the subarea. 


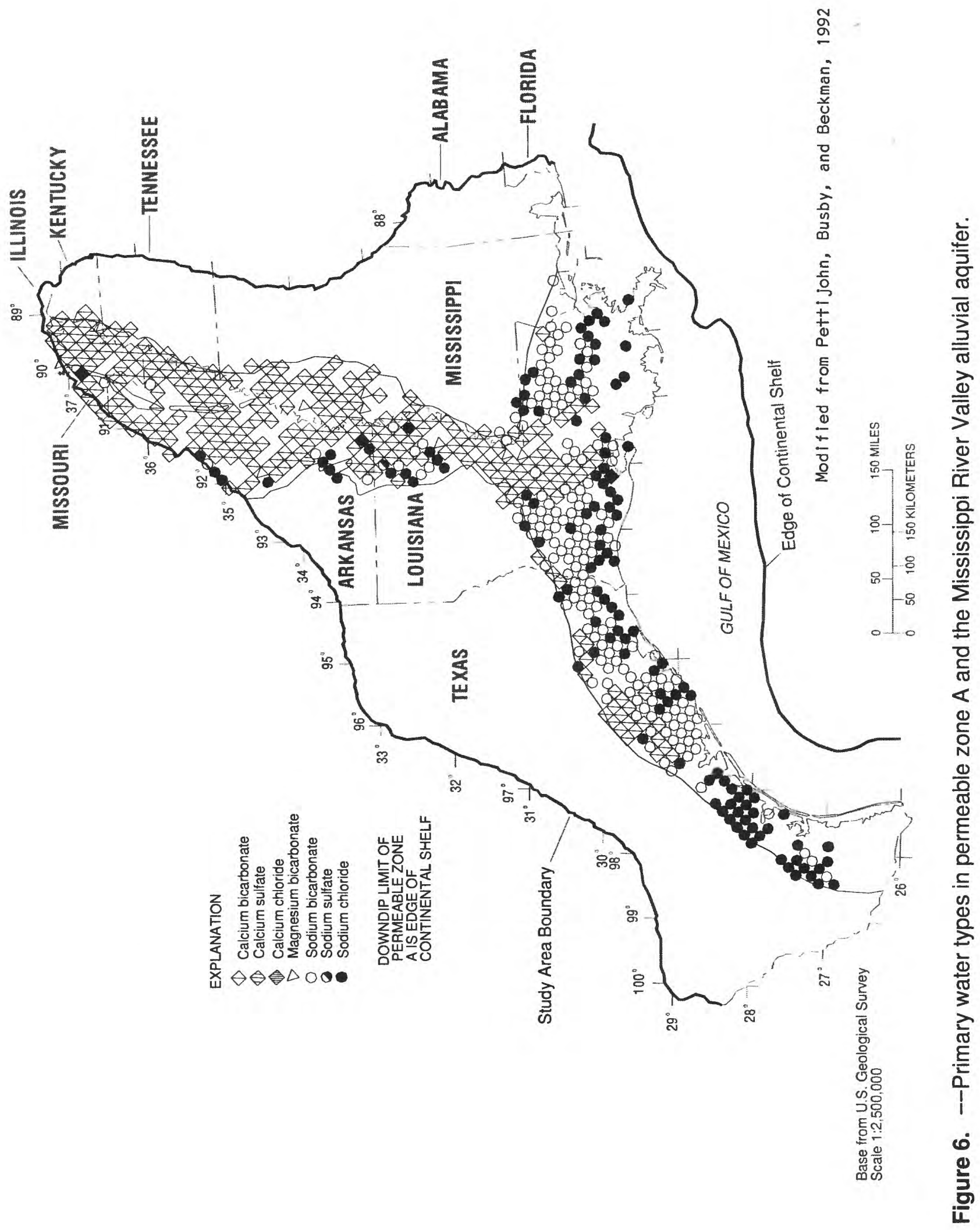




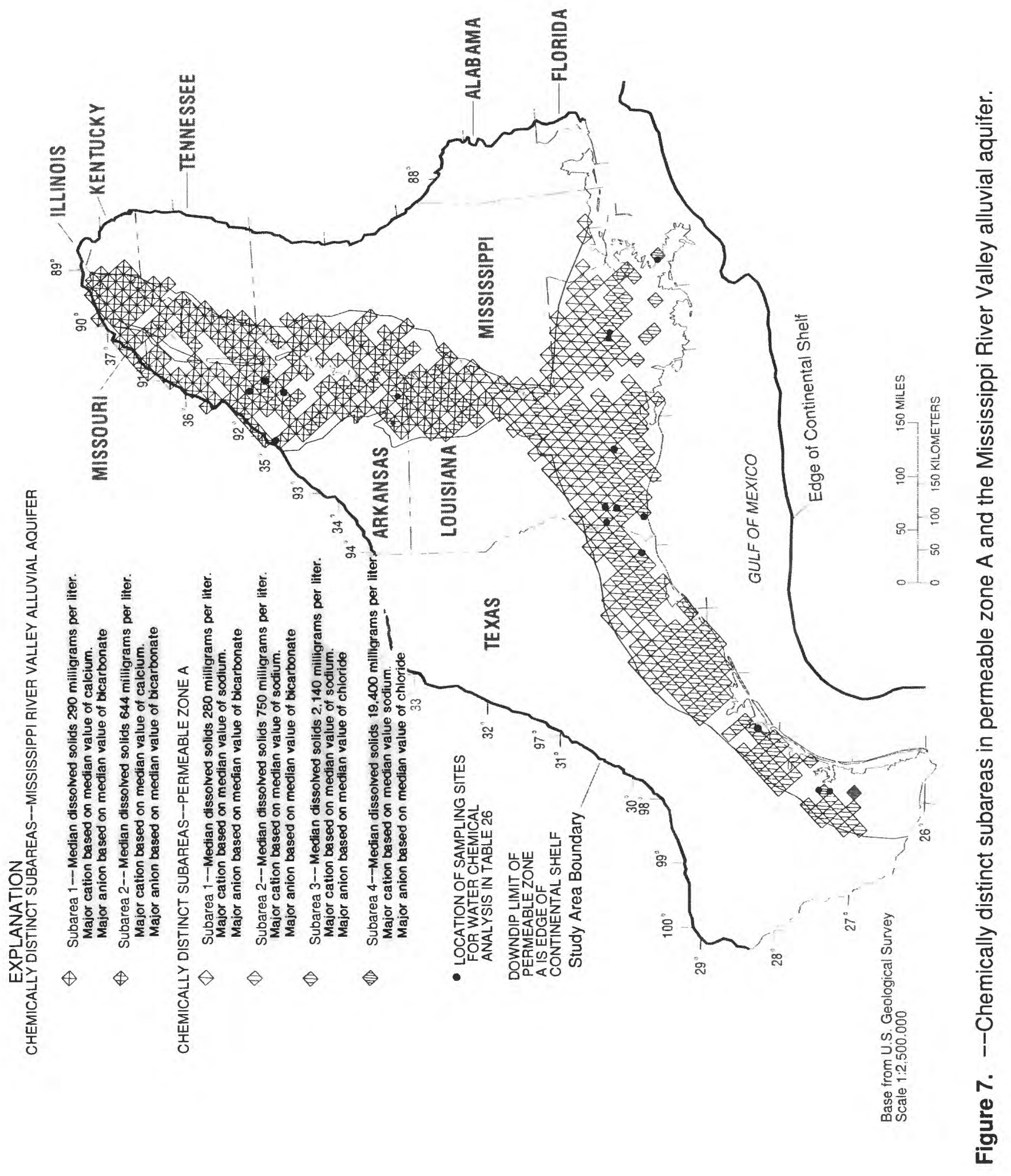


The median value for selected chemical constituents and primary and secondary water types for each of the subareas in the alluvial aquifer are shown in table 5. Major cations, anions, and dissolved-solids concentrations in the ground water of the alluvial aquifer are greater in subarea 2 than in subarea 1 . Among the major cations, calcium and sodium are 34 and $60 \mathrm{mg} / \mathrm{L}$, respectively, greater in subarea 2 than in subarea 1 , whereas the anion bicarbonate is 177 $\mathrm{mg} / \mathrm{L}$ greater and chloride is $83 \mathrm{mg} / \mathrm{L}$ greater in subarea 2 than in subarea 1 . The primary water type in both subareas is calcium bicarbonate (table 5). Also, the trilinear diagram (fig. 8), based on three representative samples from each subarea, shows as does figure 6 that water in the Mississippi River Valley alluvial aquifer is predominantly calcium bicarbonate in both subareas 1 and 2 (fig. 7).

The trilinear diagram (fig. 8) also shows that major cation composition is approximately 85 percent magnesium plus calcium in subarea 1 and 70 percent magnesium plus calcium in subarea 2 of the alluvial aquifer. The major anions composition is 89 percent bicarbonate plus carbonate in subarea 1 and 67 percent bicarbonate plus carbonate in subarea 2. Likewise the concentrations of magnesium plus calcium are greater than sodium plus potassium in the ground water of both subareas of the alluvial aquifer (fig. 8, table 5). The difference between the two pairs of cations is greater in subarea 1 than in subarea 2, whereas the dissolved-solids concentration is about 55 percent greater in subarea 2 than in subarea 1; thus sodium plus potassium concentrations account for proportionately more of the dissolved-solids concentrations than magnesium plus calcium in subarea 2 than in subarea 1.

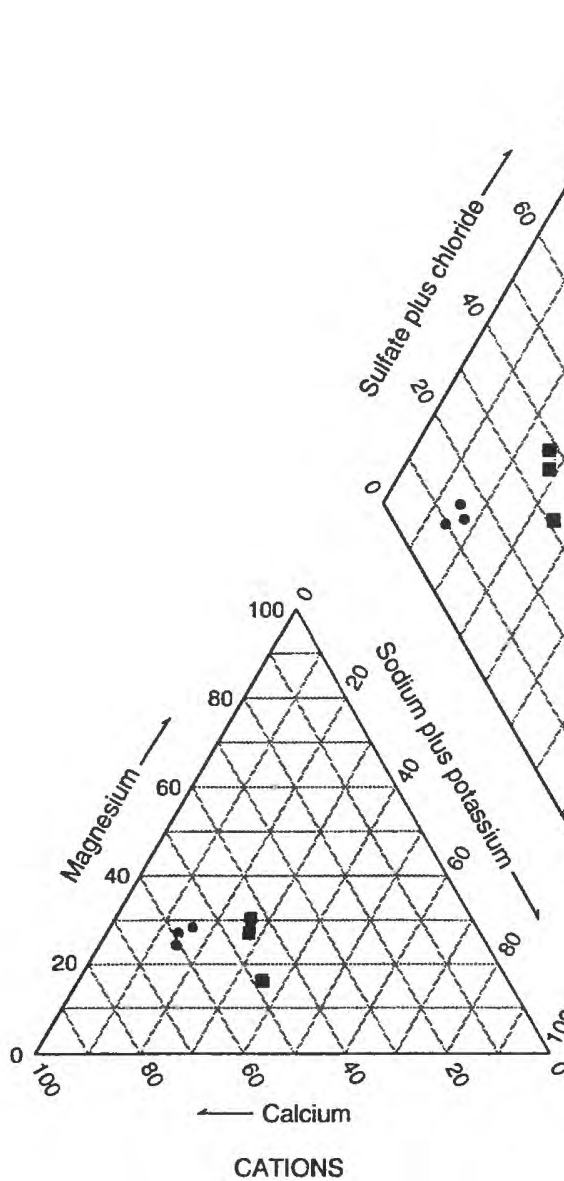

\section{EXPLANATION}

- Subarea 1

- Subarea 2

$80^{\circ}$

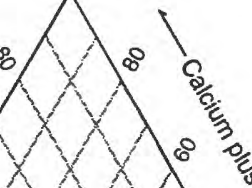

竞
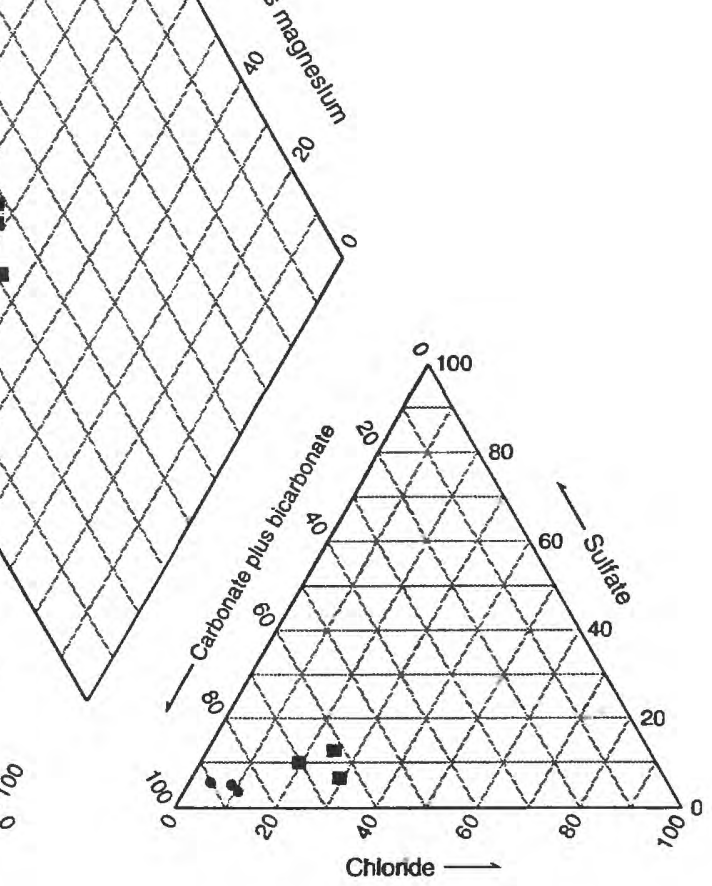

ANIONS

\section{PERCENTAGE REACTING VALUES}

Figure 8.--Change in water chemistry from subarea to subarea in the Mississippi River Valley alluvial aquifer, based on three representative samples. 
The median value for selected chemical constituents and primary and secondary water types for each of the subareas in permeable zone $\mathrm{A}$ is shown in table 5. Major cations and dissolved solids increase in concentration in the ground water from subarea 1 to subarea 4 . Among the major anions, the concentration of only chloride and sulfate increase progressively from subarea 1 to subarea 4 . Bicarbonate increases in concentration from subarea 1 to subarea 3 and than decreases in subarea 4 . The concentration of iron decreases from subarea 1 to subarea 3 , and than increases substantially in subarea 4. Manganese decreases from subarea 1 to subarea 2 and than increases in subarea 3 and again in subarea 4. The most frequently occurring primary water type is calcium bicarbonate in subarea 1, sodium bicarbonate in subarea 2, and sodium chloride in subareas 3 and 4 . The trilinear diagram (fig. 9), based on three representative samples from each subarea, shows as does figure 6 that water from permeable zone A typically is calcium bicarbonate in subarea 1 , sodium chloride and sodium bicarbonate in subarea 2 , and sodium chloride in subareas 3 and 4 . The major cations composition of water from permeable zone $A$ is about 57 percent magnesium plus calcium in subarea 1 and about 26 percent magnesium plus calcium in subarea 4 (fig. 9). The major anions composition is 81 percent bicarbonate plus carbonate in subarea 1 and 4 percent bicarbonate plus carbonate in subarea 4.

\section{EXPLANATION \\ - Subarea 1 \\ - Subarea 2 \\ - Subarea 3 \\ - Subarea 4}

Numeral by symbol indicates number of points at that location

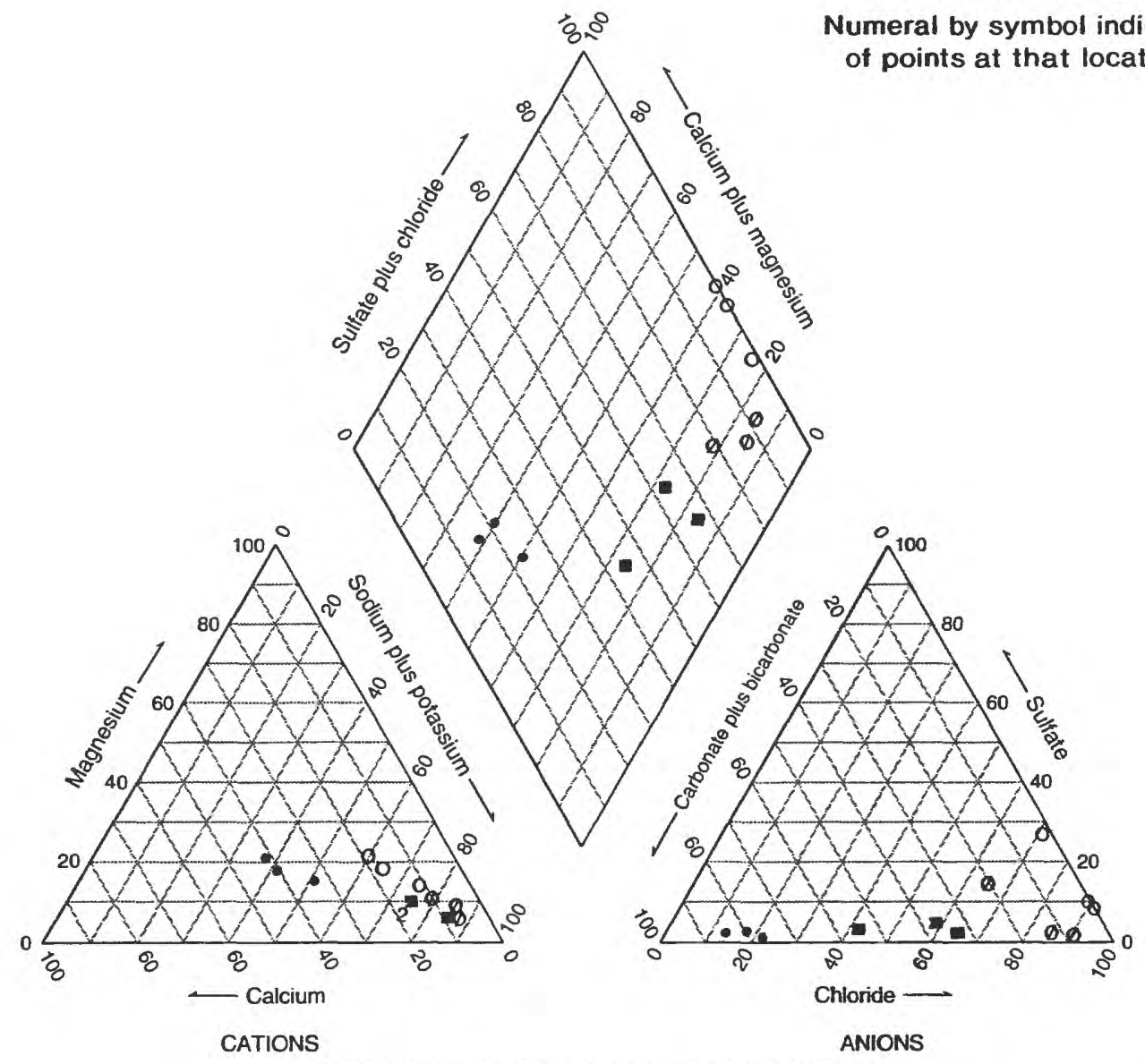

PERCENTAGE REACTING VALUES

Figure 9.--Change in water chemistry from subarea to subarea in permeable zone A (Holocene-upper Pleistocene deposits), based on three representative samples. 
The triangular part of figure 9 and the data in table 5 show that the major anions, bicarbonate plus carbonate, decrease progressively from about 81 percent in subarea 1 , to about 43 percent in subarea 2 , and to about 10 percent in subarea 3, whereas the percentage of chloride increases from about 20 percent in subarea 1 to about 85 percent in subarea 3. The major cation decreases from about 60 percent calcium in subarea 1 to about 10 percent in subarea 3 , whereas magnesium remains relatively unchanged. Sodium plus potassium increases from about 40 percent in subarea 1 to about 85 percent in subarea 3. Median dissolved-solids concentrations increase by a factor of almost 10 from subarea 1 to subarea 3 . The few analyses representing subarea 4 indicate that the water from this part of permeable zone $A$ is different from that in subarea 3 (table 5), but because of the clustering of the data the areal extent of subarea 4 cannot be defined. However, the area underlain by permeable zone $A$ that has water similar to subarea 4 probably is large because a vast area on the Continental Shelf has dissolved-solids concentrations greater than $35,000 \mathrm{mg} / \mathrm{L}$ (fig. 5).

\section{CORRELATION AMONG CHEMICAL CONSTITUENTS AND PROPERTIES OF GROUND WATER}

\section{WITHIN SUBAREAS}

The correlation among chemical constituents and properties was evaluated by factor analysis, which indicates that at least two major chemical processes or mechanisms are responsible for most of the variability in concentrations of constituents in each of the subareas of the Mississippi River Valley alluvial aquifer and permeable zone A (tables 6, 7). Thirteen constituents or properties were used in the factor analysis. The number of chemical analyses was 529 in subarea 1 and 152 in subarea 2 of the Mississippi River Valley alluvial aquifer (table 5). The number of chemical analyses was 1,017 in subarea 1,960 in subarea 2, 133 in subarea 3, and 18 in subarea 4 of permeable zone A (table 5).

TABLE 6.--Factor loading and percent communalities for water chemistry in each subarea of the Mississippi River Valley alluvial aquifer

[Bold type indicates significant factor value]

\begin{tabular}{|c|c|c|c|c|c|c|}
\hline \multirow[b]{2}{*}{$\begin{array}{c}\text { Constituent or } \\
\text { property }\end{array}$} & \multicolumn{3}{|c|}{ Subarea 1} & \multicolumn{3}{|c|}{ Subarea 2} \\
\hline & Factor I & Factor II & $\begin{array}{c}\text { Percent } \\
\text { Communality }\end{array}$ & Factor I & Factor II & $\begin{array}{c}\text { Percent } \\
\text { Communality }\end{array}$ \\
\hline Dissolved solids & 0.87 & 0.42 & 93.3 & 0.93 & 0.26 & 93.2 \\
\hline Calcium & .94 & .12 & 89.8 & .28 & .89 & 87.0 \\
\hline Magnesium & .87 & .20 & 79.7 & .43 & .75 & 74.7 \\
\hline Potassium & .12 & .12 & 2.9 & .52 & .02 & 27.1 \\
\hline Sodium & .08 & .76 & 58.4 & .95 & -.15 & 92.5 \\
\hline Chloride & -.16 & .68 & 48.8 & .91 & -.09 & 83.6 \\
\hline Sulfate & .12 & .14 & 3.4 & -.17 & .37 & 16.6 \\
\hline Bicarbonate & .92 & -.03 & 84.7 & .17 & .29 & 11.3 \\
\hline Iron & .20 & -.07 & 4.5 & .17 & .21 & 7.3 \\
\hline Manganese & .02 & .04 & .2 & .05 & .33 & 11.2 \\
\hline Silica & -.02 & .06 & .4 & -.08 & .29 & 9.0 \\
\hline $\mathrm{pH}$ & .44 & -.23 & 24.6 & .01 & -.17 & 2.9 \\
\hline Sampling depth. & .27 & .02 & 7.3 & -.24 & -.10 & 6.8 \\
\hline $\begin{array}{l}\text { Percent variability } \\
\text { accounted for by the } \\
\text { respective } \\
\text { number of factors }\end{array}$ & $54.1+$ & $18.1=72$ & & $43.9+$ & $20.8=6$ & \\
\hline
\end{tabular}


The percent variability accounted for by the factors is 64.7 in subarea 2 and 72.2 in subarea 1 of the Mississippi River Valley alluvial aquifer (table 6). The loading of each constituent or property on each factor and the percent of total variability of each constituent or property (communality) accounted for in the factor analysis are shown in table 6. Factor I of subarea 1 represents a process in which calcium, magnesium, and bicarbonate ions are added to the ground water and hydrogen ions are removed. Factor II of subarea 1 represents a process in which sodium and chloride ions are added to the ground water. The variability in concentrations of constituents and properties of water accounted for by factor I is about 54 percent and by factor II is about 18 percent. The variability in concentration of dissolved solids accounted for by factor I is 87 percent and significant, whereas for factor II it is 42 percent and nonsignificant.

Factor I of subarea 2 represents a process in which sodium, chloride, and potassium ions are added to the ground water. Factor II of subarea 2 represents a process in which calcium and magnesium ions are added to the ground water. The variability in concentrations of constituents and properties of water accounted for by factor I is about 44 percent and by factor II is about 21 percent. The variability in concentration of dissolved solids accounted for by factor I is 93 percent and significant, whereas for factor II it is 26 percent and nonsignificant.

\section{PERMEABLE ZONE A}

The percent variability accounted for by the factors range from 68.2 in subarea 1 of permeable zone A to 80.7 in subarea 4. The loading of each constituent or property on each factor and the percent of total variability of each constituent or property (communality) accounted for in the factor analysis are shown in table 7. Factor I of subarea 1 of permeable zone A represents processes in which calcium, magnesium, bicarbonate, iron, and manganese ions are added to the ground water. Factor II of subarea 1 represents a process in which sodium and bicarbonate ions are added to the ground water and hydrogen ions are removed. The variability in concentrations of constituents and properties of water accounted for by factor I is about 51 percent and by factor II is about 17 percent. The variability in concentration of dissolved solids accounted for by factor I is 63 percent and significant, and for factor II it is 75 percent and also significant.

Factor I of subarea 2 of permeable zone A represents a process in which sodium and chloride ions are added to the ground water. Factor II of subarea 2 represents processes in which calcium, magnesium, and hydrogen ions are added to the ground water. In addition, the effect of the processes on the water chemistry decreases with depth. The inverse loading of sodium on this factor, although not considered significant, indicates that sodium ions are being removed from solution. The variability in concentrations of constituents and properties of water accounted for by factor I is about 37 percent and by factor II is about 32 percent. The variability in concentration of dissolved solids accounted for by factor I is 97 percent and significant, whereas for factor II it is 18 percent and nonsignificant.

Factor I of subarea 3 of permeable zone A represents processes in which sodium, chloride, magnesium, calcium, and sulfate ions are added to the ground water. Factor II of subarea 3 represents a process in which calcium, magnesium, and hydrogen ions are added to the ground water. In addition, there is a diminishing effect of the process on the chemistry of the ground water with depth. Although not considered significant, there is inverse loading of sodium on this factor. The variability in concentrations of chemical constituents and properties of water accounted for by factor I is about 50 percent and by factor II is about 22 percent. The variability in concentration of dissolved solids accounted for by factor I is 99 percent and significant, whereas for factor II it is a negative 1 percent and nonsignificant.

Factor I of subarea 4 of permeable zone A represents processes in which calcium, magnesium, sodium, potassium, sulfate, and chloride ions are added to the ground water, and iron and manganese ions are removed. The inverse loading of depth on this factor indicates that the process is occurring at shallow depths. Factor II of subarea 4 represents processes in which potassium and most likely magnesium, sodium, chloride, and bicarbonate ions are added to the ground water, and hydrogen, iron, and manganese ions are removed. The variability in concentrations of chemical constituents and properties of water accounted for by factor I is about 66 percent and by factor II is about 15 percent. The variability in concentration of dissolved solids accounted for by factor $I$ is 81 percent and significant, and for factor II it is 53 percent and also significant. 


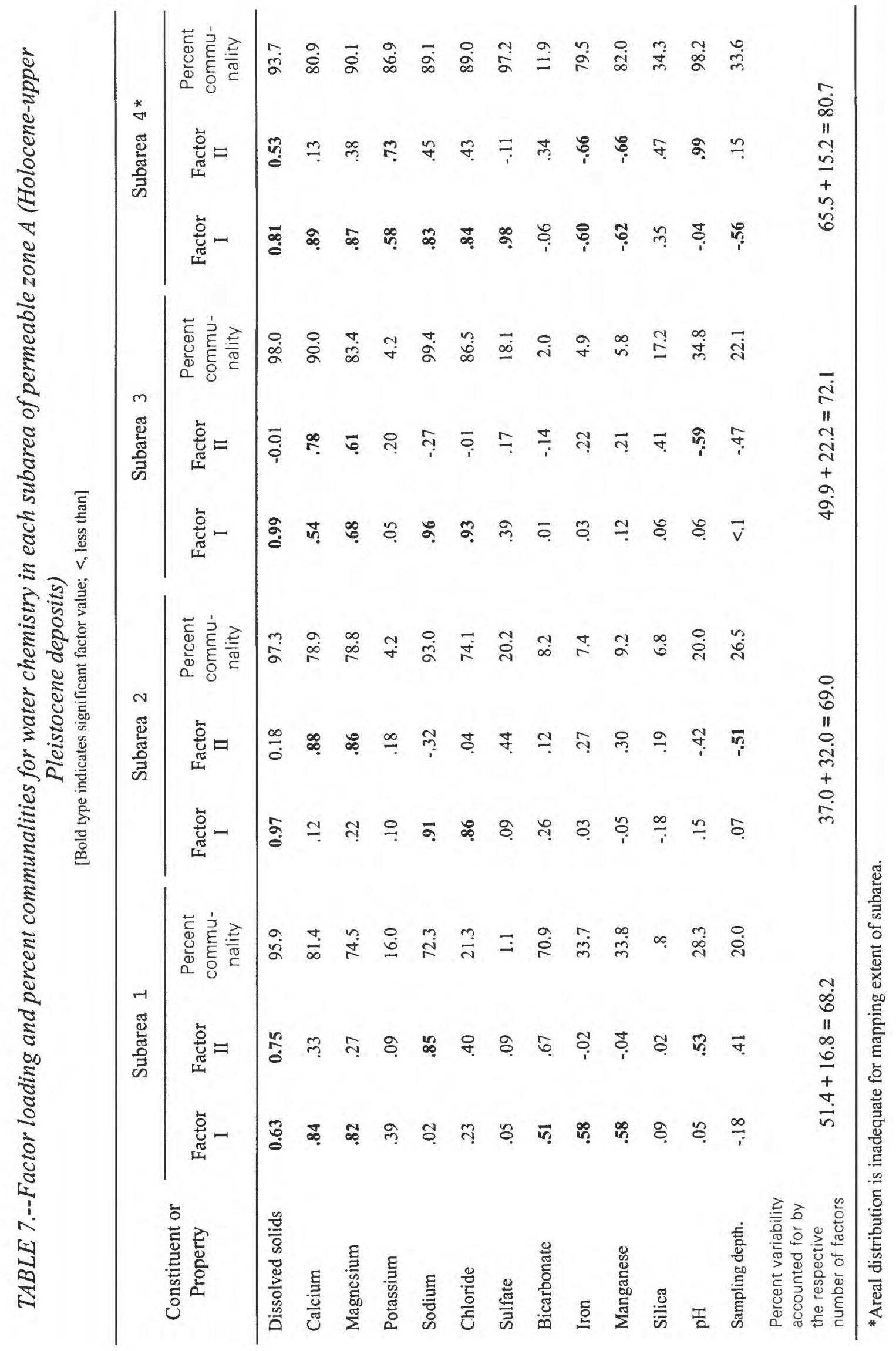




\section{RELATION OF GROUND-WATER CHEMISTRY TO CHEMICAL AND PHYSICAL PROCESSES}

The major chemical processes and mechanisms postulated for each of the chemically distinct subareas in the Mississippi River Valley alluvial aquifer and permeable zone A (Holocene-upper Pleistocene deposits) are based on the results of factor analysis in conjunction with constituent concentrations, trilinear diagrams, ground-water movement, and information on water-rock interaction and probable minerals in the deposits.

\section{ALLUVIAL AQUIFER}

The major processes postulated in subarea 1 of the alluvial aquifer are (1) dissolution of carbonate minerals such as calcite, magnesite, and dolomite (factor I), and (2) leaching of soluble salts from the unsaturated zone (factor II). The postulated dissolution of carbonates in area 1 accounts for about 36 percent more of the variability in concentrations of constituents than does the leaching of soluble salts from the unsaturated zone. Carbonate dissolution also accounts for 45 percent more of the variation in the concentration of dissolved solids than leaching of soluble salts in subarea 1.

Hydrologic, geologic, and related information that supports the two processes postulated above for chemically distinct subarea 1 are discussed briefly in the context of the water chemistry and results of factor analysis of the chemical data. The dissolution of calcite, magnesite, and dolomite (eq. 4) are supported by (1) the predominance of bicarbonate and magnesium plus calcium ions as the major constituents in the ground water (table 5), (2) the presence of carbonate minerals in these types of sediments (Sniegocki, 1964), and (3) acidified recharge water, which aids in dissolving carbonates (Freeze and Cherry, 1979). Dissolution of carbonate minerals would remove hydrogen ions from solution, which is indicated by the near significant loading of $\mathrm{pH}$ on factor $\mathrm{I}$.

Leaching of soluble salts from the unsaturated zone (eq. 15) is supported by (1) the fact that this unit is exposed at the surface, consequently precipitation passes through the soil zone leaching soluble salts as it percolates to the water table; (2) the high precipitation in the subarea; and (3) the concentration of major ions in ground water of this subarea (table 5) are in the range characteristic of leaching. Downward leakage of recharge water from precipitation in subarea 1 to the saturated zone of the Mississippi River Valley alluvial aquifer is probable because the unit crops out throughout the subarea. However, very little leakage from this unit to the underlying units occurs (fig. 4), indicating that recharge water that reaches the water table in the alluvial aquifer discharges to major stream drainage or to local ground-water discharge. Thus the major effect of downward leakage on the chemistry of the ground water in this subarea comes from the recharge water (1) absorbing oxygen and carbon dioxide gases, which then react with minerals present, and (2) leaching soluble salts from the soil zone. Upward leakage of water from underlying deposits (eq. 16) occurs throughout much of subarea 1 . However, the effect of the leakage appears to have been largely accounted for in redefining the subarea boundary through discriminant function analysis. This is indicated by the appearance of isolated pockets of subarea 2 in the original subarea 1 part of the alluvial aquifer.

The major processes controlling ground-water chemistry in subarea 2 of the alluvial aquifer are postulated to be (1) upward leakage of ground water from underlying deposits due to hydraulic-head differences (factor 1), and (2) leaching of soluble salts from the unsaturated zone (factor II). The postulated dissolution of carbonates in subarea 1 accounts for about 36 percent more of the variability in concentrations of constituents than does the leaching of soluble salts from the unsaturated zone. Carbonate dissolution also accounts for 45 percent more of the variation in the concentration of dissolved solids than leaching of soluble salts in subarea 2.

Hydrologic, geologic, and related information that supports the two processes postulated above for chemically distinct subarea 2 are discussed briefly in the context of the water chemistry and results of factor analysis of the chemical data. Upward leakage of ground water from underlying aquifers (eq. 16) is supported by (1) simulated predevelopment flow that shows vertical movement of ground water from underlying aquifers to the alluvial aquifer (fig. 4), (2) the absence of any confining unit between the alluvial aquifer and the underlying aquifers (table 2), (3) the larger median concentrations of dissolved solids and sodium and chloride ions in subarea 2 than in subarea 1 (table 5), and (4) the larger median concentration of dissolved solids and sodium and chloride ions in ground water from the underlying aquifers (table 8). 
Leaching of soluble salts from the unsaturated zone (eq. 15) is possible because the entire subarea is open to recharge from precipitation. Movement downward of precipitation through the unsaturated zone has the effect of leaching of soluble salts from the soil zone and increasing slightly to moderately their concentration in the ground water. Downward leakage of precipitation through the unsaturated zone to the water table carries dissolved gases and salts as in subarea 1 of the alluvial aquifer. The dissolved gases, primarily oxygen and carbon dioxide, increase the solvent action of ground water, whereas the dissolved salts increase the concentration of dissolved solids in the ground water. Upward leakage from underlying aquifers occurs in about 95 percent of the aquifer area underlain by the Mississippi River Valley alluvial aquifer. Upward leakage is postulated to be the process that is primarily responsible for redefining the boundary between subarea 1 and subarea 2 as a result of linear discriminant function analysis.

\section{PERMEABLE ZONE A}

The major processes postulated in subarea 1 of permeable zone A are (1) dissolution of carbonate minerals (factor I), and (2) alteration of albite (factor II). The postulated dissolution of carbonates accounts for about 34 percent more of the variability in concentrations of constituents than does the alteration of albite. The alteration of albite in subarea 1 accounts for 12 percent more of the variation in concentration of dissolved solids than does the dissolution of carbonates, thus suggesting that dissolution of carbonate minerals and the alteration of albite are the major processes controlling the water chemistry in subarea 1.

Hydrologic, geologic, and related information that supports the two processes postulated above for chemically distinct subarea 1 are discussed briefly in the context of the water chemistry and results of factor analysis of the chemical data. The dissolution of carbonate minerals (eq. 4) is supported by (1) the predominance of bicarbonate and magnesium plus calcium ions as the major constituents in the ground water (table 5), (2) the reported presence of gravel beds cemented by caliche (Plummer, 1932), and (3) the presence of acidified recharge water, which aids in dissolving carbonates. The source of the calcium and magnesium ions is caliche. The larger concentration of bicarbonate ions in comparison to other major ions is attributed to dissociation of carbonic acid that was formed when carbon dioxide from the soil and air is dissolved in recharge water.

Alteration of albite-type feldspar (eq. 1) is supported by (1) the universal presence of feldspar in most sedimentary rock (Foster, 1949), (2) the acidified ground water from precipitation recharge that would react with the albite to dissolve it (Drever, 1982), and (3) the reported presence of feldspar in an analyzed sample taken from these deposits (Plummer, 1932). Also, the concentration of bicarbonate ions in the ground water of subarea 1 is adequate for both dissolution of carbonates and the alteration of albite (table 5).

The major processes postulated in subarea 2 are (1) upward leakage of ground water from underlying deposits (factor I), (2) oxidation of pyrite and a subsequent reaction with calcite (factor II) (Drever, 1982), and (3) cation exchange (factor II). Comparison of the processes postulated from the results of factor analysis shows that the variability on factor I (table 7) represented by upward leakage from underlying deposits accounts for about 5 percent more of the variability in concentrations of constituents than factor II represented by the oxidation of pyrite and a subsequent reaction with calcite and cation exchange. The loading of dissolved solids on factor I is very high and significant, and its loading on factor II is low and nonsignificant, thus indicating that upward leakage accounts for most of the variation in concentration of dissolved solids in subarea 2.

Hydrologic, geologic, and related information that supports the three processes postulated above for chemically distinct subarea 2 are discussed briefly in the context of the water chemistry and results of factor analysis of the chemical data. Upward leakage of ground water from underlying deposits (eq. 16) is supported by (1) simulated predevelopment flow that shows vertical movement of ground water between the underlying deposits and permeable zone A is principally upward (fig. 4), (2) absence of a confining unit separating permeable zone A from permeable zone B (table 2), and (3) larger concentrations of dissolved solids in the underlying ground water that could increase ion concentrations in permeable zone $\mathrm{A}$ if leakage was significant (table 8). Although salt domes are reported to penetrate permeable zone $\mathrm{A}$ in subarea 2, the concentration of sodium and chloride ions are not as large as would be expected to attribute their presence to the dissolution of evaporites composing salt domes. 
Weathering (oxidation) of pyrite (eq. 13) and a subsequent reaction with calcite is supported by (1) the presence of caliche in samples taken from these deposits (Plummer, 1932), (2) the presence of oxygen in precipitation recharge water for the oxidation reaction, and (3) the slight increase in calcium, magnesium, and sulfate ions from subarea 1 to subarea 2 (table 5). Also, Hem (1985) and other investigators (Krauskopf, 1967; Foster, 1949) reported that sulfur is widely distributed in reduced form in sedimentary rock as metallic sulfides such as pyrite and constitute a source of both ferrous sulfide and sulfate ions in ground water. Cation exchange (eq. 3) of calcium and magnesium ions adsorbed on clays for sodium in the ground water is postulated because of the higher concentration of sodium ions that could cause the exchange to proceed due to mass action (Hem, 1985).

The major processes postulated in subarea 3 are (1) upward leakage from underlying deposits (factor I), and (2) cation exchange (factor II). Comparison of the processes postulated from the results of factor analysis shows that the variability on factor I (table 7) represented by dissolution of evaporites and upward leakage of ground water from underlying deposits accounts for 28 percent more of the variability in concentrations of constituents than factor II represented by cation exchange. The loading of dissolved solids on factor I is very high and significant, and its loading for factor II is very low, negative, and nonsignificant, thus indicating that dissolution of evaporites and upward leakage accounts for most of the variation in concentration of dissolved solids in subarea 3.

Hydrologic, geologic, and related information that supports the two processes postulated above for chemically distinct subarea 3 are discussed briefly in the context of the water chemistry and results of factor analysis of the chemical data. Upward leakage of ground water from underlying deposits (eq. 16) is supported by the same arguments given in subarea 2 for upward leakage as a major process affecting the ground-water chemistry. However, because salt domes are reported to penetrate the base of permeable zone A (Beckman and Williamson, 1990) and the concentrations of sodium and chloride ions are three and four times greater than in subarea 2, dissolution of evaporites (eq. 7) in salt domes is considered as a source of the sodium and chloride ions along with upward leakage. The trilinear diagram (fig. 5) shows that ground water in subarea 3 of permeable zone A is a sodium chloride water type. The most frequently occurring water type is also sodium chloride (table 5).

Leaching of soluble salts from the unsaturated zone (eq. 15) is nearly always present when the subarea is open to recharge from precipitation. However, the large concentration of sodium and chloride ions indicates that the magnitude of the effect of leaching on the water chemistry is small in comparison to the dissolution of evaporites and upward leakage. Cation exchange (eq. 3) is supported by the fact that when clays, which have calcium, magnesium, and hydrogen ions adsorbed on their surface, are immersed in highly concentrated sodium chloride waters, the sodium ions will exchange with these ions as a result of mass action (Hem, 1985). Also the inverse loading of sodium on the factor representing cation exchange indicates that sodium ions are being removed from solution. However, pyrite oxidation (eq. 13), which was postulated for subarea 2, could be adding hydrogen ions to the ground water even though iron and sulfate do not load significantly on factor II of subarea 3.

The major processes postulated in subarea 4 are (1) dissolution of evaporites in salt domes and associated caprock (factor I), (2) leaching of soluble salts from the unsaturated zone (factor II), and (3) weathering of potassium feldspar (factor II). Comparison of the processes postulated from the results of factor analysis shows that the variability on factor I (table 7) represented by the dissolution of evaporites in salt domes and associated caprock accounts for about 51 percent more of the variability in concentrations of constituents than factor II represented by the leaching of soluble salts from the unsaturated zone and weathering of potassium feldspar. The loading of dissolved solids on factor I is 28 percent larger than its loading on factor Il, thus indicating that dissolution of evaporites accounts for the largest part of the variation in the concentration of dissolved solids in subarea 4 . Although subarea 4 does not have the number of water analyses generally suggested for factor analysis, it was retained as a separate subarea because the concentrations of major ions in the ground water of this area were considered too large to make it a part of subarea 3. 
Hydrologic, geologic, and related information that supports the three processes postulated above for chemically distinct subarea 4 are discussed briefly in the context of the water chemistry and results of factor analysis of the chemical data. Dissolution of evaporites (eq. 7) in salt domes and associated caprock is supported by the large concentration of major ions in ground water of this subarea that are characteristic of the dissolution of anhydrites in caprock and halite in salt domes (Halbouty, 1979). Also, salt domes are reported to penetrate the base of permeable zone A in subarea 4 (Beckman and Williamson, 1990). The trilinear diagram (fig. 5) shows that ground water in subarea 4 of permeable zone $A$ is a sodium chloride type. The most frequently occurring water type, determined from the mode, is also sodium chloride (table 5).

Leaching of soluble salts from the unsaturated zone (eq. 15) is supported by the fact that all of the subarea is open to recharge from precipitation, and the depth of the aquifer in this subarea is shallow, which would enhance the effect of the leaching process. Although the cause of the large increase in iron and manganese ions and the negative loading of these constituents on both factors is not readily apparent, it is probably due to oxidation-reduction reactions (eq. 8) that are associated with leaching. For example, if ground water contains both ferrous ions and dissolved oxygen from the air, the ferrous iron may oxidize (eq. 14) to the ferric form and then precipitate as ferric hydroxide (Hem, 1985). Because of the shallowness of the aquifer in subarea 4, there most likely would be oxygen dissolved in the ground water to support oxidation and carbon dioxide to change $\mathrm{pH}$ and the solubility of iron.

Weathering of potassium feldspar (eq. 2) occurs as carbonic acid, which is formed as carbon dioxide dissolved in the ground water, reacts with the feldspar. The reaction would consume hydrogen ions and release potassium ions to the ground water. Apparently the $\mathrm{pH}$ of the ground water was not affected by the process due to the low consumption of hydrogen ions in the process and the continuous source of carbon dioxide from the air and soil zone.

\section{PERMEABLE ZONE B (LOWER PLEISTOCENE-UPPER PLIOCENE DEPOSITS)}

Permeable zone B (lower Pleistocene-upper Pliocene deposits) underlies about one-fourth of the land surface in the study area and most of the Continental Shelf (fig. 10). It has an areal extent of about $130,000 \mathrm{mi}^{2}$ and a mean thickness of 1,890 ft (Williamson and others, 1990). Median depth of samples collected for chemical analyses ranges from $540 \mathrm{ft}$ along the outcrop to $4,130 \mathrm{ft}$ near the downdip limit of permeable zone B (table 8). Outcrop areas, which are the primary source of recharge from precipitation, extend from the western boundary of the study area in southern Texas eastward to the southeastern corner of Mississippi. The width of the outcrop area varies from about $8 \mathrm{mi}$ in west-central Louisiana to about $30 \mathrm{mi}$ in southwestern Mississippi. The downdip limit of permeable zone B extends about $55 \mathrm{mi}$ from the coastline on the southern edge of Texas to about $15 \mathrm{mi}$ south of the coastline at the southern most tip of Louisiana. The largest distance from the coastline to the downdip limit is about $135 \mathrm{mi}$ south from the TexasLouisiana border. The geometric mean hydraulic conductivity of permeable zone B is about $51 \mathrm{ft} / \mathrm{d}$ (table 3 ).

The simulated horizontal direction of predevelopment ground-water flow and vertical leakage relative to the base of permeable zone B (lower Pleistocene-upper Pliocene deposits) are indicated in figure 10 (Williamson, in press). Regionally, horizontal flow is from high altitude outcrop areas toward the coastline or the Mississippi Alluvial Plain. Horizontal flow in permeable zone B appears disordered on the Continental Shelf due to a large body of water with density greater than seawater (fig. 10). Flow lines on the shelf generally meet flow lines from the outcrop area at or near the coastline. Downward leakage from permeable zone $\mathrm{B}$ to the underlying permeable zone $\mathrm{C}$ occurs in about 45 percent of the outcrop area extending from the Rio Grande in southern Texas to southwestern Alabama, whereas downward leakage from the overlying permeable zone A (Holocene-upper Pleistocene deposits) occurs in a few small areas near the updip limit of permeable zone A and throughout much of the Continental Shelf. Upward leakage of ground water from underlying deposits occurs in about 90 percent of the area underlain by permeable zone B, including the outcrop area. The concentrations of dissolved solids commonly are much larger in the underlying permeable zone. 
TABLE 8.--Median value of selected chemical constituents and properties of water, median sampling depth, water types, and number of analyses for each subarea of permeable zone $B$ (lower Pleistocene-upper Pliocene deposits)

[Concentrations are in milligrams per liter, except iron and manganese, which are in micrograms per liter. Depth is in feet; $\mathrm{pH}$ is in units; and temperature is in degrees Celsius. Chemical symbols: $\mathrm{Ca}$, calcium; $\mathrm{Mg}$, magnesium; $\mathrm{Na}$, sodium; $\mathrm{K}$, potassium; Fe, iron; $\mathrm{Mn}$, manganese: $\mathrm{HCO}_{3}$, bicarbonate; $\mathrm{SO}_{4}$, sulfate; $\mathrm{Cl}$, chloride; $\mathrm{SiO}_{2}$, silica. Water type shown is the most frequently occurring. ---, no data]

\begin{tabular}{|c|c|c|c|c|c|}
\hline \multirow{2}{*}{ Constituent or property } & \multicolumn{5}{|c|}{ Subarea } \\
\hline & 1 & 2 & 3 & 4 & 5 \\
\hline $\mathrm{Ca}$ & 7.3 & 24 & 110 & 1.100 & 2.500 \\
\hline $\mathrm{Mg}$ & 1.8 & 7.6 & 38 & 760 & 1,200 \\
\hline $\mathrm{Na}$ & 45 & 260 & 730 & 9,200 & 43.300 \\
\hline K & 1.3 & 3.0 & 9.0 & 130 & 280 \\
\hline $\mathrm{Fe}$ & 90 & 260 & 640 & 3,300 & 2,500 \\
\hline $\mathrm{Mn}$ & 20 & 100 & 220 & 1,800 & 990 \\
\hline $\mathrm{HCO}_{3}$ & 170 & 340 & 280 & 200 & 90 \\
\hline $\mathrm{SO}_{4}$ & 5.6 & 34 & 140 & 1,700 & 14 \\
\hline $\mathrm{Cl}$ & 13 & 240 & 1.200 & 17,000 & 76.000 \\
\hline $\mathrm{SiO}_{2}$ & 28 & 20 & 22 & 21 & 20 \\
\hline Dissolved solids & 210 & 890 & 2.730 & 29,500 & 123,000 \\
\hline Sampling depth & 540 & 685 & 748 & 2.151 & 4.130 \\
\hline $\mathrm{pH}$ & 7.5 & 7.8 & 7.5 & 6.9 & 6.4 \\
\hline Temperature & 23.0 & 24.4 & 27.0 & 25.0 & -- \\
\hline Primary water type & $\mathrm{NaHCO}_{3}$ & $\mathrm{NaCl}$ & $\mathrm{NaCl}$ & $\mathrm{NaCl}$ & $\mathrm{NaCl}$ \\
\hline Secondary water type & $\mathrm{CaCl}$ & $\mathrm{CaCl}$ & $\mathrm{CaHCO}_{3}$ & $\mathrm{CaSO} 4$ & $\mathrm{CaHCO}_{3}$ \\
\hline Number of analyses & 578 & 449 & 47 & 10 & 35 \\
\hline
\end{tabular}

\section{DISSOLVED-SOLIDS CONCENTRATIONS}

The areal distribution of the median concentration of dissolved solids per 100-square-mile area in water from permeable zone B (lower Pleistocene-upper Pliocene deposits) is shown in figure 11. The delimited area of permeable zone B having median concentrations of dissolved solids of less the $500 \mathrm{mg} / \mathrm{L}$ includes the northern part of permeable zone B from south-central Texas to southeastern Mississippi. About 65 percent of the outcrop area of permeable zone $\mathrm{B}$ is in this delimited area. The delimited areas of permeable zone $\mathrm{B}$ having median concentrations of dissolved solids ranging from 500 to $1,000 \mathrm{mg} / \mathrm{L}$ and 1,000 to $3,000 \mathrm{mg} / \mathrm{L}$ are mostly adjacent and downdip from the less than $500 \mathrm{mg} /$ $\mathrm{L}$ delimited area except in southern Texas where these areas encompass the outcrop. In east-central Louisiana there is a small, isolated area where median concentrations of dissolved solids range from 500 to $1,000 \mathrm{mg} / \mathrm{L}$ in and near the outcrop. From eastern Texas to eastern Louisiana, both delimited areas are very narrow in the downdip direction, indicating a transition zone where the chemistry of the ground water changes from fresh to slightly saline. 


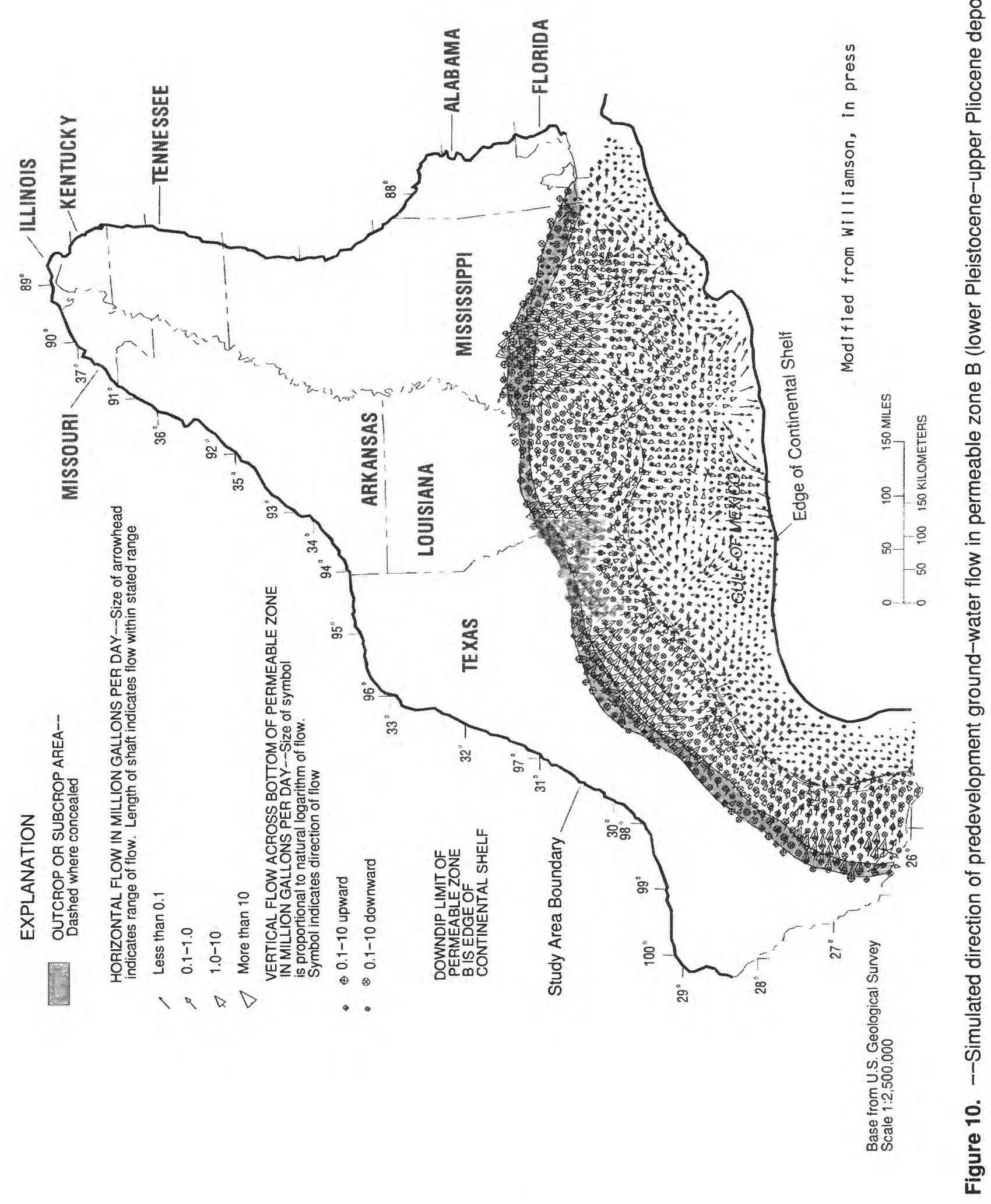




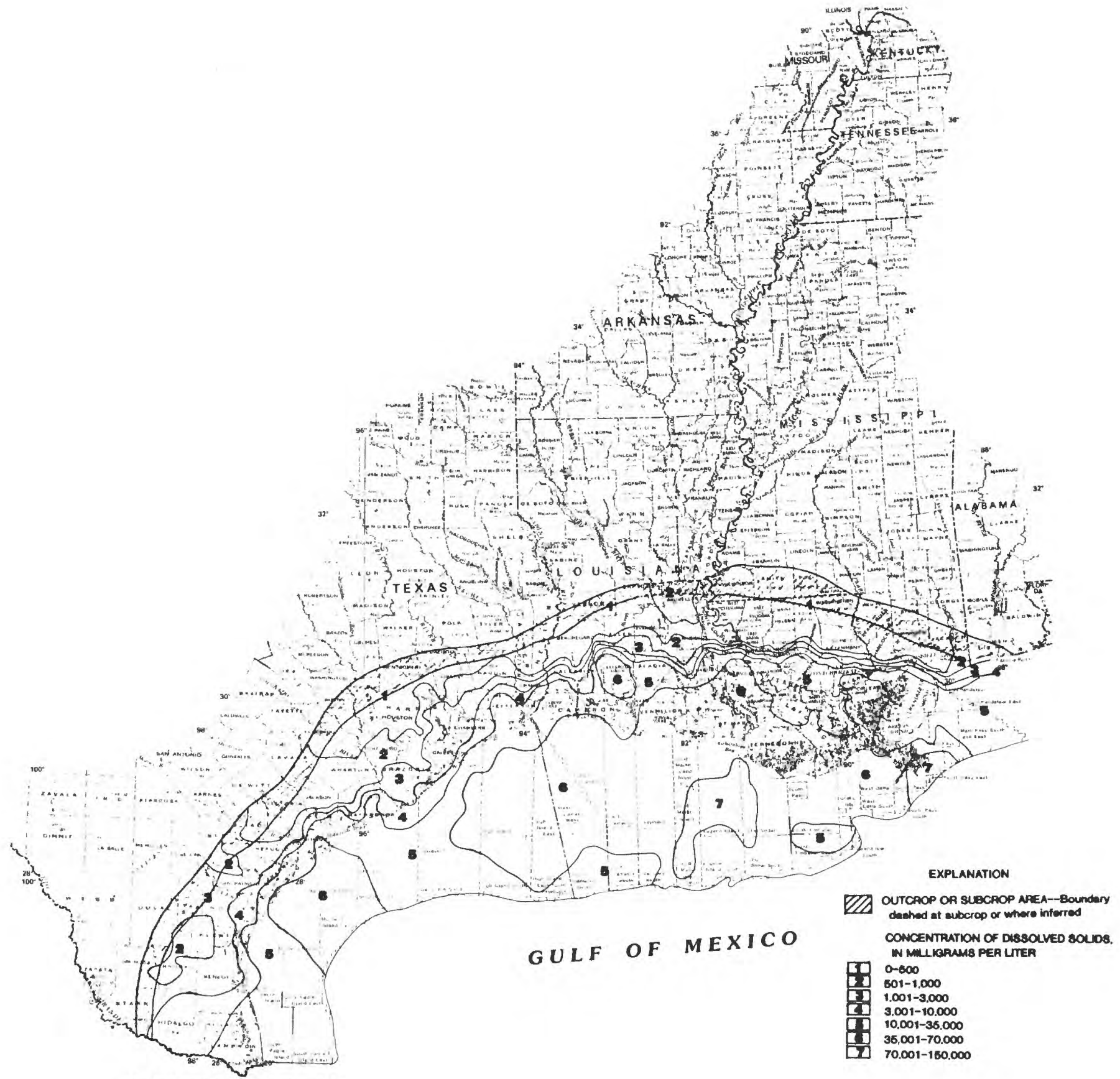

Figure 13. - Dissolved-solids concentrations in permeable zone B (lower Pleistocene-upper Pllocene deposits) 
The delimited area of permeable zone $\mathrm{B}$ having median concentrations of dissolved solids ranging from 3,000 to $10,000 \mathrm{mg} / \mathrm{L}$ is adjacent and downdip from the 1,000 to $3,000 \mathrm{mg} / \mathrm{L}$ delimited area. It is narrow in the downdip direction east of the Texas border and throughout most of Texas. The delimited area does not extend to the outcrop, and it is a transition zone where the chemistry of the ground water changes from slightly saline to highly saline. The delimited areas of permeable zone B having concentrations of dissolved solids ranging from 10,000 to $35,000 \mathrm{mg} / \mathrm{L}$ and $35,000 \mathrm{mg} / \mathrm{L}$ or greater are generally downdip from one another in consecutive order. Combined they compose the largest percent of the area underlain by permeable zone B, they do not extend to the outcrop, and they are mostly on the Continental Shelf. Because there were few water analyses south of the shoreline, concentrations of dissolved solids in these brine waters were computed primarily from borehole geophysical logs.

\section{PRIMARY WATER TYPES}

The primary water type is principally sodium bicarbonate in those areas where the median concentrations of dissolved solids are less than $500 \mathrm{mg} / \mathrm{L}$ except in Texas where the primary water type is calcium bicarbonate (fig. 12). In all areas where the median concentration of dissolved solids are 500 to $1,000 \mathrm{mg} / \mathrm{L}$ the primary water type is sodium bicarbonate. Where median concentrations of dissolved solids are greater than $3,000 \mathrm{mg} / \mathrm{L}$ the primary water type is generally sodium chloride.

\section{GROUND-WATER CHEMISTRY WITHIN SUBAREAS}

Permeable zone B (lower Pleistocene-upper Pliocene deposits) was divided into five chemically distinct subareas and the boundaries adjusted using discriminant function analysis of the chemical data from the subareas (fig. 13). Subarea 1 is separated into two parts. One part extends from south-central Texas eastward along the northern limit of zone B to east-central Louisiana. The other part extends eastward from the Mississippi River to southeastern Mississippi. About 35 percent of the area underlain by permeable zone B is in subarea 1 . Nearly 60 percent of the outcrop area through which permeable zone B receives recharge from precipitation is in subarea 1 . Subarea 2 lies adjacent and downdip from subarea 1 except in southern Texas, central Louisiana, and where some 100-square-mile areas along the outcrop are surrounded by subarea 1. In southern Texas subarea 2 begins at the outcrop and is about 30 percent of the area underlain by permeable zone B. About 40 percent of the outcrop area through which permeable zone $\mathrm{B}$ receives recharge from precipitation is in subarea 2.

Twenty-one 100-square-mile areas, which is less than 10 percent of the area underlain by permeable zone $\mathrm{B}$, make up subarea 3. The 100-square-mile areas are surrounded or downdip from subarea 2 and extends from southwestern Texas to south-central Louisiana. Recharge from precipitation in subarea 3 occurs only in the outcrop in southern Texas which is less than 5 percent of the outcrop area of permeable zone B. There are 10 analyses of ground water from subarea 4 and 35 analyses from subarea 5 (table 8 ). These analyses are clustered in twelve 100 -square-mile areas (fig. 13). Four of the 100-square-mile areas make up subarea 4 and eight make up subarea 5 . Nine of the 100-squaremile areas are scattered across southern Louisiana, one is in southeastern Mississippi, and two are offshore near the Louisiana coastline. The areal distribution of the 100-square-mile areas is inadequate to define the extent of either subareas.

The median value for selected chemical constituents and primary and secondary water types for each of the subareas are shown in table 8. Major cations and dissolved solids increase in concentration from subarea 1 to subarea 5. Among the major anions, the concentration of only chloride increases progressively from subarea 1 to subarea 5 . Sulfate increases in concentration from subarea 1 to subarea 4 and then decreases from subarea 4 to subarea 5, whereas bicarbonate concentration increases from subarea 1 to subarea 2 then decreases progressively from subarea 2 to subarea 5. Minor ions, iron and manganese, increase from subarea 1 to subarea 4 and then decrease from subarea 4 to subarea 5. The most frequently occurring (primary) water type is sodium bicarbonate in subarea 1 and sodium chloride in subareas 2, 3, 4, and 5 . 


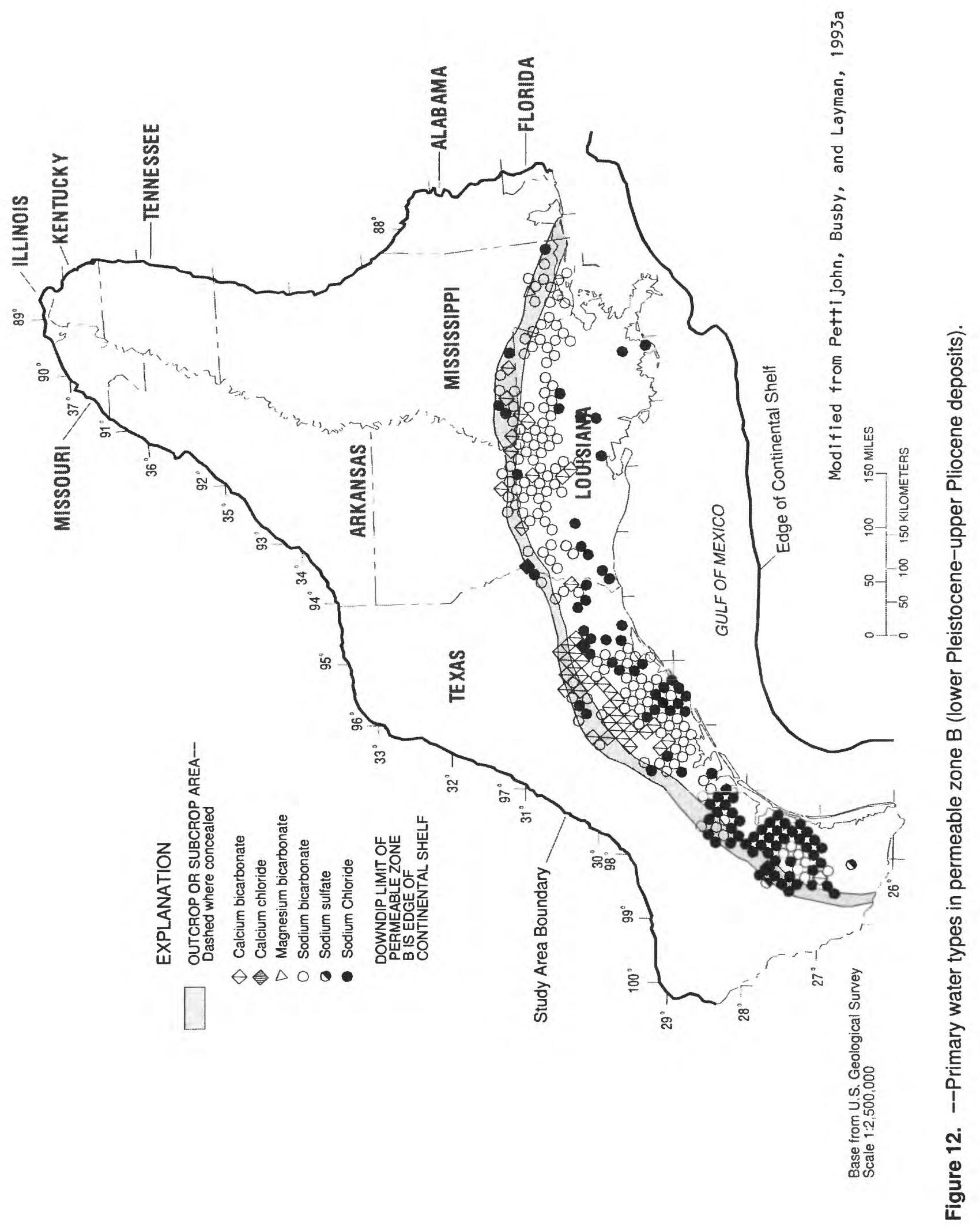




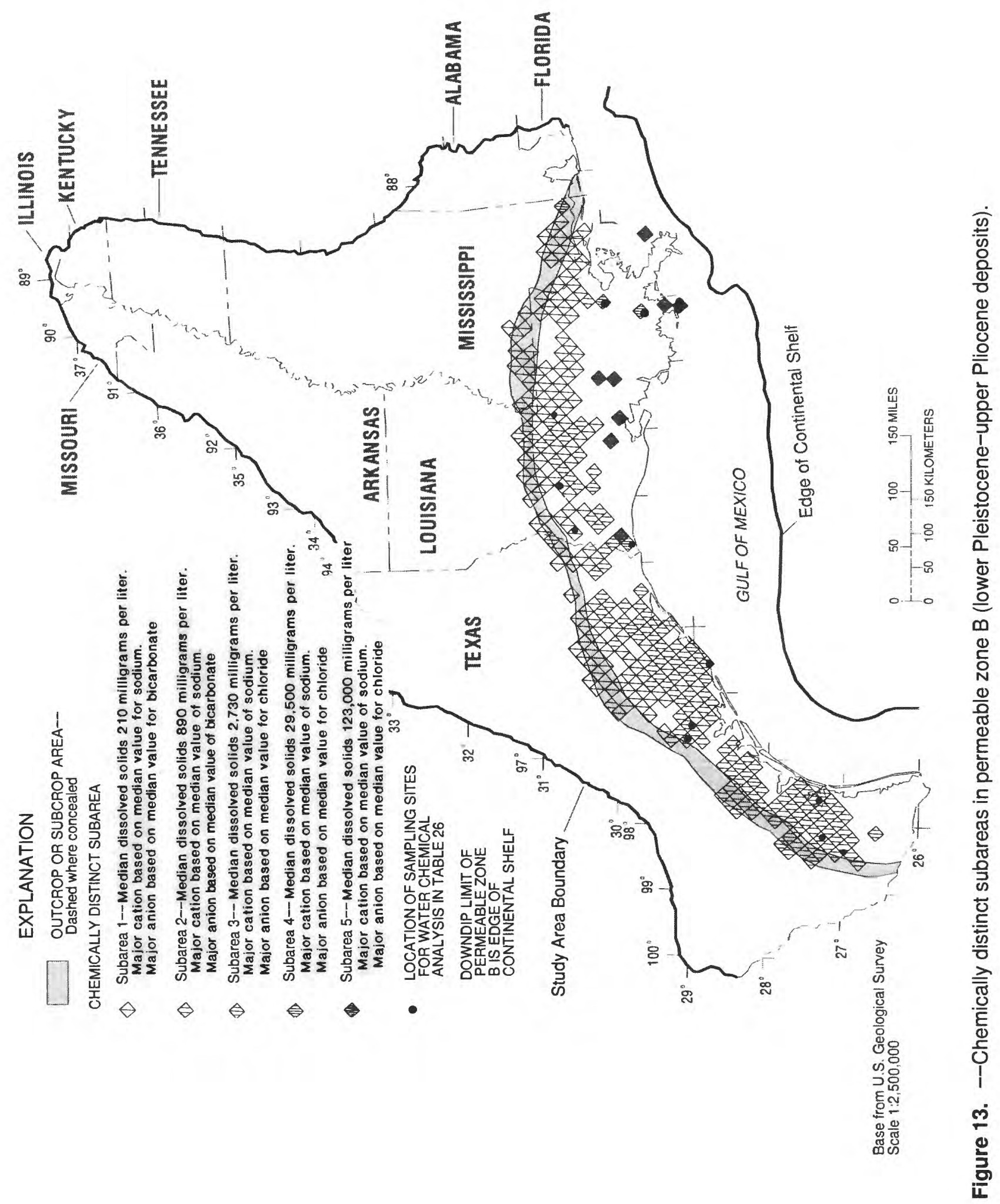


The trilinear diagram (fig. 14), based on three representative samples from each subarea, in conjunction with figure 12 shows that water in permeable zone B (lower Pleistocene-upper Pliocene deposits) is sodium bicarbonate in subarea 1 and sodium chloride in subareas $2,3,4$, and 5 . The analyses selected to represent the water chemistry in subarea 1 are all from east of the Sabine River and thus do not reflect the predominance of calcium bicarbonate water (as noted above, fig. 12) in subarea 1 west of the Sabine River. The trilinear diagram also shows that major cations concentration is approximately 20 percent magnesium plus calcium ( 80 percent sodium plus potassium) in subarea 1 and 10 percent magnesium plus calcium ( 90 percent sodium plus potassium) in subarea 5 . The major anions concentration is 89 percent bicarbonate plus carbonate ( 11 percent chloride plus sulfate) in subarea 1 and less than 0.2 percent bicarbonate plus carbonate ( 99.9 percent chloride plus sulfate) in subarea 5 .

The two triangular parts of figure 6 and the data in table 8 indicate that the chemical processes occurring in permeable zone B are increasing the sodium and chloride ions from small concentration updip to extremely large concentration downdip. The progressive increase in concentration of dissolved solids is about a factor of 4 from subarea 1 to subarea 2, a factor of 3 from subarea 2 to subarea 3, a factor of 11 from subarea 3 to subarea 4 , and a factor of 4 from subarea 4 to subarea 5 . Thus dissolved-solids concentrations increase more than a factor of 500 from subarea 1 to subarea 5 .

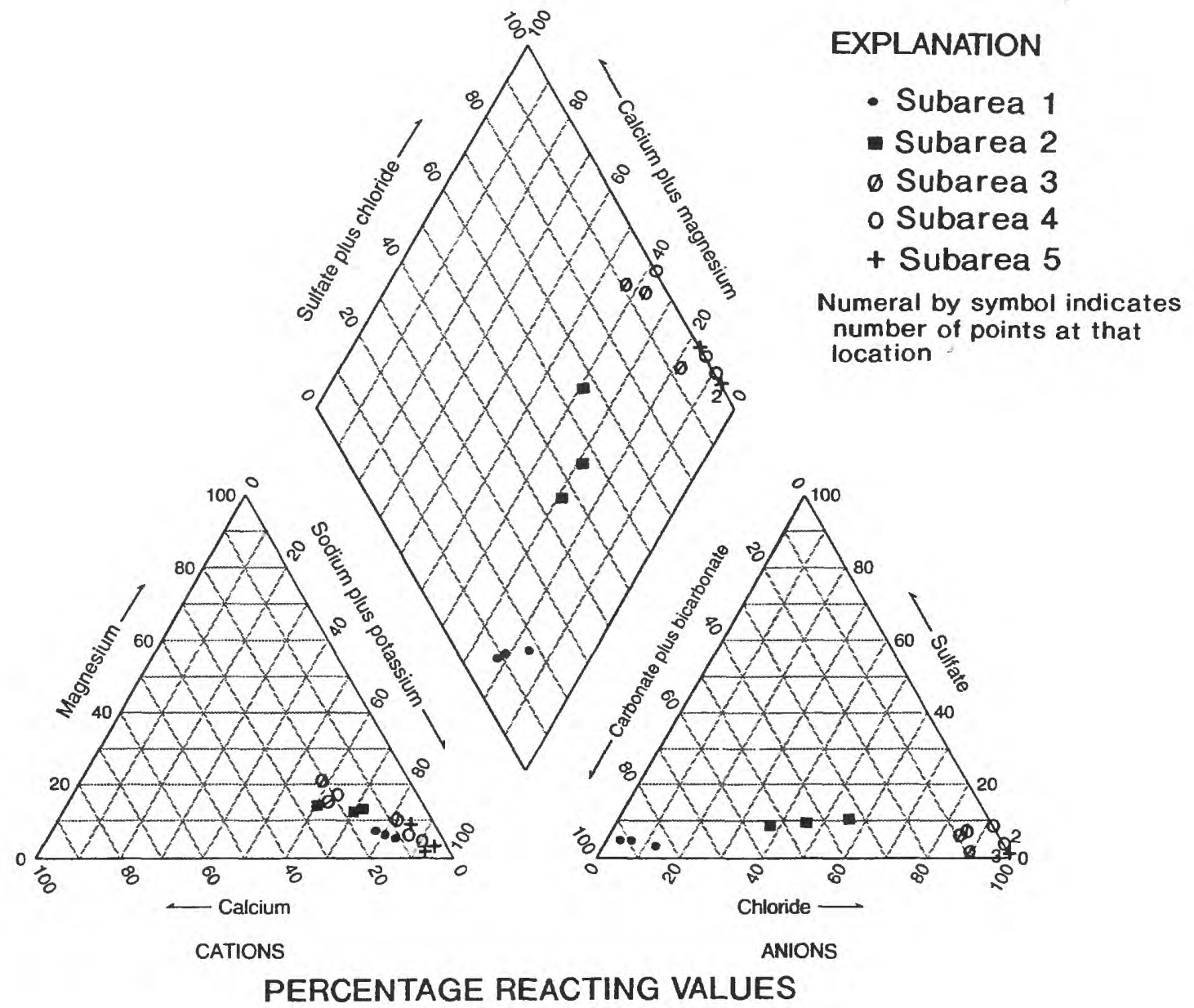

Figure 14.--Change in water chemistry from subarea to subarea in permeable zone B (lower Pleistocene-upper Pliocene deposits), based on three representative samples. 


\section{CORRELATION AMONG CHEMICAL CONSTITUENTS AND PROPERTIES OF GROUND WATER}

\section{WITHIN SUBAREAS}

The correlation among chemical constituents and properties in water from permeable zone B (lower Pleistoceneupper Pliocene deposits) was evaluated by factor analysis, which indicates that at least two major processes or mechanisms are responsible for most of the variability in concentrations of chemical constituents in subareas 1,2, and 3 and at least three in subareas 4 and 5 (table 9). Thirteen constituents or properties were used in the factor analysis. The number of chemical analyses were 578 in subarea 1, 449 in subarea 2, 47 in subarea 3,10 in subarea 4, and 35 in subarea 5 (table 8). The variability accounted for by the factors ranged from 70.6 in subarea 3 to 78.6 in subarea 5 . The loading of each constituent or property on each factor and the percent of total variability (communality) accounted for in the factor analysis is shown in table 9.

Factor I of subarea 1 represents a process in which sodium and bicarbonate ions are added to the ground water and hydrogen ions are removed. In addition, the effect of the process on the chemistry of the ground water increases with depth. Factor II of subarea 1 represents a process in which calcium, magnesium, and chloride ions are added to the ground water. The variability in concentrations of chemical constituents and properties accounted for by factor I is about 48 percent and by factor II is about 25 percent. The variability in concentration of dissolved solids accounted for by factor I is 92 percent and significant, whereas for factor II it is 42 percent and nonsignificant.

Factor I of subarea 2 represents a process in which calcium, magnesium, hydrogen, and silica are added to the ground water and sodium is removed. In addition, the effects of the processes on the water chemistry decrease with depth. Factor II of subarea 2 represents processes in which sodium, chloride, and sulfate ions are added to the ground water. The variability in concentration of chemical constituents and properties accounted for by factor I is about 42 percent and by factor II is about 28 percent. The variability in concentration of dissolved solids accounted for by factor I is a negative 23 percent and nonsignificant, whereas for factor II it is 89 percent and significant.

Factor I of subarea 3 represents a process in which sodium, chloride, and bicarbonate ions are added to the ground water. In addition, the effect of the process on the water chemistry increases with depth. Factor II of subarea 3 represents a process in which calcium, magnesium, and silica ions are added to the ground water. In addition, the effect of the process on the water chemistry decreases with depth. The variability in concentration of chemical constituents and properties accounted for by factor I is about 38 percent and by factor II is about 32 percent. The variability in concentration of dissolved solids accounted for by factor I is 97 percent and significant, whereas for factor II it is 14 percent and nonsignificant.

Factor I of subarea 4 represents a process in which sodium, chloride, iron, and silica ions are added to the ground water. In addition, the effect of the process on the chemistry of the ground water increases with depth. Factor II of subarea 4 represents a process in which magnesium, sulfate, and hydrogen ions are added to the ground water and bicarbonate is removed. Factor III of subarea 4 represents a process in which potassium and sulfate ions are added to the ground water and silica is removed. The variability in concentration of chemical constituents and properties of water accounted for by factor I is about 42 percent, by factor II is about 23 percent, and by factor III is about 13 percent. The variability in concentration of dissolved solids accounted for by factor I is 97 percent and significant, whereas for factor II it is 3 percent and nonsignificant, and for factor III it is 24 percent and nonsignificant.

In subarea 5 factor I represents a process in which sodium, potassium, and chloride ions are added to the ground water. Factor II represents a process in which calcium, magnesium, and silica ions are added to the ground water. Factor III represents a process in which hydrogen ion is added to the ground water and bicarbonate is removed. In addition, the effect of the process on the water chemistry increases with depth. The variability in concentration of chemical constituents and properties accounted for by factor I is about 43 percent, for factor II is about 22 percent, and for factor III is about 13 percent. The variability in concentration of dissolved solids accounted for by factor I is 96 percent and significant, whereas for factor II it is 25 percent and nonsignificant, and for factor III it is 12 percent and nonsignificant. 


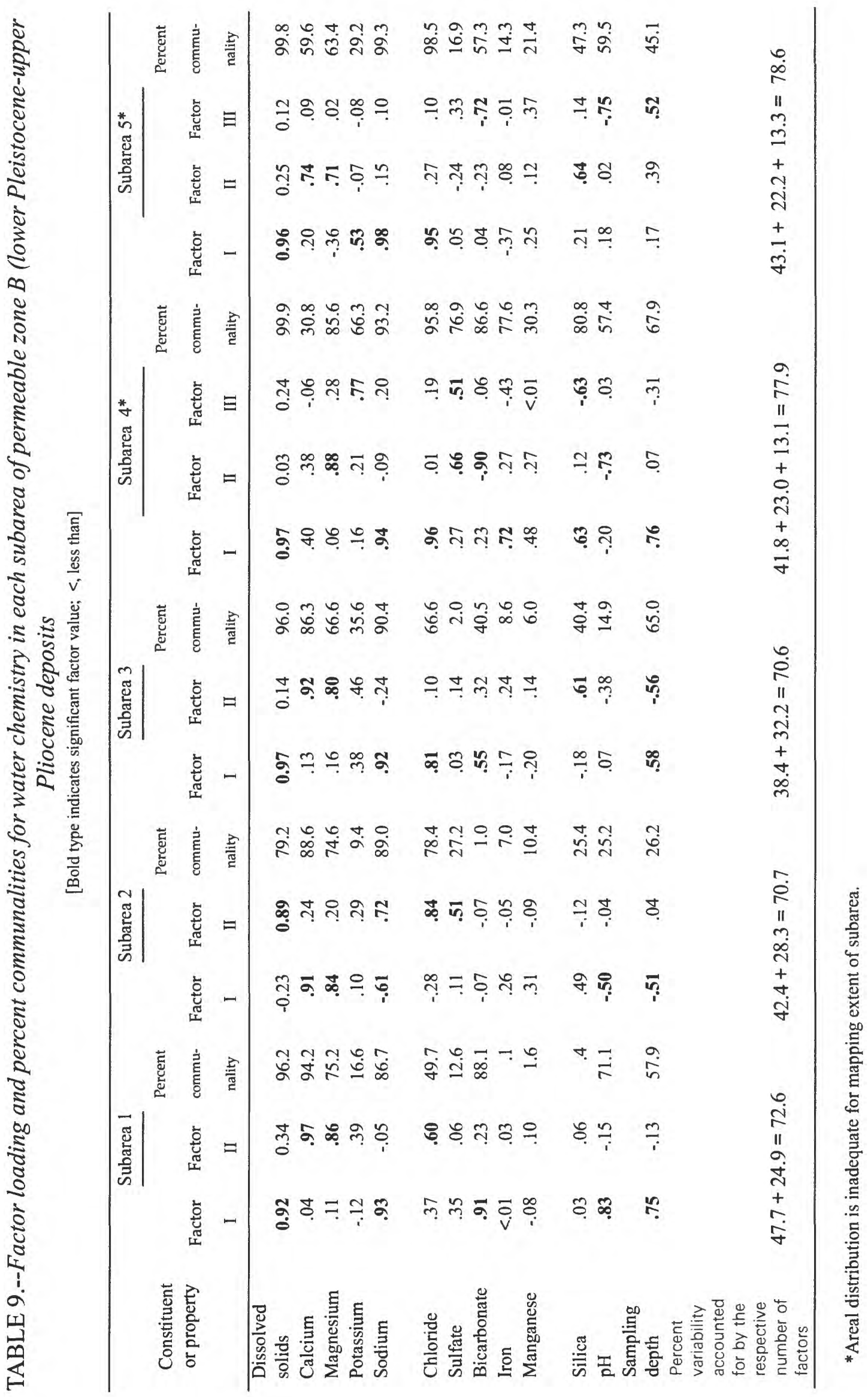




\section{RELATION OF GROUND-WATER CHEMISTRY TO CHEMICAL AND PHYSICAL PROCESSES}

The major chemical processes and mechanisms postulated for each of the chemically distinct subareas of permeable zone B (lower Pleistocene-upper Pliocene deposits) are based on the results of factor analysis in conjunction with constituent concentrations, a trilinear diagram, ground-water movement, and information on water-rock interaction and probable minerals in the deposits. The major processes postulated in subarea 1 are (1) the alteration of albite (factor I), and (2) the leaching of soluble salts from the unsaturated zone (factor II). The postulated alteration of albite (factor I) accounts for about 23 percent more of the variability in concentration of chemical constituents than does the leaching of soluble salts from the unsaturated zone (factor II). The loading of dissolved solids on factor I is very high and significant and on factor II is nonsignificant (table 9), thus indicating that alteration of albite accounts for most of the variation in concentration of dissolved solids in subarea 1.

Hydrologic, geologic, and related information that supports the two processes postulated above for chemically distinct subarea 1 are discussed briefly in the context of the water chemistry and results of factor analysis of the chemical data. The alteration of albite (eq. 1) is supported by (1) the predominance of sodium and bicarbonate ions as the major constituents in the ground water (table 8), (2) the universal presence of feldspars such as albite in sedimentary rock (Foster, 1949), and (3) the extensive outcrop areas through which carbon dioxide is supplied to the system to acidify the ground water, thus enhancing albite dissolution (fig. 13).

The effect of the process on the water chemistry increases with depth because the rate of movement of recharge water decreases with depth, increasing the effect of the alteration of albite on the ground-water chemistry due to the longer resident time.

Leaching of soluble salts from the unsaturated zone (eq. 15) is supported by the extensive outcrop areas that provide avenues for recharge water from abundant precipitation to filter through the soil removing soluble salts and carrying them to the saturated zone. Leaching is also supported by the observation that the concentration of major ions, other than sodium and bicarbonate, are only slightly above that of rainwater, a concentration level that is typical of leaching. Downward leakage of ground water (eq. 16) in this subarea from the overlying permeable zone A (Holocene-upper Pleistocene deposits) occurs in only a small part of the subarea and does not appear to have any significant effect on the ground-water chemistry regionally. However, upward leakage to permeable zone B from the underlying permeable zone $\mathrm{C}$ (lower Pliocene-upper Miocene deposits) occurs throughout most of subarea 1 downdip from the outcrop as shown by a ground-water flow analysis by Williamson (in press). He simulated upward leakage from permeable zone $\mathrm{C}$ to permeable zone $\mathrm{B}$ in subarea 1 and horizontal flow in permeable zone $\mathrm{B}$ toward a groundwater discharge area in east-central Louisiana (fig. 10).

The major processes postulated in subarea 2 are (1) hydrolysis of traces of silicate minerals of calcium and magnesium such as monticellite (factor I), (2) cation exchange or adsorption (factor I), and (3) upward leakage of ground water (factor II) containing high concentrations of dissolved solids from underlying deposits. The postulated hydrolysis of silicates of calcium and magnesium and cation exchange or adsorption of sodium ions (factor I) account for about 14 percent more of the variability in concentration of chemical constituents than does upward leakage from underlying deposits. However, the loading of dissolved solids on factor I is low, negative, and nonsignificant, whereas it is very high, positive, and significant on factor $\mathrm{Il}$, thus indicating that although hydrolysis of silicates and cation exchange or adsorption account for slightly more of the variability in concentration of chemical constituents, upward leakage accounts for most of the variation in concentration of dissolved solids in subarea 2.

Hydrologic, geologic, and related information that supports the three processes postulated above for chemically distinct subarea 2 are discussed briefly in the context of the water chemistry and results of factor analysis of the chemical data. Hydrolysis of traces of silicates (eq. 2) of calcium and magnesium is supported by (1) the low concentration of calcium and magnesium ions (table 8), (2) the positive significant loading of calcium and magnesium, (3) the near significant loading of silica, and (4) the negative loading of $\mathrm{pH}$ on factor I (table 9). During hydrolysis the silicates hydrolyze to form products of calcium and magnesium ions and a very weak silicic acid that slightly dissociates to produce silica and hydrogen ions. The exchange or adsorption of sodium ions (eq. 3 ) on secondary minerals occurs because of the moderately high concentrations of sodium and chloride ions causing the monovalent 
sodium cation to replace divalent ions by mass action. The hydrolysis and exchange processes decrease with depth because other reactions involving these ions become more prominent with depth.

Downward leakage of ground water (eq. 16) in subarea 2 from the overlying permeable zone A (Holocene- upper Pleistocene deposits) does not appear to have any significant effect on the ground-water chemistry regionally. However, upward leakage (fig. 10) to these deposits from the underlying permeable zone $C$ (lower Pliocene-upper Miocene deposits) is a major process affecting water chemistry in subarea 2.

The major processes postulated in subarea 3 of permeable zone B are (1) alteration of albite (factor I), (2) upward leakage (factor I), (3) dissolution of carbonates (caliche) (factor II), and (4) alteration of alumino- silicates to illite (factor II). Due to the areal diversity of the subarea, processes are linked together in the analysis owing to similar effect of the reaction or processes on constituent concentrations, although they are occurring totally in different parts of the subarea. For example, alteration of albite is postulated for updip areas that include outcrop, whereas most of the upward leakage is downdip from outcrop areas. The postulated upward leakage and alteration of albite (factor I) accounts for about 6 percent more of the variability in concentrations of constituents than does the dissolution of caliche and alteration of alumino-silicates to illite (factor II). The loading of dissolved solids on factor I is very high and significant and on factor II is low and nonsignificant (table 9), thus indicating that upward leakage and alteration of albite accounts for most of the variation in the concentration of dissolved solids in subarea 3.

Hydrologic, geologic, and related information that supports the four processes postulated above for chemically distinct subarea 3 are discussed briefly in the context of the water chemistry and results of factor analysis of the chemical data. Alteration of albite (eq. 1) is supported updip in this subarea by (1) the reported presence of feldspar in this subarea (Plummer, 1932), and, (2) the favorable conditions for the process. However, due to the limited area of outcrop, the amount of sodium and bicarbonate ions added to the ground water from the alteration of albite is probably small. Upward leakage (eq. 16) from permeable zone $C$ to subarea 3 of permeable zone B is supported by a ground-water flow analysis by Williamson (in press). He simulated upward flow for most of the 100-square-mile areas making up subarea 3 downdip of permeable zone B outcrop (fig. 10). The water in permeable zone $\mathrm{C}$ underlying the downdip areas of subarea 3 has dissolved-solids concentrations greater than $35,000 \mathrm{mg} / \mathrm{L}$. The volume of upward leakage to permeable zone B is equal to the horizontal flow in most of the downdip areas making up subarea 3. Alteration of albite would increase in its effect on the water chemistry with depth due to the longer resident time, whereas upward leakage would increase in its effect on the water chemistry with depth due to the closer proximity to permeable zone $\mathrm{C}$.

Dissolution of caliche (eq. 4) is postulated for the limited updip parts of the subareas, whereas the alteration of alumino-silicates (eq. 2) to illite is postulated for the downdip parts of the subarea. Dissolution of caliche is supported by (1) the reported presence of caliche in deposits of this aquifer (Plummer, 1932), and (2) the moderately high concentration of calcium ions in ground water of this subarea (table 8). Caliche accumulates in the profile of the unsaturated zone in semiarid areas such as southern Texas. Some caliche is dissolved during spring rains and each time the water rises above the caliche zone. The process would decrease with depth because dissolution of caliche occurs near the ground-water surface. Downdip the alteration of alumino-silicates to illite is likely because genesis of clays is a continuous process in most sedimentary deposits. However, the concentration of silica ions in the ground water is small, indicating that the alteration process has little effect on the overall water chemistry in subarea 3.

The major processes postulated from the results of factor analysis in subarea 4 of permeable zone B are (1) the dissolution of halite or upward leakage (factor I), (2) dissolution of iron oxide (factor I), (3) dissolution of kieserite (factor II), (4) the precipitation of magnesite (factor II), (5) dissolution of glaserite (factor III), and (6) crystallization (synthesis) of silicate clays (factor III). The postulated dissolution of halite, upward leakage, and dissolution of iron oxide (factor I) accounts for about 19 percent more of the variability in concentration of chemical constituents than does the postulated dissolution of kieserite and precipitation of magnesite (factor II) and about 29 percent more than does the postulated dissolution of glaserite and crystallization of silicate clays (factor III). The loading of dissolved solids on factor I is very high and significant, and on factors II and III it is low and nonsignificant (table 9), thus indicating that the postulated dissolution of halite, upward leakage, and dissolution of iron oxide accounts for most of the variation in concentration of dissolved solids in subarea 4 of permeable zone B. 
Hydrologic, geologic, and related information that supports the seven processes postulated above for chemically distinct subarea 4 are discussed briefly in the context of the water chemistry and results of factor analysis of the chemical data. Dissolution of halite (eq. 7) is supported by the very large concentration of sodium and chloride ions in the ground water (table 8) near the concentration of seawater and the presence of salt domes (Beckman and Williamson, 1990). Upward leakage (eq. 16) is supported by the ground-water flow analysis of Williamson (in press), which indicates that upward leakage is 10 percent or more of that volume flowing horizontally through the areas making up subarea 4 of permeable zone B (fig. 10), and the water in permeable zone $\mathrm{C}$ underlying the areas making up subarea 4 has dissolved-solids concentrations that exceed seawater $(35,000 \mathrm{mg} / \mathrm{L})$. It is not clear from the available data whether dissolution of halite or upward leakage is the predominant process represented by factor I in subarea 4 . The top of permeable zone B in the areas making up subarea 4 generally is less than $1,000 \mathrm{ft}$ below sea level, depth of burial generally is less than 3,000 ft, and dissolved-solids concentration is less than seawater. Most salt domes in the Gulf Coastal Plain that have a depth of burial of about 4,000 ft or less have caprock (Parker and McDowell, 1955), which essentially seals off the halite from the ground-water flow system. However, the increase in concentration of magnesium, sulfate, and potassium in subarea 4 may result from dissolution of minerals associated with halite as noted subsequently. Moreover, the depth to which the caprock extends down the flanks of salt domes is irregular and consequently may not preclude dissolution of halite for the full thickness of an aquifer or permeable zone. Thus the major processes represented by factor I in subarea 4 are postulated to be dissolution of halite and upward leakage along with dissolution of iron oxide (eq. 12). The processes increase with depth because salt structures increase in diameter with depth; thus more surface area is available for dissolution of halite, and the effects of upward leakage of the more highly mineralized water in the underlying permeable zone is greater near the base of permeable zone B. Dissolution of iron oxide is possible because as chloride-ion concentration increases, the solubility of iron oxide increases.

The dissolution of kieserite (eq. 7) is supported by (1) the report that it is a major constituent of evaporites in salt structures (Krauskopf, 1967), and (2) the large increase in magnesium and sulfate ions from subarea 3 to subarea 4 (table 8). Precipitation of magnesite (eq. 6) is postulated because as the concentration of magnesium ions increases from the dissolution of kieserite, the solubility of magnesite decreases due to the common-ion effect. The resulting precipitation of magnesite reduces the bicarbonate ion concentration and helps to control the amount of magnesium ions in the ground water.

The dissolution of glaserite (eq. 7) is supported by (1) the report that it is a minor constituent in evaporite sediments (Krauskopf, 1967), and (2) the increase in potassium and sulfate ions to the ground water from subarea 3 to subarea 4 (table 8). The concurrent crystallization (eq. 2) of silicate clay with dissolution of kieserite is postulated because the potassium ion is an important constituent in the genesis of silicate clays and therefore would be incorporated into the silicate clay structure as the silicate clays are formed. Also, the products of other dissolution processes such as that of iron oxide contribute to crystallization of silicate clays. Genesis of clays is most likely a continuous process in sedimentary rock and may become significant in factor analysis as the number of other processes decline in significance or if one or more of the constituents included in factor analysis becomes significant because it is involved in the synthesis of clays. However, the nearly constant concentration of silica from subarea to subarea indicates that any process involving silica has very little effect on the chemistry of the ground water in permeable zone B.

The major processes postulated from the results of factor analysis in subarea 5 of permeable zone B are (1) dissolution of halite and sylvite (factor I), (2) alteration of alumino-silicates (factor II), and (3) precipitation of the carbonate minerals calcite and magnesite (factor III). The dissolution of halite and sylvite minerals (factor I) accounts for about 21 percent more of the variability in concentrations of constituents than does the alteration of aluminosilicates to illite (factor II) and accounts for about 30 percent more than does the precipitation of calcite and magnesite (factor III). The loading of dissolved solids on factor I is high and significant and on factors II and III is low and nonsignificant (table 9), thus indicating that the postulated dissolution of halite and sylvite accounts for most of the variation in the concentration of dissolved solids in subarea 5.

Hydrologic, geologic, and related information that supports the three processes postulated above for chemically distinct subarea 5 are discussed briefly in the context of the water chemistry and results of factor analysis of the chemical data. The dissolution of halite and sylvite (eq. 7) are supported by (1) the reported presence of salt domes (Beckman and Williamson, 1990), (2) the extremely large concentration of sodium and chloride ions and large 
concentration of potassium ions in ground water of this subarea (table 8), and (3) a dissolved-solids concentration that exceeds seawater. Also, both halite and sylvite are major constituents composing salt domes, although halite is by far the most abundant of the two.

The alteration of alumino-silicate to illite (eq. 2) is supported by (1) the ongoing process of genesis of clays in most sedimentary deposits, and (2) the fact that the process adds calcium and magnesium ions to the ground water. In the alteration of alumino-silicates to illite most of the calcium and magnesium is removed from the mineral, and the silicon in the silica sheet is replaced by aluminum. The probability that alteration of alumino- silicate could account for the high concentrations of calcium and magnesium ions in the ground water of this subarea is questionable. Based on the almost 2 to 1 ratio of chloride to sodium, it appears that some of the calcium and magnesium concentration could be attributed to the dissolution of calcium and magnesium chloride salts, although the loading of chloride on factor II is not significant.

The precipitation of calcite and magnesite (eq. 6) is supported by (1) the reduced solubility of the minerals as a result of the increased concentrations of calcium and magnesium ions brought about by the dissolution of chlorides of these ions and the alteration of silicates, (2) the removal of bicarbonate ions as indicated by the high negative loading of bicarbonate on factor III, and (3) the observed decrease in bicarbonate ions from subarea 4 to subarea 5 (table 8 ). Hydrogen ions would be added to the ground water in the precipitation of carbonates. The effect of the process on the water chemistry would increase with depth because the concentrations of major cations involved in the chemical processes in this subarea increases with depth.

A complex pattern of leakage (eq. 16) to permeable zone B is indicated from the ground-water flow analysis of Williamson (in press). Downward leakage from the overlying permeable zone A to permeable zone B was simulated in an area extending from the coastal parishes of southern Louisiana offshore throughout much of the Continental Shelf. Two of the 100-square-mile areas making up subarea 5 are in the area of downward leakage. Two other areas making up subarea 5 are in an area of downward leakage from permeable zone $\mathrm{B}$ to permeable zone $\mathrm{C}$. The other four 100-square-mile areas making up subarea 5 are in areas where upward leakage was simulated from permeable zone $\mathrm{C}$ to permeable zone $\mathrm{B}$. The water in permeable zone $\mathrm{C}$ underlying the areas making up subarea 5 of permeable zone $\mathrm{B}$ generally is more highly mineralized than the water in permeable zone B. Likewise the water in permeable zone B is more highly mineralized than the water in the overlying permeable zone A. The effect of leakage on the chemistry of water in subarea 5 of permeable zone B is not clear and therefore was not postulated as a major process affecting water chemistry.

Because the number of water analyses from subareas 4 and 5 are small, factor analysis was also performed on the combined data of the two subareas. The results were almost identical to the results obtained from the factor analysis of data only from subarea 5. The processes postulated from the results of this factor analysis were dissolution of halite and sylvite, alteration of alumino-silicates, and precipitation of calcite and magnesite. The major process postulated was dissolution of halite.

\section{PERMEABLE ZONE C (LOWER PLIOCENE-UPPER MIOCENE DEPOSITS)}

Permeable zone C (lower Pliocene-upper Miocene deposits) underlies much of the southern one-third of the land surface of the study area plus a large part of the Continental Shelf (fig. 15). It has an areal extent of about $140,000 \mathrm{mi}^{2}$ and a mean thickness of $1,960 \mathrm{ft}$ (Williamson and others, 1990). The median depth of samples collected for chemical analyses ranges from $210 \mathrm{ft}$ at middip to $10,400 \mathrm{ft}$ in downdip areas (table 10). Outcrop areas extend from the west boundary of the study area in Starr County, Texas, to Walker County, Texas, to Adams Parish, Louisiana, to Baldwin County, Alabama, which is on the east boundary of the study area. The width of the outcrop area ranges from about $4 \mathrm{mi}$ at the western boundary to about $40 \mathrm{mi}$ in south-central Mississippi. The downdip limit of this water-yielding unit extends from about $50 \mathrm{mi}$ south of the shoreline in the western part of southern Texas eastward across the Continental Shelf to about $90 \mathrm{mi}$ south of the shoreline at the Alabama-Mississippi boundary. The geometric mean hydraulic conductivity of permeable zone $\mathrm{C}$ is about $50 \mathrm{ft} / \mathrm{d}$ (table 3 ). 
The simulated horizontal direction of predevelopment ground-water flow and vertical leakage relative to the base of permeable zone C (lower Pliocene-upper Miocene deposits) are indicated on figure 15 (Williamson, in press). Regionally, horizontal flow is from high altitude outcrop areas toward the shoreline or the Mississippi Alluvial Plain of east-central Louisiana. Horizontal flow in permeable zone $\mathrm{C}$ on the Continental Shelf generally is toward the edge of the shelf. However, there are large deflections in horizontal flowlines across the shelf due to a large body of water that has a density greater than seawater (fit. 15). Downward leakage through the outcrop of permeable zone $\mathrm{C}$ occurs in about 60 percent of the outcrop area that extends from southwestern Texas to southwestern Alabama, whereas downward leakage from the overlying permeable zone B (lower Pleistocene-upper Pliocene deposits) occurs in about 10 percent of the area underlain by permeable zone C. The largest area of downward leakage is in and near the outcrop area in southern Mississippi and adjacent Louisiana (fig. 10). Upward leakage of ground water from underlying deposits occurs in more than 90 percent of the area underlain by permeable zone $C$ (fig.15). Most of the upward leakage from permeable zone $\mathrm{D}$ to permeable zone $\mathrm{C}$ is downdip of permeable zone $\mathrm{D}$ outcrop areas.

TABLE 10.--Median value of selected chemical constituents and properties of water, median sampling depth water types, and number of analyses for each subarea of permeable zone C (lower Pliocene-upper Miocene deposits)

[Concentrations are in milligrams per liter, except iron and manganese, which are in micrograms per liter. Depth is in feet, $\mathrm{pH}$ is in units, and temperature is in degrees Celsius. Chemical symbols: $\mathrm{Ca}$, calcium; $\mathrm{Mg}$, magnesium; $\mathrm{Na}$, sodium; $\mathrm{K}$, potassium; $\mathrm{Fe}$, iron; $\mathrm{Mn}$, manganese; $\mathrm{HCO}_{3}$, bicarbonate; $\mathrm{SO}_{4}$, sulfate; $\mathrm{Cl}$, chloride: $\mathrm{SiO}_{2}$, silica. Water type shown is the most frequently occurring. ---, no data]

\begin{tabular}{|c|c|c|c|c|c|}
\hline \multirow{2}{*}{ Constituent or property } & \multicolumn{5}{|c|}{ Subarea } \\
\hline & 1 & 2 & 3 & 4 & 5 \\
\hline $\mathrm{Ca}$ & 3.2 & 53 & 94 & 460 & 2,500 \\
\hline $\mathrm{Mg}$ & 1.0 & 8.3 & 30 & 200 & 810 \\
\hline $\mathrm{Na}$ & 45 & 140 & 360 & 20,800 & 38.100 \\
\hline $\mathrm{K}$ & 1.0 & 2.4 & 12 & 140 & 240 \\
\hline $\mathrm{Fe}$ & 70 & 100 & 180 & 370 & 760 \\
\hline $\mathrm{Mn}$ & 20 & 68 & 250 & 150 & 2,000 \\
\hline $\mathrm{HCO}_{3}$ & 150 & 320 & 260 & 880 & 270 \\
\hline $\mathrm{SO}_{4}$ & 7.2 & 19 & 24 & 530 & 17 \\
\hline $\mathrm{Cl}$ & 5.2 & 120 & 640 & 33.000 & 65,700 \\
\hline $\mathrm{SiO}_{2}$ & 23 & 24 & 27 & 42 & 31 \\
\hline Dissolved solids & 190 & 590 & 1.390 & 56.600 & 108,000 \\
\hline Sampling depth & 529 & 291 & 210 & 10.400 & 8.660 \\
\hline $\mathrm{pH}$ & 7.5 & 7.7 & 7.5 & 7.2 & 6.9 \\
\hline Temperature & 24.0 & 23.0 & 22.0 & -- & $-\cdots$ \\
\hline Primary water type & $\mathrm{NaHCO}_{3}$ & $\mathrm{NaHCO}_{3}$ & $\mathrm{NaCl}$ & $\mathrm{NaCl}$ & $\mathrm{NaCl}$ \\
\hline Secondary water type & $\mathrm{CaSO}_{4}$ & $\mathrm{CaCl}$ & $\mathrm{CaHCO}_{3}$ & $\mathrm{CaHCO}_{3}$ & $\mathrm{CaHCO}_{3}$ \\
\hline Number of analyses & 727 & 465 & 44 & 104 & 381 \\
\hline
\end{tabular}




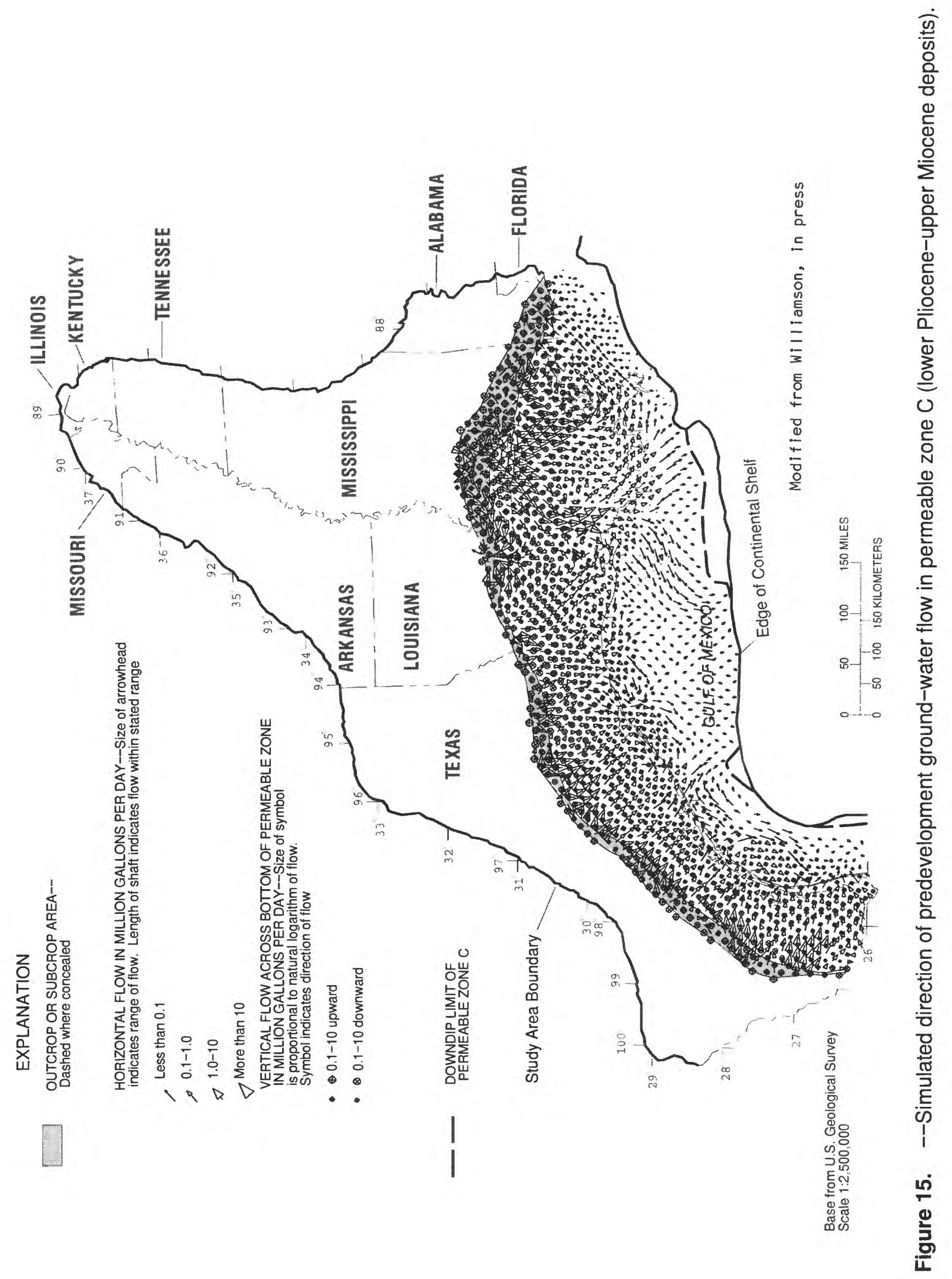




\section{DISSOLVED-SOLIDS CONCENTRATIONS}

The areal distribution of the median concentration of dissolved solids per 100-square-mile area in waters from permeable zone $C$ (lower Pliocene-upper Miocene deposits) is shown on figure 16. The delimited area of permeable zone $\mathrm{C}$ having median concentrations of dissolved solids of less than $500 \mathrm{mg} / \mathrm{L}$ consists of two parts. One part extends from near the Colorado River in Texas to the Mississippi Alluvial Plain in east-central Louisiana. The second part extends eastward from the Mississippi Alluvial Plain to southwestern Alabama. The width of the delimited area from the updip limit southward varies from about $40 \mathrm{mi}$ to $175 \mathrm{mi}$. About 70 percent of the outcrop of permeable zone C is in the delimited area. The delimited areas of permeable zone $\mathrm{C}$ having median concentrations of dissolved solids ranging from 500 to $1,000 \mathrm{mg} / \mathrm{L}$ and 1,000 to $3,000 \mathrm{mg} / \mathrm{L}$ are mostly downdip from one another in consecutive order. Both delimited areas are very narrow in the downdip direction in all but the western part of southern Texas where they widen to as much as $40 \mathrm{mi}$ in the 500 to $1,000 \mathrm{mg} / \mathrm{L}$ delimited area and to about $70 \mathrm{mi}$ in the 1,000 to $3,000 \mathrm{mg} / \mathrm{L}$ delimited area. The former delimited area contains about 15 percent of the outcrop area of permeable zone $\mathrm{C}$, whereas the latter contains about 10 percent of the outcrop area. Where the delimited areas are very narrow the median concentration of dissolved solids increases from $500 \mathrm{mg} / \mathrm{L}$ to $3,000 \mathrm{mg} / \mathrm{L}$ in about $10 \mathrm{mi}$, indicating a transition zone where the ground water changes from fresh to slightly saline.

The delimited areas of permeable zone $\mathrm{C}$ having median concentrations of dissolved solids ranging from 3,000 to $10,000 \mathrm{mg} / \mathrm{L}$ and 10,000 to $35,000 \mathrm{mg} / \mathrm{L}$ are also downdip from one another in consecutive order. Like the two previous delimited areas, they are narrow in the downdip direction everywhere except in southern Texas. The former delimited area contains less than 5 percent of the outcrop of permeable zone $\mathrm{C}$, whereas the latter delimited area has no outcrop. Where the delimited areas are narrow the median concentration of dissolved solids increases as much as a factor of 10 over a distance of about $20 \mathrm{mi}$ in the downdip direction, indicating a transition zone where the ground water changes from slightly saline to brine. The delimited areas of permeable zone $\mathrm{C}$ having concentrations of dissolved solids ranging from 35,000 to $70,000 \mathrm{mg} / \mathrm{L}$ and greater than $70,000 \mathrm{mg} / \mathrm{L}$ are mostly downdip from one another and in consecutive order. They have no outcrop, but combined they compose the largest percentage of the area underlain by permeable zone C. Concentrations of dissolved solids were computed from borehole geophysical logs for most of these areas because few water analyses are available from offshore.

\section{PRIMARY WATER TYPES}

The primary water type in those areas where the median concentrations of dissolved solids are less than $500 \mathrm{mg} /$ $\mathrm{L}$ is principally sodium bicarbonate in Louisiana and Mississippi, a mixture of major ions in southwestern Alabama, and sodium bicarbonate in southeastern Texas except in the outcrop areas where it is calcium bicarbonate (fig. 17). In areas where the median concentrations of dissolved solids are greater than $500 \mathrm{mg} / \mathrm{L}$ the primary water type generally is sodium chloride.

\section{GROUND-WATER CHEMISTRY WITHIN SUBAREAS}

Permeable zone C (lower Pliocene-upper Miocene deposits) was divided into five chemically distinct subareas and the boundaries adjusted using discriminant function analysis of the chemical data from the subareas. Subarea 1 (fig. 18) is separated into two parts as a result of discriminant function analysis. One part extends over southeastern Texas and into southwestern Louisiana. The other part extends across southern Mississippi and adjacent Louisiana and into southwestern Alabama. The subarea borders on the updip limit of the aquifer. Subarea 1 is about 18 percent of the area underlain by permeable zone $\mathrm{C}$ and contains about 45 percent of the outcrop area.

Subarea 2 lies adjacent and downdip from subarea 1 except in east-central Louisiana and in Texas from near the Trinity River westward to near the Rio Grande. In these areas it borders on the updip limit of the permeable zone. Although subarea 2 overlies only about 15 percent of permeable zone $C$, it contains about 25 percent of its outcrop area. The areal extent of subareas 3, 4, and 5 is small because of the limited areal distribution of data. The number of 100-square-mile areas making up subarea 3 is 10 and they are mostly in southern Texas. The number of 100-squaremile areas making up subarea 4 is seven and they are scattered across coastal Texas and Louisiana (fig. 18). Thirty- 


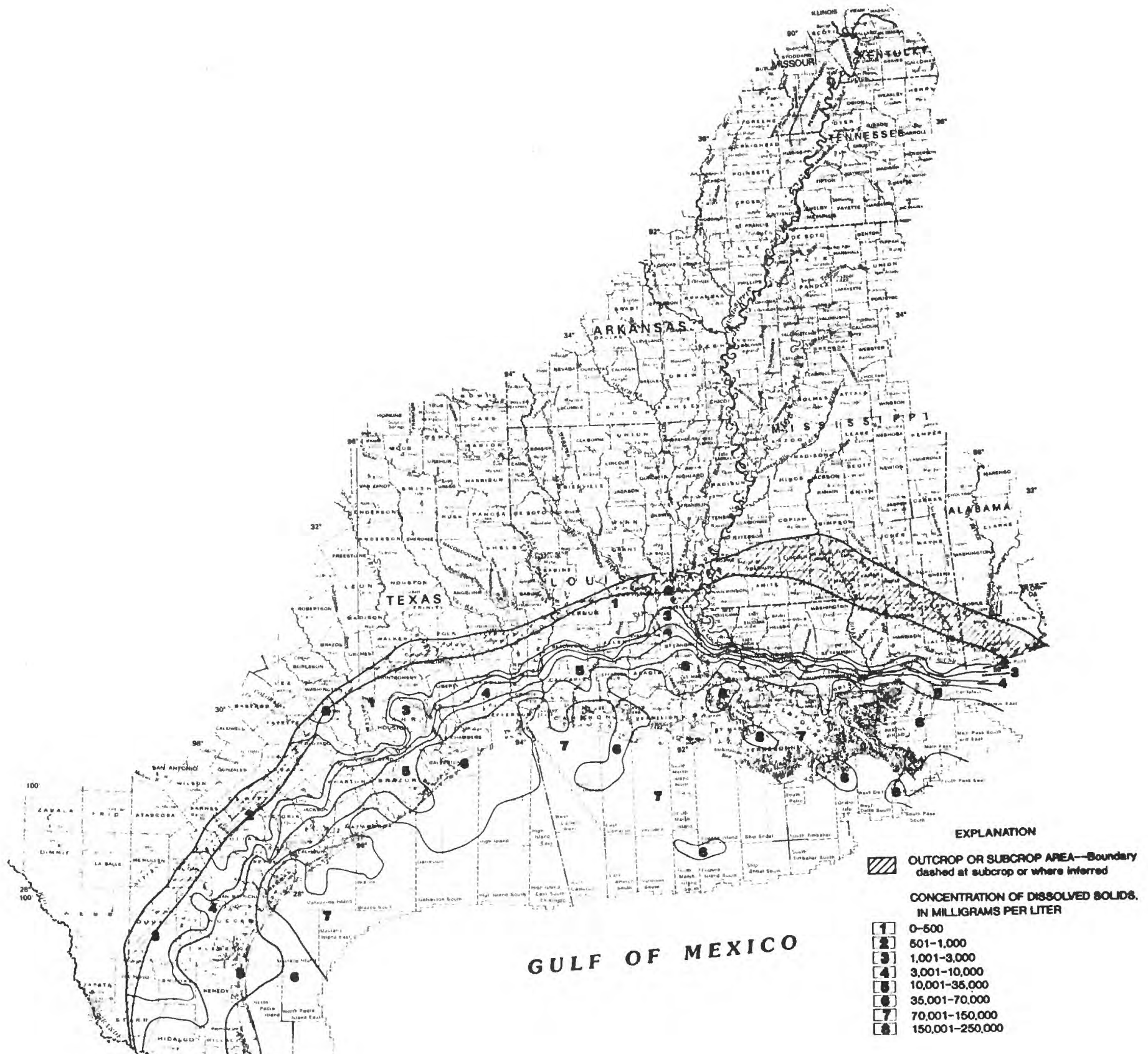

Figure 16.--Diseoived-solids concentratione in permeable zone C (lower Pliocene-upper Mlocene deposits). 


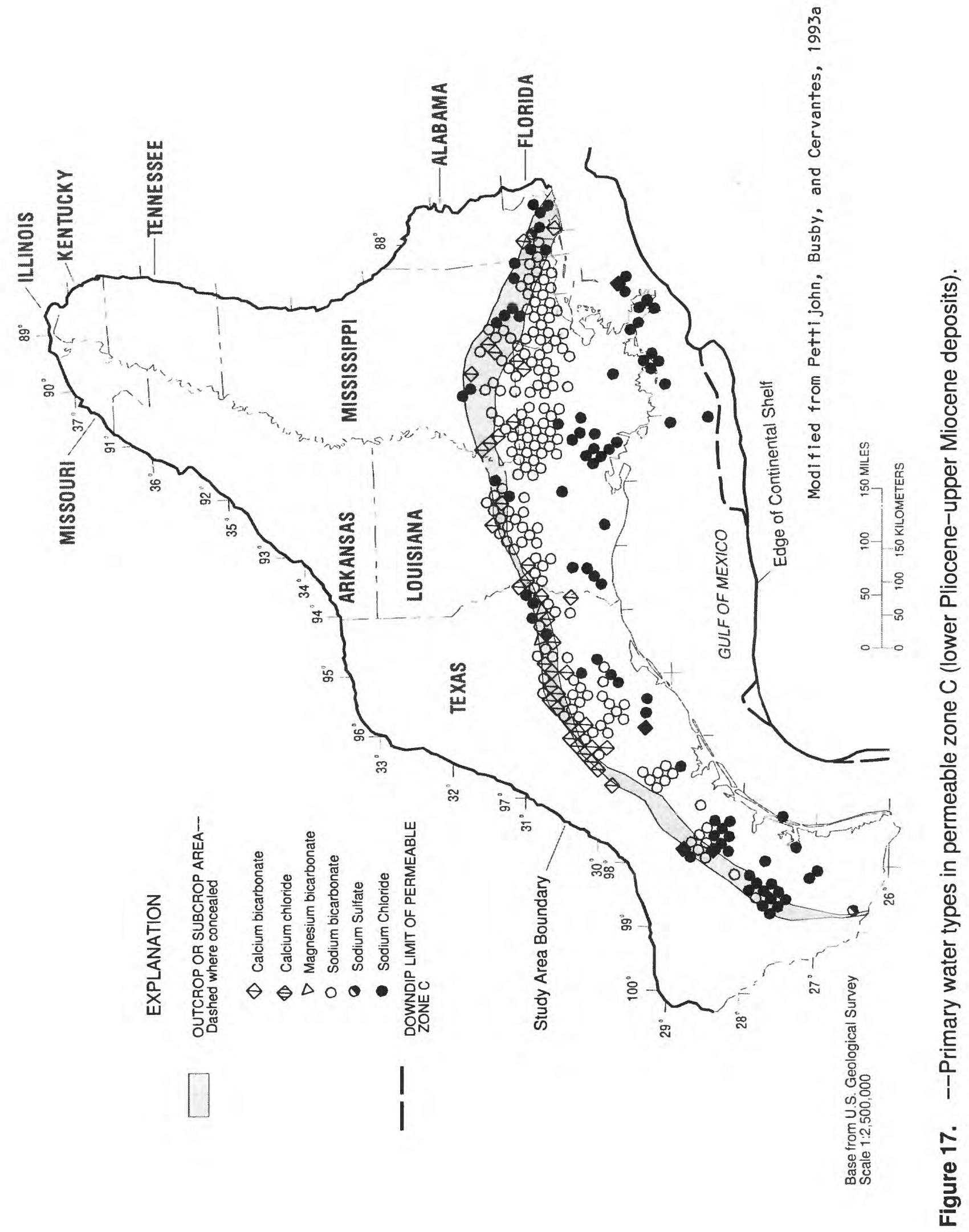




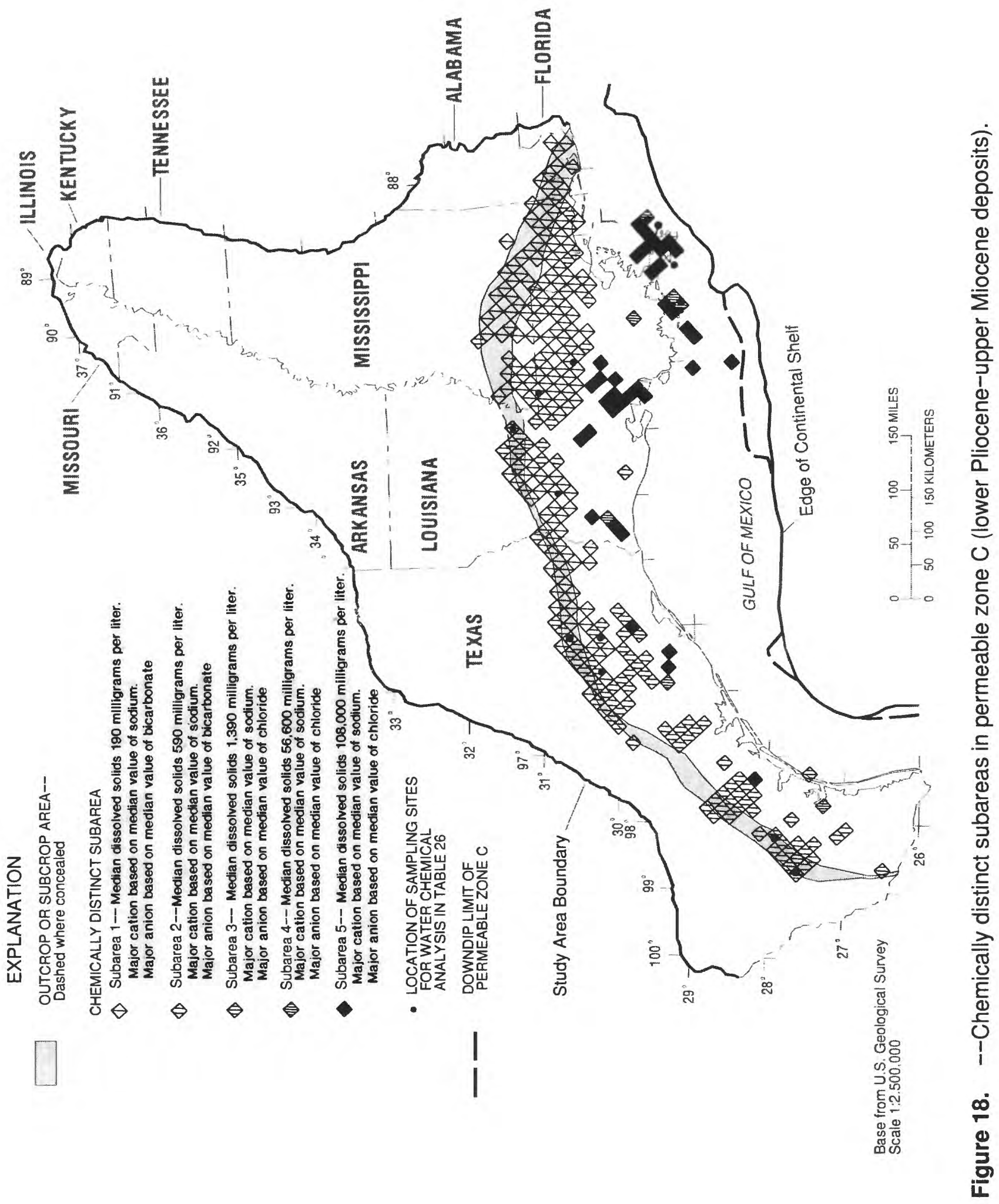


six 100-square-mile areas make up subarea 5, and they mostly are in coastal parishes of Louisiana and the adjacent Continental Shelf. Thirty-one of the 100 -square-mile areas are contiguous; thus seven areas are formed ranging in size from 200 to $1,100 \mathrm{mi}^{2}$.

The median value for selected chemical constituents and the primary and secondary water types for each of the subareas are shown in table 10. Major cations and dissolved solids increase in concentration from subarea 1 to subarea 5. Among the major anions the concentration of only chloride increases progressively from subarea 1 to subarea 5 . Sulfate increases progressively from subarea 1 to subarea 4 , then decreases from subarea 4 to subarea 5 , whereas bicarbonate increases from subarea 1 to 2 , decreases from 2 to 3 , increases from 3 to 4 , and decreases from subarea 4 to subarea 5. Minor ions, iron and manganese, generally increase from subarea 1 to subarea 5 except manganese, which decreases from subarea 3 to subarea 4 , then increases from subarea 4 to subarea 5 . The most frequently occurring (primary) water type is sodium bicarbonate in subareas 1 and 2 , and sodium chloride in subareas 3,4 , and 5 (table 10).

The trilinear diagram (fig. 19), based on three representative samples from each subarea, in conjunction with figure 17 shows that water in permeable zone $C$ (lower Pliocene-upper Miocene deposits) is sodium bicarbonate in subarea 1 , generally a mixture of calcium, magnesium, sodium, and bicarbonate ions in subarea 2 , and sodium chloride in subareas 3,4 , and 5 . The trilinear diagram also shows that major cations concentration is approximately 11 percent magnesium plus calcium ( 89 percent sodium plus potassium) in subarea 1 and 12 percent magnesium plus calcium ( 88 percent sodium plus potassium) in subarea 5 . The major anions concentration is 91 percent bicarbonate plus carbonate ( 9 percent chloride plus sulfate) in subarea 1 and less than 1 percent bicarbonate plus carbonate ( 99.7 percent chloride plus sulfate) in subarea 5 .

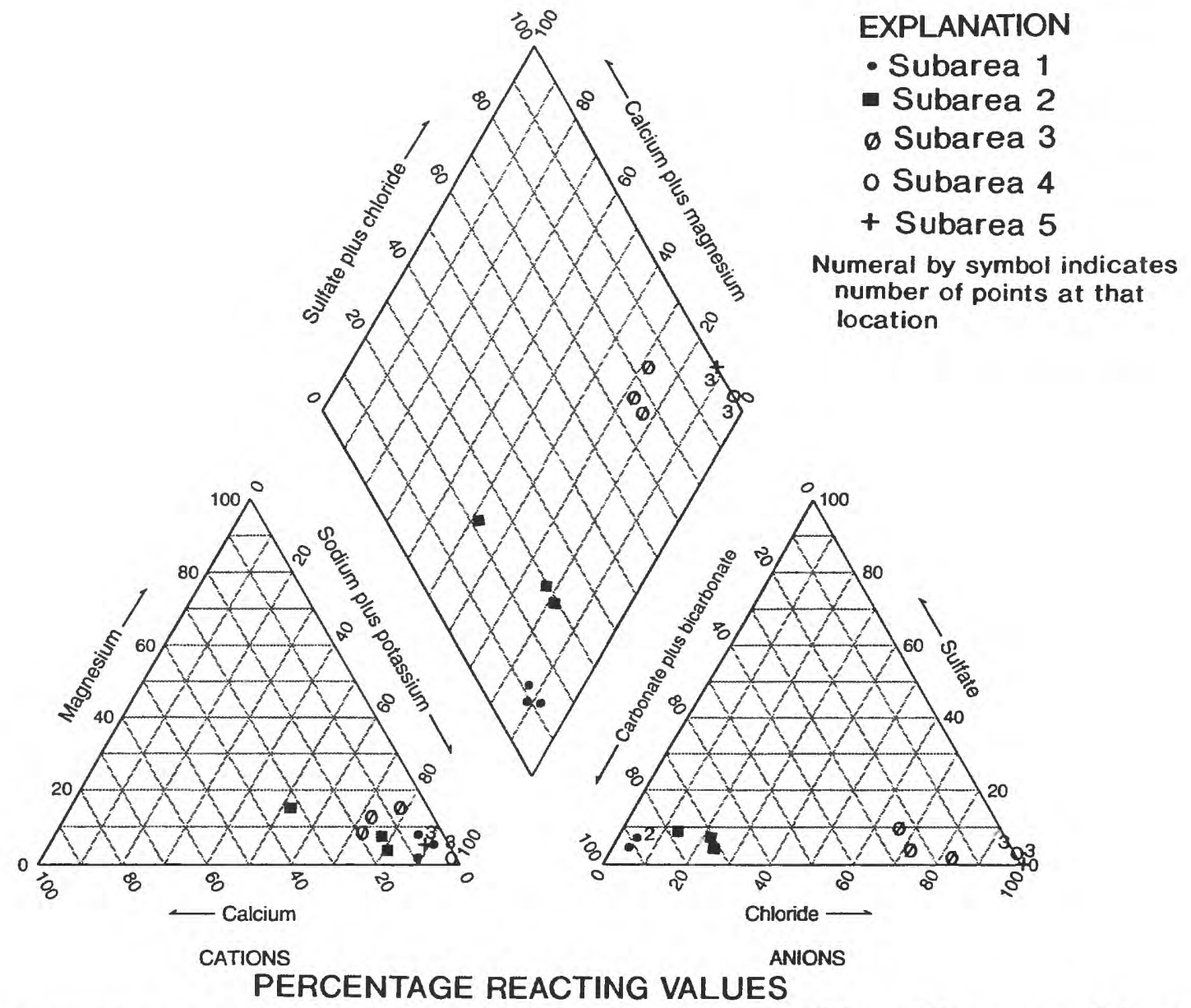

Figure 19.--Change in water chemistry from subarea to subarea in permeable zone C (lower Pliocene-upper Miocene deposits), based on three representative samples. 
The two triangular parts of the diagram (fig. 19) and the data in table 10 indicate that the chemical processes occurring in permeable zone $\mathrm{C}$ are increasing the sodium and chloride ions from small concentration updip to extremely large concentration downdip. The progressive increase in concentration of dissolved solids is about a factor of 3 from subarea 1 to subarea 2, a factor of 2.5 from subarea 2 to subarea 3 , a factor of about 40 from subarea 3 to subarea 4 , and a factor of 2 from subarea 4 to subarea 5 . Thus the dissolved-solids concentration increases more than a factor of 500 from subarea 1 to subarea 5 .

\section{CORRELATION AMONG CHEMICAL CONSTITUENTS AND PROPERTIES OF GROUND WATER WITHIN SUBAREAS}

The correlation among chemical constituents and properties in water from permeable zone $\mathrm{C}$ (lower Plioceneupper Miocene deposits) was evaluated by factor analysis, which indicates that at least two major processes or mechanisms are responsible for most of the variability in constituent concentrations in subareas 1,2 , and 5 and at least five processes in subareas 3 and 4 (table 11). Thirteen constituents or properties were used in factor analysis. The number of chemical analyses were 727 in subarea 1, 465 in subarea 2, 44 in subarea 3,104 in subarea 4, and 381 in subarea 5 (table 10). The variability accounted for by the factors ranged from 68.7 percent in subarea 2 to 93.1 percent in subarea 3. The loading of each constituent or property on each factor and the percent of total variability (communality) accounted for in the factor analysis is shown in table 11.

Factor I of subarea 1 represents a process in which sodium, bicarbonate, and sulfate ions are added to the ground water and hydrogen ions are removed. In addition, the effect of the process on the chemistry of the ground water increases with depth. Factor II of subarea 1 represents a process in which calcium, magnesium, and chloride ions are added to the ground water. The variability in concentrations of chemical constituents and properties accounted for by factor I is about 48 percent and for factor II is about 24 percent. The variability in concentration of dissolved solids accounted for by factor I is 93 percent and significant, whereas for factor II it is 31 percent and nonsignificant.

Factor I of subarea 2 represents a process in which sodium, chloride, and sulfate ions are added to the ground water. Factor II of subarea 2 represents a process in which calcium and magnesium ions are added to the ground water. In addition, the effect of the process on the chemistry of the ground water decreases with depth. The variability in concentrations of chemical constituents and properties accounted for by factor I is about 39 percent and for factor II is about 29 percent. The variability in concentration of dissolved solids accounted for by factor I is 95 percent and significant, whereas for factor II it is 17 percent and nonsignificant.

In subarea 3 factor I represents a process in which sodium and chloride ions are added to the ground water. In addition, the effect of the process on the water chemistry increases with depth. Factor II represents a process in which calcium, magnesium, and chloride ions are added to the ground water. Factor III represents a process in which bicarbonate ions and silica are added to the ground water and ferric iron is removed. Factor IV represents a process in which sulfate ions are added to the ground water and hydrogen ions are removed. Factor $\mathrm{V}$ represents a process in which potassium ions are added to the ground water. The variability in concentrations of chemical constituents and properties accounted for by factor I is about 44 percent, by factor II is about 19 percent, by factor III is about 13 percent, by factor IV is about 9 percent, and by factor $\mathrm{V}$ is about 7 percent. The variability in concentration of dissolved solids accounted for by factor I is 89 percent and significant, whereas the variability accounted for by factors II through $\mathrm{V}$ is nonsignificant and ranges from 5 to 43 percent.

In subarea 4 factor I represents a process in which calcium and chloride ions are added to the ground water. Factor II represents a process in which sodium ions are added to the ground water and potassium ions are removed. Factor III represents a process in which magnesium and sulfate ions are added to the ground water and bicarbonate ions are removed. Factor IV represents a process in which silica is added to the ground water. Factor V represents a process in which ferric iron is added to the ground water. The variability in concentrations of chemical constituents and properties accounted for by factor I is about 38 percent, by factor II is about 23 percent, by factor III is about 14 percent, by factor IV is about 10 percent, and by factor $V$ is about 8 percent. The variability in concentration of dissolved solids accounted for by factor I is 97 percent and significant, whereas the variability accounted for by factors II through $\mathrm{V}$ is nonsignificant and ranges from 2 to 10 percent. 


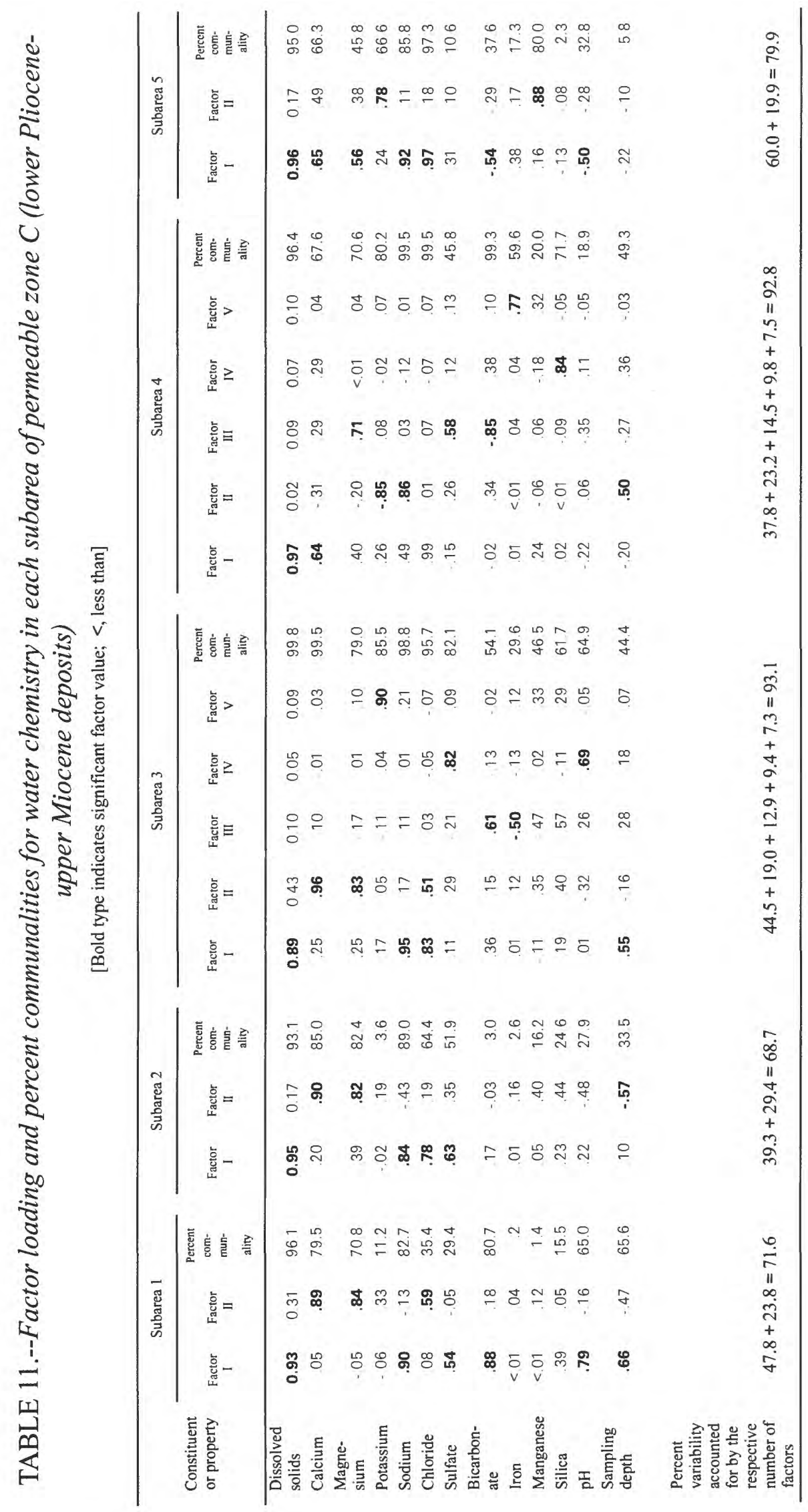


Factor I of subarea 5 represents a process in which calcium, magnesium, sodium, chloride, and hydrogen ions are added to the ground water and bicarbonate ions are removed. Factor II of subarea 5 represents a process in which potassium and manganese ions are added to the ground water. The variability in concentrations of chemical constituents and properties accounted for by factor I is about 60 percent and by factor II is about 20 percent. The variability in concentration of dissolved solids accounted for by factor I is 96 percent and significant, whereas for factor II it is 17 percent and nonsignificant.

\section{RELATION OF GROUND-WATER CHEMISTRY TO CHEMICAL AND PHYSICAL PROCESSES}

The major chemical processes and mechanisms postulated for each of the chemically distinct subareas of permeable zone $\mathrm{C}$ (lower Pliocene-upper Miocene deposits) are based on the results of factor analysis in conjunction with constituent concentrations, a trilinear diagram, ground-water movement, and information on water-rock interaction and probable minerals in the deposits.

The major processes postulated in subarea 1 of permeable zone C are (1) alteration of albite (factor I), (2) dissolution of traces of mirabilite (factor I), and (3) leaching of soluble salts from the unsaturated zone (factor II). The postulated alteration of albite and dissolution of traces of mirabilite (factor I) account for about 24 percent more of the variability in concentrations of constituents than does leaching of soluble salts (factor II) from the unsaturated zone (table 11). The loading of dissolved solids on factor I is very high and significant, and on factor II it is low and nonsignificant, thus indicating that the alteration of albite and dissolution of mirabilite account for most of the variation in the concentration of dissolved solids in subarea 1 of permeable zone $\mathrm{C}$.

Hydrologic, geologic, and related information that supports the three processes postulated above for chemically distinct subarea 1 are discussed briefly in the context of the water chemistry and results of factor analysis of the chemical data. The alteration of albite (eq. 1) is supported by (1) the predominance of sodium and bicarbonate ions in ground water of this subarea (table 10), (2) outcrop areas (fig. 16) through which carbon dioxide is supplied to precipitation that percolates to the ground-water system, and (3) the reported presence of feldspar in deposits that make up this permeable zone (Plummer, 1932). The feldspar present is most likely albite because it is the most abundant feldspar. The significant loading of $\mathrm{pH}$ on factor $\mathrm{I}$ is due to hydrogen ions being consumed in alteration of albite. The effect of the process would increase with depth due to the longer resident time associated with distance from the outcrop recharge area. The dissolution of traces of mirabilite (eq. 7) is postulated based primarily on the significant loading of sulfate and sodium on factor I.

Leaching of soluble salts (eq. 15) from the unsaturated zone is supported by (1) the large amount of outcrop (fig. 16), and (2) high rainfall that promotes both leaching and growth of vegetation, which on decay would provide soluble salts and carbon dioxide to precipitation that recharges the ground water. Leaching of soluble salts results in the concentrations of major ions becoming greater than that of rainfall, as observed in ground water of this subarea, except that sodium and bicarbonate concentrations are much greater than would be expected from leaching. Downward leakage of ground water (eq. 16) in this subarea from the overlying permeable zone B (lower Pleistocene-upper Pliocene deposits) does not appear to have any significant effect on the ground-water chemistry regionally. However, leakage upward to permeable zone $\mathrm{C}$ from the underlying permeable zone $\mathrm{D}$ (middle Miocene deposits) appears to be the reason that subarea 1 is separated into two parts in central Louisiana (fig. 15). Horizontal flow in this area of upward leakage also indicates that it is a regional discharge area (fig. 15).

The major processes postulated in subarea 2 of permeable zone $\mathrm{C}$ are (1) upward leakage of ground water from underlying deposits (factor I), and (2) leaching of soluble salts from the unsaturated zone (factor II). The postulated leakage of ground water from underlying deposits (factor I) accounts for about 10 percent more of the variability in concentrations of constituents than does the leaching of soluble salts from the unsaturated zone (factor II). The loading of dissolved solids on factor I is very high and significant, and on factor II it is low and nonsignificant, thus indicating that leakage from underlying deposits (factor I) accounts for most of the variation in the concentration of dissolved solids in subarea 2 of permeable zone $\mathrm{C}$. 
Hydrologic, geologic, and related information that supports the two processes postulated above for chemically distinct subarea 2 are discussed briefly in the context of the water chemistry and results of factor analysis of the chemical data. Upward leakage of ground water (eq. 16) from underlying deposits is supported by (1) the high loading of sodium, chloride, and sulfate on factor I of this subarea (table 11), (2) the larger concentration of dissolved solids in the underlying deposits (fig. 20), and (3) the upward leakage throughout most of the subarea and convergence of horizontal flow to the regional discharge area in east-central Louisiana (fig. 15).

Most of permeable zone C outcrop area in Texas is in subarea 2. Therefore there is ample opportunity for recharge to permeable zone $\mathrm{C}$ from precipitation. Recharge water would leach soluble salts from the unsaturated zone and carry them to the saturated zone. The process may not be as important in southern Texas due to substantially less precipitation than in southeastern Texas. Although not indicated by the results of factor analysis, the alteration of albite (eq. 1) is likely for subarea 2. This process is implied because the most frequently occurring water type is sodium bicarbonate (table 10), the predominant water type in the subarea is also sodium bicarbonate (fig.16), and the relative concentrations of sodium and bicarbonate ions and the dissolved-solids concentration (tables 5, 8, 10, and 12) are similar to other permeable zones where alteration of albite is postulated as a major process affecting water chemistry.

The major processes postulated in subarea 3 of permeable zone C are (1) upward leakage (factor I), (2) leaching of soluble salts from the unsaturated zone (factor II), (3) iron reduction (factor III), (4) dissolution of celestite (factor IV), and (5) alteration of illite to montmorillonite (factor V). The large number of factors is an indication that most of the representative processes are weak and somewhat equal in the amount of variability in concentrations of constituents accounted for by each of them in factor analysis. This equality is partly because subarea 3 is a transition zone from saline to brine water. The postulated upward leakage (factor I) accounts for about 25 percent more of the variability in concentrations of constituents than does leaching of soluble salts from the unsaturated zone (factor II), about 31 percent more than does iron reduction (factor III), about 35 percent more than does dissolution of celestite (factor IV), and about 37 percent more than does the alteration of illite to montmorillonite (factor V). The loading of dissolved solids on factor I is 46 percent greater than on factor II, 70 percent greater than on factor III, 84 percent greater than on factor IV, and 80 percent greater than on factor $\mathrm{V}$, thus indicating that upward leakage accounts for most of the variation in concentrations of dissolved solids in subarea 3 of permeable zone $C$.

Hydrologic, geologic, and related information that supports the five processes postulated above for chemically distinct subarea 3 are discussed briefly in the context of the water chemistry and results of factor analysis of the chemical data. Upward leakage (eq. 16) from permeable zone $\mathrm{D}$ to permeable zone $\mathrm{C}$ is supported by a ground-water flow analysis by Williamson (in press). He simulated upward leakage for all but three of the 100-square-mile areas that make up subarea 3 (fig. 15). The water in permeable zone D underlying subarea 3 generally has dissolved-solids concentrations that are larger than in permeable zone $\mathrm{C}$. For example, the dissolved-solids concentration in permeable zone $\mathrm{D}$, underlying the five 100-square-mile areas that make up subarea 3 outside the outcrop of permeable zone $\mathrm{C}$, is about $35,000 \mathrm{mg} / \mathrm{L}$. The volume of upward leakage to permeable zone $\mathrm{C}$ is greater than the horizontal flow in one area and at least 10 percent of the horizontal flow in the other areas outside the outcrop area (fig. 15). The moderate concentration of sodium and chloride in subarea 3 and the significant loading of sodium and chloride on factor I (table 11) are consistent with upward leakage. The effect of the process on the water chemistry would increase with depth because the water near the base of permeable zone $\mathrm{C}$ would be more like the water in permeable zone $\mathrm{D}$ than water near the top of permeable zone $C$.

The leaching of soluble salts (eq. 15) from the unsaturated zone would most likely occur only in the two isolated 100-square-mile areas in central Louisiana and in two small areas in southern Texas. These areas are mostly in the outcrop. The rate of natural leaching in southern Texas is probably slow because of low precipitation. However, any historical irrigation from the Rio Grande or pumpage would enhance the leaching process there. The concentrations of calcium and magnesium ions appear to be somewhat large (table 10) to attribute primarily to leaching. However, if caliche cements the sands and gravels of the Goliad Formation (Plummer, 1932), which is a part of permeable zone C (Weiss, 1992), dissolution of caliche could help explain the somewhat high concentration of these ions in subarea 3. Upward leakage would also contribute to the concentration of these ions.

The reduction of ferric iron (eq. 11) and perhaps manganese (factor IV) and the production of bicarbonate ions and release of silica during the reduction process, postulated from factor analysis, are probable processes in subarea 3. 
Oxides of iron and manganese may occur as coatings around silicate grains (Drever, 1982). As the oxides are reduced by reaction with lignite, bicarbonate ions are produced and silica is released (Freeze and Cherry, 1979). Conditions for a reducing environment are prevalent in the downdip part of this subarea due to the depletion of oxygen and the likelihood of anaerobic bacteria and organic matter such as lignite. Because the loading of the variables on factor III is only slightly above the significant level, the processes are considered weak. The dissolution of celestite, a sulfate mineral, is supported by its presence as a trace mineral in caprock that commonly overlies salt structures (Halbouty, 1979), and by the presence of salt domes in this subarea (Beckman and Williamson, 1990). However, most of the areas making up subarea 3 are updip from the salt domes that penetrate the base of permeable zone C (fig. 18) (Beckman and Williamson, 1990). Thus the source of the sulfate in this subarea may be upward leakage. Dissolution of gypsum (eq. 6) or anhydrite as the source of sulfate was not postulated because the loadings of calcium and magnesium on factor IV are very low.

In the genesis of clay minerals (eq. 2), alumino-silicates may be altered to form illite with a slight removal of potassium ions or they may be altered further to montmorillonite with most of the potassium ions removed (Lyon and others, 1953). The humid conditions prevalent over much of the study area would most likely result in the presence of alumino-silicates such as microcline and orthoclase. Hydrolysis of these minerals would produce illite and add potassium ions to the ground water. Further hydrolysis would produce montmorillonite as well as add more potassium ions to the ground water. The presence of montmorillonite is supported by the report that Tertiary sediments, as determined from wells along the coast of the Gulf of Mexico, consist predominantly of smectite, a montmorillonitetype clay, with only a small amount of illite (Grim, 1968). Potassium being the only major ion loading significantly on factor $\mathrm{V}$ supports a postulated process in which potassium is the major ion added to the ground water.

The major processes postulated in subarea 4 of permeable zone $\mathrm{C}$ are (1) dissolution of halite containing impurities of calcium and magnesium minerals (factor I), (2) cation exchange (factor II), (3) dissolution of kieserite and precipitation of magnesite (factor III), (4) alteration of montmorillonitic clays (factor IV), and (5) dissolution of iron oxide (factor $\mathrm{V}$ ). The large number of factors is an indication that most of the representative processes are weak and somewhat equal in the amount of variability in concentrations of constituents accounted for by each of them in factor analysis. The postulated dissolution of halite containing impurities of calcium and magnesium minerals (factor I) accounts for about 15 percent more of the variability in concentrations of constituents than does cation exchange (factor II), about 24 percent more than does dissolution of kieserite (factor III), about 28 percent more than does alteration of montmorillonitic clays (factor IV), and about 30 percent more than does the dissolution of iron oxide (factor IV). The loading of dissolved solids on factor I is extremely high and significant, whereas the loading of dissolved solids on the four other factors is low and nonsignificant, thus indicating that the dissolution of halite accounts for most of the variation in the concentration of dissolved solids in subarea 4.

Hydrologic, geologic, and related information that supports the six processes postulated above for chemically distinct subarea 4 are discussed briefly in the context of the water chemistry and results of factor analysis of the chemical data. The dissolution of halite (eq. 7) containing impurities of calcium and magnesium minerals is supported by (1) the very large concentrations of sodium and chloride ions (greater than concentrations generally found in seawater) and large concentrations of calcium and magnesium ions in the ground water (table 10), and (2) the subarea lies mostly in a salt-dome basin (Beckman and Williamson, 1990), which contains deposits called evaporites that are commonly composed of a large percentage of halite followed by anhydrite and small percentages of calcite and other minerals (Krauskopf, 1967). All but one of the 100- square-mile areas making up subarea 4 are near salt domes that penetrate the base of permeable zone $\mathrm{C}$ and have more than $4,000 \mathrm{ft}$ of overlying sediments; thus the halite is less likely to be sealed off from the ground- water flow system by caprock. The one point lack of significance of sodium on factor I is attributed to the sharing of sodium with another factor upon which it is highly significant.

Cation exchange (eq. 3), in which potassium ions are exchanged for sodium ions on the clay colloids, is highly likely because the concentration of sodium is greater than potassium by a factor of about 150 and because in highly saline ground water, such as in this subarea, potassium is greatly favored over sodium in exchange reactions involving clay (Drever, 1982). However, exchange reactions usually have little effect on the water chemistry in ground water containing large concentrations of dissolved solids. The dissolution of the kieserite, which is similar to the dissolution of halite (eq. 7), is probable because it is a major constituent in evaporite sediments (Krauskopf, 1967). Precipitation of magnesite (eq. 6) is likely because the dissolution of kieserite adds magnesium and sulfate ions to the ground water, 
thus reducing the solubility of magnesite due to the common-ion effect. The resulting precipitation of magnesite reduces the bicarbonate ion concentration and keeps the magnesium ion concentration from increasing significantly. Because the dissolution of kieserite results in the precipitation of magnesite, the processes probably have little effect on the water chemistry.

The alteration of montmorillonitic clays to hydrous mica (eq. 2) is a probable chemical process because some silica is replaced by aluminum in the alteration and because it is the only constituent in the analysis that loads significantly on the factor representing the process. Also, montmorillonite clays are reported present in the sediments that make up permeable zone C (Grim, 1968). The moderately larger concentration of silica in subarea 3 than in subarea 4 indicates that the process has little effect on the water chemistry in subarea 4 . The dissolution of iron oxide (eq. 12) is probable because of the large concentration of chloride ions, which tends to increase the solubility of iron. Again, as in the previously discussed process, the constituent in question is the only one loading significantly on the factor representing the process. Furthermore, the amount of dissolution due to the increased solubility is minimal as shown by the small concentration of iron in ground water of subarea 4. Upward leakage was simulated for all the 100square-mile areas making up subarea 4 of permeable zone $C$; however, the volumes generally are less than 10 percent of the horizontal flow through these areas (fig. 15). Some of the effect on the water chemistry attributed to dissolution of halite may be due to upward leakage in subarea 4.

The major processes postulated in subarea 5 of permeable zone $C$ are (1) dissolution of halite, which contains calcium and magnesium minerals (factor I), (2) dissolution of anhydrite and kieserite (factor I), (3) precipitation of calcite and magnesite (factor I), and (4) the simultaneous dissolution of hydrous manganese oxide and desorption of potassium ions (factor II). The postulated dissolution of halite containing calcium and magnesium minerals (factor I) accounts for about 40 percent more of the variability in concentrations of constituents than does the dissolution of hydrous manganese oxide and desorption of potassium ions (factor II). The loading of dissolved solids on factor I is high and significant and on factor II is low and nonsignificant, thus indicating that the dissolution of halite accounts for most of the variability in the concentrations of constituents and also accounts for most of the variation in the concentration of dissolved solids in subarea 5 of permeable zone $\mathrm{C}$.

Hydrologic, geologic, and related information that supports the six processes postulated above for chemically distinct subarea 5 are discussed briefly in the context of the water chemistry and results of factor analysis of the chemical data. The dissolution of halite (eq. 7) containing calcium and magnesium minerals is supported by (1) the very large concentrations of sodium and chloride ions (much greater than the concentrations in seawater) and the large concentrations of calcium and magnesium ions in the ground water (table 10), and (2) the presence of salt domes (Beckman and Williamson, 1990). The dissolution of anhydrite and kieserite are supported by the presence of these minerals in caprock that overlies salt domes (Halbouty, 1979). The precipitation of calcite and magnesite is supported by the increase in calcium and magnesium ions due to the dissolution of halite containing these ions, resulting in a change in the equilibrium constants of the two minerals. The change in the equilibrium constants causes precipitation due to the common-ion effect. The inverse loading of bicarbonate on factor I indicates the precipitation of carbonates of calcium and magnesium. The decrease in $\mathrm{pH}$ is due to the release of hydrogen ions in the precipitation of carbonates.

The dissolution of manganese oxide, which is similar to the dissolution of iron oxide (eq. 12), is supported by the universal presence of hydrous manganese and iron oxides in sediments not having strong reducing characteristics (Drever, 1982) and the adsorption potential of these oxides. Hydrous manganese and iron oxides carry a negative charge and therefore preferentially adsorb cations such as potassium out of solution (Krauskopf, 1967). As discrete grains of manganese oxides are subjected to dissolution by ground water, some of the adsorbed potassium ions are released. As a result both potassium and magnesium ions may be added to the ground water. The dissolution of manganese oxides is brought about when the solubilities of these oxides are increased due to the large concentration of chloride ions.

Downward leakage (eq. 16) from the overlying permeable zone B (lower Pleistocene-upper Miocene deposits) to permeable zone $\mathrm{C}$ was simulated in eleven 100-square-mile areas making up subarea 5 in south-central Louisiana (fig. 10). Leakage was also downward in 6 of these 11 areas in subarea 5 of permeable zone $C$ to the underlying permeable zone $\mathrm{D}$ (fig. 15). However, the volume of downward leakage from permeable zone $\mathrm{C}$ is small compared to horizontal 
flow through the eleven 100-square-mile areas. Upward leakage was simulated for all other 100-square-mile areas making up subarea 5 of permeable zone $\mathrm{C}$. The volumes of upward leakage ranged from being about equal to horizontal flow in southeastern Texas to being insignificant along the coastline of southeastern Louisiana (fig.15). Thus some of the effect on the water chemistry attributed to dissolution of halite may be due to upward leakage in subarea 5 .

\section{PERMEABLE ZONE D (MIDDLE MIOCENE DEPOSITS)}

Permeable zone D (middle Miocene deposits) underlies the southern one-third of the study area (fig. 20). It has an areal extent of about $120,000 \mathrm{mi}^{2}$ and a mean thickness of $1,760 \mathrm{ft}$ (Williamson and others, 1990). Median depth of water samples collected for chemical analyses ranges from $272 \mathrm{ft}$ at middip to $9,520 \mathrm{ft}$ in downdip areas (table 12). Outcrop areas, which are the aquifers' primary areas of recharge from precipitation, extend northeastward from Starr County, in southern Texas, to Walker County, Texas, to Grant Parish, Louisiana, to Copiah County, Mississippi, and then southeastward to Escambia County, Florida. The width of the outcrop area ranges from about $4 \mathrm{mi}$ at the western edge of the permeable zone in southern Texas to about $55 \mathrm{mi}$ at the western edge of Florida. The downdip limit of these deposits extends from the southernmost part of Texas across the Continental Shelf area to a point about $50 \mathrm{mi}$ south of the shoreline in western Florida. The downdip limit is on the average about $50 \mathrm{mi}$ south of the coastline and lies at the edge of the Continental Shelf in western Florida. The geometric mean hydraulic conductivity of permeable zone $\mathrm{D}$ is about $66 \mathrm{ft} / \mathrm{d}$ (table 3 ).

The horizontal direction of predevelopment ground-water flow and vertical leakage relative to the base of permeable zone D (middle Miocene deposits) is indicated on figure 20 (Williamson, in press). Regionally, the horizontal flow east of the Mississippi River is generally from a topographic high in southwestern Mississippi westward to a regional discharge area in east-central Louisiana, southward toward the gulf, and southeastward toward the Tombigbee River. The horizontal flow west of the Mississippi River in Louisiana is toward a regional discharge area in east-central Louisiana, whereas in Texas the flow is generally from updip outcrop areas southward toward the coastline. Downward leakage occurs through about 65 percent of the outcrop area of permeable zone D, whereas downward leakage from the overlying permeable zone $\mathrm{C}$ (lower Pliocene-upper Miocene deposits) occurs in only about 10 percent of the area underlain by permeable zone D, mostly in southwestern Mississippi. Zone D confining unit overlies permeable zone D throughout an area of coastal Texas and adjacent Continental Shelf. Upward leakage of ground water from underlying deposits occurs in more than 80 percent of the area underlain by permeable zone $\mathrm{D}$. Most of the upward leakage is from permeable zone $\mathrm{E}$, which has higher concentration of dissolved solids then permeable zone $\mathrm{D}$ and occurs in areas downdip from the outcrop of permeable zone $\mathrm{D}$.

\section{DISSOLVED-SOLIDS CONCENTRATIONS}

The areal distribution of the median concentration of dissolved solids per 100-square-mile area in waters from permeable zone $\mathrm{D}$ (middle Miocene deposits) is shown in figure 21. The delimited area of permeable zone $\mathrm{D}$ having median concentrations of dissolved solids of less than $500 \mathrm{mg} / \mathrm{L}$ extends from near the Brazos River in east-central Texas, across central Louisiana and the southern one-third of Mississippi, to southwestern Alabama, and the western tip of Florida. About 75 percent of the outcrop area of permeable zone $\mathrm{D}$ is in the delimited area. The delimited area of permeable zone D having median concentrations of dissolved solids ranging from 500 to $1,000 \mathrm{mg} / \mathrm{L}$ extends continuously from central Texas to southwestern Alabama. It is a very narrow area in the downdip direction and contains about 15 percent of permeable zone D outcrop area. 
TABLE 12.--Median value of selected chemical constituents and properties of water, median sampling depth, water types, and number of analyses for each subarea of permeable zone $D$

(middle Miocene deposits)

[Concentrations are in milligrams per liter, except iron and manganese, which are in micrograms per liter. Depth is in feet, pH is in units, and temperature is in degrees Celsius. Chemical symbols: $\mathrm{Ca}$, calcium; $\mathrm{Mg}$. magnesium; $\mathrm{Na}$, sodium; $\mathrm{K}$, potassium; $\mathrm{Fe}$, iron; $\mathrm{Mn}$, manganese; $\mathrm{HCO}_{3}$, bicarbonate; $\mathrm{SO}_{4}$, sulfate; $\mathrm{Cl}$, chloride; $\mathrm{SiO}_{2}$, silica. Water type shown is the most frequently occurring. ---,no data]

\begin{tabular}{|c|c|c|c|c|c|}
\hline \multirow{2}{*}{$\begin{array}{l}\text { Constituent or } \\
\text { property }\end{array}$} & \multicolumn{5}{|c|}{ Subarea } \\
\hline & 1 & 2 & 3 & 4 & 5 \\
\hline $\mathrm{Ca}$ & 3.1 & 30 & 96 & 360 & 2,500 \\
\hline $\mathrm{Mg}$ & 1.0 & 3.6 & 24 & 91 & 640 \\
\hline $\mathrm{Na}$ & 23 & 140 & 720 & 13,000 & 43,400 \\
\hline $\mathrm{K}$ & 1.3 & 3.4 & 16 & 91 & 230 \\
\hline $\mathrm{Fe}$ & 90 & 90 & 210 & 630 & 2.700 \\
\hline $\mathrm{Mn}$ & 20 & 20 & 240 & 190 & 1.200 \\
\hline $\mathrm{HCO} 3$ & 100 & 330 & 250 & 980 & 320 \\
\hline $\mathrm{SO}_{4}$ & 7.0 & 12 & 140 & 67 & 29 \\
\hline $\mathrm{Cl}$ & 5.0 & 90 & 1.300 & 20,600 & 72,700 \\
\hline $\mathrm{SiO}_{2}$ & 25 & 29 & 46 & 53 & 29 \\
\hline Dissolved solids & 160 & 596 & 2,970 & 34,900 & 121,000 \\
\hline Sampling depth & 340 & 364 & 272 & 9,420 & 9,520 \\
\hline $\mathrm{pH}$ & 7.0 & 7.7 & 7.4 & 7.2 & 6.9 \\
\hline Temperature & 22.0 & 23.9 & 26.1 & --- & 22.0 \\
\hline Primary water type & $\mathrm{NaHCO}_{3}$ & $\mathrm{NaHCO}_{3}$ & $\mathrm{NaCl}$ & $\mathrm{NaCl}$ & $\mathrm{NaCl}$ \\
\hline Secondary water type & $\mathrm{CaCl}$ & $\mathrm{CaCl}$ & $\mathrm{CaHCO}_{3}$ & $\mathrm{CaHCO}_{3}$ & $\mathrm{CaHCO}_{3}$ \\
\hline Number of analyses & 745 & 347 & 54 & 92 & 403 \\
\hline
\end{tabular}

The delimited areas of permeable zone $\mathrm{D}$ having median concentrations of dissolved solids ranging from 1,000 to $3,000 \mathrm{mg} / \mathrm{L}$ and 3,000 to $10,000 \mathrm{mg} / \mathrm{L}$ are mostly downdip from one another in consecutive order. Both delimited areas are narrow in the downdip direction. The 1,000 to $3,000 \mathrm{mg} / \mathrm{L}$ delimited area widens to as much as $40 \mathrm{mi}$ in southern Texas and contains about 10 percent of permeable zone $\mathrm{D}$ outcrop area. Where the delimited areas are very narrow, the concentration of dissolved solids increases by a factor of 10 in just a few miles, indicating transition zones between freshwater and highly saline water. The delimited areas of permeable zone D having concentrations of dissolved solids ranging from 10,000 to $35,000 \mathrm{mg} / \mathrm{L}$ and 35,000 to $70,000 \mathrm{mg} / \mathrm{L}$ are also mostly downdip from one another in consecutive order. Like the two previous delimited areas they are narrow in the downdip direction everywhere except in Texas and the adjacent Continental Shelf. There are no outcrop areas in these two delimited areas. Where the delimited areas are very narrow the concentration of dissolved solids increases from 10,000 to 70,000 $\mathrm{mg} / \mathrm{L}$ in less than $10 \mathrm{mi}$, indicating transition zones between highly saline water and brine. That part of permeable zone D having concentrations of dissolved solids greater than $70,000 \mathrm{mg} / \mathrm{L}$ underlies parts of coastal Texas and coastal Louisiana and the adjacent Continental Shelf. 


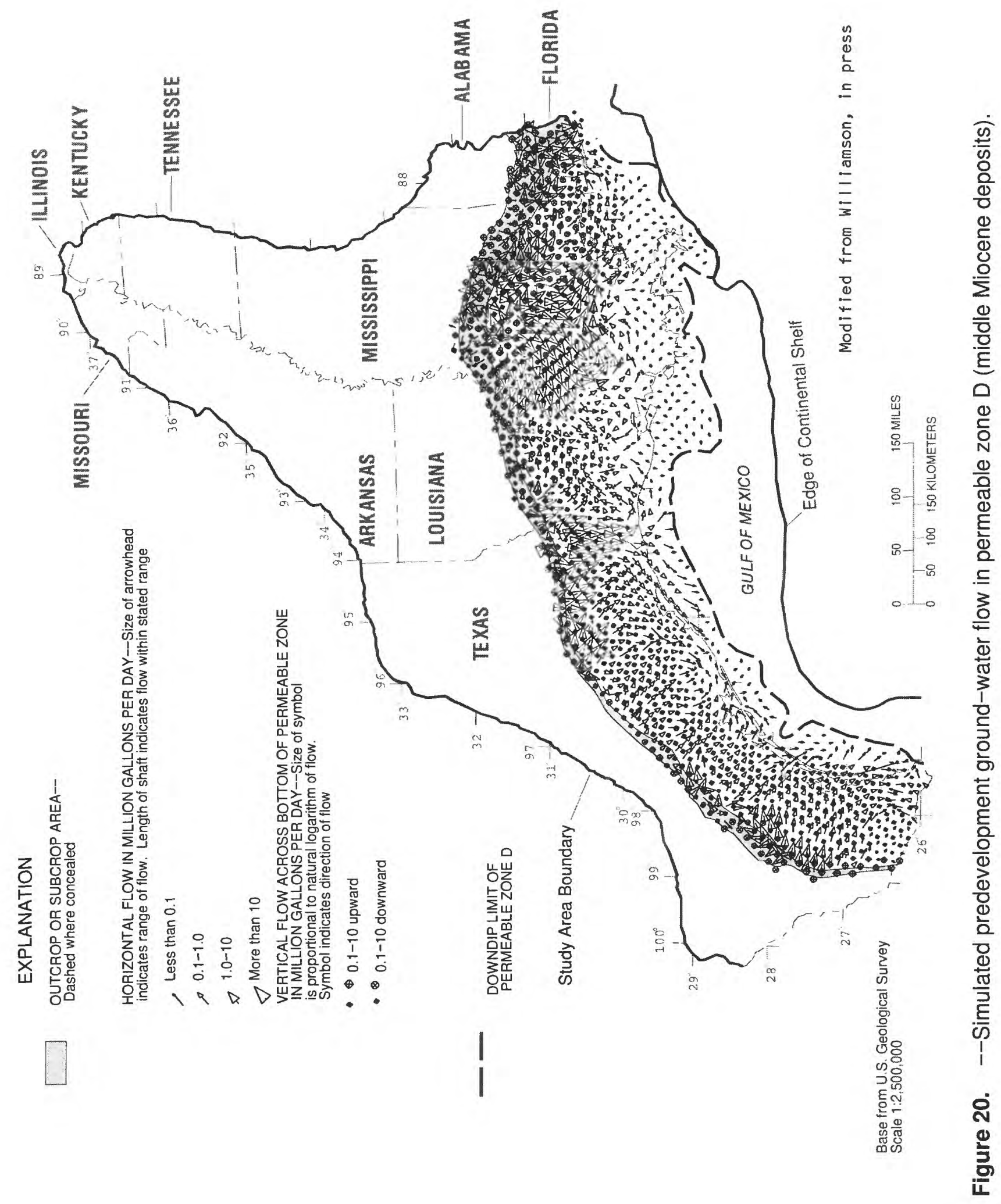




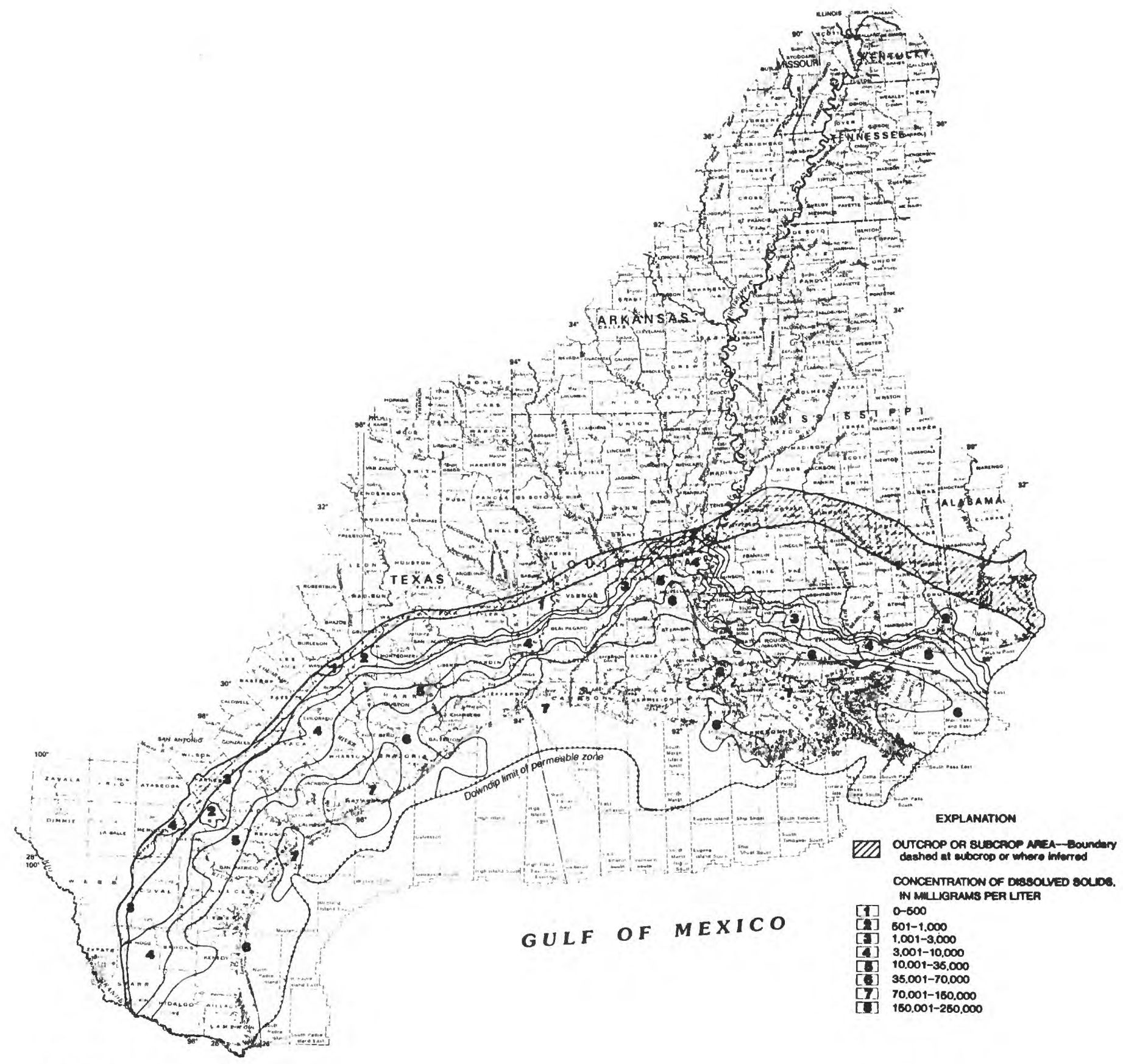

Modified from Pettijohn and others. 1980 


\section{PRIMARY WATER TYPES}

The primary water type is principally sodium bicarbonate in those areas of Louisiana and Mississippi where median dissolved-solids concentrations are less than $500 \mathrm{mg} / \mathrm{L}$ (fig. 22). The primary water types are calcium bicarbonate and sodium bicarbonate in central and eastern Texas where median dissolved-solids concentrations are less than $1,000 \mathrm{mg} / \mathrm{L}$. In Texas, southwestern Alabama, and the western tip of Florida, where the median concentration of dissolved-solids are less than $3,000 \mathrm{mg} / \mathrm{L}$, the primary water types are sodium chloride and sodium bicarbonate. However, where median dissolved-solids concentrations exceeds $3,000 \mathrm{mg} / \mathrm{L}$, the primary water type generally is sodium chloride.

\section{GROUND-WATER CHEMISTRY WITHIN SUBAREAS}

Permeable zone D (middle Miocene deposits) was divided into five chemically distinct subareas and the boundaries adjusted using discriminant function analyses of chemical data from the subareas. Subarea 1 (fig. 23) is separated into two parts. One part extends from east-central Louisiana eastward through southern Mississippi and southwestern Alabama to the western tip of Florida. The other part is in west-central Louisiana and adjacent eastcentral Texas. Subarea 1 is about 20 percent of the area underlain by permeable zone D and contains more than 50 percent of the outcrop area through which the permeable zone is recharged from precipitation.

Subarea 2 lies adjacent and downdip from subarea 1 except in central Louisiana and much of Texas where it borders on the updip limit of the permeable zone and extends southward. The subarea is about 10 percent of the area underlain by the permeable zone and contains about 25 percent of permeable zone D outcrop. Subarea 3 is made up of 11 contiguous 100-square-mile areas along the outcrop in southern Texas, 2 along the outcrop in central Louisiana, 1 along the outcrop in Alabama, and 3 at about middip in southern Texas. Subarea 4 is made up of sixteen 100-squaremile areas scattered along the southern one-half of the aquifer area from near the Rio Grande eastward to the Continental Shelf area south of the Alabama-Mississippi border (fig. 23). The scattered locations of subarea 4 suggest that the subarea is probably a narrow band between subarea 2 and 5 in southern Texas and a small discontinuous area between subarea 2 and the coastline in southern Louisiana. Subarea 5 extends across coastal Texas and Louisiana. Because of limited data the subarea is not shown as continuous and is restricted mostly to onshore parts of these two States. If subarea 5 extends to the downdip limit of the permeable zone, as both the isolated and contiguous 100square-mile areas indicate, then subarea 5 is more than 35 percent of the area underlain by permeable zone $\mathrm{D}$. There are no outcrop areas for recharge from precipitation in this subarea.

The median value for selected chemical constituents and the primary and secondary water types for each of the subareas are shown in table 12. Major cations and dissolved-solids increase in concentration from subarea 1 to subarea 5. Among the major anions, the concentration of only chloride increases progressively from subarea 1 to subarea 5. Sulfate concentration increases from subarea 1 to subarea 3 then decreases progressively to subareas 4 and 5 , whereas bicarbonate alternately increases then decreases from one subarea to the next. Minor ions, iron and manganese, generally increase in concentration from subarea 1 to subarea 5 except for a decrease in manganese from subarea 3 to subarea 4 . From subarea $I$ to subarea 2 the $\mathrm{pH}$ increases, then decreases progressively to subarea 5 . The most frequently occurring water type is sodium bicarbonate in subareas 1 and 2 and sodium chloride in subareas 3,4 , and 5 (table 12).

The trilinear diagram (fig. 24), based on three representative samples from each subarea, in conjunction with figure 22 shows that water in permeable zone D (middle Miocene deposits) is a mixture of sodium, calcium, and bicarbonate ions in subareas 1 and 2 and sodium chloride in subareas 3, 4, and 5 (fig. 24). However, in subareas 1 and 2 the predominant ions are sodium and bicarbonate. The trilinear diagram also shows that major cation concentration is approximately 35 percent magnesium plus calcium ( 65 percent sodium plus potassium) in subarea 1 and 8 percent magnesium plus calcium (92 percent sodium plus potassium) in subarea 5. The major anions concentration is 85 percent bicarbonate plus carbonate ( 15 percent chloride plus sulfate) in subarea 1 and less than 1 percent bicarbonate plus carbonate ( 99.8 percent chloride plus sulfate) in subarea 5. 


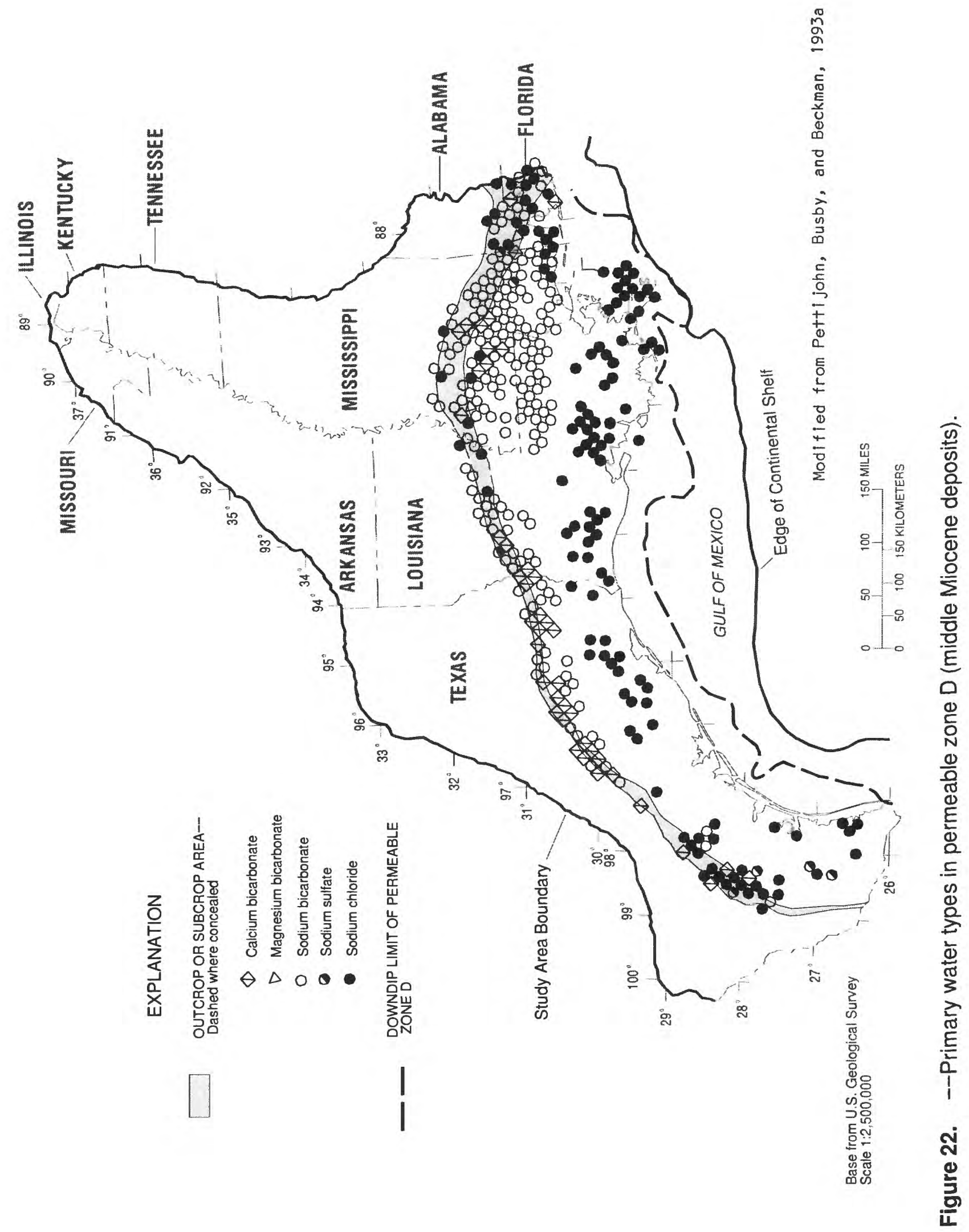




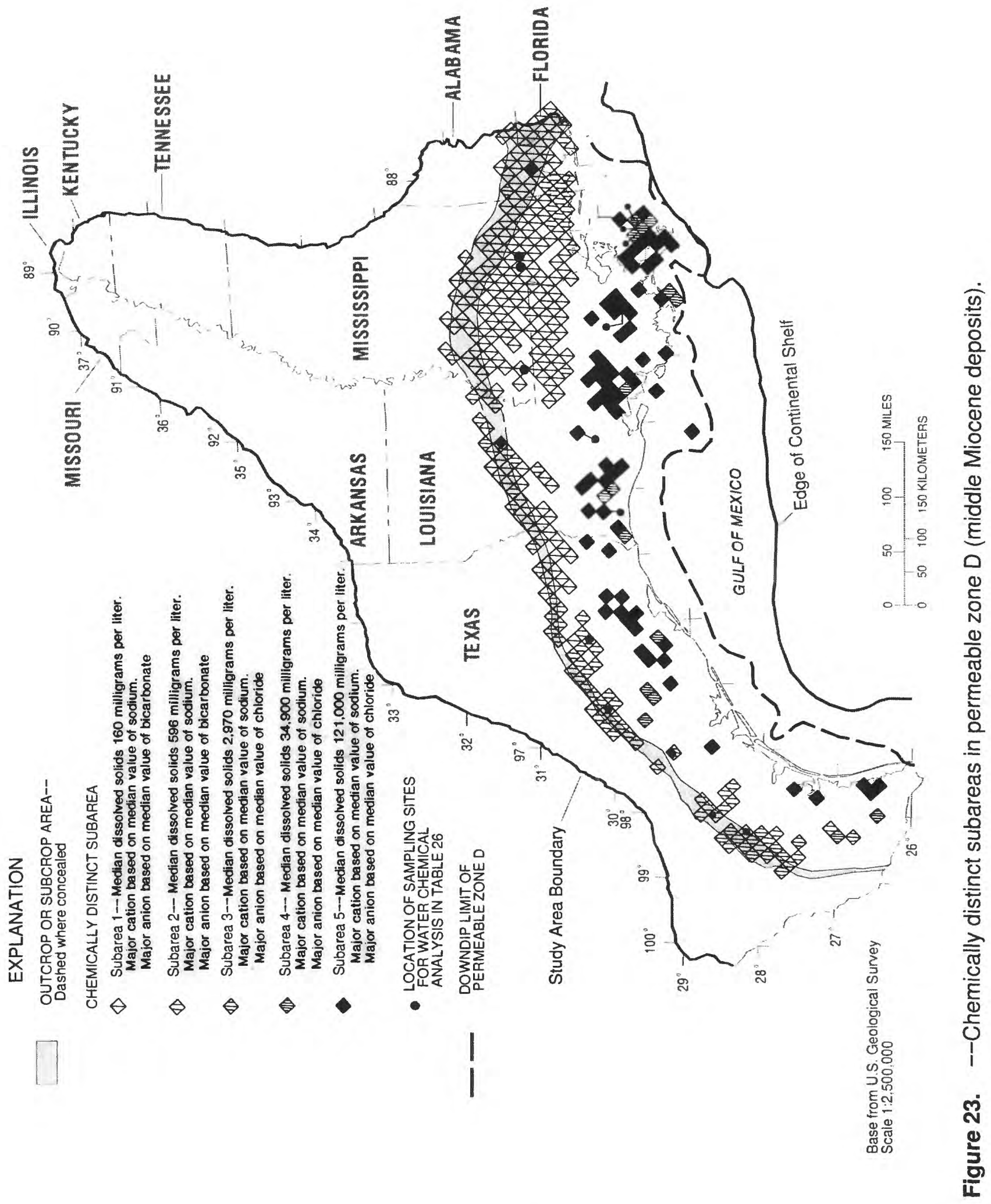




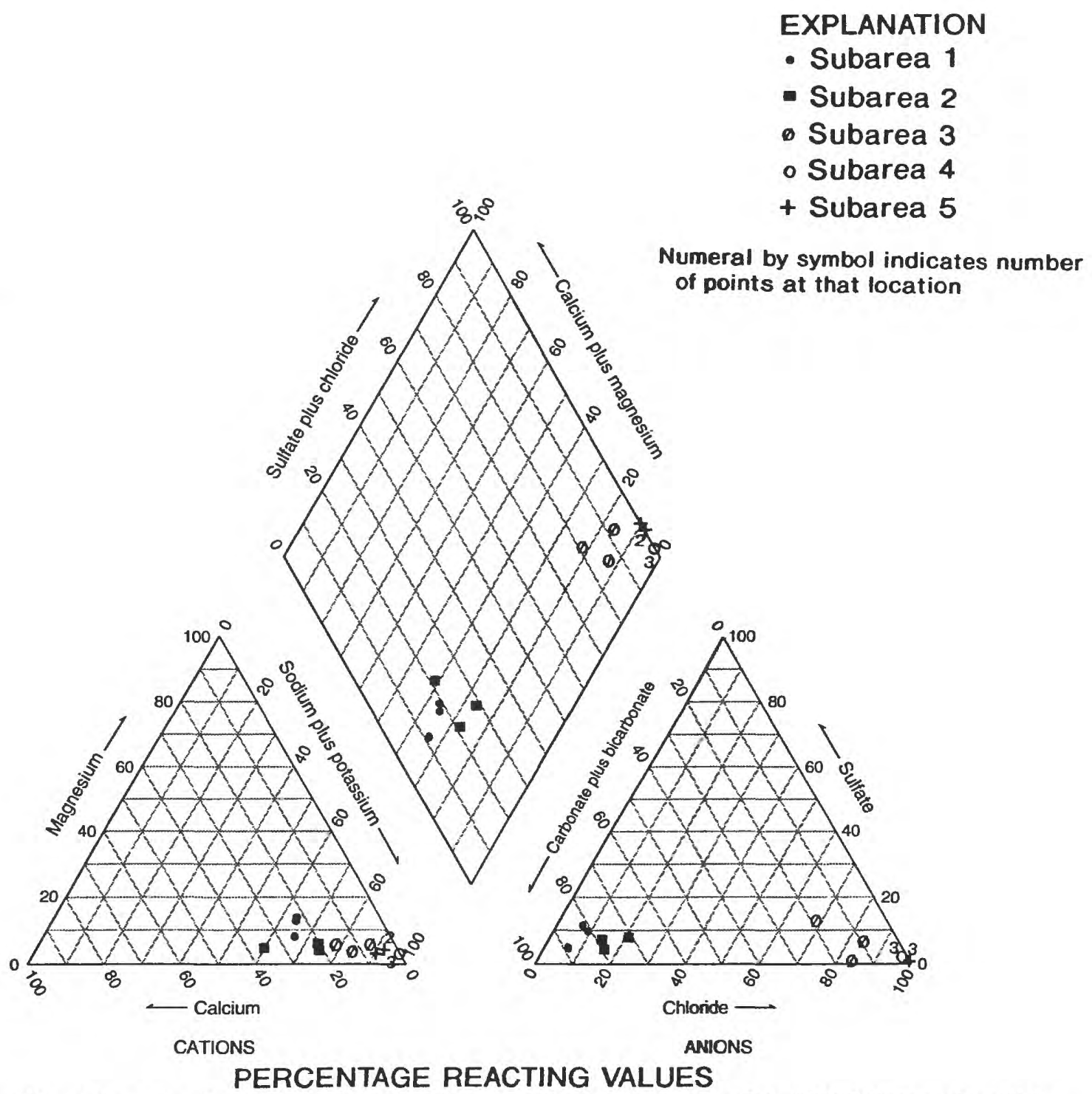

Figure 24.--Change in water chemistry from subarea to subarea in permeable zone D (middle Miocene deposits), based on three representative samples.

The triangular part of the trilinear diagram (fig. 24) and the data in table 12 indicate that the chemical processes occurring in permeable zone $\mathrm{D}$ are increasing sodium and chloride ions from small concentrations updip to extremely large concentrations downdip. The progressive increase in concentration of dissolved solids is about a factor of 4 from subarea 1 to subarea 2, a factor of 5 from subarea 2 to subarea 3, a factor of about 12 from subarea 3 to subarea 4 , and a factor of about 3 from subarea 4 to subarea 5. From subarea 1 to subarea 5 the dissolved-solids concentration increased by a factor of about 800 .

\section{CORRELATION AMONG CHEMICAL CONSTITUENTS AND PROPERTIES OF GROUND WATER WITHIN SUBAREAS}

The correlation among chemical constituents and properties was evaluated by factor analysis, which indicates that at least two major processes or mechanisms are responsible for most of the variability in concentration of constituents in subareas 1, 2, 4, and 5 and at least three major processes in subarea 3 (table 13). Twelve constituents or properties were used in the factor analysis. The number of chemical analyses was 745 in subarea 1, 347 in subarea 2, 54 in subarea 3,92 in subarea 4, and 403 in subarea 5 (table 12). The variability accounted for by the factors ranged from 75.7 percent in subarea 4 to 85.4 percent in subarea 3 . The loading of each constituent or property on each factor and the percent of total variability (communality) accounted for in the factor analysis is shown in table 13. 


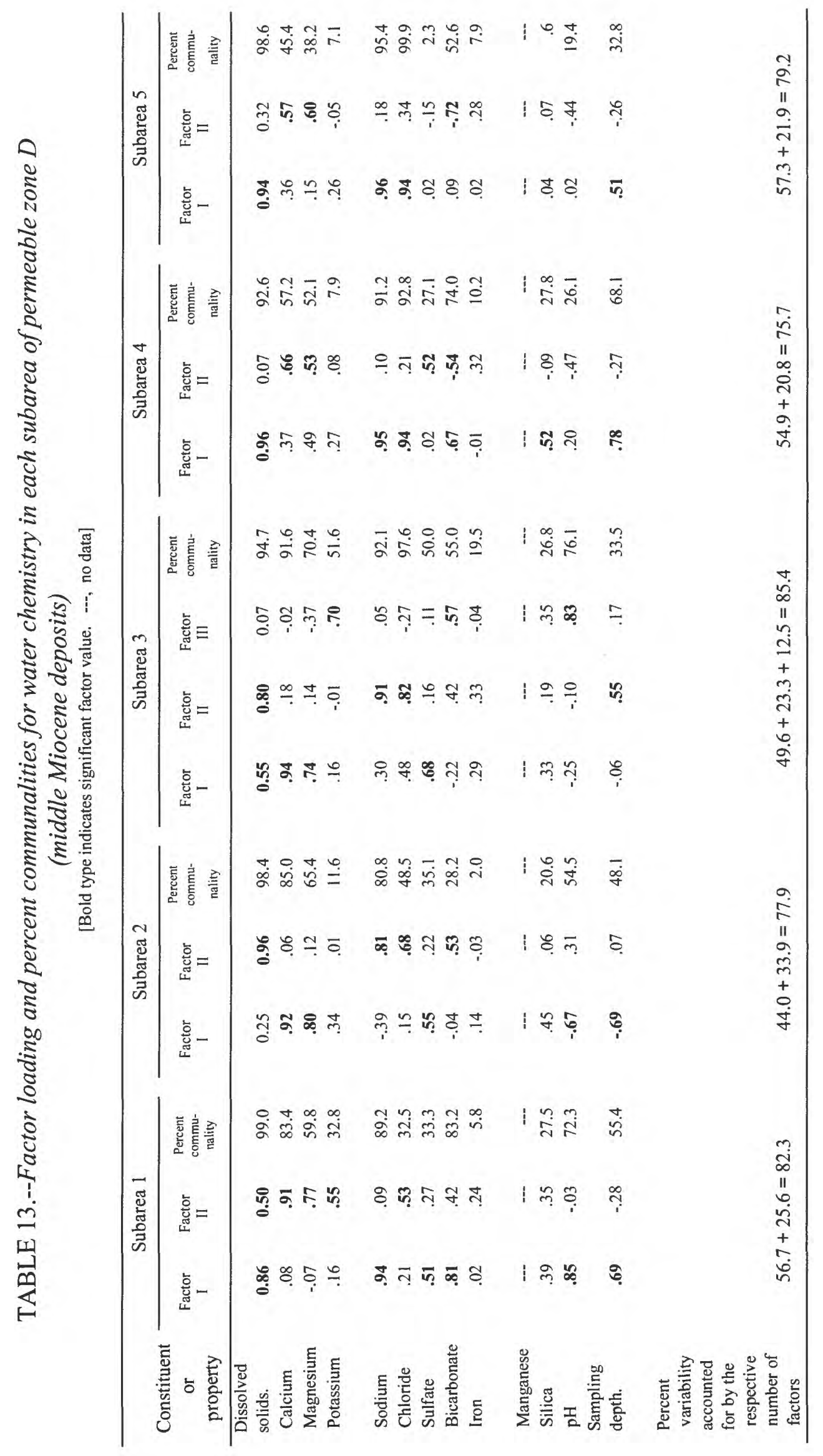


Factor I of subarea 1 represents a process in which sodium, bicarbonate, and sulfate ions are added to the ground water and hydrogen ions are removed. The effect of the process on the chemistry of the ground water increases with depth. Factor II of subarea 1 represents a process in which calcium, magnesium, potassium, and chloride ions are added to the ground water. The variability in concentrations of chemical constituents and properties accounted for by factor I is about 57 percent and by factor II is about 26 percent. The variability in concentration of dissolved solids accounted for by factor I is 86 percent and significant, whereas for factor II it is 50 percent and also significant.

Factor I of subarea 2 represents a process in which calcium, magnesium, sulfate, and hydrogen ions are added to the ground water. In addition, the effect of the process on the water chemistry decreases with depth. Factor II of subarea 2 represents a process in which sodium, bicarbonate, and chloride ions are added to the ground water. The variability in concentrations of chemical constituents and properties accounted for by factor $I$ is about 44 percent and by factor II is about 34 percent. The variability in concentration of dissolved solids accounted for by factor I is 25 percent and nonsignificant, whereas for factor II it is 96 percent and significant.

Factor I of subarea 3 represents a process in which calcium, magnesium, and sulfate ions are added to the ground water. Factor II of subarea 3 represents a process in which sodium and chloride ions are added to the ground water. Also, the effect of the process on the water chemistry increases with depth. Factor III of subarea 3 represents a process in which potassium, bicarbonate, and hydrogen ions are added to the ground water. The variability in concentrations of chemical constituents and properties accounted for by factor I is about 50 percent, by factor II is about 23 percent, and by factor III is about 12 percent. The variability in concentration of dissolved solids accounted for by factor I is 55 percent and significant and for factor II is 80 percent and also significant, whereas for factor III it is 7 percent and nonsignificant.

Factor I of subarea 4 represents a process in which sodium, chloride, and bicarbonate ions and silica are added to the ground water. In addition, the effect of the process on the chemistry of the ground water increases with depth. Factor II of subarea 4 represents a process in which calcium, magnesium, and sulfate ions are added to the ground water and bicarbonate ions are removed. The variability in concentrations of chemical constituents and properties accounted for by factor I is about 55 percent and by factor II is about 21 percent. The variation in concentration of dissolved solids accounted for by factor I is 96 percent and significant, whereas for factor II it is 7 percent and nonsignificant.

Factor I of subarea 5 represents a process in which sodium and chloride ions are added to the ground water. In addition, the effect of the process on the water chemistry increases with depth. Factor II of subarea 5 represents a process in which calcium and magnesium ions are added to the ground water and bicarbonate ions are removed. The variability in concentrations of chemical constituents and properties accounted for by factor $I$ is about 57 percent and by factor II is about 22 percent. The variability in concentration of dissolved solids accounted for by factor I is 94 percent and significant, whereas for factor II it is 32 percent and nonsignificant.

\section{RELATION OF GROUND-WATER CHEMISTRY TO CHEMICAL AND PHYSICAL PROCESSES}

The major chemical processes and mechanisms postulated for each of the chemically distinct subareas of permeable zone $\mathrm{D}$ (middle Miocene deposits) are based on the results of factor analysis in conjunction with constituent concentrations, a trilinear diagram, ground-water movement, and information on water-rock interaction and probable minerals in the deposits.

The major processes postulated in subarea 1 of permeable zone D are (1) alteration of albite (factor I), (2) dissolution of traces of mirabilite (factor I), and (3) leaching of soluble salts from the unsaturated zone (factor II). The postulated alteration of albite and dissolution of mirabilite (factor I) accounts for about 31 percent more of the variability in concentrations of constituents than does leaching of soluble salts from the unsaturated zone (factor II). The loading of dissolved solids on factor I is about 36 percent greater than its loading on factor II, thus indicating that the alteration of albite and the dissolution of mirabilite causes the most variation in the concentration of dissolved solids in subarea 1.

Hydrologic, geologic, and related information that supports the three processes postulated above for chemically 
distinct subarea 1 are discussed briefly in the context of the water chemistry and results of factor analysis of the chemical data. The alteration of albite (eq. 1) is supported by (1) the predominance of sodium and bicarbonate ions in ground water of this subarea (table 12), (2) outcrop areas (fig. 22) through which carbon dioxide is supplied to precipitation that percolates to the ground-water system, and (3) the reported presence of plagioclase in deposits that make up this permeable zone (Plummer, 1932). The $\mathrm{pH}$ would increase because hydrogen ions are consumed in the dissolution of albite. The effect of the process would increase with depth due to the longer resident time associated with distance from the recharge area where permeable zone $\mathrm{D}$ crops out. The alteration of albite adds sodium ions to the ground water. Carbon dioxide from the atmosphere and soil zone forms carbonic acid as it is dissolved in recharge water from precipitation. The acidified ground water accelerates the alteration of albite, and bicarbonate ions are added to the ground water. Because about 25 percent of the subarea is outcrop area (open system), there is a continuous source of carbon dioxide for acid formation. There are also sources of albite because shale and sandstone make up about 94 percent of the sedimentary rock, and feldspars (aluminum silicates) make up 30 and 11.5 percent of shales and sandstones, respectively (Foster, 1949). The dissolution of traces of mirabilite, which is similar to the dissolution of halite (eq. 7), is supported by the significant positive loading of sulfate and sodium on factor I.

The leaching of soluble salts (eq. 15) from the unsaturated zone is a natural process in outcrop areas as precipitation percolates from the ground surface to the saturated zone in humid-climate areas. Subarea 1 is in a humid area and the concentration of the major ions, excluding sodium and bicarbonate, are only slightly above rainwater; therefore, leaching of soluble salts is a likely process in subarea 1 . The source of the soluble salts is either decay of organic matter in the soil zone or dissolution of minerals in the unsaturated zone by acids from the decay process (Freeze and Cherry, 1979). Leakage downward of ground water (eq. 16) in this subarea from the overlying permeable zone C (lower Pliocene-upper Miocene deposits) (fig. 15) does not appear to have any significant effect on the groundwater chemistry regionally. However, upward leakage to these deposits from the underlying permeable zone $\mathrm{E}$ (lower Miocene-upper Oligocene deposits) appears to be affecting the water chemistry in an area of regional discharge in eastcentral Louisiana and in a smaller discharge area in southeastern Mississippi and southwestern Alabama. The two major indications that leakage upward could be affecting the water chemistry in the areas of regional discharge are larger concentrations of dissolved solids (fig. 21) and the intrusion of subarea 2 into what initially was subarea 1 (fig. 23).

The major processes postulated in subarea 2 are (1) oxidation of traces of pyrite (factor I), (2) leaching of the unsaturated zone (factor I), (3) alteration of albite (factor II), and (4) upward leakage (factor II). The postulated leaching of soluble salts from the unsaturated zone and the joint oxidation of pyrite--dissolution of anhydrite processes (factor I) account for about 10 percent more of the variability in concentrations of constituents than does the alteration of albite and upward leakage (factor II). However, the loading of dissolved solids on factor II is very highly significant and about four times greater than on factor I where it was not significant, thus indicating that although factor-I processes account for slightly more of the variability in concentrations of constituents, it is factor-II processes that caused the most variation in the concentration of dissolved solids in subarea 2.

Hydrologic, geologic, and related information that supports the four processes postulated above for chemically distinct subarea 2 are discussed briefly in the context of the water chemistry and results of factor analysis of the chemical data. The source of sulfate ions in the ground water of this subarea is postulated as the oxidation of traces of pyrite (eq. 13) in shales that make up a significant part of permeable zone D (Weiss, 1992) in updip areas of Texas, whereas in the narrow downdip part of the subarea sulfate ions in the ground water could come from oxidation of sulfides found in the shales interbedded within the permeable zone. However, precipitation decreases to the south in Texas, and as a result the oxidized sulfides are very slowly removed by leaching. Consequently, sulfate ions are added very slowly to the ground water in this part of the subarea, resulting in small concentrations of this ion in most of the updip areas of southern Texas. The decrease in the influence of the processes on the water chemistry with distance from the land surface is due to a decrease in oxygen and the effect of leaching with depth. Leaching of the unsaturated zone (eq. 15) is supported by the large outcrop area in subarea 2 (fig. 21).

The alteration of albite (eq. 1) is apparently a continuation in a downdip direction of a process that occurs in subarea 1 as well as in updip areas of subarea 2. Upward leakage (eq. 16) was postulated instead of dissolution of halite because of more evidence for upward leakage. For example, the reassignment of analyses originally in subarea 1 to subarea 2 (fig. 23) in areas of regional discharge and upward leakage (fig. 20) is evidence that upward leakage is 
most likely affecting the water chemistry in subarea 2 . Also, the moderate concentrations of sodium and chloride ions are more representative of upward leakage than dissolution of evaporites (table 12).

Downward leakage of ground water (eq. 16) to subarea 2 from the overlying permeable zone C (lower Plioceneupper Miocene deposits) does not appear to have any significant effect on the water chemistry regionally (fig. 22). However, upward leakage from permeable zone E (lower Miocene-upper Oligocene deposits) probably accounts for what appears to be an intrusion of this subarea into subarea 1 in east-central Louisiana and in the southeastern Mississippi-southwestern Alabama area (fig. 22).

The major chemical processes postulated in subarea 3 are (1) dissolution of gypsum (factor I), (2) upward leakage (factor II), and (3) alteration of potassium feldspar (microcline) (factor III). The postulated dissolution of gypsum (factor I) accounts for about 27 percent more of the variability in concentrations of constituents than does upward leakage (factor II) and 38 percent more of the variability in concentrations of constituents than does the alteration of microcline (factor III). However, the loading of dissolved-solids concentrations on factor II is 25 percent greater than its loading on factor $\mathrm{I}$, thus indicating that upward leakage accounts for the larger part of the variation in the concentration of dissolved solids in subarea 3.

Hydrologic, geologic, and related information that supports the three processes postulated above for chemically distinct subarea 3 is discussed briefly in the context of the water chemistry and results of factor analysis of the chemical data. The dissolution of gypsum (eq. 6) is supported by (1) the large increase in calcium, magnesium, and sulfate ions from subarea 2 to subarea 3 (table 12), (2) the presence of the Oakville Sandstone (Plummer, 1932) which most likely contains gypsum as a cementing agent, and (3) localized areas where the water has been mapped as a sulfate type (fig. 22), indicating the presence of sulfate minerals. Pyrite oxidation (eq. 13) was not postulated because the inverse loading of $\mathrm{pH}$ on factor I was not significant.

Upward leakage (eq. 16) from permeable zone $\mathrm{E}$ to permeable zone $\mathrm{D}$ is supported by a ground-water flow analysis by Williamson (in press). He simulated upward leakage for all but a few areas of subarea 3 (fig. 20) and a few additional areas in the area gulfward of subarea 2 and landward of the assumed location of subarea 3 . The water in permeable zone $\mathrm{E}$ underlying these areas typically has dissolved-solids concentrations greater than seawater, and upward leakage is a significant part of the total flow in these areas. The effect of upward leakage increases with depth because water from near the base of permeable zone $\mathrm{D}$ is likely to have a chemical character more like the water from the underlying permeable zone $E$ than from the upper part of permeable zone D. Alteration of albite (eq. 1) is not considered a major process in subarea 3 because it occurs further downdip than in subarea 2, especially in eastern and central Texas and because bicarbonate did not load significantly on factor II.

Alteration of potassium feldspar (eq. 2) is supported by the reported presence of microcline in sediments making up permeable zone D (Plummer, 1932). Microcline is altered by hydrolysis to produce potassium and bicarbonate ions, silica, and a clay mineral. Alteration of microcline would be increased in water containing hydrogen ions produced from methane fermentation (eq. 8). Lignite, which is present in most deep Gulf Coastal Plain sediments, would promote methane fermentation. The consumption of hydrogen ions in the alteration of microcline would explain the significant loading of $\mathrm{pH}$ on factor III.

The major processes postulated in subarea 4 in permeable zone $D$ are (1) dissolution of halite containing traces of calcite (factor I), (2) upward leakage (factor I), (3) dissolution of anhydrite (factor II), and (4) precipitation of calcite (factor II). The postulated dissolution of halite containing traces of calcite and upward leakage (factor I) accounts for about 34 percent more of the variability in concentrations of constituents than does the dissolution of anhydrite and precipitation of calcite (factor II). The loading of dissolved solids on factor I is very high and significant and on factor II it is very low and nonsignificant, thus indicating that upward leakage and dissolution of halite not only account for most of the variability in concentrations of constituents but also contribute most to the variation in the concentration of dissolved solids in subarea 4.

Hydrologic, geologic, and related information that supports the four processes postulated above for chemically distinct subarea 4 are discussed briefly in the context of the water chemistry and results of factor analysis of the chemical data. The dissolution of halite (eq. 7) containing traces of calcite is supported by (1) the very large 
concentration of sodium and chloride ions, which is slightly greater than seawater, and the moderately large concentration of calcium and bicarbonate ions (table 12), and (2) the subarea lies in a salt-dome basin (Beckman and Williamson, 1990). An increase in the size and distribution of salt domes with depth would account for the increase in the effect of the process on the water chemistry with depth. The dissolution of calcite may be explained by an experiment in which it was shown that small amounts of calcite are precipitated in the formation of salt beds that are primarily halite (Krauskopf, 1967). All of the 100-square-mile areas making up subarea 4 in southern Louisiana are near salt domes that have 4,000 to $11,000 \mathrm{ft}$ of overlying sediments. Thus dissolution of halite is less likely to be impeded by caprock sealing the salt dome from the ground-water flow system. These areas are where geopressured sediments form the base of permeable zone D (Weiss, 1992), and upward leakage is not a significant part of the flow (Williamson, in press), whereas only one of the 100-square- mile areas assigned to subarea 4 in southern Texas is near salt domes that have more than $4,000 \mathrm{ft}$ of overlying sediments; thus dissolution of halite from salt domes is less likely in this area. However, simulated upward leakage from permeable zone $\mathrm{E}$ is 10 percent or more of the horizontal flow through the six 100-square-mile areas in southern Texas and thus is more likely the source of both sodium and chloride in those areas.

Dissolution of anhydrite (eq. 7) is supported by (1) anhydrite composing a large part of the caprock overlying salt domes that are present in the subarea (Beckman and Williamson, 1990), and (2) the moderate concentration of sulfate ions (table 12). Anhydrite is postulated instead of gypsum because heat and pressure after burial of the evaporites do not favor the persistence of gypsum. The precipitation of calcite (eq. 6) occurs because the concentration of calcium ions is increased due to the two dissolution processes postulated, resulting in a change in the equilibrium constant of calcite. Thus precipitation occurs as a result of the common-ion effect.

The major processes postulated in subarea 5 are (1) dissolution of halite (factor I), (2) dissolution of a calciummagnesium mineral (factor II), and (3) precipitation of calcite and trona (factor II). The postulated dissolution of halite (factor I) accounts for about 35 percent more of the variability in concentrations of constituents than does dissolution of a calcium-magnesium mineral and precipitation of calcite and trona (factor II). The loading of dissolved solids on factor I is very high and significant, whereas it is nonsignificant on factor II, thus indicating that the dissolution of halite accounts for most of the variability in concentrations of constituents and also accounts for most of the variation in the concentration of dissolved solids in subarea 5.

Hydrologic, geologic, and related information that supports the three processes postulated above for chemically distinct subarea 5 are discussed briefly in the context of the water chemistry and results of factor analysis of the chemical data. The dissolution of halite (eq. 7) is supported by (1) the penetration of many salt domes, which primarily are composed of halite, through the base of permeable zone D (Beckman and Williamson, 1990), and (2) the extremely large concentration of sodium and chloride ions in ground water of this subarea (greater than the concentration in seawater by a factor of about 4 and 6, respectively) (table 12). The effect of the process on the chemistry of the ground water increases with depth because the areal extent of the salt domes is greater with depth, resulting in more exposure for salt dissolution (Halbouty, 1979). Thickness of sediments in subarea 5 ranges from about 4,000 to $16,000 \mathrm{ft}$ (Weiss, 1992), thus extensive caprock is less likely to seal the halite from the ground-water flow system. Dissolution of a calcium-magnesium mineral (eq. 4) is supported by (1) the large concentration of calcium and magnesium ions (table 12), and (2) the significant loading of calcium and magnesium on factor II. The calcium-magnesium mineral would most likely be a chloride mineral because of the very large concentration of chloride ions. However, it could be a bicarbonate or sulfate mineral that is dissolving and then precipitating almost simultaneously because of the large concentrations of major ions.

The precipitation of calcite (eq. 6) is supported by the significant negative loading of bicarbonate on factor II and the lesser concentration of bicarbonate ions in the ground water of subarea 4 than of subarea 5 . The precipitation of trona, a sodium carbonate mineral, is supported additionally because the concentration of chloride ions being nearly double that of sodium. In waters having a very large sodium chloride concentration, the sodium precipitates as trona (Drever, 1982). Both precipitation reactions would add hydrogen ions to the ground water and decrease $\mathrm{pH}$. Downward leakage (eq. 16) from the overlying permeable zone C (lower Pliocene-upper Miocene deposits) was simulated in about 20 of the 100-square-mile areas making up subarea 5 in southern Louisiana but the volumes are small, typically less than 10 percent of the horizontal flow (fig. 15). Upward leakage from permeable zone E was simulated for most of the areas making up subarea 5 in Texas and may be a mechanism of major importance to the 
water chemistry in this part of subarea 5 of permeable zone $\mathrm{D}$.

The ground-water chemistry in both subarea 4 and subarea 5 of permeable zone D (middle Miocene deposits) appears to be affected by geopressure (fig. 22). The presence of geopressure alters the normal progression of changing water chemistry in the downdip direction. Consequently, isolated areas of subarea 4 occur within an extensive area that is mostly subarea 5 . The primary reason for this occurrence is a decrease in dissolved-solids concentrations (fig.21) due to water under abnormally large pressure (geopressure) being either filtered through membranelike clays or diluted by water of crystallization, a product of diagenesis of montmorillonite to illite (Fertl, 1976).

\section{PERMEABLE ZONE E (LOWER MIOCENE- UPPER OLIGOCENE DEPOSITS)}

Permeable zone E (lower Miocene-upper Oligocene deposits) underlies about 45 percent of the study area (fig. 25). It has an areal extent of about $90,000 \mathrm{mi}^{2}$ and a mean thickness of $1,340 \mathrm{ft}$ (Williamson and others, 1990). Median depth of water samples collected for chemical analysis ranges from $208 \mathrm{ft}$ in updip areas to $6,500 \mathrm{ft}$ in downdip areas (table 14). The downdip limit of permeable zone $\mathrm{E}$ is on the Continental Shelf south of the shoreline in southern Texas, Mississippi, and Alabama. The downdip limit is near the shoreline to about $60 \mathrm{mi}$ north of the shoreline in Louisiana and most of Texas. Outcrop areas extend northward and eastward from southern Texas across the Coastal Plain of Texas, Louisiana, Mississippi, and southwestern Alabama. The permeable zone does not crop out for a distance of about 100 mi extending from Duval County, Texas, to Karnes County, Texas, but is overlapped by permeable zone D. The width of the outcrop ranges from about $4 \mathrm{mi}$ in southern Texas to about $20 \mathrm{mi}$ in southwestern Alabama. The geometric mean hydraulic conductivity of permeable zone $\mathrm{E}$ is about $59 \mathrm{ft} / \mathrm{d}$ (table 3 ).

The simulated horizontal direction of predevelopment ground-water flow and vertical leakage relative to the base of permeable zone $\mathrm{E}$ is shown in figure 25 (Williamson, in press). Regionally, the horizontal flow east of the Mississippi River is from a topographic high in southwestern Mississippi westward toward the Mississippi River, southward toward the gulf, and southeastward toward the Tombigbee River. The horizontal flow west of the Mississippi River is toward a regional discharge area in east-central Louisiana, toward the Rio Grande in southern Texas, and toward the coast or major stream valleys elsewhere. Updip flow from areas along the downdip limit is most likely due to density differences in the ground water. Simulated downward leakage from the overlying permeable zone D (middle Miocene deposits) occurs throughout a large area in southwestern Mississippi and in several smaller areas from southern Texas to western Florida (fig. 20). Upward leakage from underlying deposits occurs throughout about 45 percent of the area underlain by permeable zone E that extends from southern Texas to western Florida. The geopressured zone forms the base of permeable zone $\mathrm{E}$ throughout much of the area underlain by the permeable zone, and vertical leakage is believed to be insignificant regionally.

\section{DISSOLVED-SOLIDS CONCENTRATIONS}

The areal distribution of the median concentration of dissolved solids per 100-square-mile area in water of permeable zone $\mathrm{E}$ (lower Miocene-upper Oligocene deposits) is shown in figure 26. The delimited area of permeable zone E having median concentrations of dissolved solids less than $500 \mathrm{mg} / \mathrm{L}$ extends from southeastern Texas eastward through central Louisiana, south-central Mississippi, and southwestern Alabama. It is separated into two parts by higher median concentrations of dissolved solids in an area west of the Mississippi River. This delimited area, which includes more than 55 percent of the outcrop area for this water-yielding unit, is the principal area of recharge from precipitation to permeable zone $\mathrm{E}$. The delimited areas of the aquifer having median concentrations of dissolved solids ranging from 500 to $1,000,1,000$ to 3,000 , and 3,000 to 10,000 are mostly adjacent and downdip from one another in consecutive order from the 0 to $500 \mathrm{mg} / \mathrm{L}$ delimited area. All three delimited areas are quite narrow in the downdip direction and appear to be areas of transition from freshwater to saline water from southwestern Alabama to eastern Texas. However, that part of the three delimited areas in Texas appear to contain some freshwater based on waterwell sampling. Freshwater is apparently present because part of the delimited areas border on the updip limit and contain outcrop. 
TABLE 14.--Median value of selected chemical constituents and properties of water, median sampling depth, water types, and number of analyses for each subarea of permeable zone E (lower Miocene-Oligocene deposits)

[Concentrations are in milligrams per liter, except iron and manganese, which are in micrograms per liter. Depth is in feet, $\mathrm{pH}$ is in units, and temperature is in degrees Celsius. Chemical symbols: $\mathrm{Ca}$, calcium; $\mathrm{Mg}$, magnesium; $\mathrm{Na}$, sodium; $\mathrm{K}$, potassium; $\mathrm{Fe}$, iron; $\mathrm{Mn}$, manganese; $\mathrm{HCO}_{3}$, bicarbonate; $\mathrm{SO}_{4}$, sulfate; $\mathrm{Cl}$, chloride; $\mathrm{SiO}_{2}$, silica. Water type shown is the most frequently occurring. ---, no data]

\begin{tabular}{|c|c|c|c|c|c|}
\hline \multirow{2}{*}{$\begin{array}{l}\text { Constituent or } \\
\text { property }\end{array}$} & \multicolumn{5}{|c|}{ Subarea } \\
\hline & 1 & 2 & 3 & 4 & 5 \\
\hline $\mathrm{Ca}$ & 2.8 & 47 & 60 & 600 & 2,400 \\
\hline $\mathrm{Mg}$ & .8 & 3.3 & 9.0 & 42 & 310 \\
\hline $\mathrm{Na}$ & 38 & 98 & 870 & 10,300 & 23,200 \\
\hline K & 1.9 & 3.0 & 8.2 & 100 & 160 \\
\hline $\mathrm{Fe}$ & 150 & 105 & 250 & 3.700 & 9,700 \\
\hline $\mathrm{Mn}$ & 20 & 20 & 30 & 1.400 & 2.100 \\
\hline $\mathrm{HCO}_{3}$ & 110 & 310 & 340 & 440 & 170 \\
\hline $\mathrm{SO}_{4}$ & 7.2 & 19 & 110 & 50 & 18 \\
\hline $\mathrm{Cl}$ & 4.8 & 80 & 890 & 16.900 & 41,900 \\
\hline $\mathrm{SiO}_{2}$ & 34 & 42 & 30 & 56 & 31 \\
\hline Dissolved solids & 150 & 506 & 2.600 & 28,500 & 68,600 \\
\hline Sampling depth & 442 & 208 & 705 & 6,000 & 6.500 \\
\hline $\mathrm{pH}$ & 7.1 & 7.4 & 7.4 & 7.3 & 6.9 \\
\hline Temperature & 22.0 & 21.5 & 27.1 & 24.5 & -- \\
\hline Primary water type & $\mathrm{NaHCO}_{3}$ & $\mathrm{CaHCO}_{3}$ & $\mathrm{NaCl}$ & $\mathrm{NaCl}$ & $\mathrm{NaCl}$ \\
\hline Secondary water type & $\mathrm{CaSO}_{4}$ & $\mathrm{NaCl}$ & $\mathrm{CaHCO}_{3}$ & $\mathrm{CaHCO}_{3}$ & $\mathrm{CaHCO}_{3}$ \\
\hline Number of analyses & 420 & 253 & 59 & 217 & 221 \\
\hline
\end{tabular}

The delimited area of permeable zone $\mathrm{E}$ having concentrations of dissolved solids ranging from 10,000 to 35,000 $\mathrm{mg} / \mathrm{L}$ underlies an area from the western part of southern Texas to southwestern Alabama. The delimited area is wider than the three delimited areas of lower dissolved-solids concentration, especially in the western part of the aquifer area in Texas, and has many sampling sites. Sources of freshwater for domestic use in this delimited area of the wateryielding unit are generally from overlying deposits. Areas of permeable zone $\mathrm{E}$ having concentrations of dissolved solids greater than $35,000 \mathrm{mg} / \mathrm{L}$ underlie an area from the western part of southern Texas to southwestern Alabama. About one-half of the area underlain by this permeable zone has water with a dissolved-solids concentration greater than $35,000 \mathrm{mg} / \mathrm{L}$. Areas of permeable zone $\mathrm{E}$ having concentrations of dissolved solids greater than $70,000 \mathrm{mg} / \mathrm{L}$ generally are near the downdip limit of the permeable zone in Texas and Louisiana. 


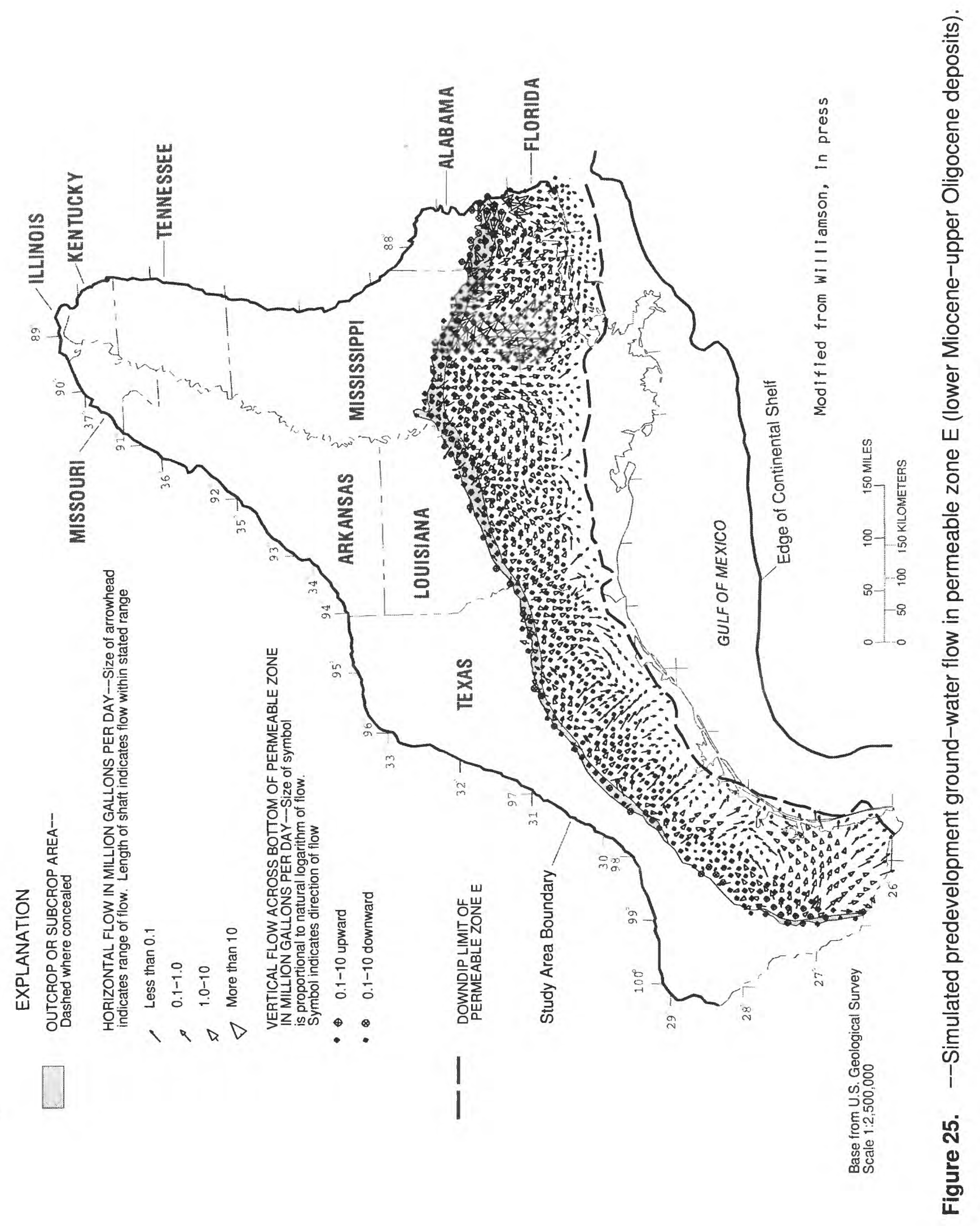




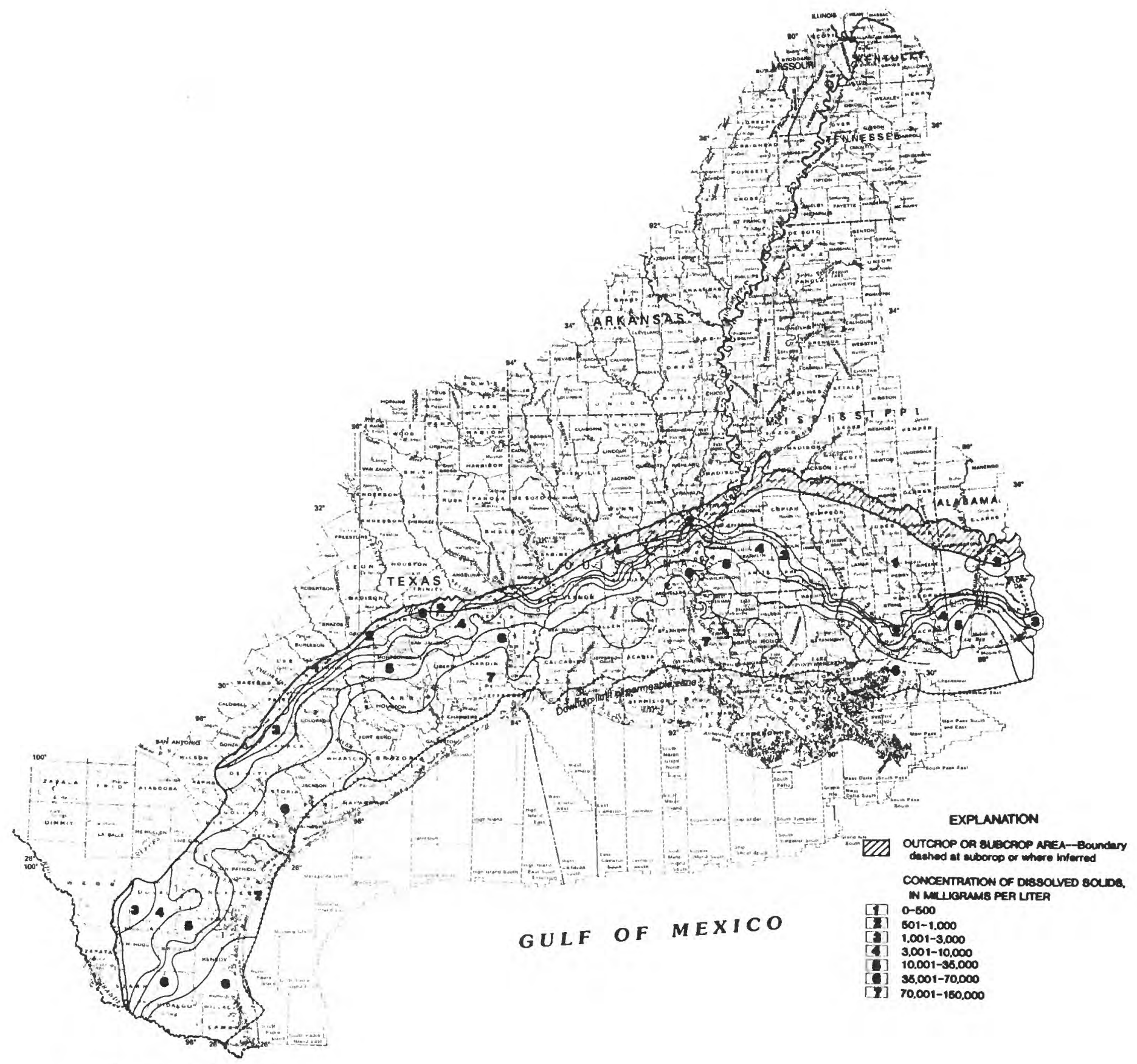

Modifled from Pettijohn and olhere, 1008 


\section{PRIMARY WATER TYPES}

The primary water type where the median concentration of dissolved solids is less than $500 \mathrm{mg} / \mathrm{L}$ is predominantly sodium bicarbonate in Louisiana and adjacent parts of Texas and Mississippi, and is a mixture of major ions in Alabama and Florida (fig. 27). In areas where the median concentration of dissolved solids range from 500 to 3,000 $\mathrm{mg} / \mathrm{L}$, the primary water type is calcium bicarbonate in central Texas and is a mixture of major ions in southeastern Texas. Sodium chloride is the predominant primary water type where the median concentration of dissolved solids exceeds $3,000 \mathrm{mg} / \mathrm{L}$.

\section{GROUND-WATER CHEMISTRY WITHIN SUBAREAS}

Permeable zone E (lower Miocene-upper Oligocene deposits) was divided into five chemically distinct subareas and the boundaries adjusted using discriminant function analysis of the chemical data from the subareas. Subarea 1 (fig 28) mostly is in west-central Louisiana and an adjacent part of Texas, and in southern Mississippi and adjacent parts of Louisiana and Alabama. Subarea 1 is about 25 percent of the area underlain by permeable zone $E$ and contains about 45 percent of the outcrop area. Subarea 2 mostly is adjacent to subarea 1 in east-central Louisiana and eastcentral Texas. Elsewhere, available data indicate several widely scattered 100 -square-mile areas that have similar water. Subarea 2 has about 8 percent of the area underlain by permeable zone $E$ and about 35 percent of the outcrop area. Subarea 3 is mostly 100 -square-mile areas scattered across the permeable zone. Ten of the 100 -square-mile areas are on or near the outcrop and five are downdip. Subarea 4 is mostly in southern Texas and is made up of thirtytwo 100-square-mile areas. Twenty-three of the 100-square-mile areas that are contiguous form areas of 200 to 900 $\mathrm{mi}^{2}$. Subarea 5 is along southern Texas and southern Louisiana and is made up of fifty-nine 100-square-mile areas that are contiguous over a large part of the area from the Rio Grande to the Mississippi River.

The median value for selected chemical constituents and the primary and secondary water types for each subarea are shown in table 14. Major cations increase in concentration from subarea 1 to subarea 5 with the greatest increase being in the sodium ion. Among the major anions, only chloride concentration increases progressively from subarea 1 to subarea 5. The bicarbonate ion concentration increases from subarea 1 to subarea 4 , then decreases from subarea 4 to subarea 5. Both sulfate ion concentration and $\mathrm{pH}$ increase from subarea 1 to subarea 3 , then decrease from subarea 3 to subarea 4 and from subarea 4 to subarea 5 . The minor cations, iron and manganese, generally increase in concentration from subarea 1 to subarea 5 , whereas silica has no consistent pattern of change. The most frequently occurring (primary) water type is sodium bicarbonate in subarea 1, calcium bicarbonate in subarea 2, and sodium chloride in subareas 3,4 , and 5 (table 14).

The trilinear diagram (fig. 29), based on three representative samples from each subarea, in conjunction with figure 27 shows that water in permeable zone E (lower Miocene-upper Oligocene deposits) is sodium bicarbonate in subarea 1, a mixture of calcium, magnesium, sodium, and bicarbonate ions in subarea 2, and sodium chloride in subareas 3,4 , and 5 . The trilinear diagram also shows that major cations concentration is approximately 7 percent magnesium plus calcium ( 93 percent sodium plus potassium) in subarea 1 and 11 percent magnesium plus calcium (89 percent sodium plus potassium) in subarea 5 . The major anions concentration is 87 percent bicarbonate plus carbonate (13 percent chloride plus sulfate) in subarea 1 and less than 1 percent bicarbonate plus carbonate (greater than 99 percent chloride plus sulfate) in subarea 5. The triangular part of the trilinear diagram (fig. 9) and the data in table 14 indicate that the chemical processes occurring in permeable zone $\mathrm{E}$ are increasing sodium from small concentrations in subarea 1 to extremely large concentrations in subarea 5. Similarly, the chloride ion concentration increases from subarea 1 to subarea 5 .

The progressive increase in concentration of dissolved solids is a factor of about 3 from subarea 1 to subarea 2, a factor of about 5 from subarea 2 to subarea 3 , a factor of about 11 from subarea 3 to subarea 4 , and a factor of about 2 from subarea 4 to subarea 5 . Thus the dissolved-solids concentration increased by a factor of about 450 from subarea 1 to subarea 5 . 


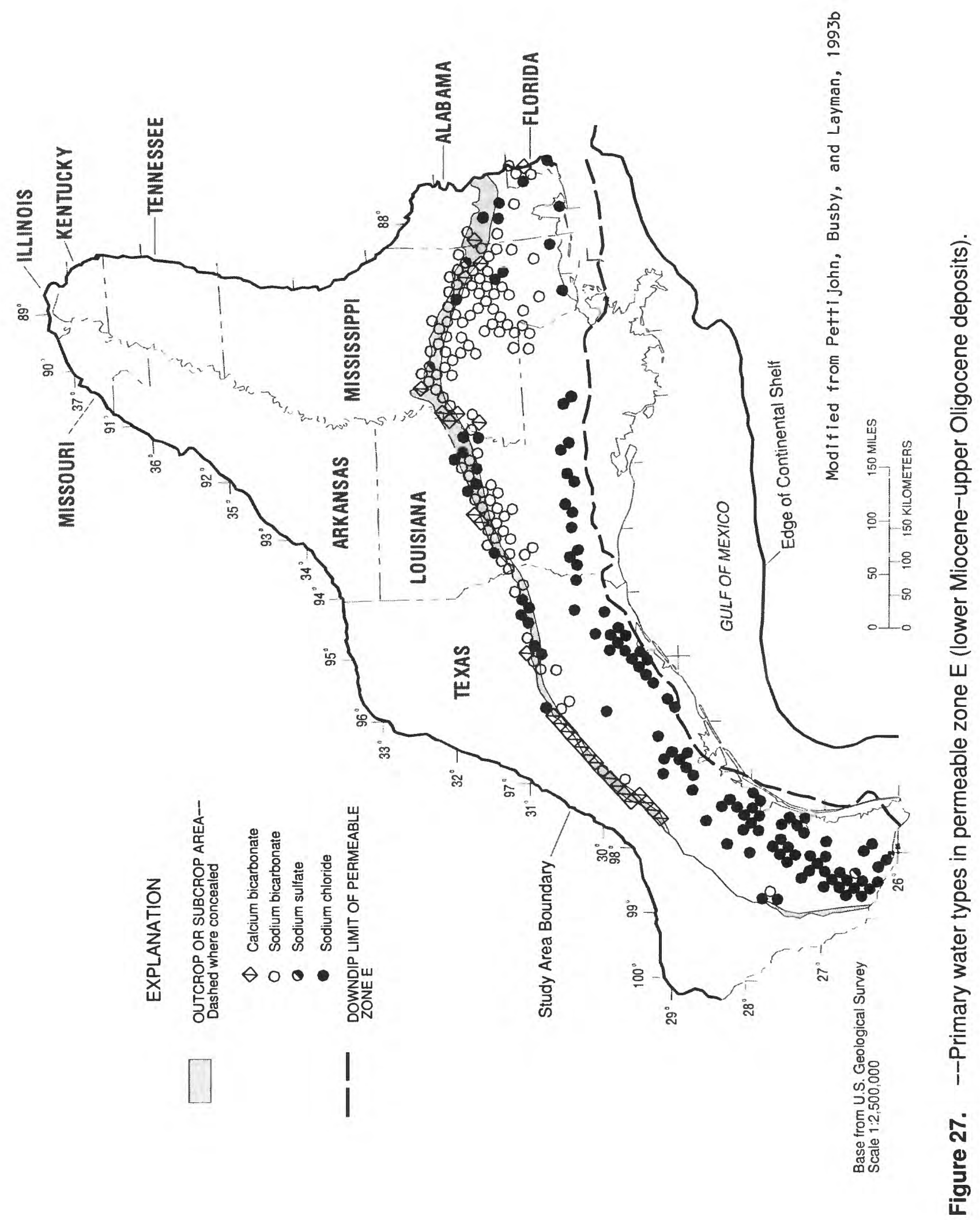




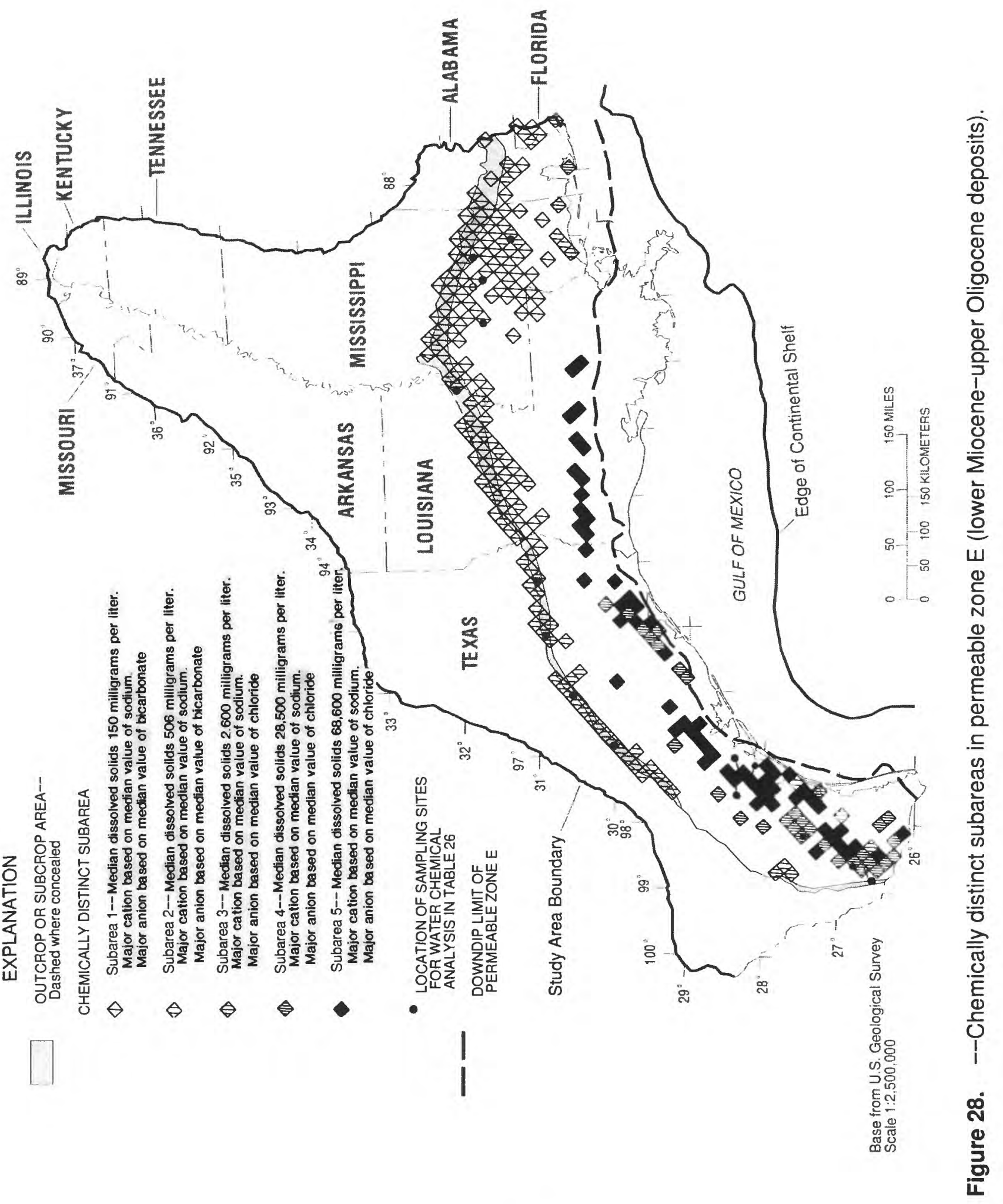




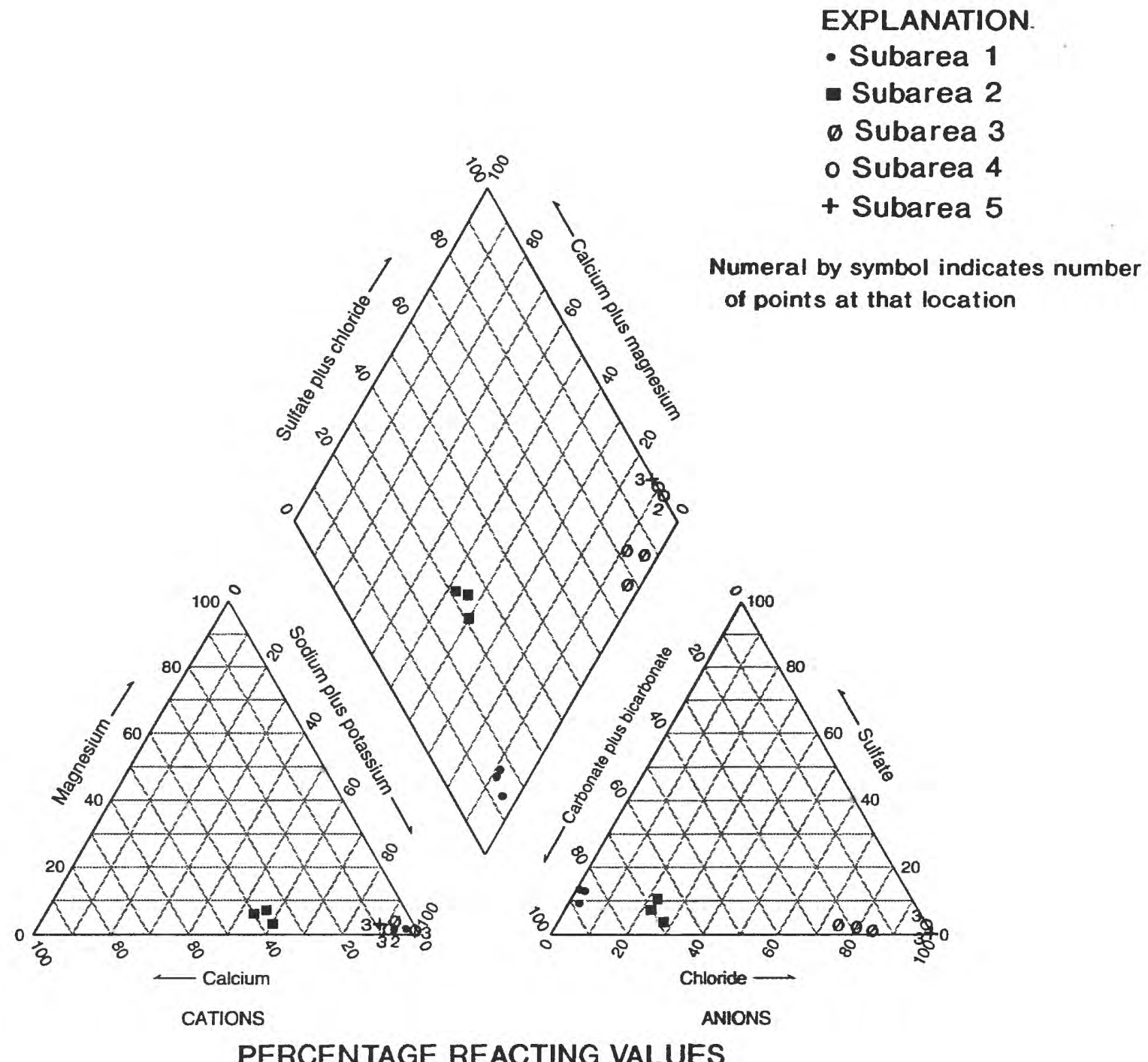

Figure 29.--Change in water chemistry from subarea to subarea in permeable zone E (lower Miocene-upper Oligocene deposits), based on three representative samples.

\section{CORRELATION AMONG CHEMICAL CONSTITUENTS AND PROPERTIES OF GROUND WATER WITHIN SUBAREAS}

The correlation among chemical constituents and properties of water from permeable zone $\mathrm{E}$ (lower Mioceneupper Oligocene deposits) was evaluated by factor analysis, which indicates that at least two major processes or mechanisms are responsible for most of the variability in constituent concentrations in subareas 1,2,3, and 5 and as many as five processes in subarea 4 (table 15). Twelve constituents or properties were used in the factor analysis. The number of chemical analyses was 420 in subarea 1, 253 in subarea 2, 59 in subarea 3, 217 in subarea 4, and 221 in subarea 5 (table 14). The variability accounted for by the factors ranged from 59.4 percent in subarea 3 to 92.9 percent in subarea 4. The loading of each constituent or property on each factor and the percent of total variability (communality) accounted for in factor analysis is shown in table 15. 


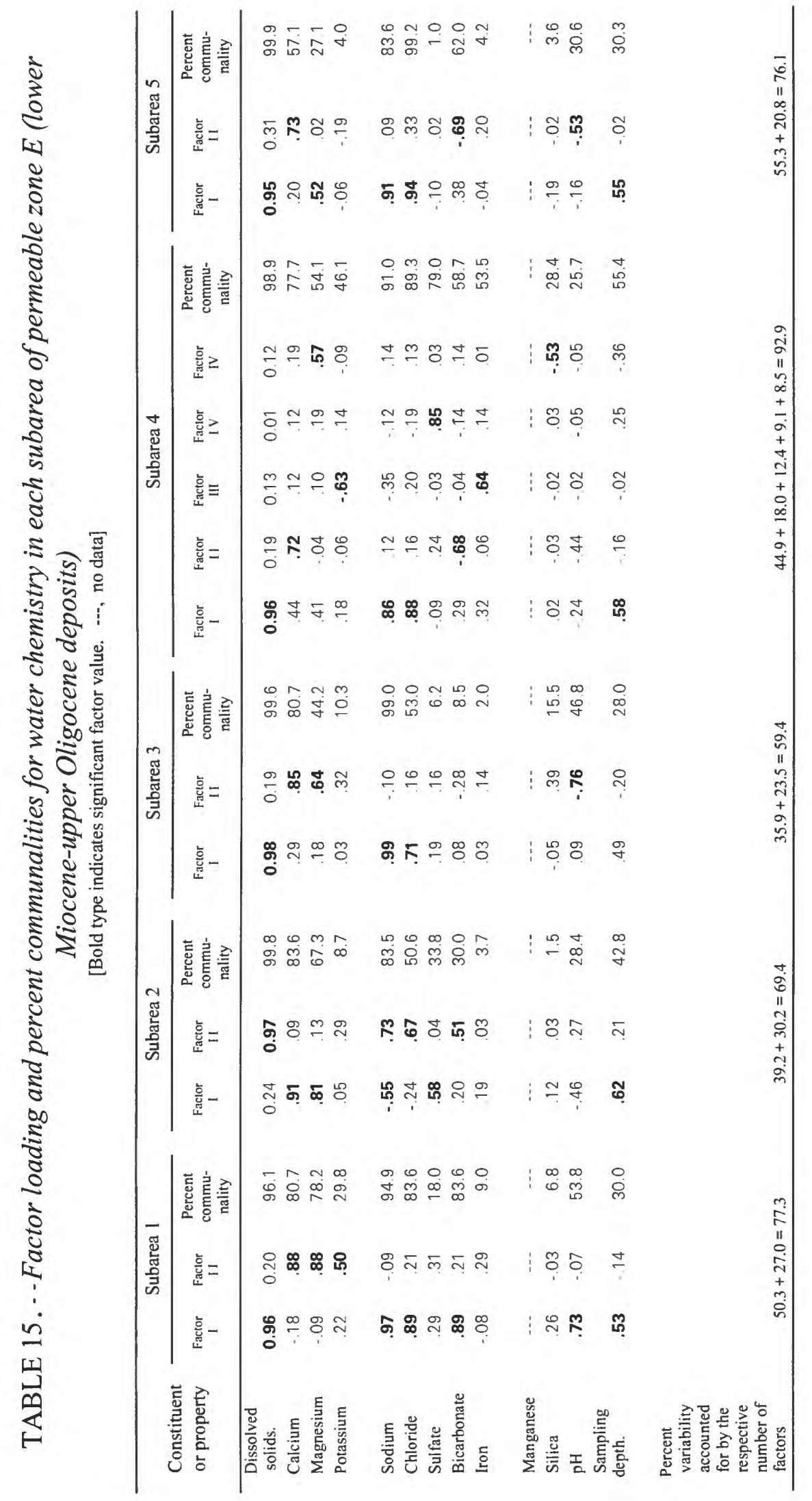


Factor I of subarea 1 of permeable zone E represents a process in which sodium, bicarbonate, and chloride ions are added to the ground water and hydrogen ions are removed. The effect of the process on the water chemistry increases with depth. Factor II of subarea 1 represents a process in which calcium, magnesium, and potassium ions are added to the ground water. The variability in concentration of chemical constituents and properties accounted for by factor I is about 50 percent and by factor II is about 27 percent. The variability in concentration of dissolved solids accounted for by factor I is 96 percent and significant, whereas for factor II it is 20 percent and nonsignificant.

Factor I of subarea 2 of permeable zone E represents a process in which calcium, magnesium, and sulfate ions are added to the ground water and sodium ions are removed. The effect of the process on the water chemistry decreases with depth. Factor II of subarea 2 represents a process in which sodium, chloride, and bicarbonate ions are added to the ground water. The variability in concentration of chemical constituents and properties accounted for by factor $I$ is about 39 percent and by factor II is about 30 percent. The variability in concentration of dissolved solids accounted for by factor I is 24 percent and nonsignificant, whereas for factor II it is 97 percent and significant.

Factor I of subarea 3 of permeable zone E represents a process in which sodium and chloride ions are added to the ground water. Factor II of subarea 3 represents a process in which calcium, magnesium, and hydrogen ions are added to the ground water. The variability in concentration of chemical constituents and properties accounted for by factor I is about 36 percent and by factor II is about 24 percent. The variability in concentration of dissolved solids accounted for by factor I is 98 percent and significant, whereas for factor II it is 19 percent and nonsignificant.

Factor I of subarea 4 of permeable zone $E$ represents a process in which sodium and chloride ions are added to the ground water, and the effect of the process on the chemistry of the water increases with depth. Factor II of subarea 4 represents a process in which calcium ions are added to the ground water and bicarbonate ions are removed. Factor III of subarea 4 represents a process in which ferric ions are added to the ground water and potassium ions are removed. Factor IV of subarea 4 represents a process in which sulfate ions are added to the ground water. Factor V of subarea 4 represents a process in which magnesium ions are added to the ground water and silica ions are removed. The variability in concentration of chemical constituents and properties accounted for by factor I is about 45 percent, by factor II is about 18 percent, by factor III is about 12 percent, by factor IV is about 9 percent, and by factor V is about 8 percent (table 15). The variability in concentration of dissolved solids accounted for by factor I is 96 percent and significant, whereas for factor II it is 19 percent and nonsignificant, for factor III it is 13 percent and nonsignificant, for factor IV it is 1 percent and nonsignificant, and for factor $\mathrm{V}$ it is 12 percent and nonsignificant.

Factor I of subarea 5 of permeable zone $\mathrm{E}$ represents a process in which sodium, magnesium, and chloride ions are added to the ground water, and the effect of the process on the water chemistry increases with depth. Factor II of subarea 5 represents a process in which calcium and hydrogen ions are added to the ground water and bicarbonate ions are removed. The variability in concentration of chemical constituents and properties accounted for by factor I is about 55 percent and by factor II is about 21 percent. The variability in concentration of dissolved solids accounted for by factor I is 95 percent and significant, whereas for factor II it is 31 percent and nonsignificant.

\section{RELATION OF GROUND-WATER CHEMISTRY TO CHEMICAL AND PHYSICAL PROCESSES}

The major chemical processes and mechanisms postulated for each of the chemically distinct subareas of permeable zone E (lower Miocene-upper Oligocene deposits) are based on the results of factor analysis in conjunction with constituent concentrations, a trilinear diagram, ground-water movement, and information on water-rock interaction and probable minerals in the deposits.

The major processes postulated in chemically distinct subarea 1 of permeable zone $\mathrm{E}$ are (1) alteration of albite (factor I), (2) dissolution of halite (factor I), and (3) leaching of soluble salts from the unsaturated zone (factor II). The postulated alteration of albite and dissolution of halite (factor I) account for about 23 percent more of the variability in concentrations of constituents than does leaching of soluble salts from the unsaturated zone (factor II). The loading of dissolved solids on factor I is very high and significant, and its loading on factor II is low and nonsignificant, thus indicating that the alteration of albite accounts for most of the variation in concentration of dissolved solids in subarea 1 of permeable zone $E$. 
Hydrologic, geologic, and related information that supports the three processes postulated above for chemically distinct subarea 1 are discussed briefly in the context of the water chemistry and results of factor analysis of the chemical data. The alteration of albite (eq. 1) is supported by (1) the presence of feldspar in the aquifer deposits (Plummer, 1932), (2) the predominance of sodium and bicarbonate ions in the ground water (table 14), (3) the loss of hydrogen ions indicated by the significant loading of $\mathrm{pH}$ on factor I, and (4) outcrop areas through which carbon dioxide is supplied to the ground water (fig. 26). Dissolution of halite (eq. 7) was postulated because chloride loaded significantly on factor I (table 15). It is possible that the halite is derived from the salt domes that penetrate the base of permeable zone $\mathrm{E}$ in subarea 1 . However, only four salt domes penetrate the base of the permeable zone in this subarea (Beckman and Williamson, 1990), and they generally are overlain by less than $3,000 \mathrm{ft}$ of sediment. Salt domes buried at these depths typically are sealed by caprock from the ground-water flow system. The concentration of chloride ions is much smaller than the concentration found in water near actively dissolved salt domes. Therefore, the source of the chloride is more likely residual crystals of sodium chloride that dissolve during the alteration of albite. The leaching of soluble salts (eq. 15) from the unsaturated zone is supported by (1) the presence of outcrop areas and sufficient precipitation for leaching to occur, and (2) the loadings on factor II of constituents that commonly make up most of the soluble salts in soil zones.

The major processes postulated in chemically distinct subarea 2 of permeable zone $E$ are (1) dissolution of gypsum containing traces of magnesium sulfate (factor I), (2) cation exchange (factor I), (3) alteration of albite (factor II), and (4) upward leakage or dissolution of halite (factor II). The postulated dissolution of gypsum and cation exchange (factor I) account for about 9 percent more of the variability in concentration of chemical constituents than does alteration of albite and upward leakage (factor II). The loading of dissolved solids on factor I is low and nonsignificant, and its loading on factor II is very high and significant, thus indicating that the alteration of albite and upward leakage account for most of the variation in concentration of dissolved solids in subarea 2 of permeable zone $\mathrm{E}$.

Hydrologic, geologic, and related information that supports the four processes postulated above for chemically distinct subarea 2 are discussed briefly in the context of the water chemistry and results of factor analysis of the chemical data. The alteration of albite (eq. 1) is supported by (1) the reported presence of feldspar in the sediments of the permeable zone (Plummer, 1932), (2) outcrop areas through which carbon dioxide is dissolved in the ground water, and (3) the predominance of sodium and bicarbonate ions in the ground water (table 14). However, the decrease in the ratio of sodium ions to chloride ions from subarea 1 to subarea 2 is evidence that there is another source of chloride ions. This source is either from dissolution of halite or upward leakage. Dissolution of halite (eq. 7) from salt domes is unlikely because only two salt domes penetrate the base of permeable zone $\mathrm{E}$ in subarea 2 and they are likely sealed by caprock as described above for subarea 1. Upward leakage (eq. 16) is indicated by the ground-water flow analysis of Williamson (in press). He simulated upward leakage for most of subarea 2, and the vertical flow is 10 percent or more of the horizontal flow. Dissolution of gypsum (eq. 6) containing traces of magnesium sulfate is supported by (1) the significant loading of calcium, magnesium, and sulfate on factor I (table 15), (2) the reported presence of gypsum in deposits that make up this permeable zone (Plummer, 1932), and (3) the moderately larger concentration of calcium and sulfate ions in subarea 2 than in subarea 1 (table 14). The decrease in $\mathrm{pH}$, indicated by the negative loading of $\mathrm{pH}$ on factor I, is attributed to an increase in hydrogen ions from carbon dioxide being dissolved in the recharge water. The negative loading of sodium on factor I may be attributed to either cation exchange (eq. 3 ) or albitization (eq. 2). Albitization was not postulated as the process because the significant loading of depth on this factor is negative.

The major processes postulated from the results of factor analysis as occurring in subarea 3 of permeable zone $\mathrm{E}$ are (1) upward leakage (factor 1), (2) the leaching of soluble salts from the unsaturated zone (factor II), and (3) dissolution of gypsum (factor II). The postulated upward leakage (factor I) accounts for about 12 percent more of the variability in concentration of chemical constituents than leaching of soluble salts from the unsaturated zone and dissolution of gypsum (factor II). The loading of dissolved solids on factor I is very high and significant and its loading on factor II is low and nonsignificant, thus indicating that upward leakage accounts for most of the variation in concentration of dissolved solids in subarea 3.

Hydrologic, geologic, and related information that supports the three processes postulated above for chemically distinct subarea 3 are discussed briefly in the context of the water chemistry and results of factor analysis of the chemical data. Upward leakage (eq. 16) is supported by (1) the high loading on sodium and chloride, (2) the large concentration of dissolved solids in the underlying upper Claiborne aquifer, and (3) a ground-water flow analysis that 
indicates vertical leakage from the upper Claiborne aquifer to most 100-square- mile areas making up subarea 3 of permeable zone $\mathrm{E}$ (Williamson, in press). Because a part of subarea 3 is updip and includes outcrop areas, leaching (eq. 15) is undoubtedly a major process. Also the increase in hydrogen ions in the ground water indicated by the significant negative loading of $\mathrm{pH}$ on factor II (table 15), is attributed to leaching of precipitation through which carbon dioxide is added to the ground water. However, the moderately high concentrations of calcium and sulfate ions in the ground water indicates that leaching probably is not the only process that is contributing to the moderate concentrations of these ions in subarea 3. Although sulfate did not have a high loading on the factor to which leaching was attributed in factor analysis, it appears, based on the concentration level of calcium and sulfate ions, that the dissolution of gypsum (eq. 6) is most likely the other process contributing to the moderate concentration of calcium and sulfate ions in subarea 3.

The major processes postulated from the results of factor analysis in subarea 4 of permeable zone $\mathrm{E}$ are (1) dissolution of halite and upward leakage (factor I), (2) illitization and calcite precipitation (factor II), (3) genesis of silicate clay (factor III), (4) dissolution of gypsum (factor IV), and (5) precipitation of secondary minerals (factor V). The postulated dissolution of halite and upward leakage (factor I) account for about 27 percent more of the variability in concentration of chemical constituents than does illitization and calcite precipitation (factor II), about 33 percent more than does genesis of silicate clay (factor III), about 36 percent more than does dissolution of gypsum (factor IV), and about 37 percent more than does precipitation of a secondary mineral (factor V). The loading of dissolved solids on factor I is significant and 77 percent higher than on other factors. Its loading on the other four factors is low and nonsignificant, thus indicating that dissolution of halite and upward leakage accounts for most of the variation in concentration of dissolved solids in subarea 4 of permeable zone $\mathrm{E}$.

Hydrologic, geologic, and related information that supports the seven processes postulated above for chemically distinct subarea 4 are discussed briefly in the context of the water chemistry and results of factor analysis of the chemical data. The dissolution of halite (eq. 7) is supported by (1) the very large concentration of sodium and chloride ions in the ground water (table 14), (2) the very high significant loading of sodium and chloride on factor I, and (3) salt domes that penetrate the base of permeable zone $\mathrm{E}$ near the 100-square-mile areas making up subarea 4 in southeastern Texas (Beckman and Williamson, 1990). Upward leakage (eq. 16) from the upper Claiborne aquifer is more likely the source of sodium and chloride in the two areas that are a part of subarea 4 in southern Texas (fig. 25) than is dissolution of halite. Neither of these areas are near salt domes that penetrate the base of permeable zone $\mathrm{E}$ (Beckman and Williamson, 1990), and upward leakage was simulated in both areas (Williamson, in press) (fig. 25). Illitization (eq. 2) and subsequent calcite precipitation (eq. 6) processes are supported by the large increase in calcium ion concentration and the small increase in bicarbonate ions from subarea 3 to subarea 4 (table 14). Also, calcite may precipitate due to the common-ion effect when the process of illitization adds calcium ions to the ground water that is already highly concentrated with calcium ions. The genesis of silicate clay (eqs. 1,2) is a continuous process in most aquifer deposits because silicate minerals are widely distributed in sedimentary rocks (Grim, 1968). It is highly probable that ferric ions adsorbed on silicate minerals could be released in the genesis process. Whereas, potassium ions in solution would be adsorbed or fixed (Grim, 1968) in the formation of secondary clay minerals because they are highly favored on the exchange sites over other cations, especially in relatively saline water (Drever, 1982). The dissolution of gypsum (eq. 6) is highly probable because of its association with halite and other minerals in salt domes (Halbouty, 1979). Gypsum makes up a large percentage of the caprock overlying salt domes and may occur as anhydrite. The moderate concentration of sulfate ions in comparison to the two other major anions in the ground water of this subarea suggest that the process is minor in its effect on the water chemistry. The precipitation of secondary minerals (eqs. 1,2) may result in the replacement of the aluminum ion by the silica ion in the mineral lattice. The valence change caused by this substitution may result in the release of magnesium ions adsorbed on the mineral. Thus magnesium ions are added to the ground water and silica is removed.

The major processes postulated from the results of factor analysis in subarea 5 of permeable zone $\mathrm{E}$ are (1) dissolution of halite containing traces of bischofite (factor I), (2) illitization (factor II), and (3) precipitation of calcite (factor II). The postulated dissolution of halite containing traces of bischofite (factor I) accounts for about 34 percent more of the variability in concentration of chemical constituents than does illitization and precipitation of calcite (factor II). The loading of dissolved solids on factor I is significant and about 44 percent higher than on factor II, which is not significant, thus indicating that the dissolution of halite not only accounts for most of the variability in constituent concentrations but also accounts for most of the variation in dissolved-solids concentration in subarea 5 
of permeable zone $\mathrm{E}$.

Hydrologic, geologic, and related information that supports the three processes postulated above for chemically distinct subarea 5 are discussed briefly in the context of the water chemistry and results of factor analysis of the chemical data. Dissolution of halite (eq. 7) containing traces of bischofite is supported by (1) the extremely high concentrations of sodium and chloride ions (greater than seawater) and high concentration of magnesium ions in the ground water (table 14), and (2) the numerous salt domes that penetrate the base of permeable zone $\mathrm{E}$ in subarea 5 (Beckman and Williamson, 1990). The salt domes in this area are overlain by 4,000 to $12,000 \mathrm{ft}$ of sediments, which is a more favorable condition for dissolution of halite than for salt domes buried at shallower depths. The increase in the effect of the process with depth is due to more of the salt dome being exposed to dissolution with depth. Dissolution of traces of bischofite with halite is supported by (1) the presence of this mineral in marine evaporites (Krauskopf, 1967), and (2) the significant loading of magnesium on factor 1. Illitization (eq. 2) and precipitation of calcite (eq. 6) are supported by the significant positive loading of calcium and significant negative loading of bicarbonate on factor II as in subarea 4. The products of illitization include calcium and hydrogen ions, and thus the subsequent increase in calcium-ion concentration could result in precipitation of calcite due to the common-ion effect.

\section{UPPER CLAIBORNE AQUIFER}

The upper Claiborne aquifer extends from the Rio Grande in southern Texas northeastward to southwestern Alabama and northward to western Kentucky (fig. 30). It has an areal extent of about $90,000 \mathrm{mi}^{2}$ and a mean thickness of $500 \mathrm{ft}$ (Williamson and others, 1990). Median depth of water samples collected for chemical analysis ranges from $168 \mathrm{ft}$ in outcrop areas to 5,370 in downdip areas (table 16). The downdip limit is as close as $35 \mathrm{mi}$ north of the shoreline in southeastern Texas to about $140 \mathrm{mi}$ in Louisiana. The outcrop of the aquifer approximately parallels the coastline across Texas and western Louisiana. It is about $30 \mathrm{mi}$ wide in southern Texas and narrows to about $2 \mathrm{mi} \mathrm{in}$ central Louisiana. In northern Louisiana and southern Arkansas the aquifer outcrop is about $60 \mathrm{mi}$ wide. The upper Claiborne aquifer underlies the Mississippi River Valley alluvial aquifer in northeastern Louisiana, adjacent Mississippi, and most of the area in the Mississippi embayment to the north. The aquifer outcrop extends southeastward from near the Yazoo River in central Mississippi to southwestern Alabama. The outcrop is 2 mi wide or less through southwestern Alabama (Hosman and Weiss, 1991). The geometric mean hydraulic conductivity of this aquifer is about $52 \mathrm{ft} / \mathrm{d}$ (table 3 ).

The simulated horizontal direction of predevelopment ground-water flow and vertical leakage to or from the base of the upper Claiborne aquifer is shown in figure 30 (Williamson, in press). Regionally, the horizontal flow east of the Mississippi River generally is westward from the outcrop areas toward the Mississippi River and southeastward in southeastern Mississippi toward the Tombigbee River. West of the Mississippi River the flow is generally southeastward in Arkansas and eastward in Louisiana. In far southwestern Texas the flow is toward the Rio Grande from updip areas. Elsewhere in Texas the flow is from updip areas southeastward or southwestward depending upon the direction to major stream valleys. Vertical leakage is downward from the upper Claiborne aquifer to the middle Claiborne aquifer in southern Texas, north-central Louisiana, south-central Arkansas, and southeastern Mississippi. Vertical leakage also is downward from the overlying permeable zone E (lower Miocene-upper Oligocene deposits) to the upper Claiborne aquifer throughout a large area in southern Mississippi and smaller areas in south-central Louisiana and southwestern Alabama. Upward leakage from the middle Claiborne aquifer is indicated for much of the area underlain by the upper Claiborne aquifer (fig. 30).

\section{DISSOLVED-SOLIDS CONCENTRATIONS}

The areal distribution of the median concentration of dissolved solids per 100-square-mile area in water from the upper Claiborne aquifer is shown on figure 31. The delimited area of the aquifer having median concentrations of dissolved solids of less than $500 \mathrm{mg} / \mathrm{L}$ extends from north-central Louisiana northward through Arkansas, Tennessee, and Missouri and eastward through much of northwestern and central Mississippi into southwestern Alabama. Most of the delimited area is either outcrop or subcrop and thus is the delimited area through which most recharge to the aquifer from precipitation occurs. 
TABLE 16.--Median value of selected chemical constituents and properties of water, median sampling depth, water types, and number of analyses for each subarea of the upper Claiborne aquifer

\footnotetext{
[Concentrations are in milligrams per liter, except iron and manganese, which are in micrograms per liter. Depth is in feet, $\mathrm{pH}$ is in units, and

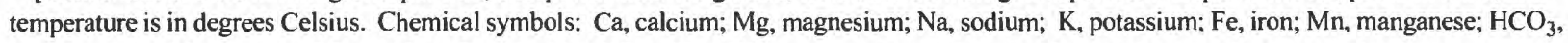
bicarbonate; $\mathrm{SO}_{4}$, sulfate; $\mathrm{Cl}$, chloride; $\mathrm{SiO}_{2}$, silica. Water type shown is the most frequently occurring. ---, no data]
}

\begin{tabular}{|c|c|c|c|c|c|}
\hline \multirow{2}{*}{$\begin{array}{l}\text { Constituent or } \\
\text { property }\end{array}$} & \multicolumn{5}{|c|}{ Subarea } \\
\hline & 1 & 2 & 3 & 4 & 5 \\
\hline $\mathrm{Ca}$ & 18 & 23 & 26 & 76 & 900 \\
\hline $\mathrm{Mg}$ & 6.0 & 5.7 & 9.0 & 43 & 220 \\
\hline $\mathrm{Na}$ & 29 & 240 & 2.000 & 6.900 & 22,600 \\
\hline $\mathrm{K}$ & 2.0 & 3.2 & 17 & --- & 120 \\
\hline $\mathrm{Fe}$ & 280 & 100 & 580 & -- & 4,900 \\
\hline $\mathrm{Mn}$ & 70 & 30 & 660 & --- & 2.400 \\
\hline $\mathrm{HCO}_{3}$ & 230 & 380 & 1.500 & 1,300 & 380 \\
\hline $\mathrm{SO}_{4}$ & 7.9 & 100 & 24 & 14 & 11 \\
\hline $\mathrm{Cl}$ & 12 & 120 & 1.700 & 10,000 & 37,000 \\
\hline $\mathrm{SiO}_{2}$ & 23 & 22 & 20 & 23 & 16 \\
\hline Dissolved solids & 260 & 825 & 6.170 & 18,600 & 63,200 \\
\hline Sampling depth & 168 & 290 & 2,040 & 2.270 & 5,370 \\
\hline $\mathrm{pH}$ & 7.3 & 7.6 & 8.2 & 7.7 & 7.2 \\
\hline Temperature & 19.5 & 21.0 & 20.0 & -- & 37.2 \\
\hline Primary water type & $\mathrm{NaHCO}_{3}$ & $\mathrm{NaHCO}_{3}$ & $\mathrm{NaCl}$ & $\mathrm{NaCl}$ & $\mathrm{NaCl}$ \\
\hline Secondary water type & $\mathrm{CaCl}$ & $\mathrm{CaCl}$ & $\mathrm{CaHCO}_{3}$ & $\mathrm{CaHCO}_{3}$ & $\mathrm{CaHCO}_{3}$ \\
\hline Number of analyses & 390 & 317 & 76 & 115 & 80 \\
\hline
\end{tabular}

The delimited area of the upper Claiborne aquifer having median concentrations of dissolved solids ranging from 500 to $1,000 \mathrm{mg} / \mathrm{L}$ extends from central Texas to southwestern Mississippi. It is composed of several discontinuous segments in Texas, a large area on either side of the Mississippi River in northeastern Louisiana, in southwestern Arkansas, and west-central Mississippi and a narrow band-shaped area elsewhere. The delimited areas of the upper Claiborne aquifer having median concentrations of dissolved solids ranging from 1,000 to 3,000 and from 3,000 to $10,000 \mathrm{mg} / \mathrm{L}$ extend from southern Texas to southwestern Mississippi. Except in Texas, the increase in median concentration of dissolved solids from 1,000 to $10,000 \mathrm{mg} / \mathrm{L}$ occurs over a relatively short distance in the downdip direction. The delimited area of the upper Claiborne aquifer having concentrations of dissolved solids ranging from 10,000 to $35,000 \mathrm{mg} / \mathrm{L}$ extends from southern Texas to southwestern Mississippi. A wide area having concentrations of dissolved solids ranging from 35,000 to $70,000 \mathrm{mg} / \mathrm{L}$ extends from southeastern Texas to southwestern Mississippi. This area is adjacent to the downdip limit of the upper Claiborne aquifer and encompasses four smaller areas having concentrations of dissolved solids greater than $70,000 \mathrm{mg} / \mathrm{L}$. Two of the areas are in southeastern Texas and two are in south-central Louisiana. 


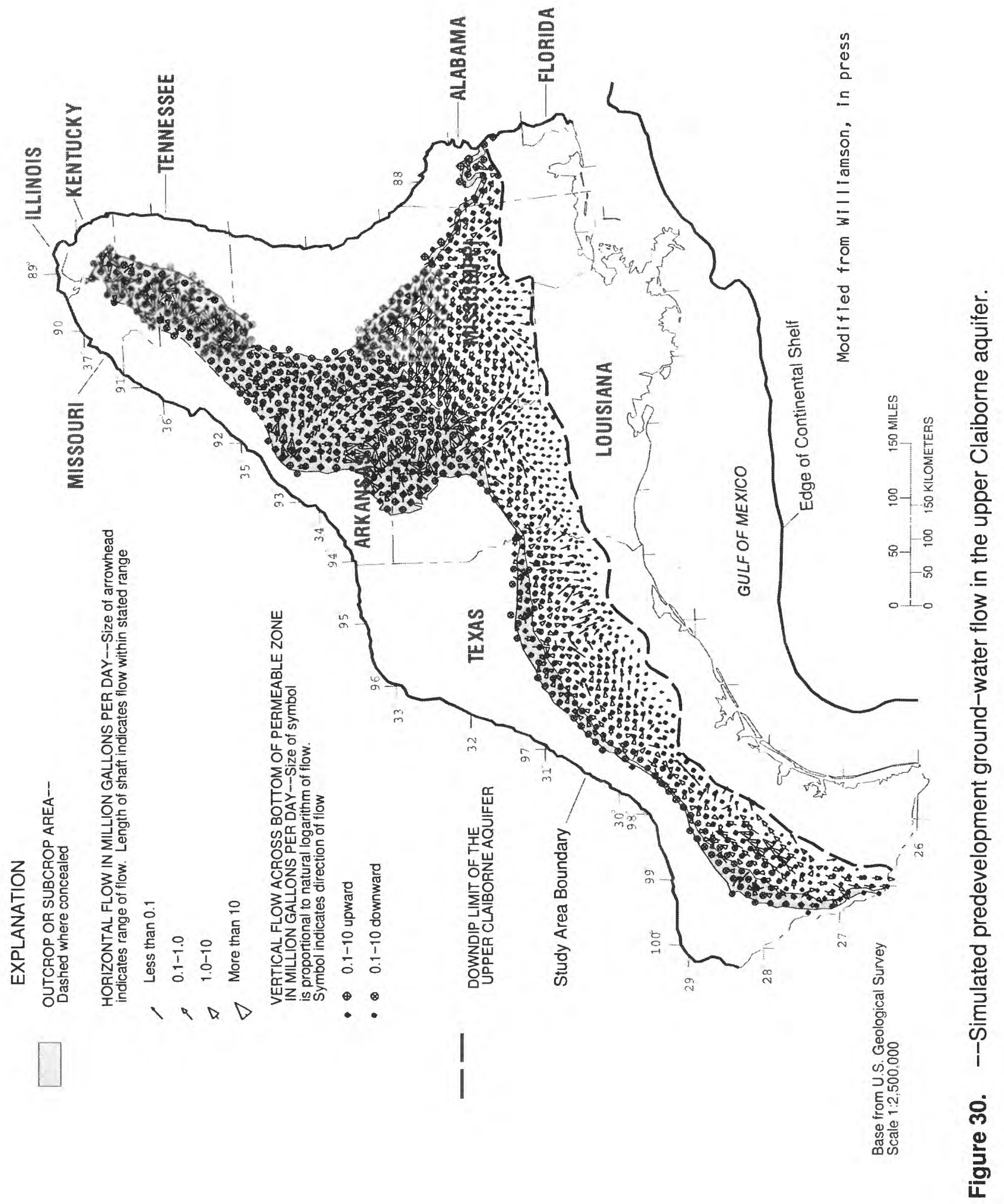




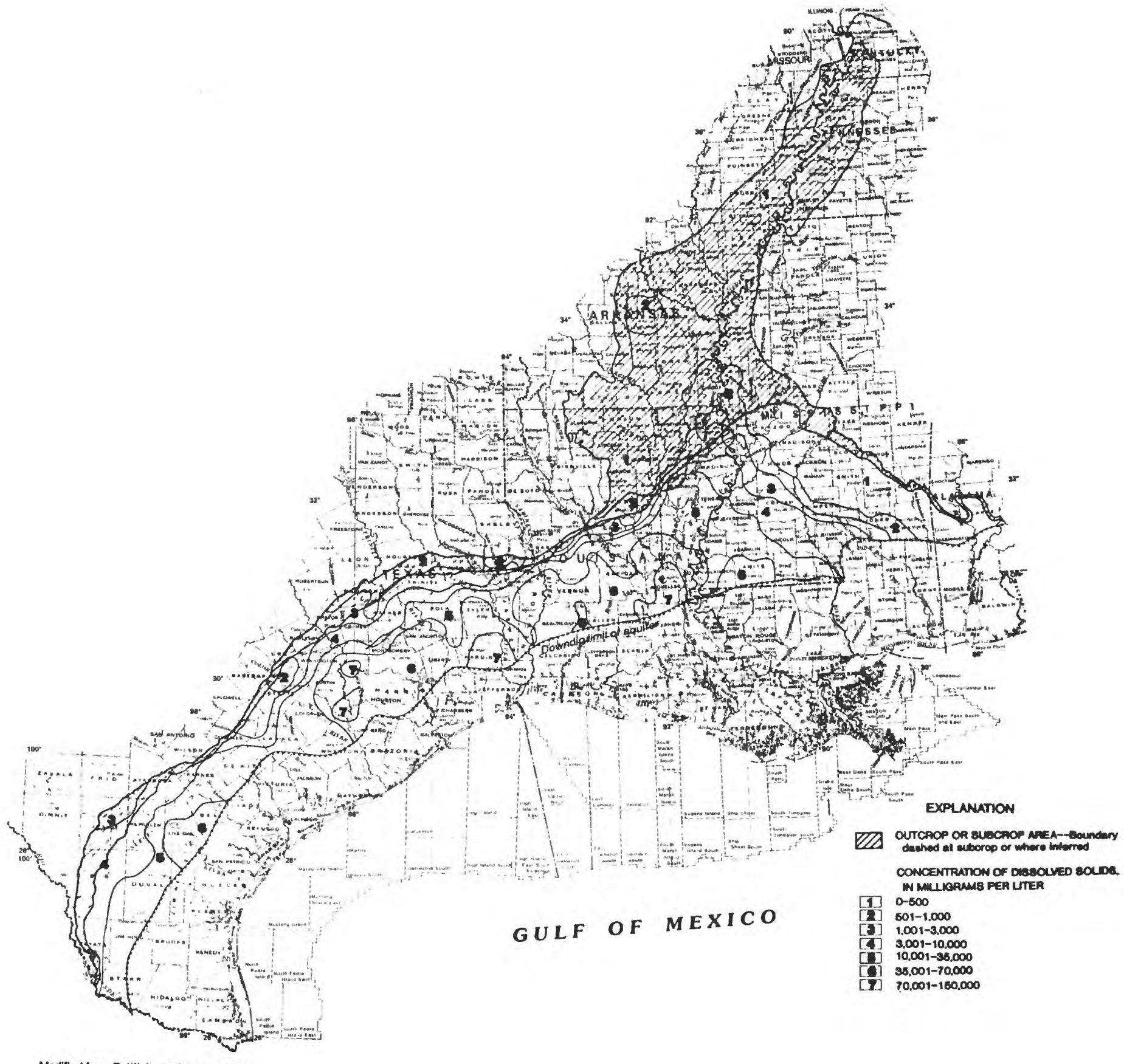

Modilied from Pettljohn and othere. 1060 


\section{PRIMARY WATER TYPES}

The primary water type is calcium bicarbonate in northeastern Arkansas and western Tennessee; sodium bicarbonate in southern Arkansas, Louisiana, Mississippi, and in outcrop areas of southeastern Texas. The primary water type is sodium chloride in southern Texas and downdip of the outcrop in southeastern Texas (fig. 32). The primary water types are mostly calcium bicarbonate and sodium bicarbonate in areas where the median concentrations of dissolved solids are less than $3,000 \mathrm{mg} / \mathrm{L}$. In areas where the median concentrations of dissolved solids are greater than $3,000 \mathrm{mg} / \mathrm{L}$ the primary water type is sodium chloride.

\section{GROUND-WATER CHEMISTRY WITHIN SUBAREAS}

The upper Claiborne aquifer was divided into five chemically distinct subareas and the boundaries adjusted using discriminant function analysis of the chemical data from the subareas (fig. 33). Subarea 1 extends from west-central Louisiana northeastward through Arkansas and adjacent parts of Tennessee into Kentucky. From east-central Arkansas subarea 1 extends to the southeast into south-central Mississippi. Also included in the subarea are three 100square-mile areas in eastern Texas and two in southwestern Alabama. Less than one-half of the subarea (about 900 $\mathrm{mi}^{2}$ ) is in the outcrop area of the aquifer where it is recharged by precipitation.

Subarea 2 extends northeastward along the outcrop area of the upper Claiborne aquifer in southeastern Texas to northeastern Louisiana. It extends northward for about $60 \mathrm{mi}$ into Arkansas and Mississippi. From central Louisiana eastward it is adjacent to and downdip from subarea 1 . Subarea 2 is about $30 \mathrm{mi}$ wide in northeastern Louisiana and adjacent parts of Mississippi. Several noncontiguous areas in the northern Mississippi embayment are part of subarea 2. Most of the subarea in Texas, Tennessee, and Kentucky is in the outcrop area of the upper Claiborne aquifer where the aquifer is recharged by precipitation. Subarea 3 is mostly along the outcrop in southern Texas. Five isolated 100square-mile areas in Texas, Louisiana, and Arkansas also are a part of subarea 3. Based on the areal distribution of dissolved-solids concentrations (fig. 31), subarea 3 probably extends from southern Texas to southwestern Alabama in an almost continuous, narrow, elongate band. However, chemical data are not available to show the extent of the subarea, except as noted above. Subarea 4 is in southern and east-central Texas. Four isolated 100-square-mile areas, all in Texas and between middip and downdip, are a part of subarea 4. Subarea 4, like subarea 3, probably extends throughout a much larger part of the aquifer area but, because of the lack of chemical data, the extent is not shown. Subarea 5 is primarily between middip and the downdip limit of the aquifer in southern Texas. Three isolated 100square- mile areas in southern Louisiana and Mississippi are also a part of subarea 5. Subarea 5 is probably a much larger area, but data are not available to define its areal extent.

The median value for selected chemical constituents and the primary and secondary water types for each subarea are shown in table 16. Major cations increase in concentration from subarea 1 to subarea 5, with the greatest increase occurring in the sodium ion concentration. Among the major anions, only chloride progressively increases from subarea 1 to subarea 5. Bicarbonate increases progressively from subarea 1 to subarea 3 then decreases from subarea 3 to subarea 4 and from subarea 4 to subarea 5 , whereas sulfate increases from subarea 1 to subarea 2 then decreases progressively from subarea 3 to subarea 5. Iron, manganese, and temperature generally increase in a downdip direction. The $\mathrm{pH}$ increases and then decreases in a downdip direction, whereas silica remains nearly constant. The most frequently occurring (primary) water type was sodium bicarbonate in subareas 1 and 2 and sodium chloride in subareas 3,4 , and 5 (table 16 ).

The trilinear diagram (fig. 34), based on three representative samples from each subarea, in conjunction with figure 32, shows that water in the upper Claiborne aquifer is calcium bicarbonate in subarea 1 and a mixture of major ions that is predominantly sodium bicarbonate in subarea 2 . In subarea 3 the water type is sodium chloride, which is also the predominant type in subareas 4 and 5. The trilinear diagram also shows that water in the upper Claiborne aquifer has a major cations concentration that is approximately 67 percent magnesium plus calcium ( 33 percent sodium plus potassium) in subarea 1 and about 6 percent magnesium plus calcium ( 94 percent sodium plus potassium) in subarea 5. The major anions concentration is 86 percent bicarbonate plus carbonate ( 14 percent chloride plus sulfate) in subarea 1 and 1 percent bicarbonate plus carbonate ( 99 percent chloride plus sulfate) in subarea 5 . Although most of 


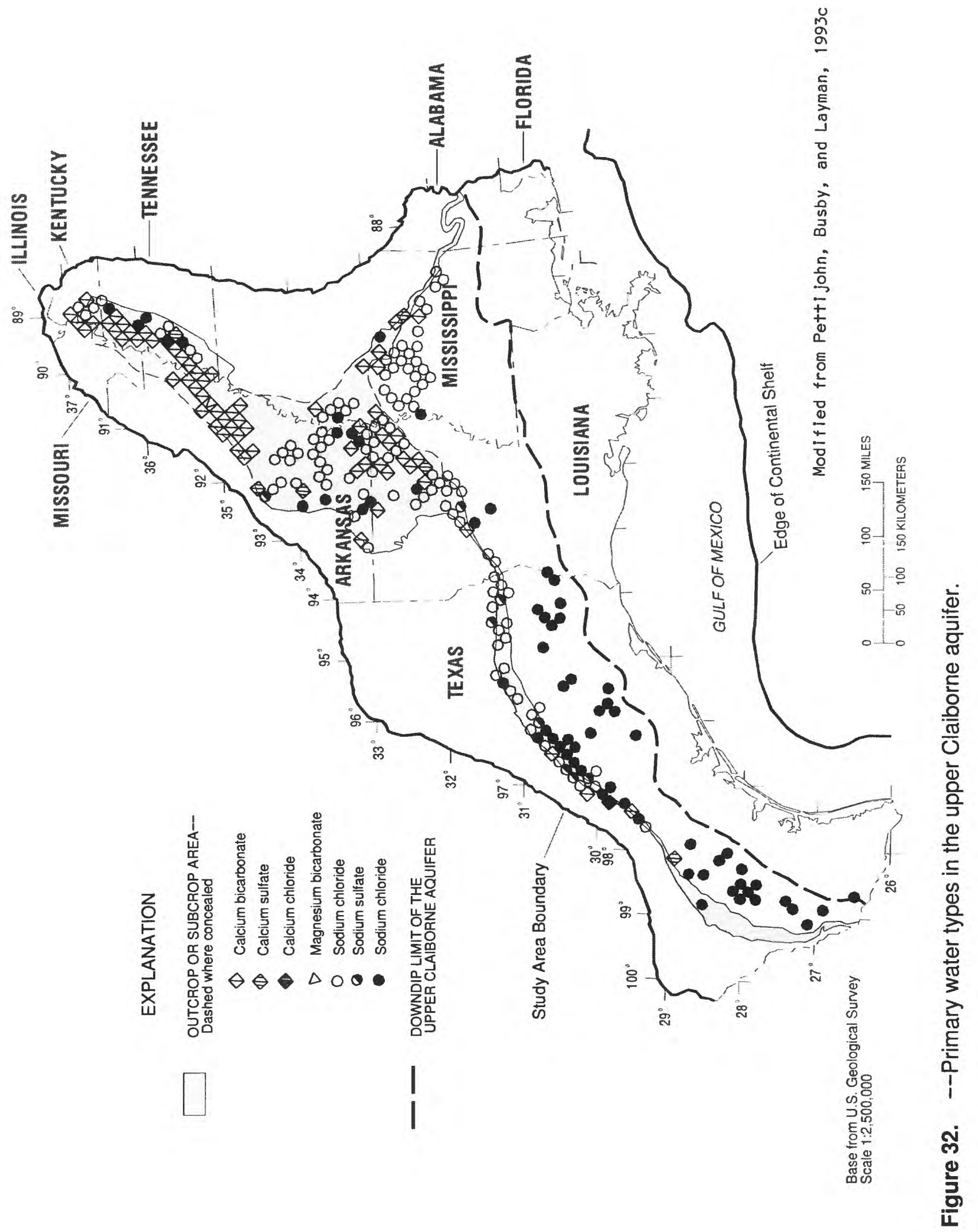




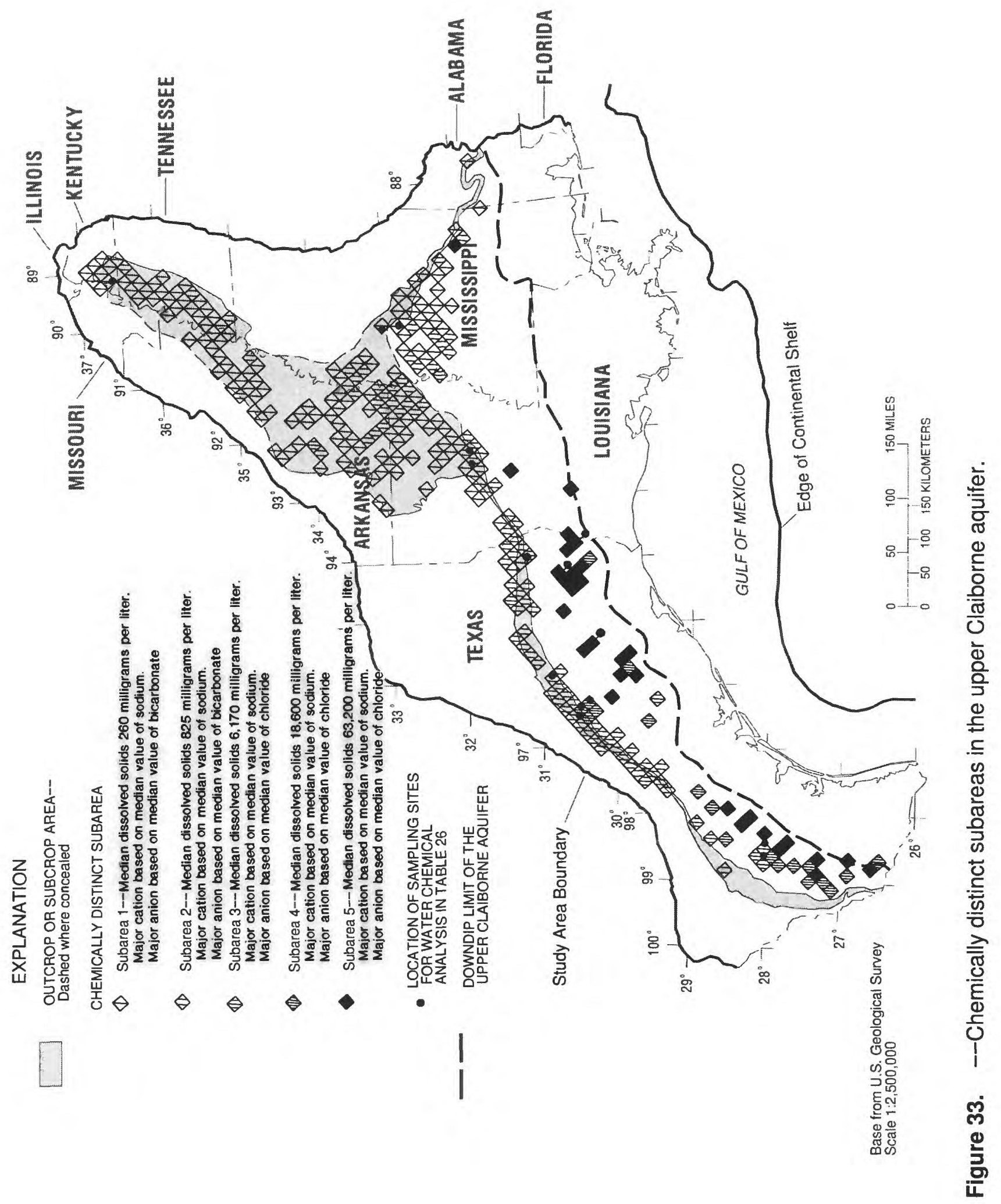


the 100-square-mile areas that are a part of subarea 1 have a predominant water type that is calcium bicarbonate, 100-square-mile areas that have sodium bicarbonate water have a larger number of chemical analyses than 100-squaremile areas with calcium bicarbonate water, thus there is a lack of agreement between table 16 , figure 32, and figure 34 .

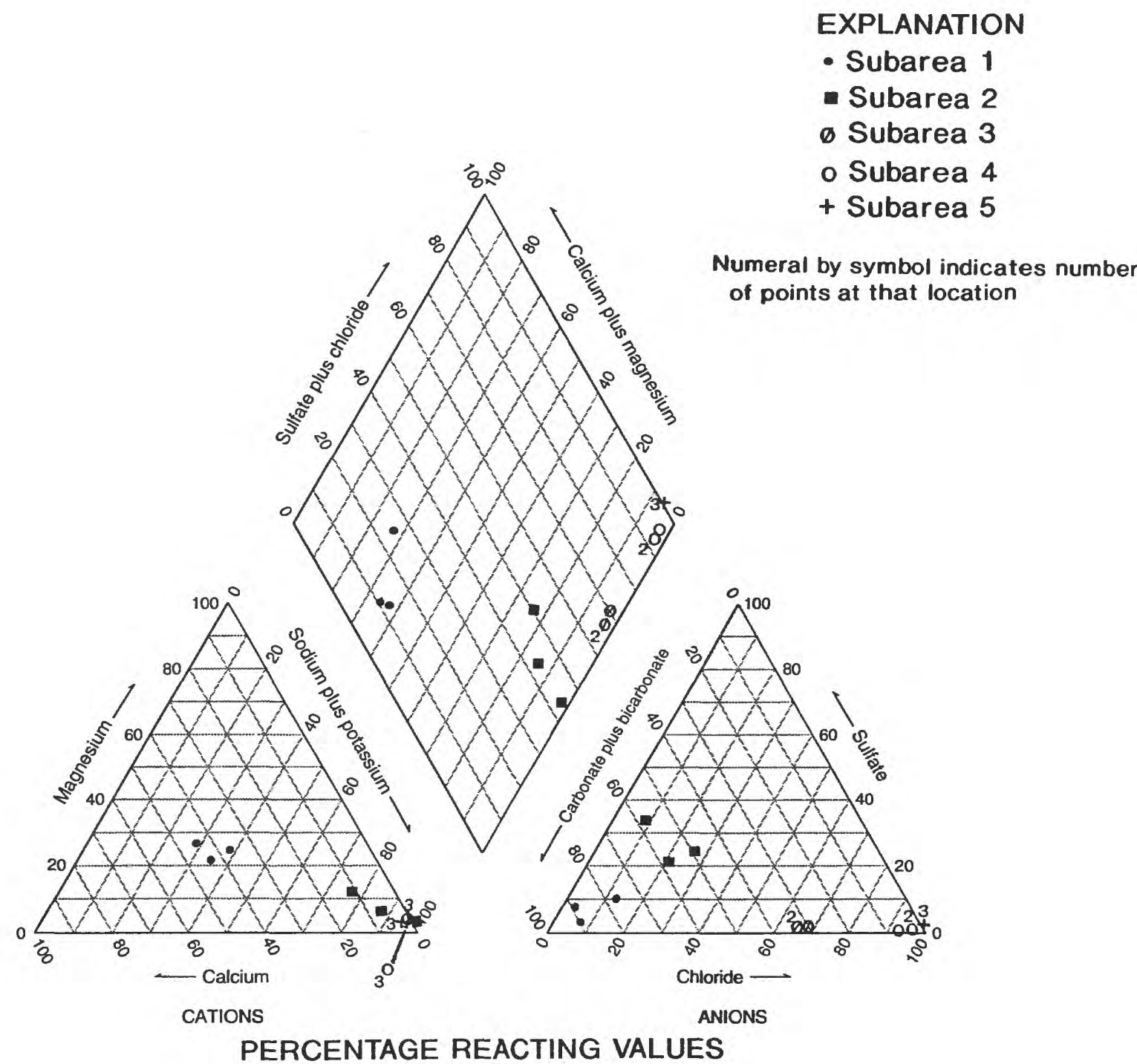

Figure 34.--Change in water chemistry from subarea to subarea in the upper Claiborne aquifer, based on three representative samples.

The triangular part of figure 34 and the data in table 16 indicate that the chemical processes in the upper Claiborne aquifer are increasing the sodium and chloride ions from small concentrations updip to large concentrations downdip. The progressive increase in dissolved-solids concentrations is about a factor of 3 from subarea 1 to subarea 2, about a factor of 7 from subarea 2 to subarea 3, about a factor of 3 from subarea 3 to subarea 4 , and about a factor of 3 from subarea 4 to subarea 5. Thus dissolved-solids concentrations increase by a factor of about 240 from subarea 1 to subarea 5 . 


\section{CORRELATION AMONG CHEMICAL CONSTITUENTS AND PROPERTIES OF GROUND WATER WITHIN SUBAREAS}

The correlation among chemical constituents and properties in water from the upper Claiborne aquifer was evaluated by factor analysis, which indicates that at least two major chemical processes or mechanisms are responsible for most of the variability in constituent concentrations in each of the subareas (table 17). Eleven constituents or properties were used in the factor analysis. Although 13 constituents or properties were used in most of the aquifer analyses, iron and silica were omitted because of insufficient data, or they were not significant in an analysis of variance. The number of chemical analyses were 390 for subarea 1,317 for subarea 2,76 for subarea 3,115 for subarea 4 , and 80 for subarea 5 (table 16). The variability accounted for by the factors ranged from 76.4 percent in subarea 1 to 83.6 percent in subarea 4 . The loading of each constituent or property on each factor and the percent of total variability (communality) accounted for in factor analysis is shown in table 17.

Factor I of subarea 1 represents a process in which sodium and bicarbonate ions are added to the ground water and hydrogen ions are removed. The effect of the process on the water chemistry increases with depth. Factor II of subarea 1 represents a process in which calcium, magnesium, and bicarbonate ions are added to the ground water, resulting in a corresponding increase in the concentration of dissolved solids. Subarea 1 is considered to be largely an open system because of the relatively large outcrop area of the upper Claiborne aquifer assigned to the subarea. The variability in concentration of chemical constituents and properties accounted for by factor I is about 44 percent and by factor II is about 32 percent. The variability in concentration of dissolved solids accounted for by factor I is 76 percent and significant, and for factor II it is 61 percent and also significant.

Factor I of subarea 2 represents a process in which calcium, magnesium, and hydrogen ions are added to the ground water. The effect of the process on the water chemistry decreases with depth. Factor II of subarea 2 represents a process in which sodium, chloride, and, to some extent, bicarbonate and sulfate ions are added to the ground water. The subarea is considered an open system because much of the area assigned to subarea 2 is outcrop of the upper Claiborne aquifer. The variability in concentration of chemical constituents and properties accounted for by factor I is about 44 percent and by factor II is about 37 percent. The variability in concentration of dissolved solids accounted for by factor I is 5 percent and nonsignificant, whereas for factor II it is 99 percent and significant.

Factor I of subarea 3 represents a process in which sodium and chloride ions are added to the ground water and hydrogen ions are removed. The effect of the process on the water chemistry increases with depth. Factor II of subarea 3 represents a process in which calcium, magnesium, sulfate, and hydrogen ions are added to the ground water, and the process occurs largely in the upper part of the aquifer. Bicarbonate loads negatively on this factor, indicating that the process has an opposite effect on bicarbonate-ion concentration than it has on the concentrations of the other four ions. The variability in concentration of chemical constituents and properties of water accounted for by factor I is about 55 percent and by factor II is about 22 percent. The variability in concentration of dissolved solids accounted for by factor I is 98 percent and significant, whereas for factor II it is 2 percent and nonsignificant.

Factor I of subarea 4 represents a process in which calcium, magnesium, sodium, and chloride ions are added to the ground water. Factor II of subarea 4 represents a process in which bicarbonate ions are added to the ground water and calcium and sulfate ions are removed. This process is indicated by the positive loading of bicarbonate and negative, but not quite significant, loading of calcium and sulfate on this factor. The variability in concentration of chemical constituents and properties accounted for by factor I is about 67 percent and for factor II is about 17 percent. The variability in concentration of dissolved solids accounted for by factor I is 99 percent and significant, whereas the variability accounted for by factor II is 7 percent and nonsignificant.

Factor I of subarea 5 represents a process in which calcium, magnesium, sodium, and chloride ions are added to the ground water. Factor II of subarea 5 represents a process in which bicarbonate ions are added to the ground water and sulfate ions are removed. The effect of the process on the water chemistry increases with depth. The variability in concentration of chemical constituents and properties accounted for by factor I is about 57 percent and by factor II is about 22 percent. The variability in concentration of dissolved solids accounted for by factor I is 92 percent and significant, whereas for factor II it is $\mathbf{3 4}$ percent and nonsignificant. 


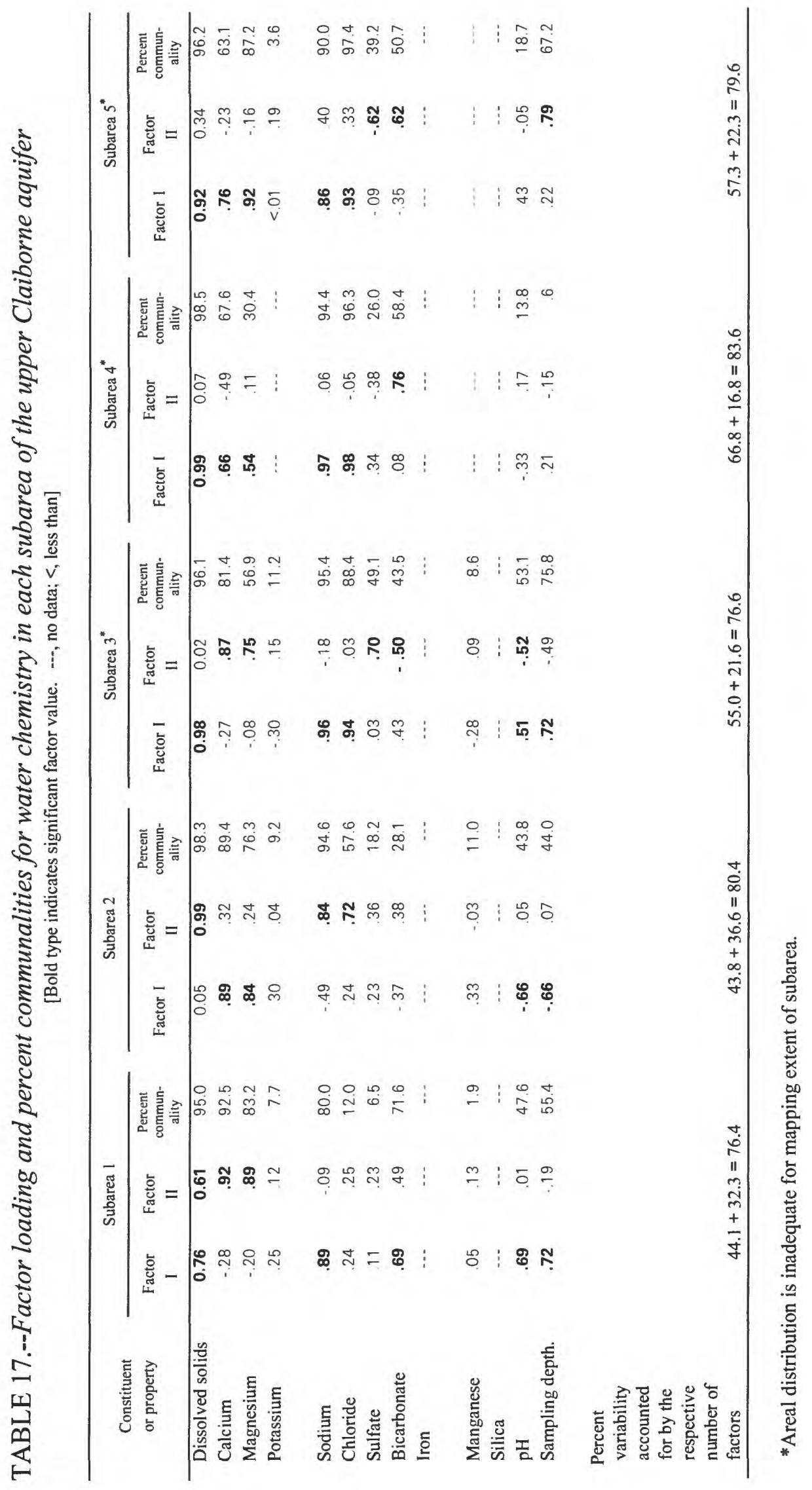




\section{RELATION OF GROUND-WATER CHEMISTRY TO CHEMICAL AND PHYSICAL PROCESSES}

The major chemical processes and mechanisms postulated for each of the chemically distinct subareas of the upper Claiborne aquifer are based on the results of factor analysis in conjunction with constituent concentrations, a trilinear diagram, ground-water movement, and information on water-rock interaction and probable minerals in the deposits. The major processes postulated in chemically distinct subarea 1 of the upper Claiborne aquifer are (1) the alteration of albite (factor I), (2) the hydrolysis of anorthite containing some adsorbed magnesium (factor II), and (3) the leaching of soluble salts from the unsaturated zone (factor II). Cation exchange, although a minor process in subarea 1, may also be represented by factor I, as indicated by the negative but not significant loading of calcium and magnesium on factor I. The postulated alteration of albite (factor I) accounts for about 12 percent more of the variability in concentration of chemical constituents than does hydrolysis of anorthite containing adsorbed magnesium and leaching of soluble salts (factor II). The loading of dissolved solids is significant on both factor I and II; however, factor I loading is 15 percent higher than factor II, thus indicating that the alteration of albite contributed more to the variation in concentration of dissolved solids than does hydrolysis of anorthite and leaching in subarea 1.

The hydrologic, geologic, and related information that supports the three processes postulated above for chemically distinct subarea 1 are discussed briefly in the context of the water chemistry and results of factor analysis of the chemical data. The alteration of albite (eq. 1) is supported by (1) the availability of carbonic acid supplied to the ground water by recharge from precipitation, (2) the presence in the aquifer matrix of shales, which in sedimentary deposits contain 30 percent feldspar (Foster, 1949), (3) the predominance of sodium and bicarbonate ions in the ground water (table 16), and (4) the consumption of hydrogen ions, which is indicated by the significant loading of $\mathrm{pH}$ on factor I and the slightly alkaline $\mathrm{pH}$. The effect of the process on the water chemistry would increase with depth due to the longer resident time. The hydrolysis of anorthite, which is similar to the hydrolysis of albite (eq. 1), containing some adsorbed magnesium is supported by (1) the reported presence of plagioclase in the overlying aquifer (Plummer, 1932 ) and, (2) the significant loading of calcium and magnesium and near significant loading of bicarbonate on factor II. Hydrolysis rather than alteration was postulated as the process because of the very low loading of $\mathrm{pH}$ on factor II, which indicated that carbonic acid was probably not involved in the process. Leaching of the unsaturated zone (eq. 15 ) is supported by the relatively large area of outcrop that allows leaching of soluble salts by recharge water as it passes through the soil to the ground-water flow system. The source of the salts in the soil and the unsaturated zones comes from the oxidation of organic matter, the interaction of carbon dioxide-rich water with mineral constituents, and residual salts. Vertical leakage (eq. 16) downward from the overlying Mississippi River Valley alluvial aquifer to the upper Claiborne aquifer was simulated for a few 100-square-mile areas mostly in Arkansas (fig. 4) (Williamson, in press). Downward leakage from the overlying permeable zone $E$ affect the water chemistry in subarea $I$ of the upper Claiborne aquifer where subarea 1 extends 40 to $60 \mathrm{mi}$ downdip from the subcrop area of the aquifer in southwestern Mississippi. Vertical leakage is upward (fig. 30) from the underlying middle Claiborne aquifer to most of subarea 1 of the upper Claiborne aquifer.

The major processes postulated in chemically distinct subarea 2 of the upper Claiborne aquifer are (1) leaching of soluble salts from the unsaturated zone (factor I), (2) cation exchange (factor I), (3) alteration of albite (factor II), and (4) upward leakage of sodium chloride water (factor II). The postulated leaching of soluble salts from the unsaturated zone and cation exchange (factor I) account for about 7 percent more of the variability in concentration of chemical constituents than does alteration of albite and upward leakage (factor II). However, the loading of dissolved solids on factor I is very low and nonsignificant, and on factor II it is very high and significant, thus indicating that alteration of albite and upward leakage cause the most variation in concentration of dissolved solids in subarea 2.

Hydrologic, geologic, and related information that supports the four processes postulated above for chemically distinct subarea 2 are discussed briefly in the context of the water chemistry and results of factor analysis of the chemical data. Leaching of soluble salts from the unsaturated zone (eq. 15) is supported by (1) much of the subarea being in the outcrop area of the upper Claiborne aquifer, especially in Texas, and (2) the climate being primarily subhumid, thus ample precipitation is available for recharge. The effect of leaching on the ground-water chemistry would decrease with depth due to increase in distance from the leaching area. A decrease in $\mathrm{pH}$ of the ground water would occur as carbon dioxide from the soil zone dissolves in the percolating recharge water from precipitation. Cation exchange (eq. 3 ) of sodium ions in solution for calcium, magnesium, or hydrogen ions on clay colloids is 
postulated based on the negative loading of sodium on factor I.

Upward leakage (eq. 16) is supported by (1) the moderate concentrations of sodium and chloride (table 16), (2) the significant loading of sodium and chloride on factor II, and (3) the ground-water flow analysis noted previously (Williamson, in press) in which vertical leakage upward was simulated from the underlying middle Claiborne aquifer to the upper Claiborne aquifer (fig. 30). Generally, salt domes that penetrate the base of the upper Claiborne aquifer are far removed from 100-square-mile areas assigned to subarea 2 (Beckman and Williamson, 1990) and are not a likely source of sodium and chloride.

Although bicarbonate did not load significantly on factor II, alteration of albite (eq. 1) is most likely occurring in subarea 2. This process is based on the availability of carbonic acid and feldspar in subarea 2, and because of the greater than 1 sodium-to-chloride ratio that indicates more than one source of sodium ions. Similarly, dissolution of gypsum (eq. 6) is most likely occurring in some parts of this subarea, based on the large concentration of sulfate ions.

The major processes postulated in chemically distinct subarea 3 of the upper Claiborne aquifer are (1) upward leakage (factor I), (2) alteration of albite (factor I), (3) dissolution of gypsum (factor II), (4) cation exchange (factor II), and (5) precipitation of calcite (factor II). The postulated upward leakage and alteration of albite (factor I) accounts for about 33 percent more of the variation in concentration of chemical constituents than does dissolution of gypsum, cation exchange, and precipitation of calcite (factor II). The loading of dissolved solids on factor I is very high and significant, and on factor II it is very low and nonsignificant (table 17), thus indicating that upward leakage and alteration of albite account for most of the variability in concentration of chemical constituents and also for most of the variation in concentration of dissolved solids in subarea 3 .

Hydrologic, geologic, and related information that supports the five processes postulated above for chemically distinct subarea 3 are discussed briefly in the context of the water chemistry and results of factor analysis of the chemical data. Upward leakage is supported by (1) the large concentrations of sodium and chloride ions in the ground water (table 16), (2) the significant loading of sodium and chloride on factor I (table 17), and (3) a ground-water flow analysis (Williamson, in press) in which vertical leakage upward was simulated from the underlying middle Claiborne aquifer. The alteration of albite (eq. 1) is supported by the large bicarbonate concentration (table 16) and by the ratio (1.2) of sodium concentration to chloride concentration, which is about double that of seawater $(0.56)$. The source of carbon dioxide that acidified the ground water, thus aiding in the dissolution of albite, may be the diagenesis of lignite (eq. 8) in downdip areas.

Dissolution of gypsum (eq. 6) is supported by (1) the large concentration of sulfate in ground water from subarea 3 (fig. 32), (2) the significant loading of sulfate on factor II (table 17), and (3) the reported presence of gypsum in the aquifer deposits (Payne, 1970). Cation exchange (eq. 3), in which sodium displaces calcium on exchange sites of clays in the aquifer deposits, although a very weak process, may be due to the salinity of the ground water (Drever, 1982). The precipitation of calcite (eq. 6) is supported by a change in the solubility of calcite as a result of the dissolution of gypsum and the increase in $\mathrm{pH}$ from subarea 2 to subarea 3 . Increasing $\mathrm{pH}$ is attributed to unreplenished carbon dioxide as the system changes from one that is open to carbon dioxide to one that is closed.

The major processes postulated in chemically distinct subarea 4 of the upper Claiborne aquifer are (1) the dissolution of halite containing traces of calcium and magnesium minerals (factor I), (2) upward leakage (factor I), (3) sulfate reduction (factor II), and (4) cation exchange (factor II). The postulated dissolution of halite containing traces of calcium and magnesium minerals and upward leakage (factor I) account for about 50 percent more of the variability in concentration of chemical constituents than does the postulated reduction of sulfate and cation exchange (factor II). The loading of dissolved solids on factor I is very high and significant, and on factor II it is very low and nonsignificant (table 17), thus indicating that the dissolution of halite and upward leakage not only account for most of the variability in concentrations of constituents but also account for most of the variation in concentration of dissolved solids in subarea 4.

Hydrologic, geologic, and related information that supports the four processes postulated above for chemically distinct subarea 4 are discussed briefly in the context of the water chemistry and results of factor analysis of the chemical data. The dissolution of halite is supported by (1) large sodium and chloride concentrations (table 16), (2) 
the significant loading on factor I of both sodium and chloride (table 17), and (3) the presence of salt domes that penetrate the base of the upper Claiborne aquifer (Beckman and Williamson, 1990) in the vicinity of locations assigned to subarea 4. Upward leakage (eq. 16) is supported by a ground-water flow analysis that shows flow from underlying aquifers throughout about one-half of the subarea delineated in southernmost Texas and in all but one of the isolated 100-square-mile areas making up subarea 4 (fig. 30). Moreover, the water in the aquifers underlying subarea 4 of the upper Claiborne aquifer generally has a much larger dissolved-solids concentration than does the water from subarea 4. In addition the conditions most favorable for the dissolution of halite from salt domes are not met for parts of subarea 4 . The dissolved-solids concentration of water from subarea 4 is less than seawater $(35,000 \mathrm{mg} / \mathrm{L})$ (fig. 31 , table 16), and only three salt domes in the vicinity of isolated 100-square-mile areas making up subarea 4 have depth of burial greater than $4,000 \mathrm{ft}$. Thus upward leakage is more likely to have the larger effect on water chemistry in subarea 4 than dissolution of halite from salt domes.

Sulfate reduction (eq. 13) is supported by (1) the presence of lignite (Payne, 1970), which reacts with sulfate, an oxidizing agent, to produce bicarbonate ions and hydrogen sulfide, and (2) the negative loading of sulfate on factor II and the positive and significant loading of bicarbonate on factor II (table 17). Cation exchange (eq. 3 ) is supported by the near significant, negative loading of calcium on factor II (table 17). Sulfate reduction and cation exchange are processes that remove sulfate and calcium ions from the ground water, respectively. Because the quantities are small relative to other chemical constituents in the water of subarea 4, the processes have little effect on the overall water chemistry.

The major chemical processes postulated in chemically distinct subarea 5 of the upper Claiborne aquifer are (1) the dissolution of halite containing traces of calcium and magnesium minerals (factor I), and (2) sulfate reduction (factor II). The postulated dissolution of halite containing traces of calcium and magnesium minerals (factor I) accounts for about 35 percent more of the variability in concentration of chemical constituents than does sulfate reduction (factor II) (table 17). The loading of dissolved solids on factor I is very high and significant, whereas the loading on factor II is not significant, thus indicating that the dissolution of halite accounts for most of the variability in concentration of chemical constituents as well as most of the variation in concentration of dissolved solids in subarea 5 of the upper Claiborne aquifer.

Hydrologic, geologic, and related information that supports the two processes postulated above for chemically distinct subarea 5 are discussed briefly in the context of the water chemistry and results of factor analysis of the chemical data. The dissolution of halite (eq. 7) is supported by (1) the extremely large concentration of sodium and chloride ions (table 16), (2) the significant loading of sodium and chloride on factor I (table 17), and (3) the presence of salt domes that penetrate the base of the upper Claiborne aquifer (Beckman and Williamson, 1990). The high concentrations of calcium and magnesium ions (table 1) are probably from dissolution of traces of calcium and magnesium minerals commonly found in halite. However, upward leakage may add to the concentrations of sodium and chloride ions because a substantial volume of upward flow to the upper Claiborne aquifer was simulated by Williamson (in press) in parts of subarea 4 that are not near salt domes.

The presence of gypsum and lignite in the aquifer (Payne, 1970) and a decrease in the concentration of sulfate ions in the ground water from updip subareas (table 16) support sulfate reduction (eq. 13). Because the aquifer in this subarea is at depths where all the oxygen would normally have been consumed, oxidation of organic matter such as lignite is by oxidizing agents. The oxidizing agent in this subarea was postulated from factor analysis to be sulfate. The oxidation of lignite (eq. 10) by sulfate would result in a decrease in sulfate ion concentration and yield hydrogen sulfide ions rather than hydrogen sulfide gas because the $\mathrm{pH}$ is above 7 (Drever, 1982). There also would be some increase in bicarbonate and hydrogen ion concentration and corresponding decrease in $\mathrm{pH}$ in the sulfate reduction process. Data in table 16 shows a decrease in $\mathrm{pH}$ and sulfate concentration below other subareas of this aquifer and a moderate concentration level of bicarbonate ions. 


\section{MIDDLE CLAIBORNE AQUIFER}

The middle Claiborne aquifer underlies about 80 percent of the study area (fig. 35). It has an areal extent of about $140,000 \mathrm{mi}^{2}$ and a mean thickness of $470 \mathrm{ft}$ (Williamson and others, 1990). Median depth of water samples collected for chemical analysis ranges from about $345 \mathrm{ft}$ in outcrop areas to $2,500 \mathrm{ft}$ in downdip areas (table 18). The downdip limit of the aquifer is as near as $40 \mathrm{mi}$ north of the shoreline in southern Texas to as far as $110 \mathrm{mi}$ north of the shoreline in southeastern Louisiana. The outcrop area of the aquifer extends from the Rio Grande in southern Texas to the Texas-Louisiana-Arkansas State boundary. It is about $30 \mathrm{mi}$ wide in southern Texas and widens to about $50 \mathrm{mi}$ in northeastern Texas. The aquifer outcrop area extends northeastward from southwestern Arkansas through southeastern Missouri into western Kentucky. From western Kentucky the aquifer outcrop extends to the southwest through western Tennessee into west-central Mississippi, and from west-central Mississippi it extends to the southeast into southwestern Alabama. This arcuate aquifer outcrop band approximately parallels the inland boundary of the Mississippi embayment. Throughout the Mississippi embayment the aquifer outcrop area ranges from 5 to $20 \mathrm{mi}$ in width (Hosman and Weiss, 1991). The geometric mean hydraulic conductivity of this aquifer is about $57 \mathrm{ft} / \mathrm{d}$ (table 3 ).

TABLE 18.--Median value of selected chemical constituents and properties of water, median sampling depth, water types, and number of analyses for each subarea of the middle Claiborne aquifer

[Concentrations are in milligrams per liter, except iron and manganese, which are in micrograms per liter. Depth is in feet, $\mathrm{pH}$ is in units, and temperature is in degrees Celsius. Chemical symbols: $\mathrm{Ca}$, calcium; $\mathrm{Mg}$, magnesium; $\mathrm{Na}$, sodium; $\mathrm{K}$, potassium; Fe, iron; $\mathrm{Mn}$, manganese; $\mathrm{HCO}_{3}$, bicarbonate: $\mathrm{SO}_{4}$. sulfate; $\mathrm{Cl}$, chloride; $\mathrm{SiO}_{2}$, silica. Water type shown is the most frequently occurring]

\begin{tabular}{|c|c|c|c|c|c|}
\hline \multirow{2}{*}{$\begin{array}{c}\text { Constituent or } \\
\text { property }\end{array}$} & \multicolumn{5}{|c|}{ Subarea } \\
\hline & 1 & 2 & 3 & 4 & 5 \\
\hline $\mathrm{Ca}$ & 6.0 & 5.6 & 52 & 87 & 290 \\
\hline $\mathrm{Mg}$ & 2.0 & 3.0 & 20 & 50 & 150 \\
\hline $\mathrm{Na}$ & 28 & 210 & 250 & 3.500 & 27,000 \\
\hline $\mathrm{K}$ & 1.7 & 2.1 & 12 & 21 & 140 \\
\hline $\mathrm{Fe}$ & 150 & 100 & 280 & 800 & 2.800 \\
\hline $\mathrm{Mn}$ & 20 & 10 & 20 & 140 & 150 \\
\hline $\mathrm{HCO}_{3}$ & 120 & 330 & 260 & 800 & 290 \\
\hline $\mathrm{SO}_{4}$ & 5.5 & 25 & 210 & 25 & 120 \\
\hline $\mathrm{Cl}$ & 6.7 & 110 & 250 & 4,600 & 44.000 \\
\hline $\mathrm{SiO}_{2}$ & 17 & 14 & 16 & 7.8 & 16 \\
\hline Dissolved solids & 170 & 650 & 1,270 & 11.000 & 73.000 \\
\hline Sampling depth & 345 & 500 & 367 & 1,610 & 2,500 \\
\hline $\mathrm{pH}$ & 7.3 & 8.0 & 7.4 & 7.6 & 7.2 \\
\hline Temperature & 20.0 & 23.0 & 22.0 & 20.8 & 32.0 \\
\hline Primary water type & $\mathrm{NaHCO}_{3}$ & $\mathrm{NaHCO}_{3}$ & $\mathrm{NaCl}$ & $\mathrm{NaCl}$ & $\mathrm{NaCl}$ \\
\hline Secondary water type & $\mathrm{CaCl}$ & $\mathrm{CaCl}$ & $\mathrm{CaCl}$ & $\mathrm{MgHCO}_{3}$ & $\mathrm{MgHCO}_{3}$ \\
\hline Number of analyses & 956 & 431 & 80 & 11 & 3 \\
\hline
\end{tabular}




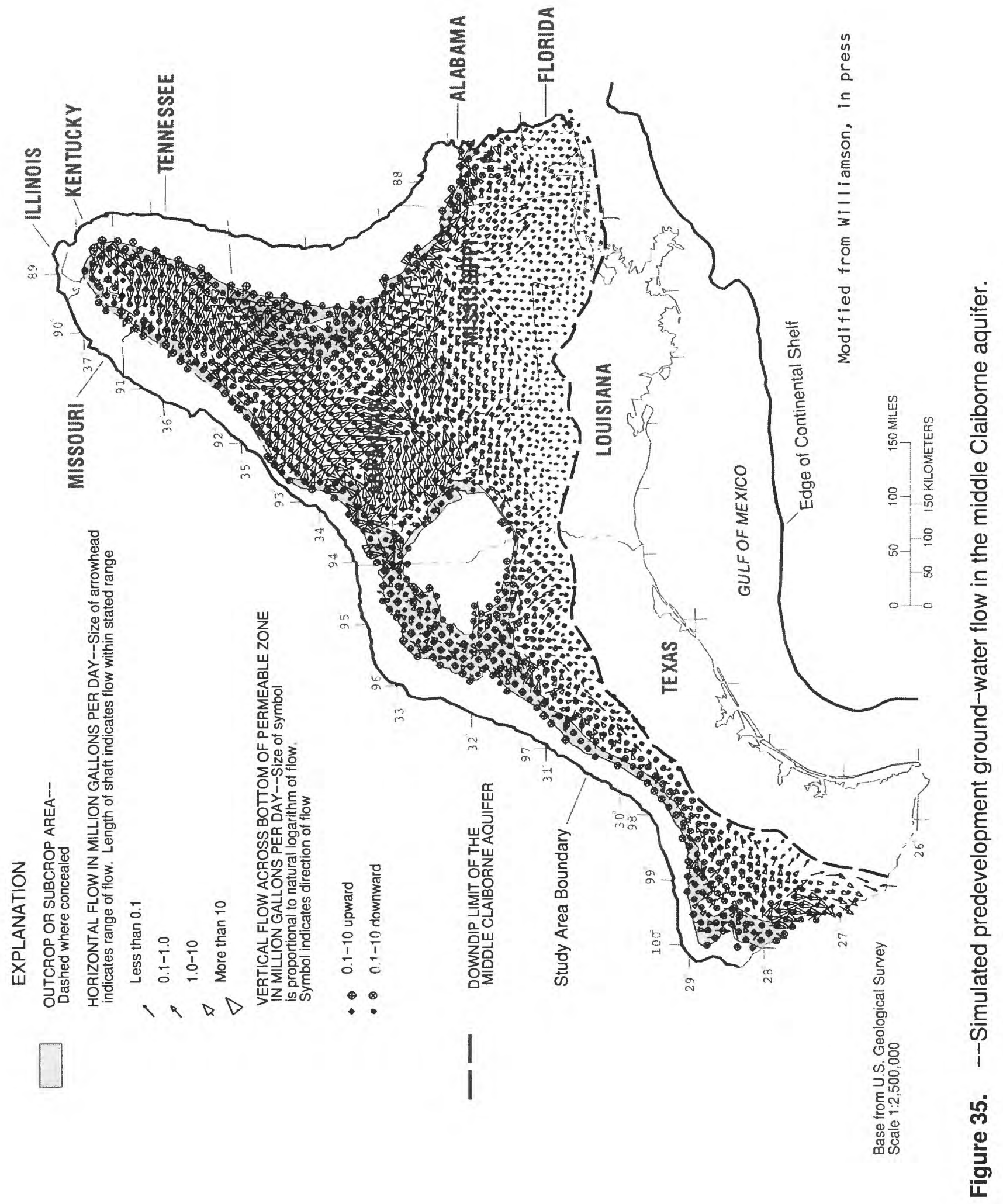


The simulated horizontal direction of predevelopment ground-water flow and vertical leakage relative to the base of the aquifer is shown in figure 35 (Williamson, in press). Regionally, the horizontal flow east of the Mississippi River generally is westward from high land-surface altitudes in the aquifer outcrop areas toward low-lying outcrop areas along the western side of the Mississippi embayment. In northwestern Mississippi the flow is toward the Yazoo River and its major tributaries. In southeastern Mississippi and southwestern Alabama the flow is toward the Tombigbee River. The horizontal flow in southern Arkansas and Louisiana west of the Mississippi River is generally from aquifer outcrop areas toward a regional discharge area in northeastern Louisiana. In Texas the flow is from aquifer outcrop areas having high land-surface altitude toward major stream valleys. Vertical leakage is downward from the middle Claiborne aquifer outcrop areas in southern Texas, northeastern Texas, Louisiana, Arkansas, and Mississippi. Vertical leakage is also downward to the lower Claiborne-upper Wilcox aquifer from a few 100-squaremile areas of the middle Claiborne aquifer outcrop area in Kentucky, Tennessee, and Alabama. Most of the area underlain by the middle Claiborne aquifer receives upward leakage from the lower Claiborne-upper Wilcox aquifer. However, vertical leakage is downward from the middle Claiborne aquifer to the lower Claiborne-upper Wilcox aquifer throughout four large areas that are downdip of the middle Claiborne aquifer outcrop area. The areas of downward leakage are in north-central Louisiana and adjacent parts of Arkansas; east-central Louisiana, southern Alabama and adjacent parts of Florida, and southern Mississippi. The area of downward leakage to the underlying lower Claiborne-upper Wilcox aquifer in southern Mississippi begins in the middle Claiborne aquifer outcrop area in southeastern Mississippi and is coincident with part of an area where vertical leakage is downward from the overlying upper Claiborne aquifer to the middle Claiborne aquifer (figs. 30, 35).

\section{DISSOLVED-SOLIDS CONCENTRATIONS}

The areal distribution of the median concentration of dissolved solids per 100-square-mile area in water from the middle Claiborne aquifer is shown in figure 36. The delimited area of the aquifer having median concentrations of dissolved solids less than $500 \mathrm{mg} / \mathrm{L}$ extends from northeastern Texas, throughout northwestern Louisiana, most of Arkansas, all of Missouri, Kentucky, and Tennessee, the northern two-thirds of Mississippi, and into southwestern Alabama. About 50 percent of the area underlain by the middle Claiborne aquifer has water with less than $500 \mathrm{mg} / \mathrm{L}$ concentration of dissolved solids.

The delimited areas of the aquifer having median concentrations of dissolved solids ranging from 500 to 1,000 $\mathrm{mg} / \mathrm{L}$ are mostly adjacent and downdip from the 0 to $500 \mathrm{mg} / \mathrm{L}$ delimited area. The delimited area is narrow in width and includes aquifer outcrop areas in western Louisiana and central and eastern Texas. The delimited areas of the aquifer having median concentrations of dissolved solids ranging from 1,000 to 3,000 and 3,000 to $10,000 \mathrm{mg} / \mathrm{L}$ extends from the Rio Grande in Texas to southwestern Alabama. The aquifer outcrop area is included in the delimited area having median concentrations of dissolved solids ranging from 1,000 to $3,000 \mathrm{mg} / \mathrm{L}$. Delimited areas of the aquifer having concentrations of dissolved solids greater than $10,000 \mathrm{mg} / \mathrm{L}$ extend from the Rio Grande in Texas to southwestern Alabama and include about one-third of the area underlain by the middle Claiborne aquifer. Two small delimited areas of the aquifer having concentrations of dissolved solids greater than $70,000 \mathrm{mg} / \mathrm{L}$ are in central Louisiana near the downdip limit of the middle Claiborne aquifer.

\section{PRIMARY WATER TYPES}

The primary water type is sodium bicarbonate in east-central Texas, Louisiana, and in most of Arkansas and Mississippi (fig. 37), whereas in Kentucky, Tennessee, northeastern Texas, and along the aquifer outcrop areas the predominant primary water type is calcium bicarbonate or sodium bicarbonate. The primary water type is sodium chloride in southern Texas and in southern Mississippi. 


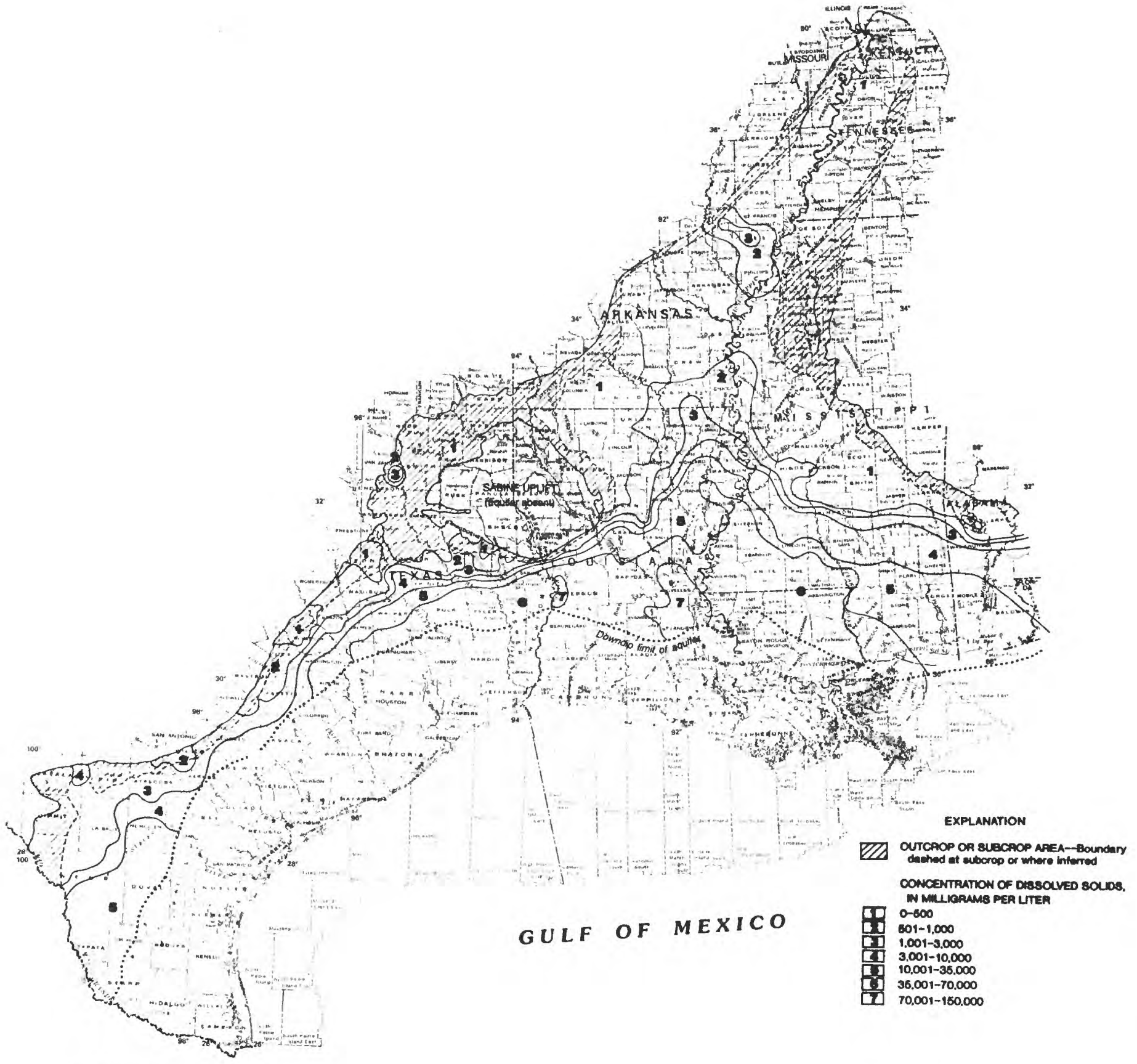

Modified from Pettlyohn and others. 1988 


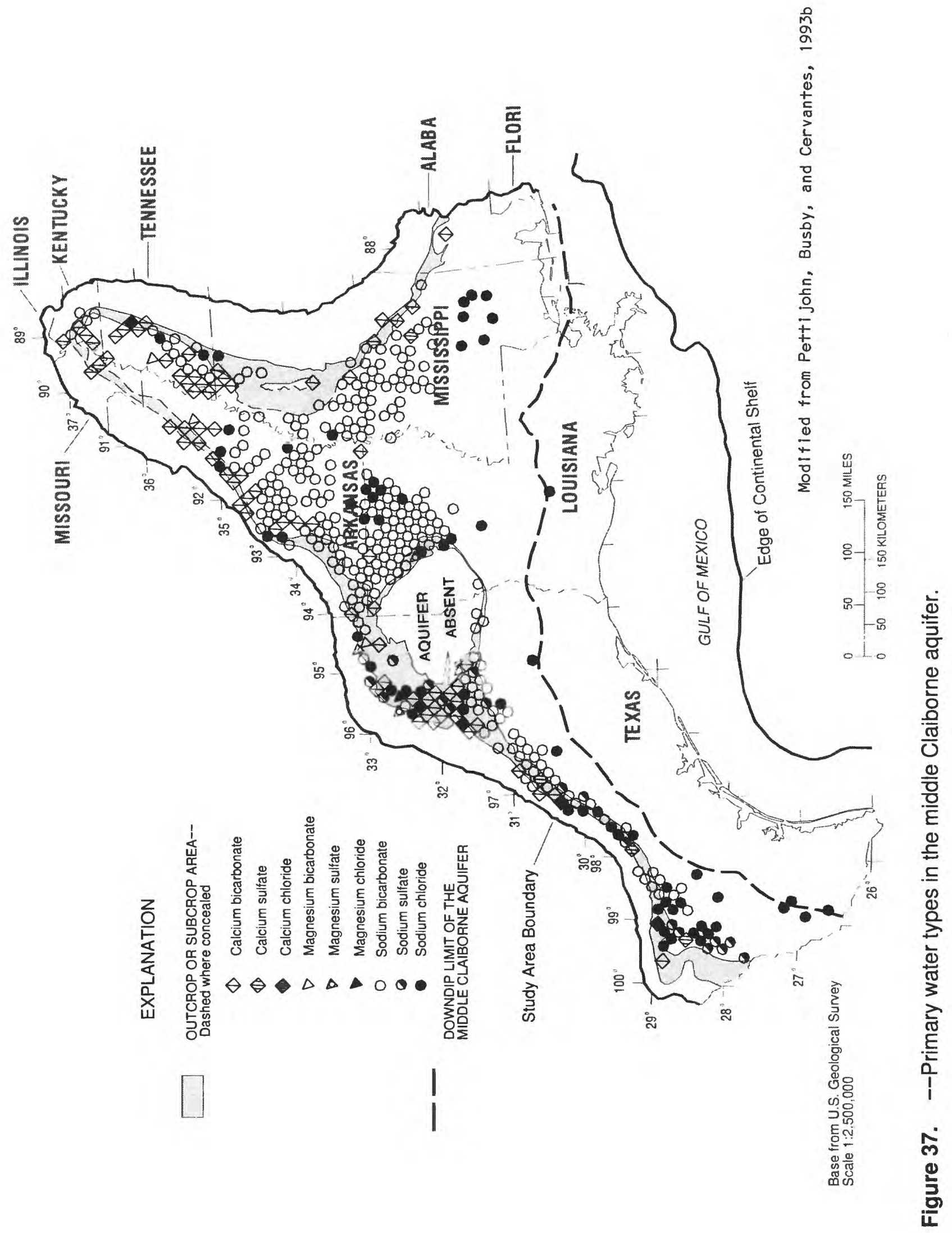




\section{GROUND-WATER CHEMISTRY WITHIN SUBAREAS}

The middle Claiborne aquifer was divided into five chemically distinct subareas and the boundaries adjusted using discriminant function analyses of the chemical data from the subareas (fig. 38). Subarea 1 extends from northeastern Texas to the north and to the east through parts of Louisiana, Arkansas, Kentucky, Tennessee, and Mississippi. Many isolated 100-square-mile areas are a part of subarea 1, and much of the aquifer outcrop area is included in subarea 1. Subarea 2 generally is adjacent and downdip from subarea 1 except in southern Texas where subarea 1 is absent and subarea 2 extends to the updip limit of the aquifer and includes some outcrop. About one-half or 66 of the 100 -squaremile areas that are a part of subarea 2 are in the area originally delineated as subarea 1 . Chemical data are adequate to define subarea 3 throughout about $2,400 \mathrm{mi} 2$ of the aquifer area. The subarea consists of a 700 -mi 2 contiguous area in southern Texas and 17 isolated 100-square-mile areas scattered across the aquifer area. Subareas 4 and 5 consist of 10 isolated 100-square-mile areas that generally are downdip of subarea 3. Based on the areal distribution of dissolved-solids concentrations (fig. 36), subarea 4 probably extends across much of southern Texas and subarea 5 across much of southeastern Texas and southern Louisiana.

The median value for selected chemical constituents and the primary and secondary water types for each subarea are shown in table 18. Major cations increase in concentration from subarea 1 to subarea 5 with the greatest increase occurring in the sodium ion concentration. Among the major anions, only chloride increases progressively from subarea 1 to subarea 5. The bicarbonate ion concentration and $\mathrm{pH}$ increase from subarea 1 to subarea 2 , then decrease from subarea 2 to subarea 3 , increase from subarea 3 to subarea 4 , and then decrease from subarea 4 to subarea 5 . Sulfate ion concentration increases progressively from subarea 1 to subarea 3, decreases from subarea 3 to subarea 4 , and than increases from subarea 4 to subarea 5 . Iron and manganese generally increase progressively from subarea 1 to subarea 5. Silica is nearly constant except for a decrease from subarea 3 to subarea 4 , whereas temperature is nearly constant from subarea 1 to subarea 4 than increases from subarea 4 to subarea 5 . The primary water type is sodium bicarbonate in subareas 1 and 2 , and sodium chloride in subareas 3,4 , and 5 .

The trilinear diagram (fig. 39), based on three representative samples from each subarea, in conjunction with figure 37 shows that water in the middle Claiborne aquifer is sodium bicarbonate in subareas 1 and 2 and sodium chloride in subareas 3,4, and 5 (fig. 39). The diagram also shows that ground water in the middle Claiborne aquifer has major cations concentration that is approximately 24 percent magnesium plus calcium ( 76 percent sodium plus potassium) in subarea $I$ and about 4 percent magnesium plus calcium ( 96 percent sodium plus potassium) in subarea 5. The major anions concentration is about 88 percent bicarbonate plus carbonate ( 12 percent chloride plus sulfate) in subarea 1 and about 1 percent bicarbonate plus carbonate ( 99 percent chloride plus sulfate) in subarea 5 . The triangular parts of figure 39 along with the data in table 18 indicate that the chemical processes in the middle Claiborne aquifer are increasing the sodium and chloride ions from small concentrations updip to very large concentrations downdip.

The progressive increase in concentration of dissolved solids is about a factor of 4 from subarea 1 to subarea 2 , about a factor of 2 from subarea 2 to subarea 3, about a factor of 9 from subarea 3 to subarea 4 , and about a factor of 7 from subarea 4 to subarea 5 (table 18). Thus dissolved-solids concentrations increase by a factor of about 430 from subarea 1 to subarea 5 .

\section{CORRELATION AMONG CHEMICAL CONSTITUENTS AND PROPERTIES OF GROUND WATER}

\section{WITHIN SUBAREAS}

The correlation among chemical constituents and properties in water from the middle Claiborne aquifer was evaluated by factor analysis, which indicates that at least two major chemical processes or mechanisms are responsible for most of the variability in the concentration of constituents in subareas $1,2,3$, and 5 and three processes in subarea 4 (table 19). Thirteen constituents or properties were used in the factor analysis. The number of chemical analyses were 956 in subarea 1,431 in subarea 2, 80 in subarea 3,11 in subarea 4 , and 3 in subarea 5 (table 18). The variability accounted for by the factors ranged from 67.7 in subarea 1 to 100 percent in subarea 5 . The loading of each constituent or property on each factor and the percent of total variability (communality) accounted for in factor analysis is shown in table 19. 


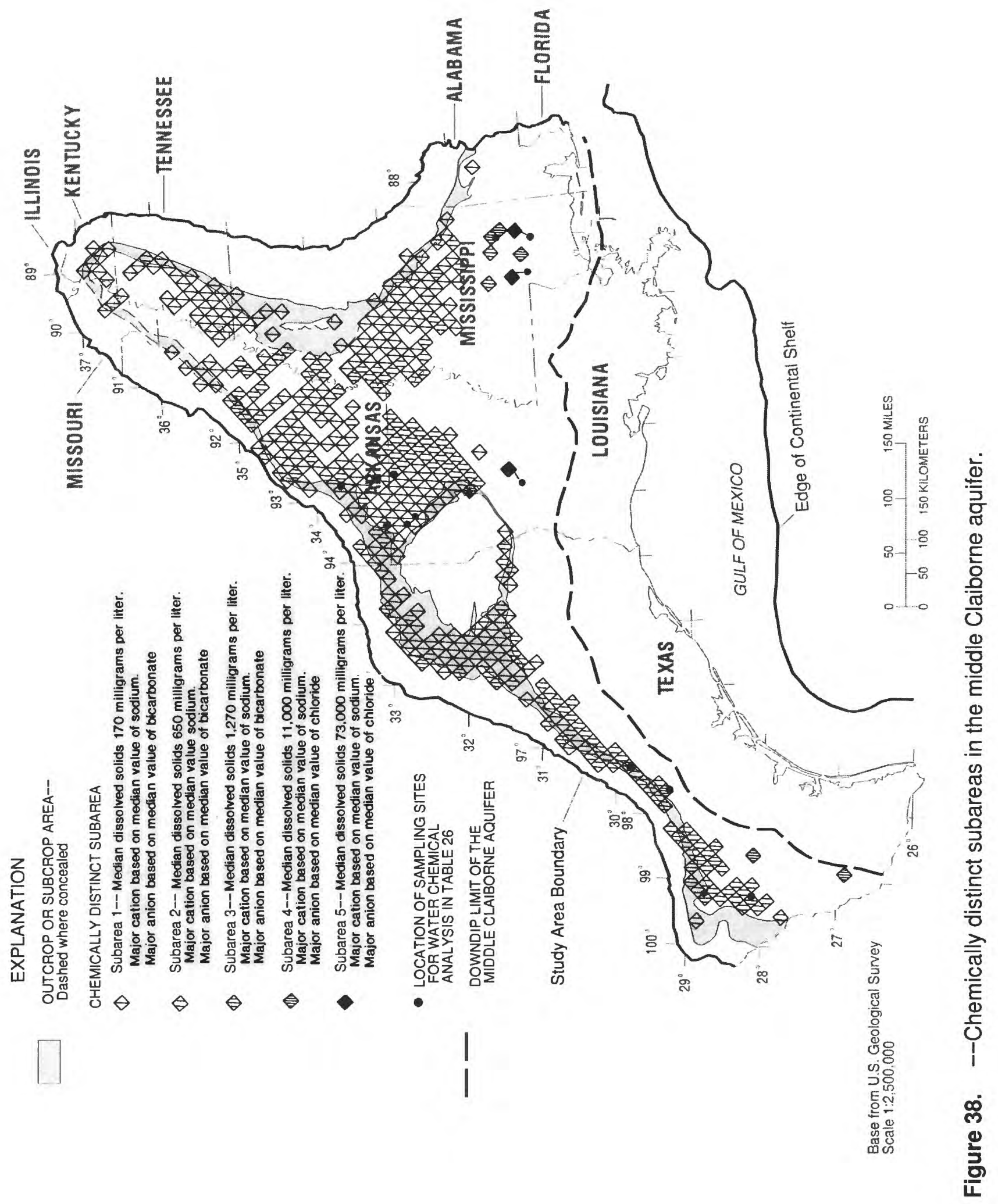




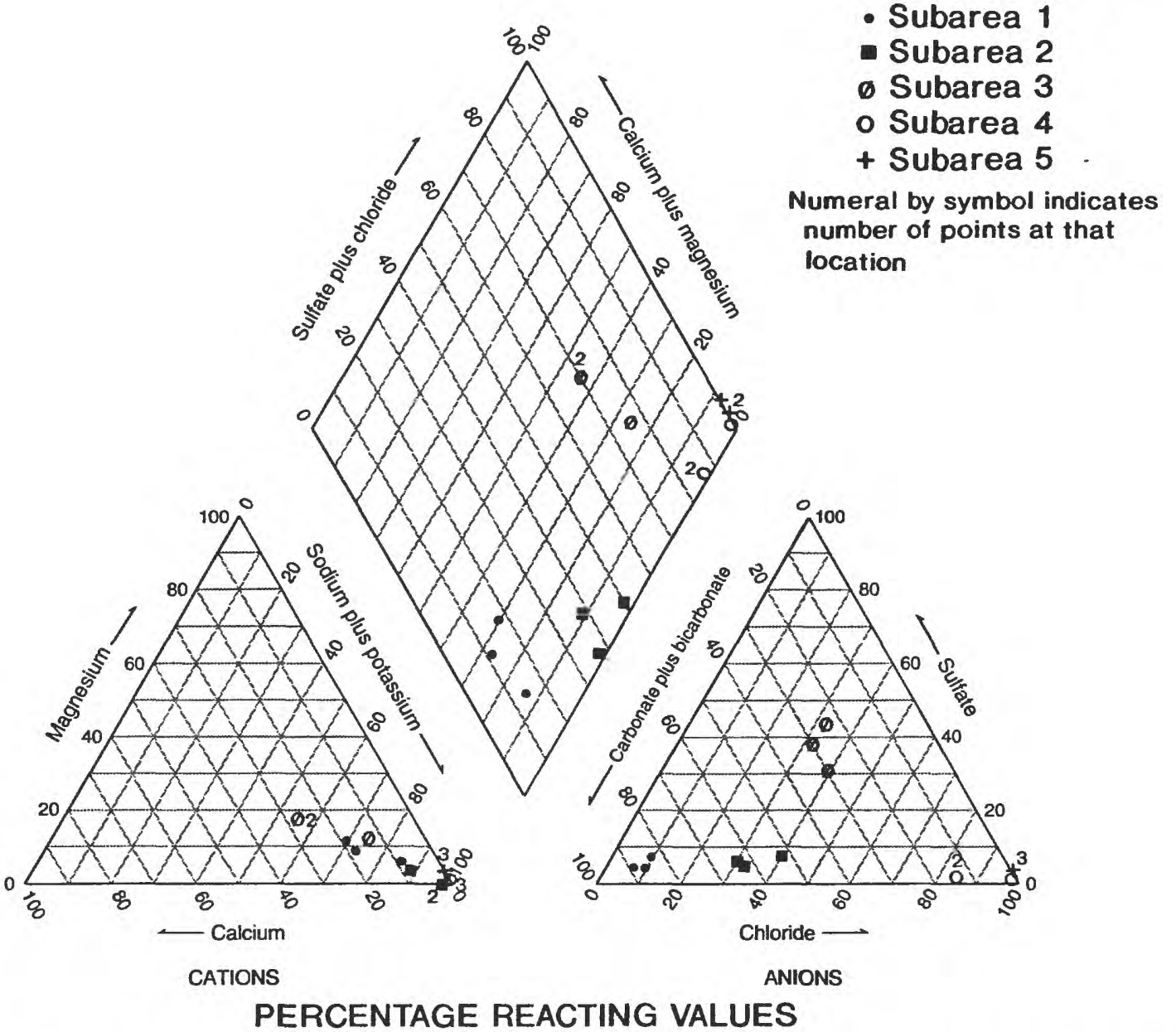

Figure 39.--Change in water chemistry from subarea to subarea in the middle Claiborne aquifer, based on three representative samples.

Factor I of subarea 1 represents a process in which sodium and bicarbonate ions are added to the ground water and hydrogen ions are removed. The effect of the process on the water chemistry increases with depth. Factor II of subarea 1 represents a process in which calcium and magnesium ions are added to the ground water. The variability in concentration of chemical constituents and properties of water accounted for by factor I is about 41 percent and by factor II is 27 percent. The variability in concentration of dissolved solids accounted for by factor I is 88 percent and significant, whereas for factor II it is 41 percent and nonsignificant.

Factor I of subarea 2 represents a process in which calcium, magnesium, hydrogen, and sulfate ions are added to the ground water. Also, the effect of the process on the water chemistry decreases with depth. Factor II of subarea 2 represents a process in which sodium, chloride, and bicarbonate ions are added to the ground water. The variability in concentration of chemical constituents and properties of water accounted for by factor $I$ is about 47 percent and by factor II is about 31 percent. The variability in concentration of dissolved solids accounted for by factor I is 24 percent and nonsignificant, whereas for factor II it is 97 percent and highly significant.

Factor I of subarea 3 represents a process in which sodium, chloride, and bicarbonate ions are added to the ground water. Factor II of subarea 3 represents a process in which calcium, magnesium, hydrogen, and sulfate ions are added to the ground water. The variability in concentration of chemical constituents and properties of water accounted for by factor I is about 40 percent and by factor II is about 31 percent. The variability in concentration of dissolved solids accounted for by factor I is 90 percent and significant, whereas for factor II it is 37 percent and nonsignificant. 


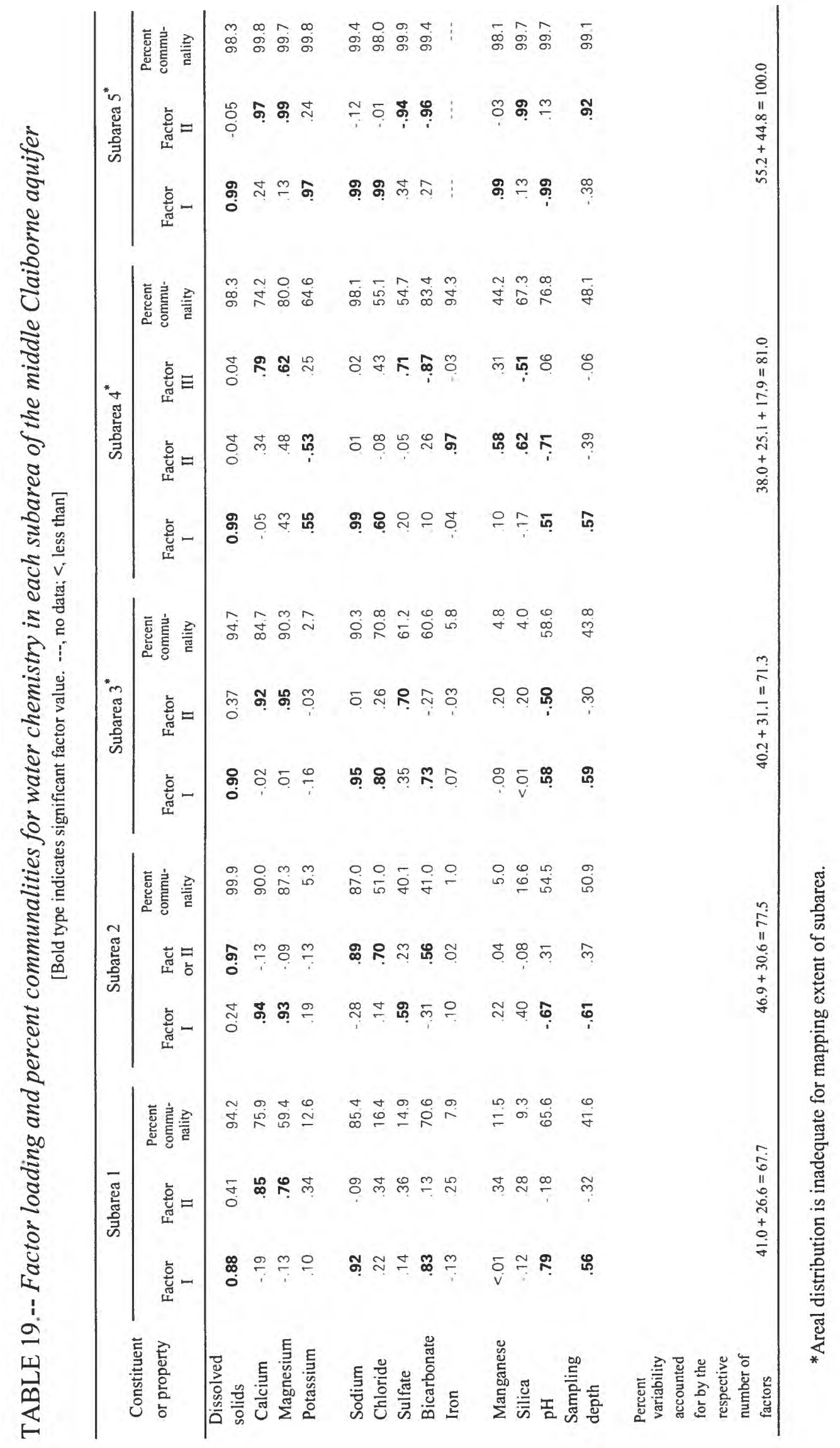


Factor I of subarea 4 represents a process in which sodium, potassium, and chloride ions are added to the ground water and hydrogen ions are removed. The effect of the process on the water chemistry increases with depth. Factor II of subarea 4 represents a process in which iron, manganese, hydrogen, and silica ions are added to the ground water, and potassium ions are removed. Factor III of subarea 4 represents a process in which calcium, magnesium, hydrogen, and sulfate ions are added to the ground water, and silica and bicarbonate ions are removed. The variability in concentration of chemical constituents and properties of water accounted for by factor I is about 38 percent, by factor II is about 25 percent, and by factor III is about 18 percent. The variability in concentration of dissolved solids accounted for by factor I is 99 percent and highly significant, whereas for factor II it is 4 percent and nonsignificant, and for factor III it is also 4 percent and nonsignificant.

Factor I of subarea 5 represents a process in which sodium, potassium, manganese, hydrogen, and chloride ions are added to the ground water. Factor II of subarea 5 represents a process in which calcium, magnesium, and silica ions are added to the ground water, and sulfate and bicarbonate ions are removed. The effect of the process on the water chemistry increases with depth. The variability in concentrations of chemical constituents and properties of water accounted for by factor I is about 55 percent and for factor II is about 45 percent. The variability in concentration of dissolved solids accounted for by factor I is 99 percent and highly significant, whereas for factor II it is a negative 5 percent and nonsignificant.

\section{RELATION OF GROUND-WATER CHEMISTRY TO CHEMICAL AND PHYSICAL PROCESSES}

The major chemical processes and mechanisms postulated for each of the chemically distinct subareas in the middle Claiborne aquifer are based on the results of factor analysis in conjunction with constituent concentrations, a trilinear diagram, ground-water movement, and information on water-rock interaction and probable minerals in the deposits. The major processes postulated in subarea 1 are (1) the alteration of albite (factor I), and (2) the leaching of soluble salts (factor II) from the unsaturated zone. The postulated alteration of albite (factor I) accounts for about 14 percent more of the variability in concentration of chemical constituents than does the postulated leaching of soluble salts from the unsaturated zone (factor II). The loading of dissolved solids on factor I is high and significant, and its loading on factor II is nonsignificant, thus indicating that the alteration of albite accounts for most of the variation in the concentration of dissolved solids in subarea 1 of the middle Claiborne aquifer.

Hydrologic, geologic, and related information that supports the two processes postulated above for chemically distinct subarea 1 are discussed briefly in the context of the water chemistry and results of factor analysis of the chemical data. The alteration of albite (eq. 1) is supported by (1) the predominance of sodium and bicarbonate ions in the ground water (table 18), (2) the significant, positive loading of both sodium and bicarbonate on factor I (table 19), and (3) the presence of shales in the aquifer deposits (Payne, 1972) that contain, on the average, 30 percent feldspar (Foster, 1949). Alteration of albite occurs as recharge water acidified by carbon dioxide in the soil zone reacts with the sodium feldspar mineral to produce clay minerals and sodium and bicarbonate ions. Extensive outcrop in this subarea provides the source of carbon dioxide to precipitation as it percolates through the soil zone to the saturated zone. The recharge water from precipitation leaches soluble salts from the soil as it percolates to the saturated zone. The soluble salts may come from either the decay of organic matter or dissolution of minerals in soils by acids from the decay process. The concentrations of major ions in ground water of subarea 1, except for sodium and bicarbonate, are only slightly above concentrations observed in rain and snow (table 18). These observations lend support to leaching of soluble salts from the soil zone as a major process in subarea 1 of the middle Claiborne aquifer. Although not postulated, upward leakage to this aquifer from the underlying lower Claiborne-upper Wilcox aquifer may be affecting the water chemistry, as indicated by the assignment, as a result of the discriminant function analysis, of several isolated 100-square-mile areas within the original delimited subarea 1 in northeastern Texas and Arkansas to subarea 2 (fig. 35).

The major processes postulated from the results of factor analysis as occurring in subarea 2 are (1) leaching of soluble salts from the unsaturated zone (factor I), (2) oxidation of pyrite (factor I), (3) upward leakage (factor II), and (4) alteration of albite (factor II). The postulated leaching of soluble salts from the unsaturated zone (factor I) and oxidation of pyrite (factor I) had 16 percent more of the variation in constituent concentrations than do alteration of albite (factor II) and upward leakage (factor II). However, the loading of dissolved solids on factor Il was very highly 
significant and on factor I not significant, thus indicating that although the leaching of soluble salts and oxidization of pyrite account for most of the variability in concentration of chemical constituents, it is the alteration of albite and upward leakage that account for most of the variation in concentration of dissolved solids in subarea 2.

Hydrologic, geologic, and related information that supports the four processes postulated above for chemically distinct subarea 2 is discussed briefly in the context of the water chemistry and results of factor analysis of the chemical data. Leaching of soluble salts (eq. 15) from the unsaturated zone and pyrite oxidation (eq. 13) in outcrop areas are supported by (1) the positive, significant loading of calcium, magnesium, and sulfate on factor I (table 19), (2) adequate rainfall, (3) oxygen supply, and (4) reported presence of pyrite (Plummer, 1932). Pyrite is a common mineral in bedrock of the Gulf Coastal Plain (Freeze and Cherry, 1979). Recharge water from precipitation will generally absorb oxygen and leach soluble salts from the soil zone as it percolates to the saturated zone in the aquifer outcrop area. As a result the oxygen dissolved in the ground water will react with pyrite to produce sulfate and hydrogen ions. However, the processes are considered weak because of the low concentration of sulfate ions and no decrease in $\mathrm{pH}$ from subarea 1 to subarea 2 (table 18 ).

The alteration of albite (eq. 1) is supported by conditions similar to those in subarea 1 where alteration of albite was postulated. But, because a part of the subarea is downdip from subarea $I$ and the outcrop areas, the amount of carbon dioxide available would begin to decrease, resulting in a decrease in alteration of albite. Upward leakage (eq. 16) is supported by (1) a ground-water flow analysis (Williamson, in press) described below, (2) the much larger concentration of dissolved solids in the lower Claiborne-upper Wilcox aquifer than the concentration in the middle Claiborne aquifer, especially in northern Louisiana and southern Arkansas (figs. 36, 41), and (3) the significant positive loading of dissolved solids, sodium, and chloride on factor II (table 19). Upward leakage was simulated from the lower Claiborne-upper Wilcox aquifer for most of the isolated 100-square-mile areas that make up subarea 2 of the middle Claiborne aquifer (Williamson, in press) (fig. 35). The simulation showed that the volume of upward leakage is 10 percent or more of the horizontal flow through most the areas of subarea 2 and may affect the water chemistry.

The major processes postulated from the results of factor analysis in subarea 3 are (1) upward leakage (factor I), (2) alteration of albite (factor I), and (3) dissolution of gypsum (factor II). The postulated upward leakage (factor I) and the alteration of albite (factor I) account for 9 percent more variability in concentration of chemical constituents than does dissolution of gypsum (factor II) (table 19). The loading of dissolved solids on factor I is very highly significant and about twice that of factor II which is not significant, thus indicating that upward leakage and alteration of albite account for most of the variation in concentration of dissolved solids in subarea 3.

Hydrologic, geologic, and related information that supports the three processes postulated above for chemically distinct subarea 3 are discussed briefly in the context of the water chemistry and results of factor analysis of the chemical data. Alteration of albite (eq. 1) and upward leakage (eq. 16) are a continuation of processes postulated for subarea 2. However, the decrease, in bicarbonate ion concentration and the increase in chloride ion concentration from subarea 2 to subarea 3 (table 18) indicate that the amount of albite alteration is somewhat reduced, and the effect of upward leakage is increased. These conditions are likely because the source of carbon dioxide necessary for albite alteration decreases, and the volume of vertical leakage of water having larger concentrations of chemical constituents from the lower Claiborne-upper Wilcox aquifer is a greater proportion of the horizontal flow in the middle Claiborne aquifer. In addition, the effect of the postulated process increases with depth and raises the $\mathrm{pH}$. The rise in $\mathrm{pH}$ would occur because the source of carbon dioxide is reduced, and hydrogen ions are consumed in albite alteration. The effects of the more highly mineralized water in the underlying aquifer are greater near the base of the middle Claiborne aquifer than near its top.

The dissolution of gypsum (eq. 6) is supported by the large concentration of sulfate ions, the moderate increase in concentrations of calcium and magnesium ions from subarea 2 to subarea 3 (table 18), and the positive significant loading of sulfate on factor II (table 19). The dissolution of gypsum is probably the major process affecting water chemistry in most of the areas that make up subarea 3 in Texas.

The major process postulated from the results of factor analysis in subareas 4 and 5 is the dissolution of halite containing traces of sylvite or upward leakage (factor I). Several other minor processes (factor II) could be postulated, 
but the small amount of data (only 10 of the 100-square-mile areas were assigned to subareas 4 and 5) does not warrant the extensive discussion of processes postulated that were given for other subareas in the middle Claiborne aquifer. The postulated dissolution of halite containing traces of sylvite or upward leakage (factor I) accounts for about 13 to 18 percent more of the variability in concentration of chemical constituents than does other processes (factor II) in subarea 4 of the middle Claiborne aquifer (table 19). Additionally, the high and significant loading of dissolved solids on factor I, which represents dissolution of halite or upward leakage, accounts for most of the variation in concentration of dissolved solids in subarea 4. The postulated dissolution of halite and sylvite minerals (factor I) accounts for 10 percent more of the variability in concentration of chemical constituents than does other minor processes (factor II) in subarea 5 of the middle Claiborne aquifer. The loading of dissolved solids on factor I is very high and significant, and its loading on factor II is very low, negative, and nonsignificant, thus indicating that the dissolution of halite accounts for most of the variation in concentration of dissolved solids in subarea 5.

Hydrologic, geologic, and related information that supports the processes postulated above for chemically distinct subarea 4 are discussed briefly in the context of the water chemistry and results of factor analysis of the chemical data. Dissolution of halite (eq. 7) is supported by (1) the very large concentration of sodium and chloride ions in the ground water (table 18), (2) the significant positive loading of sodium and chloride on factor I (table 19), and (3) the presence of salt domes (Beckman and Williamson, 1990). The much higher concentration of chloride ions than sodium ions suggest that more than one chloride mineral is being dissolved, such as sylvite or carnallite. Upward leakage (eq. 16) is probably the major factor affecting water chemistry in the 100-square-mile areas of subarea 4 in Texas because they are not near salt domes that penetrate the base of the middle Claiborne aquifer.

\section{LOWER CLAIBORNE-UPPER WILCOX AQUIFER}

The lower Claiborne-upper Wilcox aquifer underlies the northern two-thirds of the study area (fig. 40). It has an areal extent of about $110,000 \mathrm{mi}^{2}$ and a mean thickness of $260 \mathrm{ft}$ (Williamson and others, 1990). Median depth of water samples collected for chemical analysis ranges from $250 \mathrm{ft}$ in downdip areas to $1,240 \mathrm{ft}$ in middip areas (table 20). The outcrop area of the aquifer extends northeastward from the Rio Grande across Texas in a nearly continuous band to southeastern Texas. The aquifer outcrop area extends northeastward from southwestern Arkansas into southeastern Missouri and western Kentucky. From western Kentucky the outcrop extends south-westward across western Tennessee into central Mississippi, and from central Mississippi it extends southeastward into southwestern Alabama. The width of the outcrop area varies from several miles in Texas to more than $20 \mathrm{mi}$ along its eastern boundary in Tennessee and Mississippi. The downdip limit of the aquifer is about 60 to $120 \mathrm{mi}$ north of the shoreline in Texas and as much as $200 \mathrm{mi}$ north of the shoreline in Louisiana (Hosman and Weiss, 1991). The geometric mean hydraulic conductivity of the lower Claiborne-upper Wilcox aquifer is about $43 \mathrm{ft} / \mathrm{d}$ (table 3 ).

The simulated horizontal direction of predevelopment ground-water flow and vertical leakage relative to the base of the lower Claiborne-upper Wilcox aquifer is shown in figure 40 (Williamson, in press). Regionally, the horizontal flow east of the Mississippi River generally is from the outcrop area westward toward and beyond the Mississippi River and southward toward the Gulf of Mexico (fig. 40). West of the Mississippi River the flow generally is from the outcrop areas southward; however, in southern and south-central Texas the flow turns eastward as it approaches the downdip limit of the aquifer. Vertical leakage generally is downward from the lower Claiborne-upper Wilcox aquifer area of outcrop to the middle Wilcox aquifer (fig. 40). Additionally, vertical leakage is downward throughout large areas downdip of the aquifer outcrop area (1) both east and west of the Sabine uplift, (2) from western Kentucky through western Tennessee into northern Mississippi, and (3) from south-central Mississippi to the downdip limit of the aquifer. Vertical leakage is upward from the middle Wilcox aquifer to the lower Claiborne-upper Wilcox aquifer throughout most of the remaining area underlain by the lower Claiborne-upper Wilcox aquifer. 
TABLE 20.--Median value of selected chemical constituents and properties of water, median sampling depth, water types, and number of analyses for each subarea of the lower Claiborneupper Wilcox aquifer

[Concentrations are in milligrams per liter, except iron and manganese. which are in micrograms per liter. Depth is in feet, $\mathrm{pH}$ is in units, and temperature is in degrees Celsius. Chemical symbols: $\mathrm{Ca}$, calcium; $\mathrm{Mg}$, magnesium; $\mathrm{Na}$, sodium; $\mathrm{K}$, potassium; $\mathrm{Fe}$, iron; $\mathrm{Mn}$, manganese: $\mathrm{HCO}_{3}$, bicarbonate; $\mathrm{SO}_{4}$, sulfate; $\mathrm{Cl}$, chloride; $\mathrm{SiO}_{2}$, silica. Water type shown is the most frequently occurring]

\begin{tabular}{lccc}
\hline \multirow{2}{*}{ Constituent or property } & \multicolumn{3}{c}{ Subarea } \\
\cline { 2 - 4 } & 1 & 2 & 3 \\
\hline $\mathrm{Ca}$ & 20 & 3.0 & 89 \\
$\mathrm{Mg}$ & 5.0 & 1.0 & 29 \\
$\mathrm{Na}$ & 22 & 200 & 100 \\
$\mathrm{~K}$ & 4.1 & 2.1 & 9.0 \\
$\mathrm{Fe}$ & 260 & 120 & 60 \\
& & & \\
$\mathrm{Mn}_{\mathrm{HCO}_{3}}$ & 20 & 8 & 210 \\
$\mathrm{SO}_{4}$ & 120 & 380 & 250 \\
$\mathrm{Cl}$ & 19 & 20 & 180 \\
$\mathrm{SiO}_{2}$ & 16 & 37 & 150 \\
& 17 & 17 & 22 \\
Dissolved solids & 180 & 535 & 780 \\
Sampling depth & 420 & 1.240 & 250 \\
pH & 7.2 & 8.1 & 7.2 \\
Temperature & 18.0 & 24.0 & 21.7 \\
& & & \\
Primary water type & $\mathrm{CaHCO}$ & $\mathrm{NaHCO}$ & $\mathrm{NaCl}$ \\
Secondary water type & $\mathrm{NaCl}_{3}$ & $\mathrm{CaCl}$ & $\mathrm{CaCl}$ \\
Number of analyses & 582 & 270 & 103 \\
\hline
\end{tabular}

\section{DISSOLVED-SOLIDS CONCENTRATIONS}

The areal distribution of the median concentrations of dissolved solids per 100 -square-mile area in water from the lower Claiborne-upper Wilcox aquifer is shown in figure 41. The delimited area of the aquifer having median dissolved-solids concentrations of less then $500 \mathrm{mg} / \mathrm{L}$ extends eastward from northeastern Texas into northwestern Louisiana; from there it extends northeastward across Arkansas, southeastern Missouri, western Kentucky, and western Tennessee, and from western Tennessee it extends southeastward across Mississippi into southwestern Alabama. From northeastern Texas southwestward to near the Rio Grande the delimited areas of the aquifer having median dissolved-solids concentrations of less than $500 \mathrm{mg} / \mathrm{L}$ are discontinuous.

The delimited areas of the aquifer having median dissolved-solids concentrations ranging from 500 to $1,000 \mathrm{mg} / \mathrm{L}$ 


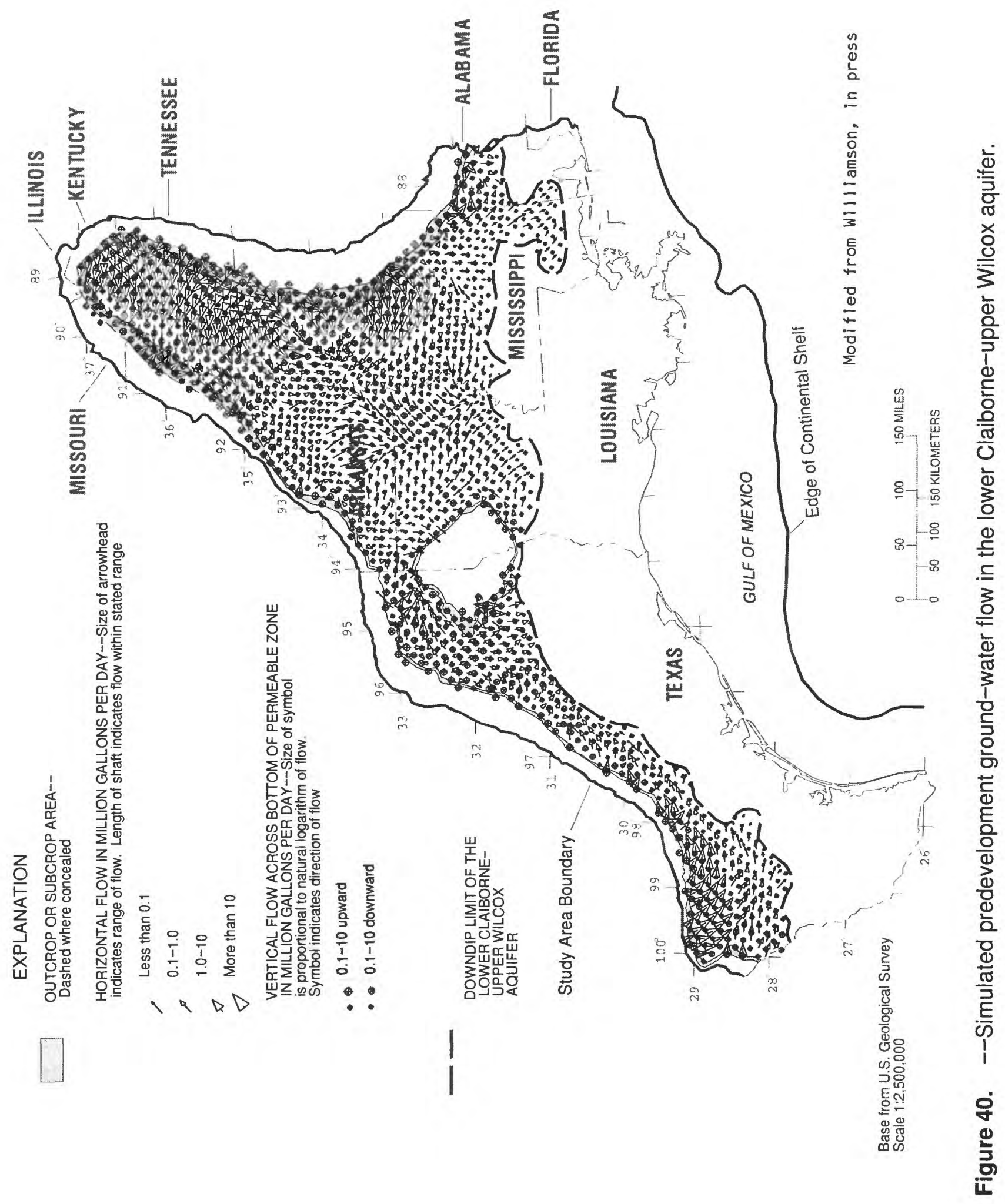




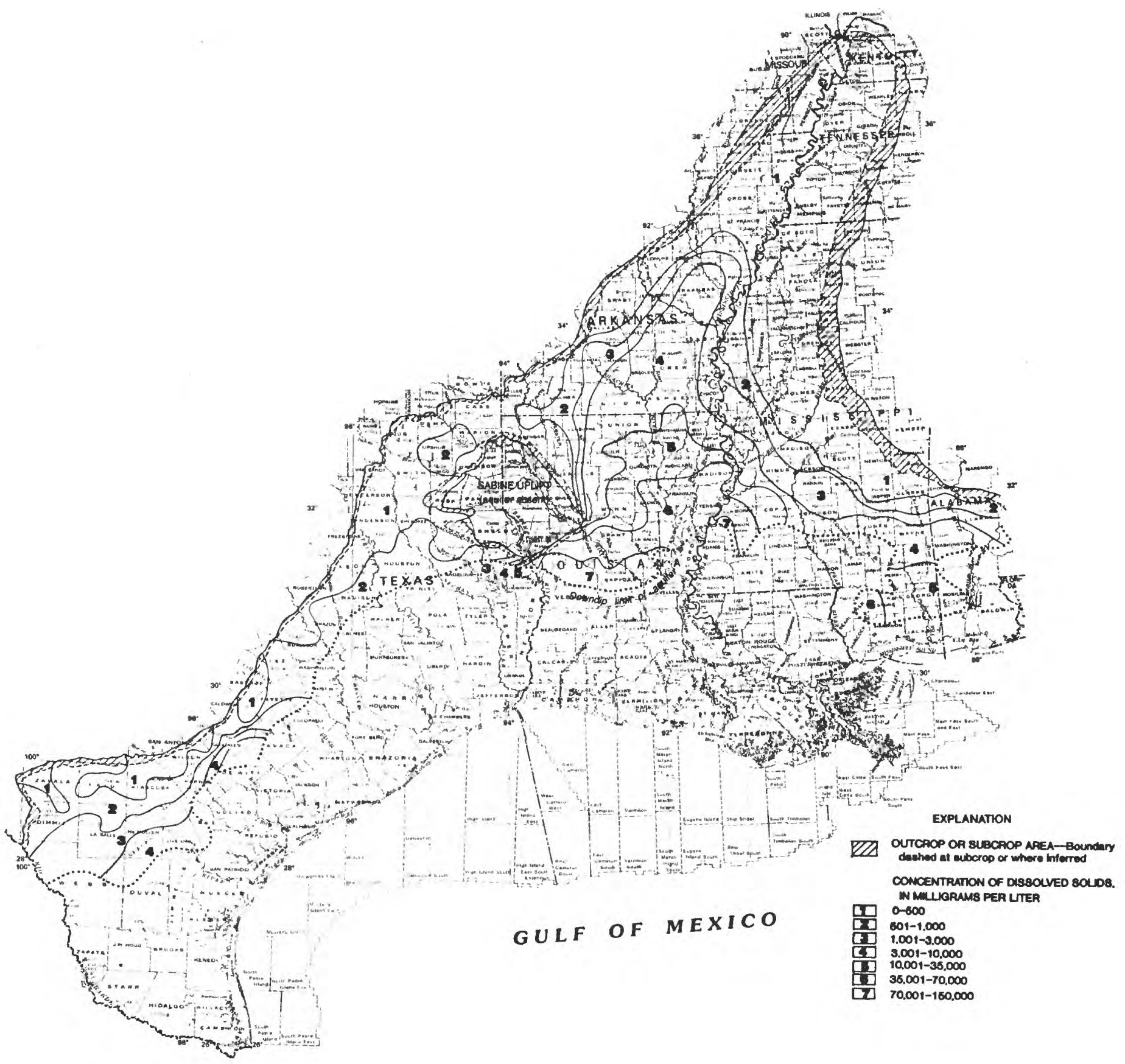

Modflied from Pettljohn and others, 1088 
are adjacent and downdip from the less than $500 \mathrm{mg} / \mathrm{L}$ delimited area. The delimited areas are separated into two parts by the Sabine uplift. Only a small part of the delimited areas extend updip to the outcrop in southern Texas. The delimited areas of the aquifer having median dissolved-solids concentrations ranging from 1,000 to $10,000 \mathrm{mg} / \mathrm{L}$ are in southern Texas, southeastern Arkansas, northeastern Louisiana, southern Mississippi and southwestern Alabama. Except for the area in Arkansas, the increase in median dissolved-solids concentrations from 1,000 to $10,000 \mathrm{mg} / \mathrm{L}$ occurs over a relatively short distance in the downdip direction. The delimited area of the aquifer having dissolvedsolids concentrations greater than $10,000 \mathrm{mg} / \mathrm{L}$ primarily is in northern Louisiana. There are small areas having dissolved-solids concentrations greater than $10,000 \mathrm{mg} / \mathrm{L}$ in southern Mississippi, southwestern Alabama, and southcentral Texas.

\section{PRIMARY WATER TYPES}

The primary water type is calcium bicarbonate in Arkansas, Missouri, and Tennessee (fig. 42). The primary water type is sodium bicarbonate in Louisiana, Mississippi, and northeastern Texas. Elsewhere in Texas the primary water type is a mixture of calcium, sodium, and bicarbonate ions in areas having median dissolved-solids concentrations less than $1,000 \mathrm{mg} / \mathrm{L}$ and sodium bicarbonate in areas having median dissolved-solids concentrations ranging from 1,000 to $10,000 \mathrm{mg} / \mathrm{L}$. A small amount of data indicates that the primary water type generally is sodium chloride in areas having dissolved-solids concentrations greater then $10,000 \mathrm{mg} / \mathrm{L}$.

\section{GROUND-WATER CHEMISTRY WITHIN SUBAREAS}

The lower Claiborne-upper Wilcox aquifer was divided into three chemically distinct subareas and the boundaries adjusted using discriminant function analyses of the chemical data from the subareas. Subarea 1 (fig. 43) extends from southeastern Missouri and adjacent parts of western Kentucky southwestward through western Tennessee. From central Mississippi the subarea extends to the southeast into southwestern Alabama. The remainder of subarea 1 consists of smaller isolated areas in and near the aquifer area of outcrop in Arkansas, Texas, and Louisiana. Subarea 1 includes nearly all the outcrop area in Kentucky, Tennessee, and Mississippi. Subarea 2 is mostly adjacent to and downdip from subarea 1 in Texas, Louisiana, Arkansas, and Mississippi. Subarea 2 extends to the updip limit of the aquifer at several locations. A few isolated 100-square-mile areas that are a part of subarea 2 are surrounded by subarea 1. The main part of subarea 3 consists of two areas formed by contiguous 100-square-mile areas in and near the aquifer outcrop in the central part of the study area in Texas. The remainder of subarea 3 consists of 14 isolated 100-square-mile areas scattered through Texas, Arkansas, Tennessee, and Mississippi. Nine of the 100-square-mile areas are in or near the outcrop and five are near middip.

The median value for selected constituents and the primary and secondary water types for each subarea of the lower Claiborne-upper Wilcox aquifer is shown in table 20. Sodium, bicarbonate, and chloride ions increased in concentration in the ground water from subarea 1 to subarea 2, whereas sodium and bicarbonate ions decreased in concentration from subarea 2 to subarea 3. The concentrations of calcium, magnesium, and sulfate are much higher in subarea 3 than in either subarea 1 or subarea 2 . The primary water type is calcium bicarbonate in subarea 1 , sodium bicarbonate in subarea 2 , and sodium chloride in subarea 3.

The trilinear diagram (fig. 44), based on three representative samples from each subarea, in conjunction with figure 42, shows that water in the lower Claiborne-upper Wilcox aquifer is calcium or magnesium bicarbonate in subarea 1, sodium bicarbonate in subarea 2, and a mixture of calcium, magnesium, sodium, bicarbonate, sulfate, and chloride ions in subarea 3. The trilinear diagram also shows that the major cations concentration in water from this aquifer is approximately 58 percent magnesium plus calcium ( 42 percent sodium plus potassium) in subarea 1 and about 4 percent magnesium plus calcium ( 96 percent sodium plus potassium) in subarea 2. The major anions concentration is approximately 77 percent bicarbonate plus carbonate ( 23 percent chloride plus sulfate) in subarea 1 and about 78 percent bicarbonate plus carbonate ( 22 percent chloride plus sulfate) in subarea 2 . In subarea 3 the magnesium plus calcium concentration is about 62 percent ( 38 percent sodium plus sulfate), and bicarbonate plus carbonate is about 42 percent ( 58 percent chloride plus sulfate). Dissolved-solids concentrations increased by a factor of about 3 from subarea 1 to subarea 2 and by a factor of about 0.7 from subarea 2 to subarea 3 (table 20). 


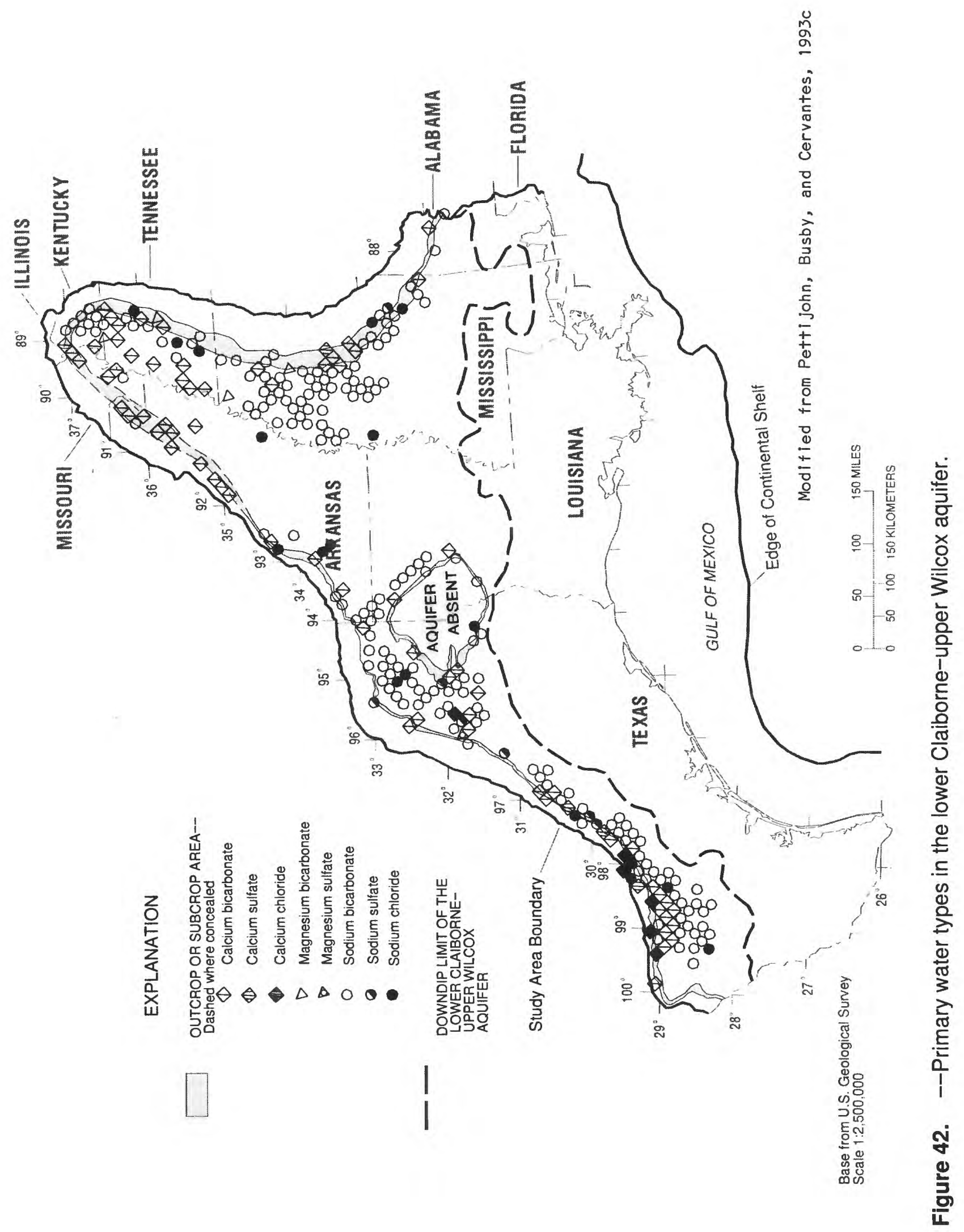




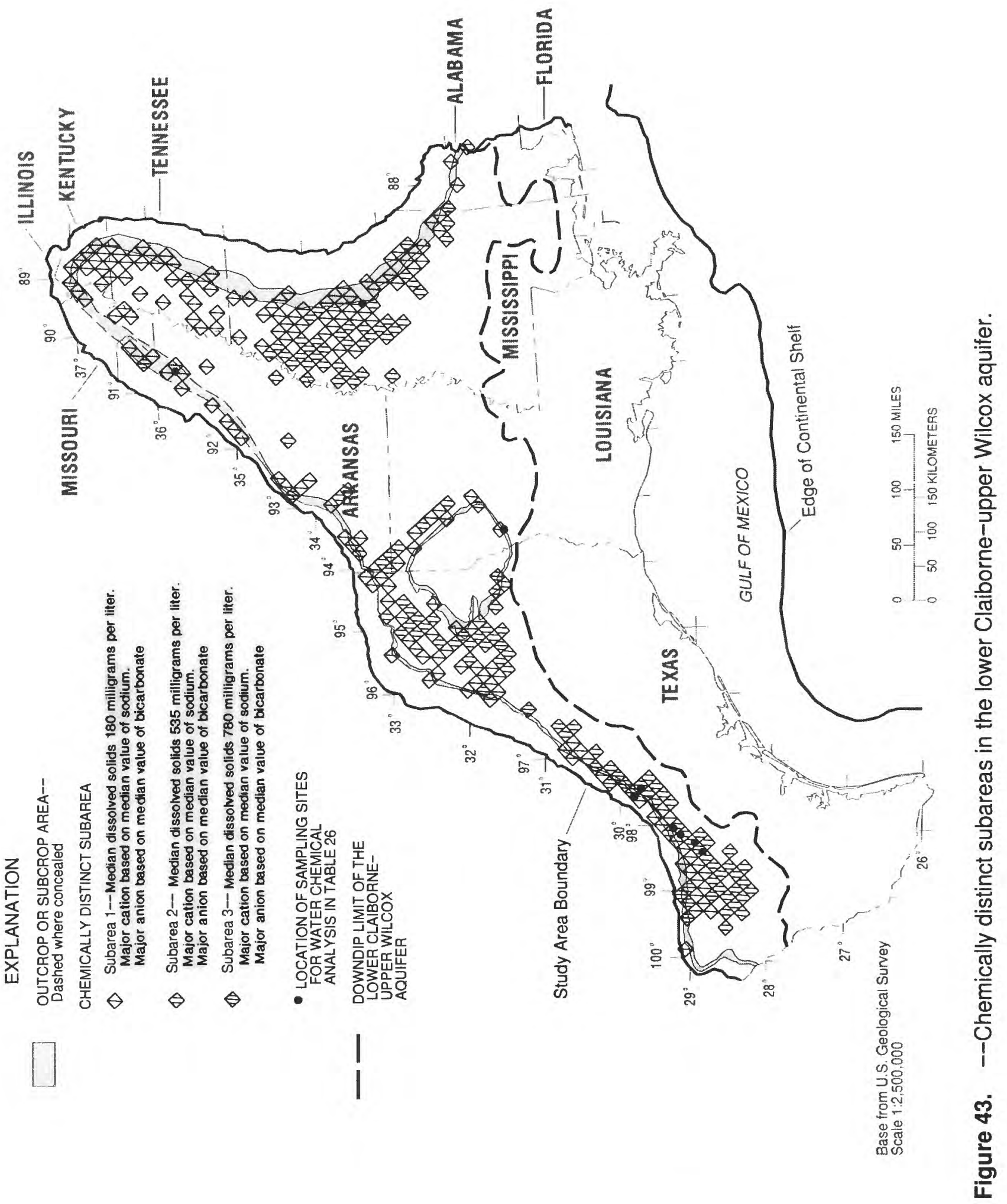




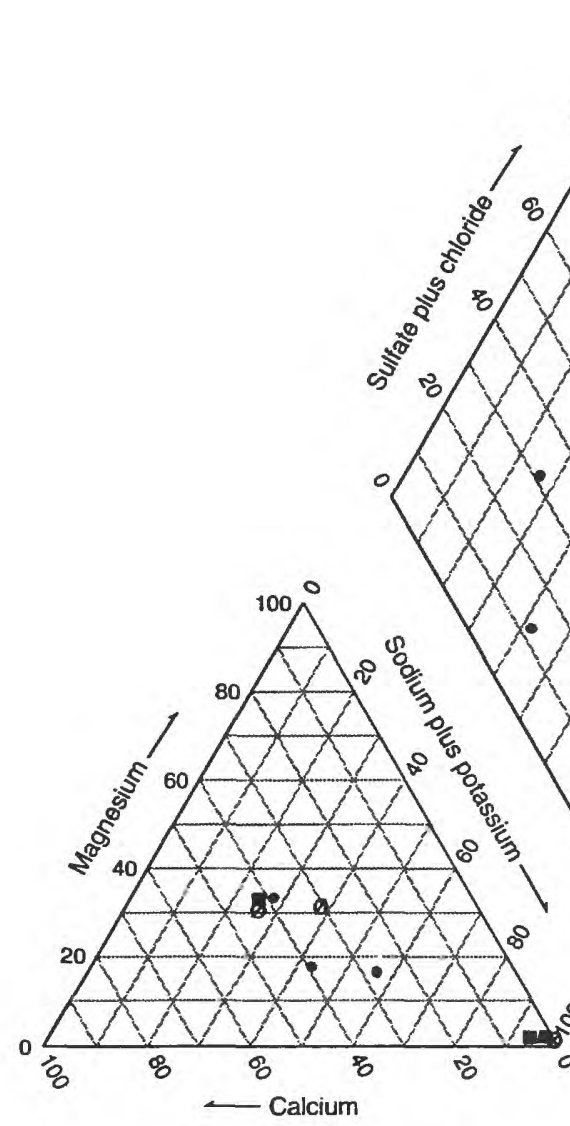

CATIONS
EXPLANATION

- Subarea 1

- Subarea 2

- Subarea 3

PERCENTAGE REACTING VALUES

Figure 44.--Change in water chemistry from subarea to subarea in the lower Claiborne-upper Wilcox aquifer, based on three representative samples.

\section{CORRELATION AMONG CHEMICAL CONSTITUENTS AND PROPERTIES OF GROUND WATER WITHIN SUBAREAS}

The correlation among chemical constituents and properties of water from the lower Claiborne-upper Wilcox aquifer was evaluated by factor analysis, which indicates that at least two major chemical processes or mechanisms are responsible for most of the variability in the concentration of chemical constituents in subareas 1 and 2 and three in subarea 3 (table 21). Thirteen constituents or properties were used in the factor analysis. The number of chemical analyses were 582 for subarea 1,270 for subarea 2, and 103 for subarea 3 (table 20). The variability accounted for by the factors range from 72.7 percent in subarea 2 to 78.9 percent in subarea 3 . The loading of each constituent or property on each factor and the percent of total variability (communality) accounted for in the factor analysis are shown in table 21.

Factor I of subarea 1 represents processes in which calcium, magnesium, potassium, sulfate, and chloride ions are added to the ground water. Factor II of subarea 1 represents a process in which sodium and bicarbonate ions are added to the ground water and hydrogen ions are removed. The variability in concentration of chemical constituents and properties of water accounted for by factor I is about 65 percent and by factor II is about 10 percent. The variability in concentration of dissolved solids accounted for by factor I is 63 percent and significant, and for factor II it is 75 percent and also significant. 
TABLE 21.--Factor loading and percent communalities for water chemistry in each subarea of the lower Claiborne-upper Wilcox aquifer

[Bold type indicates significant factor value]

\begin{tabular}{|c|c|c|c|c|c|c|c|c|c|c|}
\hline \multirow{2}{*}{$\begin{array}{c}\text { Constituent or } \\
\text { property }\end{array}$} & \multicolumn{3}{|c|}{ Subarea 1} & \multicolumn{3}{|c|}{ Subarea 2} & \multicolumn{4}{|c|}{ Subarea 3} \\
\hline & $\begin{array}{c}\text { Factor } \\
\text { I }\end{array}$ & $\begin{array}{c}\text { Factor } \\
\text { II }\end{array}$ & $\begin{array}{c}\text { Percent } \\
\text { commu- } \\
\text { nality }\end{array}$ & $\begin{array}{c}\text { Factor } \\
\text { I }\end{array}$ & $\begin{array}{c}\text { Factor } \\
\text { II }\end{array}$ & $\begin{array}{l}\text { Percent } \\
\text { commu- } \\
\text { nality }\end{array}$ & $\begin{array}{c}\text { Factor } \\
\text { I }\end{array}$ & $\begin{array}{c}\text { Factor } \\
\text { II }\end{array}$ & $\begin{array}{c}\text { Factor } \\
\text { III }\end{array}$ & $\begin{array}{c}\text { Percent } \\
\text { commu- } \\
\text { nality }\end{array}$ \\
\hline Dissolved solids. & 0.63 & 0.75 & 95.9 & 0.92 & 0.35 & 96.9 & 0.93 & 0.28 & 0.15 & 96.6 \\
\hline Calcium & .77 & .46 & 80.4 & -.01 & .91 & 82.8 & .92 & -.02 & -.05 & 84.9 \\
\hline Magnesium & .65 & 40 & 58.2 & .19 & .85 & 72.2 & .81 & .02 & .02 & 65.7 \\
\hline Potassium & .67 & .31 & 54.5 & .13 & .67 & 46.6 & .26 & .54 & -.16 & 38.5 \\
\hline Sodium & .30 & .66 & 52.6 & .95 & .13 & 91.9 & .60 & .34 & .26 & 54.3 \\
\hline Chloride & .80 & .19 & 67.6 & .58 & 49 & 57.6 & .79 & .23 & -.01 & 67.7 \\
\hline Sulfate & .79 & .35 & 74.7 & .01 & .35 & 12.3 & .63 & .53 & .10 & 68.8 \\
\hline Bicarbonate & .29 & .89 & 87.6 & .83 & .03 & 69.0 & .71 & .01 & .56 & 81.8 \\
\hline Iron & -.03 & .01 & 1 & 08 & -.06 & 1.0 & -.22 & -.33 & -14 & 17.7 \\
\hline Manganese & .14 & .22 & 6.8 & .19 & .85 & 75.9 & -.01 & .23 & .01 & 5.3 \\
\hline Silica & .11 & .04 & 1.4 & .02 & 12 & 1.5 & .11 & -.12 & -.50 & 27.6 \\
\hline $\mathrm{pH}$ & .11 & .78 & 62.0 & .43 & -.45 & 38.7 & .39 & .02 & .75 & 71.5 \\
\hline Sampling depth. & .32 & 49 & 34.2 & 40 & -.03 & 16.1 & .02 & .67 & .31 & 54.5 \\
\hline $\begin{array}{l}\text { Percent variability } \\
\text { accounted for by } \\
\text { the respective } \\
\text { number of factors }\end{array}$ & \multicolumn{3}{|c|}{$65.3+10.4=75.7$} & \multicolumn{3}{|c|}{$42.9+29.8=72.7$} & \multicolumn{4}{|c|}{$56.0+12.5+10.4=78.9$} \\
\hline
\end{tabular}

Factor I of subarea 2 represents a process in which sodium, bicarbonate, and chloride ions are added to the ground water. Factor II of subarea 2 represents a process in which calcium, magnesium, manganese, and potassium ions are added to the ground water. The variability in concentration of chemical constituents and properties of water accounted for by factor I is about 43 percent and by factor II is about 30 percent. The variability in concentration of dissolved solids accounted for by factor I is 92 percent and significant, whereas for factor II it is 35 percent and nonsignificant.

Factor I of subarea 3 represents a process in which calcium, magnesium, sodium, bicarbonate, sulfate, and chloride ions are added to the ground water. Factor II of subarea 3 represents a process in which potassium and sulfate ions are added to the ground water as depth increases. Factor III of subarea 3 represents a process in which hydrogen and bicarbonate ions are added to the ground water and silica is removed. The variability in concentration of chemical constituents and properties of water accounted for by factor I is about 56 percent, by factor II is about 12 percent, and by factor III is about 10 percent. The variability in concentration of dissolved solids accounted for by factor I is 93 percent and significant, whereas for factor II it is 28 percent and nonsignificant, and for factor III it is 15 percent and nonsignificant.

\section{RELATION OF GROUND-WATER CHEMISTRY TO CHEMICAL AND PHYSICAL PROCESSES}

The major chemical processes and mechanisms postulated for each of the chemically distinct subareas of the lower Claiborne-upper Wilcox aquifer are based on the results of factor analysis in conjunction with constituent concentrations, a trilinear diagram, ground-water movement, and information on water-rock interaction and probable minerals in the deposits. The major processes postulated in subarea 1 are (1) leaching of soluble salts from the unsaturated zone (factor I), (2) dissolution of gypsum (factor I), and (3) alteration of plagioclase (factor II). The 
postulated leaching of soluble salts from the unsaturated zone (factor I) and dissolution of gypsum (factor I) account for about 55 percent more of the variability in concentration of chemical constituents than does the alteration of plagioclase (factor II). The loading of dissolved solids is significant on both factor 1 and factor II. However, the loading on factor II is 12 percent more than it is on factor I, thus indicating that the leaching of soluble salts and dissolution of gypsum accounts for most of the variability in the concentration of chemical constituents, but the alteration of plagioclase contributes slightly more to the variation in concentration of dissolved solids in subarea 1 .

Hydrologic, geologic, and related information that supports the three processes postulated above for chemically distinct subarea 1 are discussed briefly in the context of the water chemistry and results of factor analysis of the chemical data. Leaching of soluble salts from the unsaturated zone (eq. 15) is supported by (1) the concentrations of major ions, except sodium and bicarbonate, that are only slightly larger than concentrations observed in precipitation; (2) the significant positive loading of calcium, magnesium, potassium, chloride, and sulfate on factor I; and (3) the fact that most of the aquifer outcrop area was assigned to subarea I, thus providing ample opportunity for precipitation to move soluble salts from the soil zone to the aquifer. The source of the salts is the reaction of carbon dioxide and oxygen-rich water with organic matter and mineral constituents. Thus the concentrations observed in this subarea for magnesium, potassium, chloride, and most of the calcium ions are most likely the result of leaching of dissolved ions from the unsaturated zone (table 20). Although leaching could account for the concentration of sulfate ions, it is more likely that the sulfate ions came from the dissolution of gypsum (eq. 6), which occurs as rock fragments or cementing material in the aquifer matrix.

The alteration of plagioclase (eq. 2) is supported by (1) the reported presence of plagioclase in the aquifer matrix (Plummer, 1932); (2) the significant loading of sodium, bicarbonate, and $\mathrm{pH}$ on factor II (table 21); and (3) the predominance of sodium, calcium, and bicarbonate ions in the ground water (table 20). The near significant loading of calcium on factor II is also an indication that the silicate feldspar being altered is plagioclase. Alteration occurs when carbon dioxide-charged water moving through soil and aquifer material comes in contact with albite and calcite and begins to alter or dissolve them under the influence of carbonic acid. The carbonic acid is consumed in the mineral-water reaction, and the products are a clay mineral and ions of bicarbonate, sodium, and calcium.

Although vertical leakage (eq. 16) was not postulated, vertical leakage downward from the overlying middle Claiborne aquifer was simulated (Williamson, in press) in three areas that are in part coincident with subarea 1 of the lower Claiborne-upper Wilcox aquifer and this leakage could contribute to the water chemistry observed in subarea 1. The three areas are in northeastern Texas, northwestern Louisiana, and southeastern Mississippi (fig. 35). Vertical leakage is also downward from the lower Claiborne-upper Wilcox aquifer to the underlying middle Wilcox aquifer in most of subarea 1 in Texas, Louisiana, Mississippi, Tennessee, and Kentucky (fig. 40).

The major processes postulated in subarea 2 are (1) alteration of albite (factor I), (2) upward leakage from underlying deposits (factor I), and (3) leaching of soluble salts from the unsaturated zone (factor II). The postulated alteration of albite (factor I) and upward leakage (factor I) accounts for about 13 percent more of the variability in concentration of chemical constituents than does leaching (factor II) and subsequent cation adsorption (factor II). The loading of dissolved solids on factor I is very high and significant and its loading on factor II is nonsignificant, thus indicating that the alteration of albite and upward leakage accounts for most of the variation in concentration of dissolved solids in subarea 2.

Hydrologic, geologic, and related information that supports the three processes postulated above for chemically distinct subarea 2 are discussed briefly in the context of the water chemistry and results of factor analysis of the chemical data. Alteration of albite (eq. 1) is supported by (1) the very large predominance of sodium and bicarbonate ions in ground water of this subarea (table 20), (2) the reported presence of plagioclase feldspar in the aquifer matrix (Plummer, 1932), and (3) the significant positive loading of sodium and bicarbonate on factor I (table 21). The larger concentrations of sodium and bicarbonate ions in water of subarea 2 than of subarea 1 is attributed to enhanced alteration of albite due to the longer residence time for water moving from the outcrop to downdip subarea 2 than from outcrop to the saturated zone of subarea 1 .

Upward leakage (eq. 16) is supported by (1) simulated vertical leakage that is shown to be upward (fig. 40,) (2) the larger concentration of dissolved solids in the underlying aquifer, and (3) the significant positive loading of sodium 
and chloride on factor I (table 21). The much larger concentration of sodium relative to chloride is indicative of a process such as albite alteration, a coprocess with upward leakage of water having larger concentrations of dissolved solids. Leaching of soluble salts from the unsaturated zone (eq. 15) is supported by (1) the subarea lies along the updip limit and contains outcrop (fig. 41), (2) rainfall is ample for leaching processes, and (3) the significant positive loading of calcium, magnesium, and potassium on factor II. However, the concentrations of calcium, magnesium, potassium, and manganese ions are in the range of rainwater, which might indicate that some of the cations leached from the unsaturated zone were absorbed on clays. The adsorption of cations on the surface of clay minerals is highly probable because of an abundance of clay minerals in the marine sediments, the $\mathrm{pH}$ is high, indicating negatively charged surfaces, and only cations appear to be involved in the process. In addition, the concentrations of calcium, magnesium, manganese, and potassium, the cations that load significantly on factor II, are less than those of subarea 1, indicating that these cations are being removed from water where it moves downdip in the aquifer.

No major processes are postulated in subarea 3 because the widely scattered locations that make up this subarea (fig. 43) do not present a regional picture of the water chemistry. However, factor analysis (table 21) indicates that several processes are probable, but the areal coverage is inadequate to develop a coherent interpretation.

\section{MIDDLE WILCOX AQUIFER}

The middle Wilcox aquifer underlies the northern three-fourths of the study area (fig. 45). It has an areal extent of about $170,000 \mathrm{mi}^{2}$ and a mean thickness of $1,250 \mathrm{ft}$ (Williamson and others, 1990). Median depth of water samples collected for chemical analyses ranges from $111 \mathrm{ft}$ in middip areas to $8,010 \mathrm{ft}$ in downdip areas (table 22). The aquifer outcrop area extends from the Rio Grande in Texas eastward along or near the northern and eastern border of the study area to southwestern Alabama. Aquifer outcrop areas range in width from about $1 \mathrm{mi}$ to about $25 \mathrm{mi}$. The downdip limit of the aquifer extends across the study area about 30 to $70 \mathrm{mi}$ inland from the shoreline. The geometric mean hydraulic conductivity of the aquifer is about $20 \mathrm{ft} / \mathrm{d}$ (table 3 ).

The simulated horizontal direction of predevelopment ground-water flow and vertical leakage relative to the base of the middle Wilcox aquifer is shown in figure 45 (Williamson, in press). Regionally, the horizontal flow east of the Mississippi River generally is from the outcrop area westward toward and beyond the Mississippi River and southeastward toward the Tombigbee River. West of the Mississippi River in Arkansas the flow is generally toward discharge areas along the Ouachita, White, and Saint Francis Rivers and toward a regional discharge area in northern Louisiana. In Louisiana the flow is toward regional discharge areas in the northeastern and northwestern parts of the State. In Texas the ground-water flow is southward to about middip where it diverges in a large regional pattern northeastward across Texas to Louisiana and southward to the Rio Grande. Updip many flow lines diverge to discharge areas along major stream valleys. Downward leakage to the middle Wilcox aquifer from the overlying lower Claiborne-upper Wilcox aquifer was simulated in areas adjacent and downdip of the middle Wilcox outcrop area in southern, south-central and northeastern Texas (fig. 45). Vertical leakage downward to the middle Wilcox aquifer was simulated throughout a large area of northwestern Louisiana and adjacent part of southwestern Arkansas. The downward leakage areas are generally associated with topographic highs. Several of the downward leakage areas extend for considerable distance downdip of the outcrop areas. The most noticeable of these areas are in central Mississippi, on the border of Tennessee and Mississippi, and in eastern and central Texas. Upward leakage to the middle Wilcox aquifer from the lower Wilcox aquifer was simulated throughout most of southeastern Missouri, eastern Arkansas, northeastern Louisiana, west-central Mississippi, and southeastern Mississippi and adjacent parts of Alabama (fig. 45). The lower Wilcox aquifer is absent in Texas, and the middle Wilcox is underlain by the Midway confining unit, which is assumed to be impermeable.

\section{DISSOLVED-SOLIDS CONCENTRATIONS}

The areal distribution of the median concentration of dissolved-solids per 100-square-mile area in water from the middle Wilcox aquifer is shown in figure 46. The delimited area of the aquifer having median dissolved-solids concentrations of less then $500 \mathrm{mg} / \mathrm{L}$ extends from southern Texas northeastward into Arkansas, southeastern Missouri, and western Kentucky. From western Kentucky the area extends through western Tennessee, much of 
northern Mississippi into east-central Mississippi and adjacent Alabama. The delimited area is discontinuous in Texas where the 500 to $1,000 \mathrm{mg} / \mathrm{L}$ delimited area extends to the updip limit of the aquifer. Most of the aquifer outcrop area is included in the delimited area having median dissolved-solids concentration of less than $500 \mathrm{mg} / \mathrm{L}$.

TABLE 22.--Median value of selected chemical constituents and properties of water, median sampling depth, water types, and number of analyses for each subarea of the middle Wilcox aquifer

[Concentrations are in milligrams per liter, except iron and manganese, which are in micrograms per liter. Depth is in feet, $\mathrm{pH}$ is in units, and temperature is in degrees Celsius. Chemical symbols: $\mathrm{Ca}$, calcium; $\mathrm{Mg}$, magnesium; $\mathrm{Na}$, sodium; $\mathrm{K}$, potassium; Fe, iron; Mn, manganese; $\mathrm{HCO}_{3}$, bicarbonate; $\mathrm{SO}_{4}$, sulfate; $\mathrm{Cl}$, chloride; $\mathrm{SiO}_{2}$, silica. Water type shown is the most frequently occurring]

\begin{tabular}{|c|c|c|c|c|c|}
\hline \multirow{2}{*}{ Constituent or property } & \multicolumn{5}{|c|}{ Subarea } \\
\hline & 1 & 2 & 3 & 4 & 5 \\
\hline $\mathrm{Ca}$ & 17 & 8.0 & 140 & 140 & 1.500 \\
\hline $\mathrm{Mg}$ & 4.0 & 4.6 & 48 & 40 & 340 \\
\hline $\mathrm{Na}$ & 42 & 170 & 240 & 6.800 & 21,600 \\
\hline K & 2.8 & 2.3 & 6.0 & 39 & 150 \\
\hline $\mathrm{Fe}$ & 110 & 260 & 4,800 & 1,400 & 1,100 \\
\hline $\mathrm{Mn}$ & 30 & 66 & 710 & 60 & 200 \\
\hline $\mathrm{HCO}_{3}$ & 190 & 390 & 260 & 1,200 & 410 \\
\hline $\mathrm{SO}_{4}$ & 21 & 50 & 260 & 40 & 21 \\
\hline $\mathrm{Cl}$ & 18 & 88 & 470 & 11.300 & 36,700 \\
\hline $\mathrm{SiO}_{2}$ & 17 & 19 & 20 & 19 & 21 \\
\hline Dissolved solids & 268 & 690 & 1,500 & 21,800 & 60,500 \\
\hline Sampling depth & 420 & 380 & 111 & 7,670 & 8.010 \\
\hline $\mathrm{pH}$ & 7.5 & 7.9 & 7.3 & 7.4 & 6.9 \\
\hline Temperature & 21.0 & 21.5 & 21.0 & 23.0 & 28.2 \\
\hline Primary water type & $\mathrm{NaHCO}_{3}$ & $\mathrm{NaHCO}_{3}$ & $\mathrm{NaCl}$ & $\mathrm{NaCl}$ & $\mathrm{NaCl}$ \\
\hline Secondary water type & $\mathrm{CaSO}_{4}$ & $\mathrm{CaCl}$ & $\mathrm{CaSO}_{4}$ & $\mathrm{CaHCO}_{3}$ & $\mathrm{CaHCO}_{3}$ \\
\hline Number of analyses & 1,252 & 838 & 123 & 47 & 74 \\
\hline
\end{tabular}

The delimited area of the aquifer having median dissolved-solids concentrations ranging from 500 to $1,000 \mathrm{mg} /$ $\mathrm{L}$ extends northeastward from southern Texas into northwestern Louisiana. From northwestern Louisiana the delimited area extends to the northeast into east-central Arkansas, and from east-central Arkansas it extends to the southeast across Mississippi into southwestern Alabama (fig. 46). This delimited area coincides with aquifer outcrop at locations in Texas, Louisiana, Arkansas, and Alabama. Directly downdip is a delimited area of the aquifer having median dissolved-solids concentrations ranging from 1,000 to $3,000 \mathrm{mg} / \mathrm{L}$. The area is a continuous, narrow band from southern Texas across Louisiana, Arkansas, and Mississippi to Alabama. Areas having dissolved-solids concentrations between 3,000 and 35,000 mg/L extend throughout Texas, Louisiana, Mississippi, and Alabama. The $3,000 \mathrm{mg} / \mathrm{L}$ line of equal median concentration extends into east-central Arkansas, but the $10,000 \mathrm{mg} / \mathrm{L}$ line is south of Arkansas. The increase in median dissolved-solids concentrations from 1,000 to $10,000 \mathrm{mg} / \mathrm{L}$ occurs over a short 


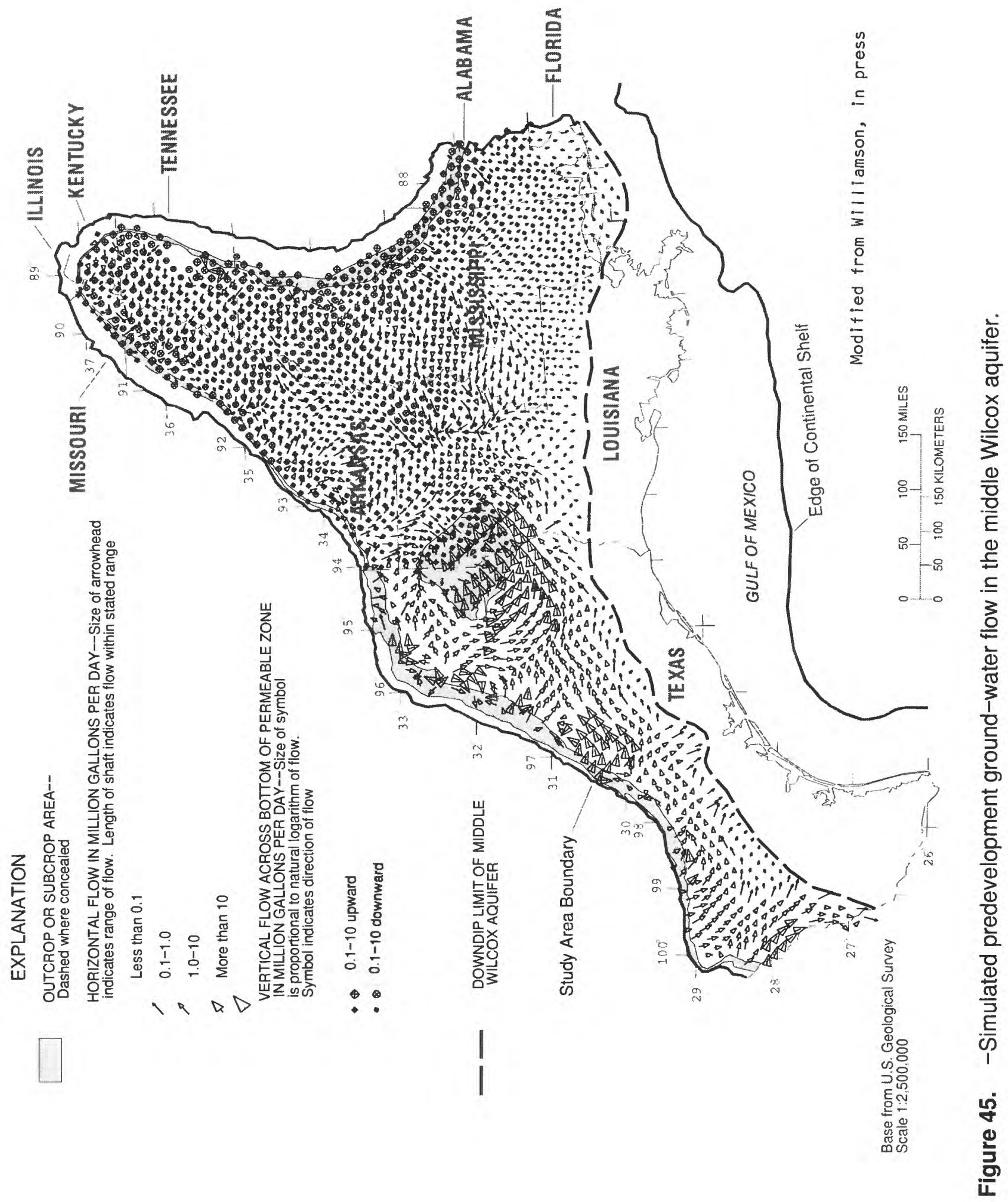




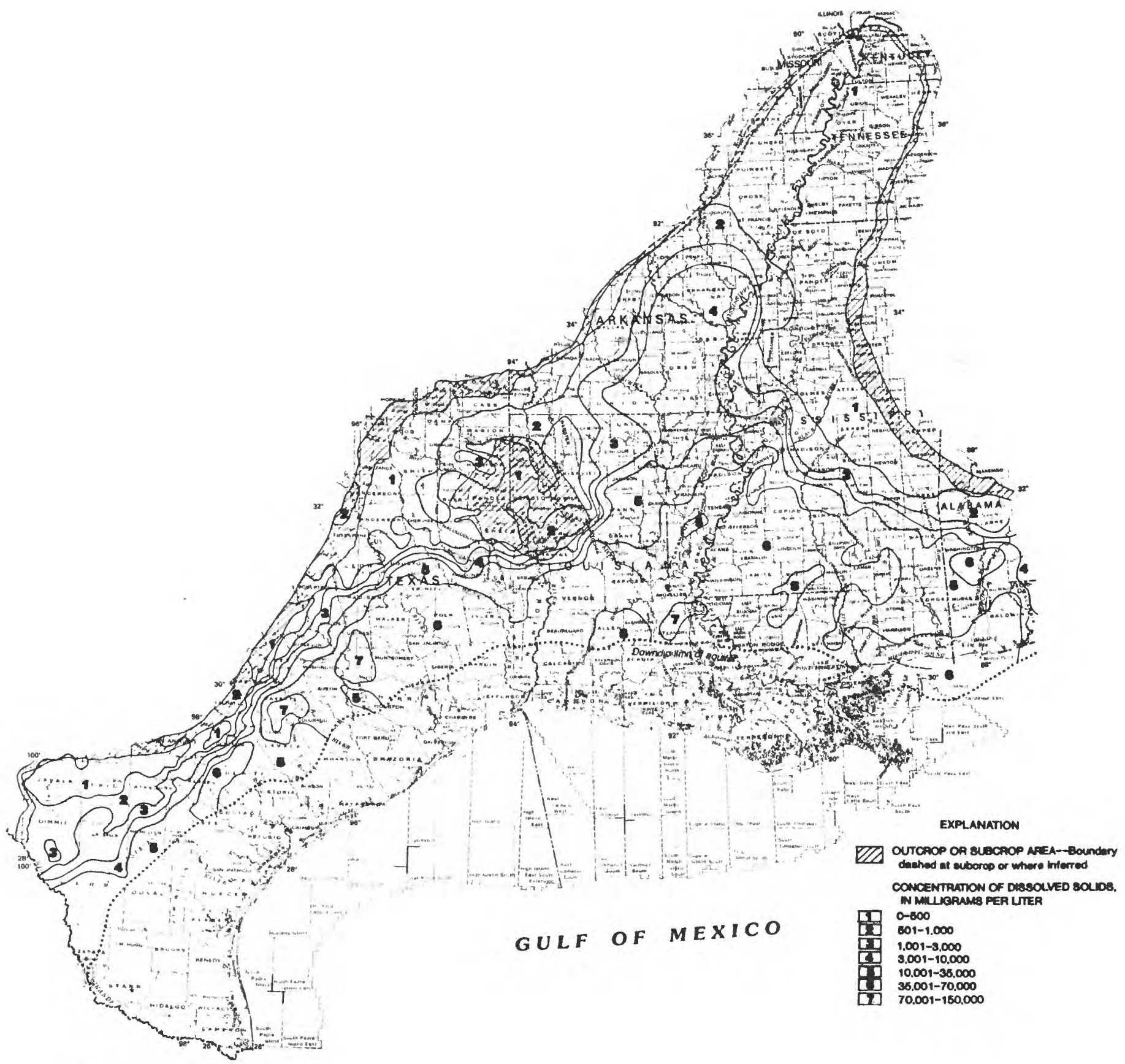

Moditied from Pettijohn and others, 1988 
distance in the downdip direction in most of the area underlain by the middle Wilcox aquifer. Delimited areas having concentrations of dissolved-solids greater than $35,000 \mathrm{mg} / \mathrm{L}$ extend to the downdip limit of the aquifer in much of Texas and most of Louisiana, Mississippi, and Alabama.

\section{PRIMARY WATER TYPES}

The primary water type is sodium bicarbonate in those areas where median dissolved-solids concentrations are less than $1,000 \mathrm{mg} / \mathrm{L}$ (fig. 47) except for outcrop areas in southern and south-central Texas where the primary water type is calcium bicarbonate. The primary water type is sodium chloride in areas where median dissolved-solids concentrations are greater then $1,000 \mathrm{mg} / \mathrm{L}$. The primary water type is sodium sulfate at several localized areas in northeastern Texas (fig. 47).

\section{GROUND-WATER CHEMISTRY WITHIN SUBAREAS}

The middle Wilcox aquifer was divided into five chemically distinct subareas and the boundaries adjusted using discriminant function analysis of the chemical data from the subareas. Subarea 1 (fig. 48) extends discontinuously from the Rio Grande in southern Texas to southwestern Arkansas. Others areas delineated as subarea 1 are in northwestern Louisiana, western Kentucky, western Tennessee, and eastern Mississippi. Subarea 1 includes nearly all the aquifer outcrop areas in Texas, Kentucky, Tennessee, and Mississippi.

Subarea 2 of the middle Wilcox aquifer is mostly adjacent to and downdip from subarea 1 except where it extends to the updip limit of the aquifer at a few locations in Texas and in northwestern Louisiana. The largest areas delineated as subarea 2 are in southwestern and northwestern Texas, northwestern Louisiana, and northwestern Mississippi. A few isolated 100-square-mile areas are also a part of subarea 2. Subarea 3 is made up of 3 pairs of adjacent 100 -squaremile areas plus 12 isolated 100-square-mile areas. All but five of the areas are in the outcrop. Most of the 100-squaremile areas are in Texas, and their number and distribution are inadequate to develop a contiguous regional subarea. Subarea 4 is made up of a $200-\mathrm{mi}^{2}$ area and a $300-\mathrm{mi}^{2}$ area in southeastern Texas and southeastern Mississippi, respectively, and 12 isolated 100-square-mile areas mostly near the downdip limit of the aquifer in Texas. Subarea 5 is made up of 6 areas that range in size from 200 to $400 \mathrm{mi}^{2}$ and 10 isolated 100 -square-mile areas. Nearly all the areas are near the downdip limit of the middle Wilcox aquifer in Texas.

The median value for selected constituents and the primary and secondary water types for each of the subareas is shown in table 22. Sodium, chloride, and dissolved solids increase progressively in concentration from subarea 1 to subarea 5. Sulfate, manganese, and iron concentrations increase progressively from subarea 1 to subarea 3 and then decrease progressively from subarea 3 to subarea 5 except manganese which decreases from subarea 3 to subarea 4 and then increases from subarea 4 to subarea 5 . The primary water type is sodium bicarbonate in subarea 1 and 2 and sodium chloride in subarea 3,4 , and 5 .

The trilinear diagram (fig. 49), based on three representative samples from each subarea, in conjunction with figure 47 indicates that water in the middle Wilcox aquifer is approximately 49 percent magnesium plus calcium (51 percent sodium plus potassium) in subarea 1 and 9 percent magnesium plus calcium (91 percent sodium plus potassium) in subarea 5 . The trilinear plot also shows that the major anions concentration is approximately 78 percent bicarbonate plus carbonate ( 22 percent chloride plus sulfate) in subarea 1 and less than 1 percent bicarbonate plus carbonate ( 99 percent chloride plus sulfate) in subarea 5. The predominant cation in all subareas is sodium, whereas the predominant anion is bicarbonate in subareas 1 and 2 and chloride in subareas 3,4, and 5 . The water types in the middle Wilcox aquifer as indicated by the diamond-shaped upper part of the trilinear diagram are magnesium-calcium bicarbonate in subarea 1 , sodium bicarbonate in subarea 2 , and sodium chloride in subarea 3,4 , and 5 .

The progressive increase in dissolved-solids concentrations is about a factor of 3 from subarea 1 to subarea 2, a factor of about 2 from subarea 2 to subarea 3 , a factor of about 14 from subarea 3 to subarea 4 , and a factor of about 3 from subarea 4 to subarea 5 (table 22). Thus dissolved-solids concentrations increase by a factor of about 225 from subarea 1 to subarea 5 . 


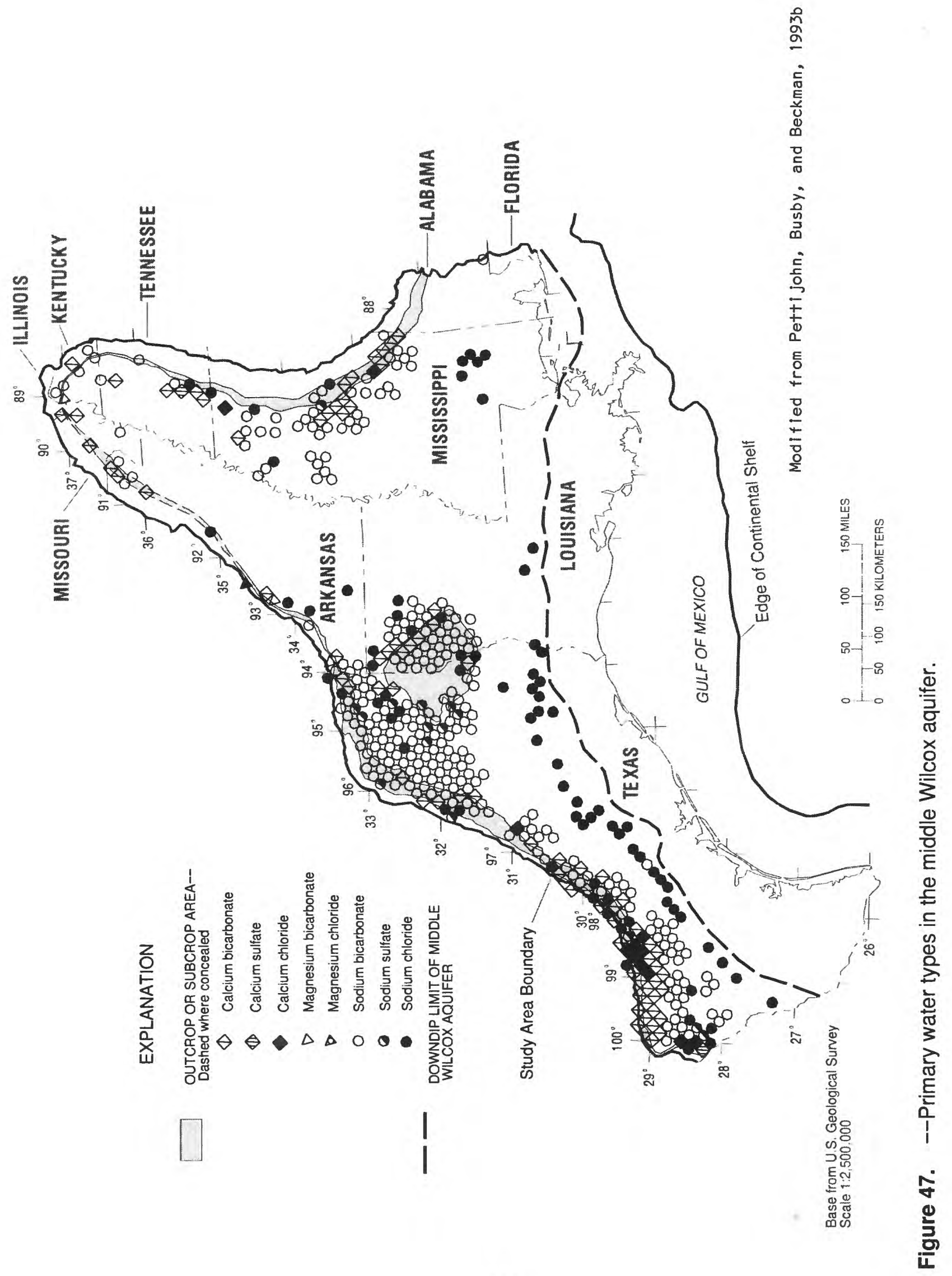




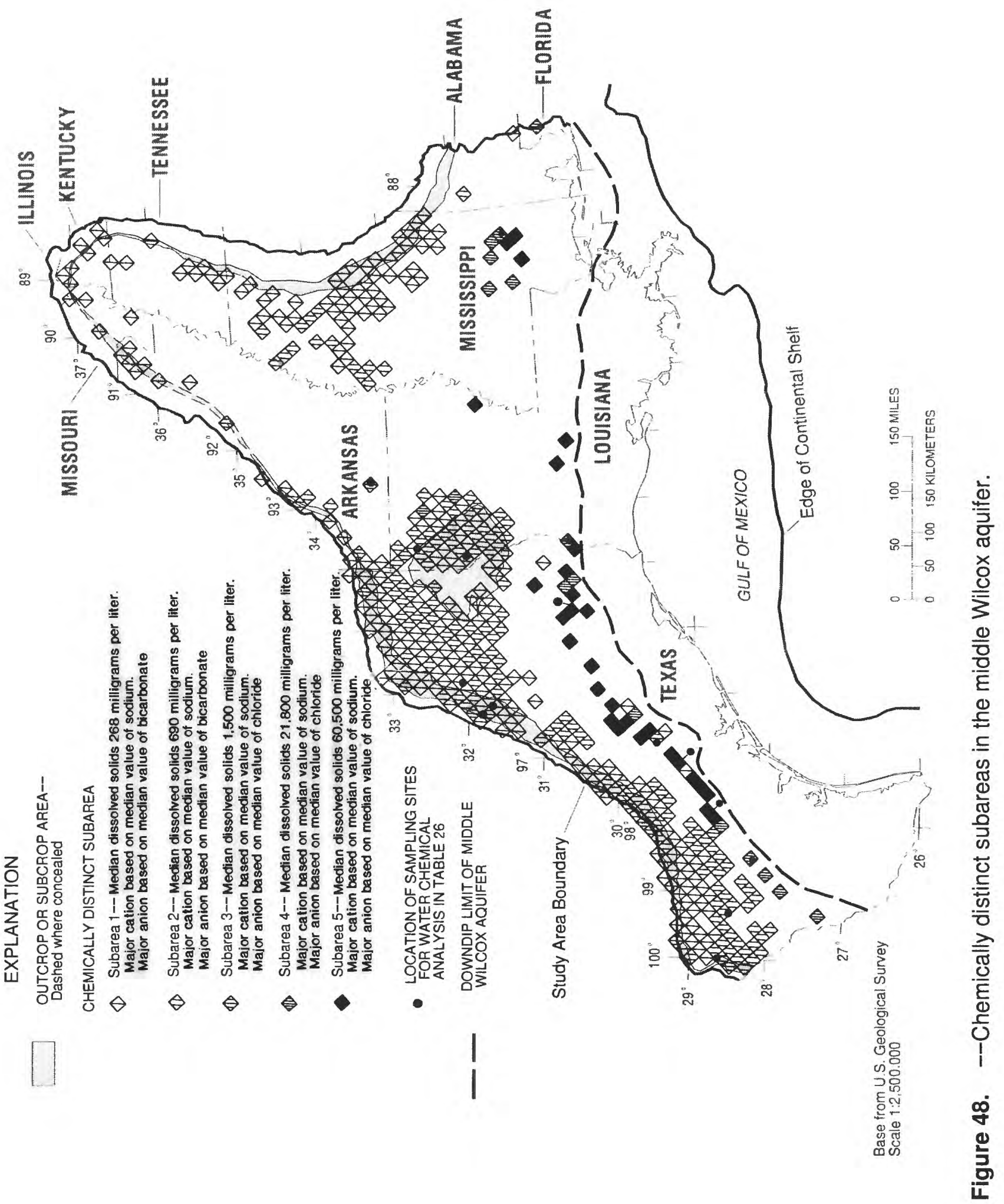




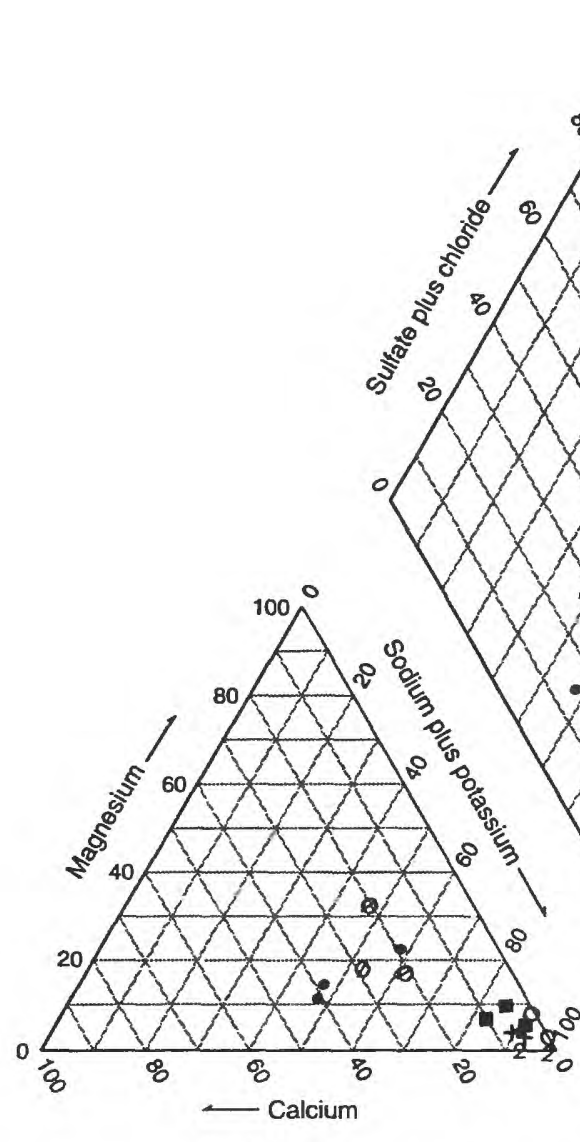

CATIONS
EXPLANATION

Subarea 1

- Subarea 2

- Subarea 3

- Subarea 4

+ Subarea 5

Numeral by symbol indicates number of points at that location

\section{PERCENTAGE REACTING VALUES}

Figure 49.--Change in water chemistry from subarea to subarea in the middle Wilcox aquifer, based on three representative samples.

\section{CORRELATION AMONG CHEMICAL CONSTITUENTS AND PROPERTIES OF GROUND WATER WITHIN SUBAREAS}

The correlation among chemical constituents and properties in water from the middle Wilcox aquifer was evaluated by factor analysis. The factor analysis indicates that at least two chemical processes or mechanisms are responsible for most of the variability in the concentrations of constituents in subareas 1,2 , and 3 (table 23), three processes in subarea 5, and six processes in subarea 4. A large number of extracted factors indicate that most of the representative processes are weak and that they have equal but small effect on the water chemistry. Thirteen constituents or properties were used in the factor analysis. The number of chemical analyses were 1,252 for subarea $1 ; 838$ for subarea $2 ; 123$ for subarea $3 ; 47$ for subarea 4 ; and 74 for subarea 5 (table 22). The variability accounted for by the factors ranges from 67.9 percent in subarea 3 to 94.1 percent in subarea 4 (table 23). The loading of each constituent or property on each factor and the percent of total variability (communality) accounted for in the factor analysis are shown in table 23.

Factor I of subarea 1 represents a process in which calcium, magnesium, potassium, sulfate, and chloride ions are added to the ground water. Factor II of subarea 1 represents a process in which sodium and bicarbonate ions are added to the ground water and hydrogen ions are removed. The variability in concentration of chemical constituents and properties of water accounted for by factor I is about 42 percent and by factor II is about 31 percent. The variability in concentration of dissolved solids accounted for by factor I is 52 percent and significant, whereas for factor II it is 78 percent and also significant. 


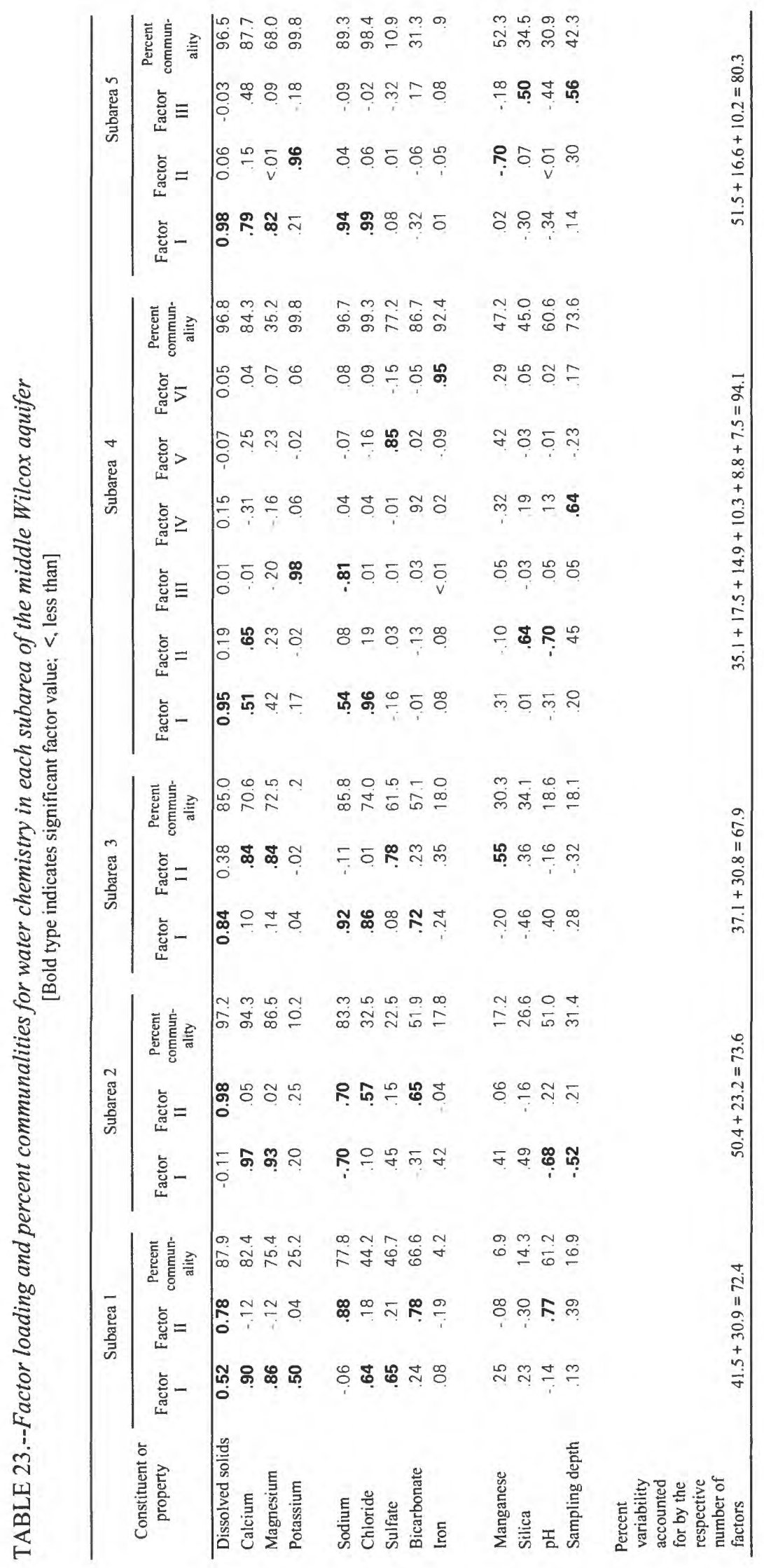


Factor I of subarea 2 represents a process in which calcium, magnesium, and hydrogen ions are added to the ground water and sodium ions are removed. Factor II of subarea 2 represents a process in which sodium, chloride, and bicarbonate ions are added to the ground water. The variability in concentration of chemical constituents and properties of water accounted for by factor I is about 50 percent and by factor II is about 23 percent. The variability in concentration of dissolved solids accounted for by factor I is a negative 11 percent and nonsignificant, whereas for factor II it is 98 percent and significant.

Factor I of subarea 3 represents a process in which sodium, chloride, and bicarbonate ions are added to the ground water. Factor II of subarea 3 represents a process in which calcium, magnesium, sulfate, and manganese ions are added to the ground water. The amount of variability in concentrations of constituents and properties of water accounted for by factor I is about 37 percent and by factor II is about 31 percent. The amount of variability in concentration of dissolved solids accounted for by factor I is 84 percent and significant, whereas for factor II it is 38 percent and nonsignificant.

Factor 1 of subarea 4 represents a process in which sodium, calcium, and chloride ions are added to the ground water. Factor II represents a process in which silica, calcium, and hydrogen ions are added to the ground water. Factor III represents a process in which potassium ions are added to the ground water and sodium ions are removed. Factor IV represents a process in which bicarbonate ions are added to the ground water, and the effect of the process on the water chemistry increases with depth. Factor $\mathrm{V}$ represents a process in which sulfate ions are added to the ground water. Factor VI represents a process in which ferric ions are added to the ground water. The variability in concentration of chemical constituents and properties of water accounted for by factor $I$ is about 35 percent, by factor II it is about 18 percent, by factor III it is about 15 percent, by factor IV it is about 10 percent, by factor $\mathrm{V}$ it is about 9 percent, and by factor VI it is about 8 percent. The variability in concentration of dissolved solids accounted for by factor I is 95 percent and significant, whereas for factors II through VI it ranges from 1 to 19 percent and all are nonsignificant.

Factor I of subarea 5 represents a process in which calcium, magnesium, sodium, and chloride ions are added to the ground water. Factor II represents a process in which potassium ions are added to the ground water and manganese ions are removed. Factor III represents a process that increases silica concentration with depth. The variability in concentrations of constituents and properties of water accounted for by factor I is about 52 percent, by factor II is about 17 percent, and by factor III is about 10 percent. The variability in concentration of dissolved solids accounted for by factor I is 98 percent and significant, whereas for factor II it is 6 percent and nonsignificant and for factor III it is a negative 3 percent and nonsignificant.

\section{RELATION OF GROUND-WATER CHEMISTRY TO CHEMICAL AND PHYSICAL PROCESSES}

The major chemical processes and mechanisms postulated for each of the chemically distinct subareas of the middle Wilcox aquifer are based on the results of factor analysis in conjunction with constituent concentrations, a trilinear diagram, ground-water movement, and information on water-rock interaction and probable minerals in the deposits. The major processes postulated in subarea 1 are (1) leaching of soluble salts from the unsaturated zone (factor I), (2) dissolution of gypsum (factor I), and (3) alteration of albite (factor II). The postulated leaching of soluble salts from the unsaturated zone (factor I) and dissolution of gypsum (factor I) account for about 11 percent more of the variability in concentration of chemical constituents than does the alteration of albite (factor II). However, the loading of dissolved solids on factor I is 26 percent less than on factor II, thus indicating that the alteration of albite accounts for the largest part of the variation in concentration of dissolved solids in subarea 1 of the middle Wilcox aquifer, although leaching and dissolution of gypsum are also significant.

Hydrologic, geologic, and related information that supports the three processes postulated above for chemically distinct subarea 1 are discussed briefly in the context of the water chemistry and results of factor analysis of the chemical data. Leaching of the unsaturated zone (eq. 15) is supported by (1) major-ion concentrations, except sodium and bicarbonate, that are only slightly larger than those observed in precipitation, (2) the significant positive loading of calcium, magnesium, potassium, chloride, and sulfate on factor I, and (3) the fact that most of the aquifer outcrop area was assigned to subarea 1 , thus providing ample opportunity for precipitation to move solutes from the soil zone 
to the aquifer.

Dissolution of gypsum (eq. 6) is supported by (1) the significant positive loading of sulfate on factor I (table 23), and (2) the presence of sand beds (Hosman and Weiss, 1991) that may contain traces of gypsum as cementing material. Gypsum, which is widespread in sedimentary rocks (Foster, 1949) and soluble in moving ground water, could dissolve to produce the concentrations of calcium and sulfate ions observed in the ground water of subarea 1 . The amount of gypsum dissolved would be limited by the amount of gypsum available and less by resident time.

Alteration of albite (eq. 1) is supported by (1) the availability of carbon dioxide from both the atmosphere and soil zone to form carbonic acid, (2) the reported presence of feldspar in the aquifer deposits (Plummer, 1932), and (3) the significant positive loading of sodium and bicarbonate on factor II. Feldspars such as albite may be present as dust particles or rock fragments in sedimentary rocks of coastal plain provinces (Plummer, 1932). Alteration of albite produces kaolinite, a secondary mineral, and releases sodium and bicarbonate ions into solution. Because the subarea is updip and a primary recharge area, the resident time of ground water in this part of the aquifer would be relatively short, resulting in low to moderate concentrations of sodium and bicarbonate ions from albite alteration. Also, as the ground water moves downdip the source of carbon dioxide will decrease and thus decrease the amount of albite alteration. Simulated vertical leakage is downward from the overlying lower Claiborne-upper Wilcox to the middle Wilcox aquifer throughout most of subarea 1 (fig. 40). Likewise most of the vertical leakage is downward from subarea 1 of the middle Wilcox aquifer to the lower Wilcox aquifer in Louisiana, Arkansas, Kentucky, Tennessee, and Mississippi (fig. 45).

The major processes postulated in subarea 2 are (1) cation exchange (factor I) and (2) alteration of albite (factor II). The postulated process of cation exchange (factor I) accounts for about 27 percent more of the variability in concentration of chemical constituents than does the alteration of albite (factor II). However, the loading of dissolved solids on factor I is low, negative, and nonsignificant, and on factor II it is very high and significant, thus indicating that the alteration of albite accounts for most of the variation in concentration of dissolved solids in subarea 2 of the middle Wilcox aquifer.

Hydrologic, geologic, and related information that supports the two processes postulated above for chemically distinct subarea 2 are discussed briefly in the context of the water chemistry and results of factor analysis of the chemical data. Cation exchange (eq. 3 ) is supported primarily by (1) the moderately high negative loading of sodium, and (2) the low negative loading of dissolved solids on factor I (table 23). Negative loading of sodium indicates that sodium ions are being removed from solution by exchange with calcium and magnesium ions on clay colloids. The low negative loading of dissolved solids indicates that the process caused little variation in concentration of dissolved solids. The significant negative loading of $\mathrm{pH}$ on factor I indicates that hydrogen ions on clay colloids were also exchanging with sodium. The negative loading of depth on this factor indicates that the exchange processes decrease with depth.

Alteration of albite (eq. 1), which is postulated in subarea 1, would most likely continue in that part of subarea 2 adjacent to and downdip from subarea 1. The lower loading of sodium and bicarbonate on factor II in subarea 2 than is shown on factor II in subarea 1 is probably due to a decrease in carbon dioxide as water moves from an open system (recharge areas) to a closed system (downdip areas). Thus the increase in concentrations of sodium and bicarbonate ions from subarea 1 to subarea 2 is attributed to the increase in resident time as the ground water moves downdip. Whether albite dissolves to kaolinite or smectite is purely conjecture, but the postulation of cation exchange as a major process in this subarea would indicate an increase in the cation exchange capacity of the clay, which in turn would indicate that smectite could be one of the dissolution products.

Most of subarea 2 of the middle Wilcox aquifer outside of Texas receives vertical leakage (eq. 16) from the underlying lower Wilcox aquifer (fig. 45). The water in the lower Wilcox aquifer generally has a larger dissolvedsolids concentration than the water in the middle Wilcox aquifer; thus the upward leakage in subarea 2, although not postulated, would tend to increase the dissolved-solids concentration in the middle Wilcox aquifer. However, simulated vertical leakage downward from the overlying lower Claiborne-upper Wilcox aquifer to subarea 2 of the middle Wilcox aquifer occurs only in a small part of the subarea in southern Texas, northeastern Texas, and northwestern Louisiana (fig. 40). 
Because of the small number of 100-square-mile areas making up subarea 3 of the middle Wilcox aquifer and their location relative to each other (fig. 48), no regional interpretation regarding water chemistry is postulated. However, because the number of chemical analyses was adequate for factor analysis, major processes were postulated for the few 100-square-mile areas making up subarea 3. The major processes are (1) dissolution of halite (factor I), (2) alteration of albite (factor I), and (3) dissolution of gypsum (factor II). The postulated processes of dissolution of halite (factor I) and alteration of albite (factor I) accounts for about 6 percent more of the variability in concentration of chemical constituents than does dissolution of gypsum (factor II). The loading of dissolved solids on factor I is high and significant and on factor II is low and nonsignificant, thus indicating that the dissolution of residual halite and alteration of albite account for most of the variation in concentration of dissolved solids in the 100-square-mile areas assigned to subarea 3 .

Hydrologic, geologic, and related information that supports the three processes postulated above for chemically distinct subarea 3 are discussed briefly in the context of the water chemistry and results of factor analysis of the chemical data. The dissolution of halite (eq. 7) is supported by (1) the significant loading of sodium and chloride on factor I and (2) marine sediments in the middle Wilcox aquifer (Robertson Research (US) inc., 1980) that were most likely impregnated with sodium chloride during their history. Also, there are no upward leakage or salt domes to provide sodium chloride in the 100-square-mile areas that makes up subarea 3. Alteration of albite (eq. 1) and dissolution of gypsum (eq. 6) are supported by the argument given for subarea $I$ and 2 for these processes.

The major process postulated in subarea 4 is dissolution of halite. Five minor processes are postulated for subarea 4 but because of the small number of 100-square-mile areas making up the subarea, the discussion is limited to the listing of them, which follows: (1) chloritization; (2) cation exchange; (3) methane fermentation; (4) dissolution of anhydrite; and (5) iron desorption. The postulated dissolution of halite accounts for two to four times the variability in concentration of chemical constituents accounted for by any of the individual minor processes listed above (table 23), and dissolution of halite accounts for most of the variation in concentration of dissolved solids in subarea 4 .

Hydrologic, geologic, and related information that supports one of the processes postulated above for chemically distinct subarea 4 are discussed briefly in the context of the water chemistry and results of factor analysis of the chemical data. Dissolution of halite (eq. 7) is supported largely by (1) the 28 -fold and 24 -fold increase in sodium and chloride ions respectively from subarea 3 to subarea 4 (table 22), (2) the significant positive loading of sodium and chloride on factor I, and (3) the presence of salt domes that have penetrated the base of the middle Wilcox aquifer (Beckman and Williamson, 1990). The traces of calcium and magnesium minerals in halite are most likely chlorides.

For most aquifers discussed previously, upward leakage (eq. 16) was postulated as the source of sodium and chloride where the concentration of these two ions was less than seawater as it is in subarea 4 of the middle Wilcox aquifer. However, flow upward from the lower Wilcox aquifer was not simulated for most of the areas that make up subarea 4 (fig. 45). Thus the source of sodium and chloride may be water included at the time of deposition in the numerous thin, interbedded clays that characterize the middle Wilcox aquifer.

The major processes postulated in subarea 5 are (1) the dissolution of halite and magnesium-calcium minerals in salt domes and associated caprock (factor I), (2) cation exchange (factor II), and (3) chloritization (factor III). The postulated dissolution of halite and magnesium-calcium minerals (factor l) accounts for three to four times the variability in concentration of chemical constituents than does cation exchange (factor II) and chloritization (factor III), respectively (table 23). The loading of dissolved solids on factor I is very high and significant, and its loading on factors II and III are very low and nonsignificant, thus indicating that the dissolution of halite accounts for most of the variation in concentration of dissolved solids in subarea 5.

Hydrologic, geologic, and related information that supports the three processes postulated above for chemically distinct subarea 5 are discussed briefly in the context of the water chemistry and results of factor analysis of the chemical data. Dissolution of halite and magnesium-calcium minerals (eq. 7) is supported by (1) the approximate 15,000 and $25,000 \mathrm{mg} / \mathrm{L}$ increase in sodium and chloride ion concentrations, respectively, and the approximate 1,400 and $300 \mathrm{mg} / \mathrm{L}$ increase in calcium and magnesium ion concentration, respectively, from subarea 4 to subarea 5 (table 22); (2) the significant positive loading of calcium, magnesium, sodium, and chloride on factor I (table 23); and (3) the presence of salt domes that penetrate the base of the middle Wilcox aquifer in the vicinity of subarea 5 (Beckman 
and Williamson, 1990).

The cation exchange process (eq. 3), in which manganese ions in solution replace potassium ions in the silicate structure of clays, is supported by an increase in potassium ion concentration in the ground water (table 22). However, neither the magnitude of the manganese concentration or the change in its concentration from subarea 4 to subarea 5 supports such a cation exchange reaction. It may be that some other unidentified process is producing the negative relationship of manganese to potassium or that manganese solubility changed with a change in the $\mathrm{pH}$ of the ground water from alkaline in subarea 4 to acidic in subarea 5 .

Chloritization, a weathering process similar to that shown in equation 2, is supported by (1) the significant loading of silica and near significant loading of calcium and $\mathrm{pH}$ on factor III (table 23), and (2) the fact that the process adds calcium, hydrogen, and silica ions to the ground water. The low significant loading of silica on factor III indicates that the process is weak and therefore has little effect on the water chemistry in subarea 5 .

\section{LOWER WILCOX AQUIFER}

The lower Wilcox aquifer underlies the northern three-fourths of the study area east of the Texas-Louisiana border (fig. 50). It has an areal extent of about $100,000 \mathrm{mi}^{2}$ and a mean thickness of $300 \mathrm{ft}$ (Williamson and others, 1990). Median depth of water samples collected for chemical analysis ranges from $1,070 \mathrm{ft}$ in outcrop areas to 4,455 $\mathrm{ft}$ in downdip areas (table 24). Narrow aquifer outcrop areas extend along the northern and eastern sides of the study area from southwestern Arkansas to southwestern Alabama. The downdip limit of the aquifer extends across Louisiana from west-central Louisiana in a southerly direction to Lake Pontchartrain, then northeastward to northern Escambia County, Florida. The geometric mean hydraulic conductivity of the aquifer is about $76 \mathrm{ft} / \mathrm{d}$ (table 3 ).

The simulated horizontal direction of predevelopment flow in the lower Wilcox aquifer is shown in figure 50 (Williamson, in press). Regionally, the horizontal flow east of the Mississippi River is generally from the aquifer outcrop and topographically high areas westward toward and beyond the Mississippi River in Kentucky, Tennessee, and northern Mississippi and southeastward toward the Tombigbee River in central and southeastern Mississippi. Horizontal flow west of the Mississippi River in south-central Louisiana is northward toward a regional discharge area in northeastern Louisiana, whereas in southwestern Arkansas it is southeastward. Vertical leakage to the lower Wilcox aquifer from the overlying middle Wilcox aquifer is downward in central and northern Mississippi, Kentucky, Tennessee, southwestern Arkansas, and northwestern Louisiana (fig. 45). The Midway confining unit underlies the lower Wilcox aquifer, and no leakage was simulated relative to the aquifer base.

\section{DISSOLVED-SOLIDS CONCENTRATIONS}

The areal distribution of the median dissolved-solids concentration per 100-square-mile area in water from the lower Wilcox aquifer is shown in figure 51. There were no water analyses for the central and southern parts of the lower Wilcox aquifer. Consequently, the lines separating delimited areas of dissolved-solids concentrations were based on dissolved-solids concentrations computed from electric-log data (Pettijohn and others, 1988).

The delimited areas of the aquifer having median dissolved-solids concentrations of less then $500 \mathrm{mg} / \mathrm{L}$ extend eastward from southeastern Missouri and northeastern Arkansas across western Kentucky and western Tennessee to the eastern limit of the lower Wilcox aquifer and then southeastward from Tennessee through Mississippi into southwestern Alabama. A large area having dissolved-solids concentrations ranging from 10,000 to $35,000 \mathrm{mg} / \mathrm{L}$ extends from northwestern Louisiana, northward into southwestern Arkansas and adjacent parts of Mississippi; the area is continuous in a southeastward direction across Mississippi as a relatively narrow band into southwestern Alabama. Most of the area underlain by the lower Wilcox aquifer to the south has a dissolved-solids concentration from 35,000 to $70,000 \mathrm{mg} / \mathrm{L}$. Large increases in dissolved-solids concentrations in water of the lower Wilcox aquifer over short distances are common from southwestern Alabama northwestward across Mississippi into east-central Arkansas. This area marks a transition zone from freshwater to the north and east to very saline water to the south and west. The transition zone is the delimited areas of the aquifer having median dissolved-solids concentrations ranging from 500 to $10,000 \mathrm{mg} / \mathrm{L}$. 
TABLE 24.--Median value of selected chemical constituents and properties of water, median sampling depth, water types, and number of analyses for each subarea of the lower Wilcox aquifer [Concentrations are in milligrams per liter, except iron and manganese, which are in micrograms per liter. Depth is in feet, $\mathrm{pH}$ is in units, and
temperature is in degrees Celsius. Chemical symbols: $\mathrm{Ca}$, calcium; $\mathrm{Mg}$, magnesium; $\mathrm{Na}$, sodium; $\mathrm{K}$, potassium; $\mathrm{Fe}$, iron; $\mathrm{Mn}$, manganese; $\mathrm{HCO}$,
bicarbonate; $\mathrm{SO}_{4}$, sulfate; $\mathrm{Cl}$, chloride; $\mathrm{SiO}_{2}$, silica. Water type is the most frequently occurring; ---, no data]

\begin{tabular}{lcr}
\hline \multirow{2}{*}{ Constituent or property } & \multicolumn{2}{c}{ Subarea } \\
\cline { 2 - 3 } & 3.0 & \multicolumn{1}{c}{2} \\
\hline $\mathrm{Ca}$ & 1.0 & 1.270 \\
$\mathrm{Mg}$ & 46 & 480 \\
$\mathrm{Na}$ & 1.8 & 3.480 \\
$\mathrm{~K}$ & 180 & 230 \\
$\mathrm{Fe}$ & & 83.000 \\
& 20 & \\
$\mathrm{Mn}$ & 140 & 950 \\
$\mathrm{HCO}_{3}$ & 3.3 & 172 \\
$\mathrm{SO}_{4}$ & 5.0 & --- \\
$\mathrm{Cl}$ & 13 & 56.000 \\
$\mathrm{SiO}$ & & 66 \\
& 160 & \\
Dissolved solids & 1.070 & 93.000 \\
Sampling depth & 7.8 & 4.455 \\
pH & 22.5 & 6.7 \\
Temperature & & 47.0 \\
& $\mathrm{NaHCO}$ &.-- \\
Primary water type & $\mathrm{CaCl}$ &.-- \\
Secondary water type & 195 & 2 \\
Number of analyses & & \\
\hline
\end{tabular}

\section{PRIMARY WATER TYPES}

The primary water type is sodium bicarbonate in those areas where the median concentration of dissolved solids is less than $3,000 \mathrm{mg} / \mathrm{L}$ (fig. 52). Although there are no water analyses for the area where the median concentration of dissolved solids exceed $3,000 \mathrm{mg} / \mathrm{L}$, the primary water type is most likely sodium chloride. This conclusion is based on water-analyses data for other aquifers in the gulf coast aquifer systems, which show that primary water type generally is sodium chloride where the concentration of dissolved solids exceeds $10,000 \mathrm{mg} / \mathrm{L}$. Concentrations of dissolved solids, computed from electric logs, exceed $10,000 \mathrm{mg} / \mathrm{L}$ for most of the area having no water-type data (fig. $52)$. 


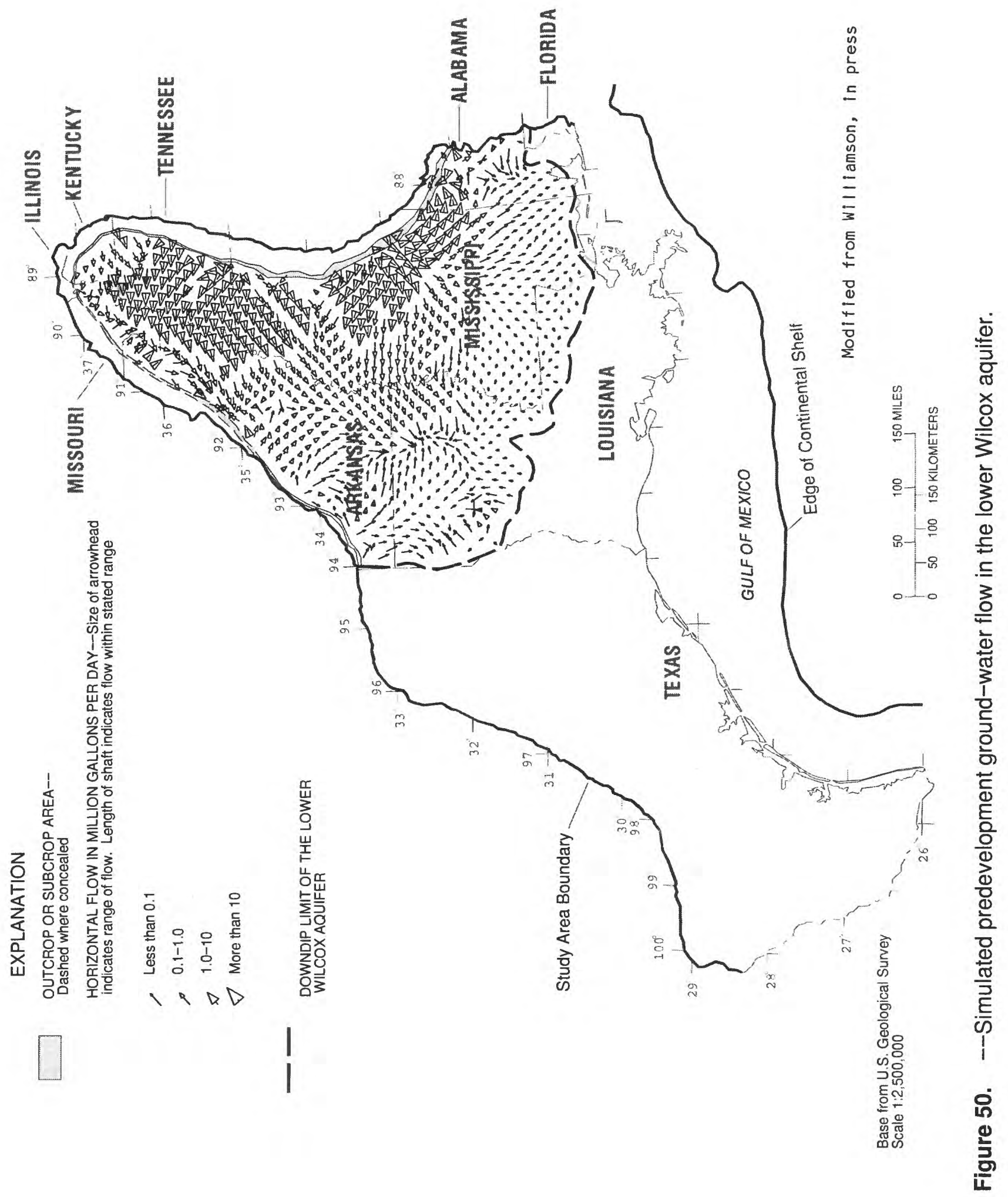




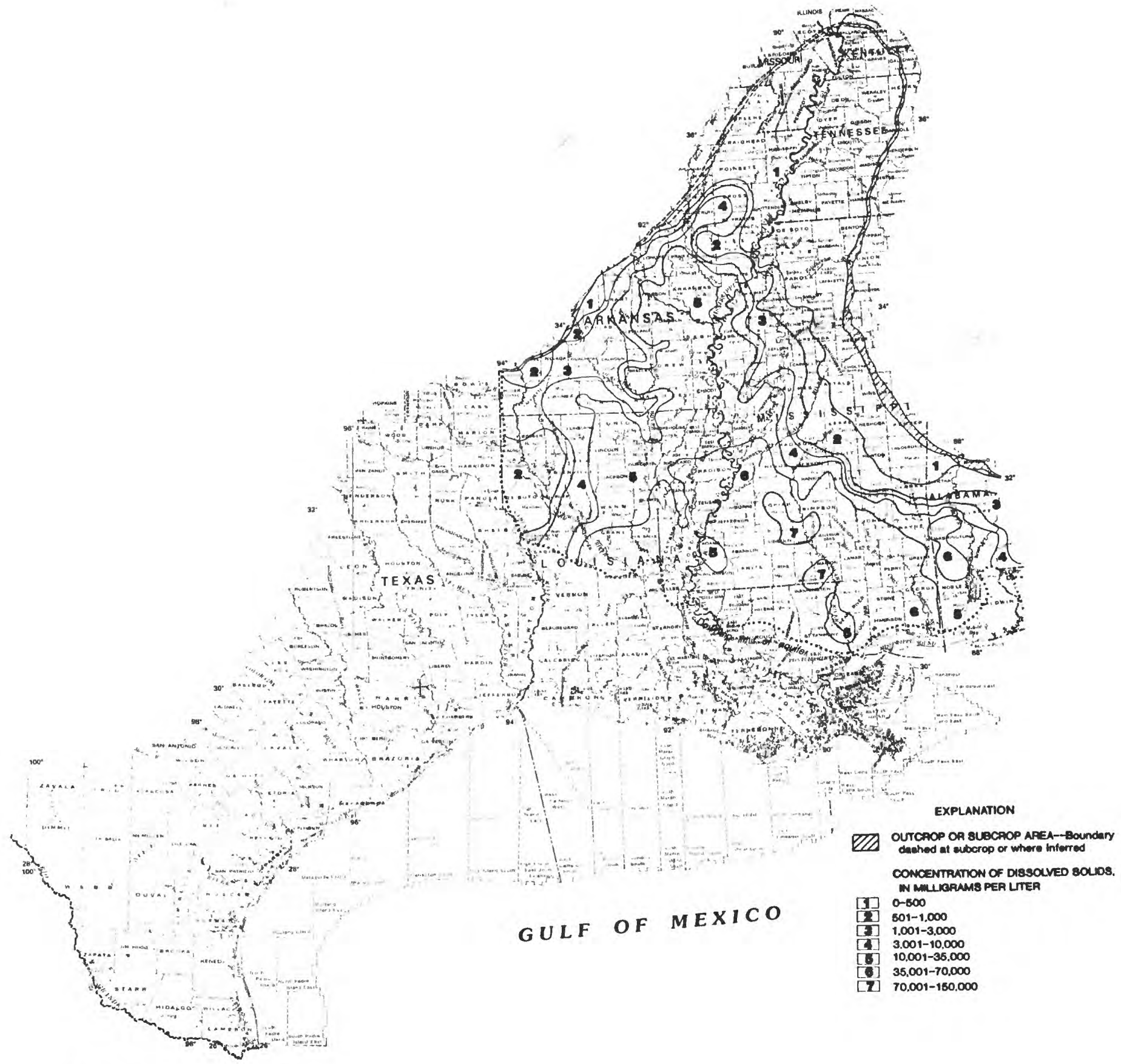

Modified from Pettljohn and others. 1006 


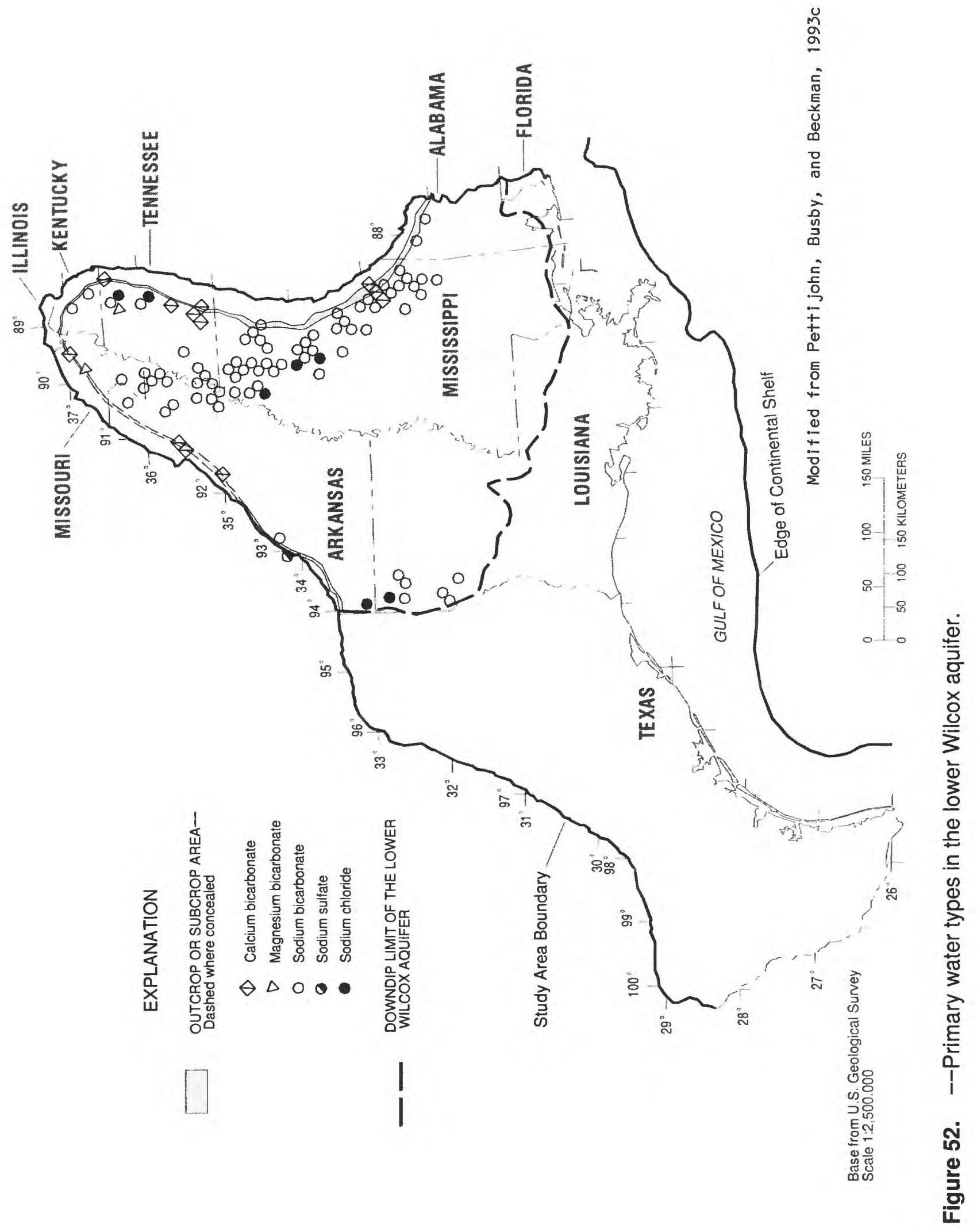




\section{GROUND-WATER CHEMISTRY WITHIN SUBAREAS}

The lower Wilcox aquifer was divided into two chemically distinct subareas and the boundaries adjusted using discriminant function analyses of the chemical data from the subareas (fig. 53). All of the chemical data except for two analysis were from subarea 1 . The two excepted analyses are from two isolated 100-square-mile areas in southern Mississippi that make up subarea 2. Subarea I of the lower Wilcox aquifer consists of 4 nearly contiguous areas and 18 isolated 100-square-mile areas. The four nearly contiguous areas of subarea 1 are in (1) southwestern Arkansas and adjacent northwestern Louisiana, (2) northeastern Arkansas and southeastern Missouri, (3) western Tennessee, and (4) eastern Mississippi from the Mississippi-Alabama boundary north- westward to the northwestern corner of Mississippi and adjacent small parts of Arkansas and Tennessee. Most of the isolated 100-square-mile areas of subarea 1 are in Arkansas, and most of the aquifer outcrop in subarea 1 is in Tennessee and Mississippi. The median concentration of all major ions in subarea 1 of the lower Wilcox aquifer is similar to concentrations in subarea 1 of most other aquifers (tables 16, 18, 20,22) in the study area. Comparisons and contrasts of median concentrations in subarea 1 with two analyses assigned to subarea 2 are not meaningful and therefore are not included in the following discussion.

The trilinear diagram (fig. 54), based on three representative samples from subarea 1 and two samples from subarea 2, in conjunction with figure 52 shows that water in subarea 1 of the lower Wilcox aquifer is 8 percent magnesium plus calcium ( 92 percent sodium plus potassium) and 95 percent bicarbonate plus carbonate ( 5 percent chloride plus sulfate). The predominant cation pair in subarea 1 is sodium plus potassium, whereas the predominant anion pair is bicarbonate plus carbonate. The primary water type in subarea 1 of the lower Wilcox aquifer, as indicated by the diamond-shaped upper part of the trilinear diagram, is sodium bicarbonate. Also, the most frequently occurring water type in subarea 1 is sodium bicarbonate (table 24).

\section{CORRELATION AMONG CHEMICAL CONSTITUENTS AND PROPERTIES OF GROUND WATER WITHIN SUBAREAS}

At least two major chemical processes or mechanisms are responsible for most of the variability in the concentration of chemical constituents in the lower Wilcox aquifer. This conclusion is indicated by the extraction of two factors in factor analysis in subarea 1 (table 25). The number of chemical analyses included in the factor analysis of subarea 1 were 195, and subarea 2 were 2 (table 24). Two analyses are insufficient for factor analysis; however, the data from subarea 2 was retained separate from subarea 1 data in tables 24 and 25 . The variability in subarea 1 accounted for by the two factors is 74.8 (table 25). The loading of each constituent or property on each factor and the percent of total variability (communality) accounted for in factor analysis is shown in table 25 .

Factor I of subarea 1 represents a process in which sodium, bicarbonate, and chloride ions are added to the ground water with a concurrent increase in $\mathrm{pH}$. Factor II of this subarea represents a process in which calcium and magnesium ions are added to the ground water, and to a lesser extent, ions of potassium, iron, and sulfate. The negative loading of sampling depth on factor II indicates that the quantity of ions added to the ground water decreases with depth. The variability in concentration of chemical constituents and properties of water accounted for by factor $I$ is about 46 percent and by factor II is about 29 percent. The variability in concentration of dissolved solids accounted for by factor $\mathrm{I}$ is 98 percent and significant, whereas for factor II it is 14 percent and nonsignificant. 


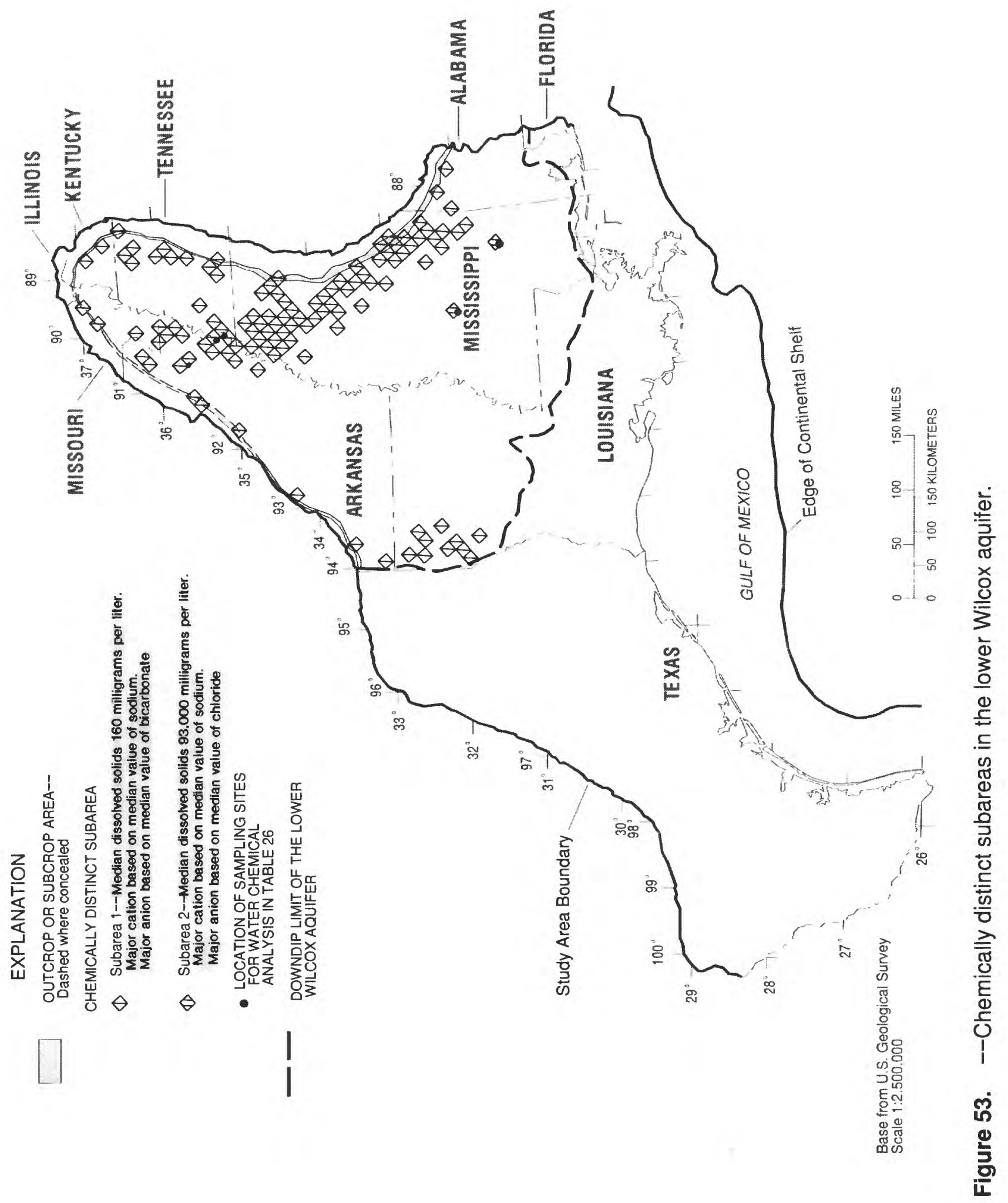




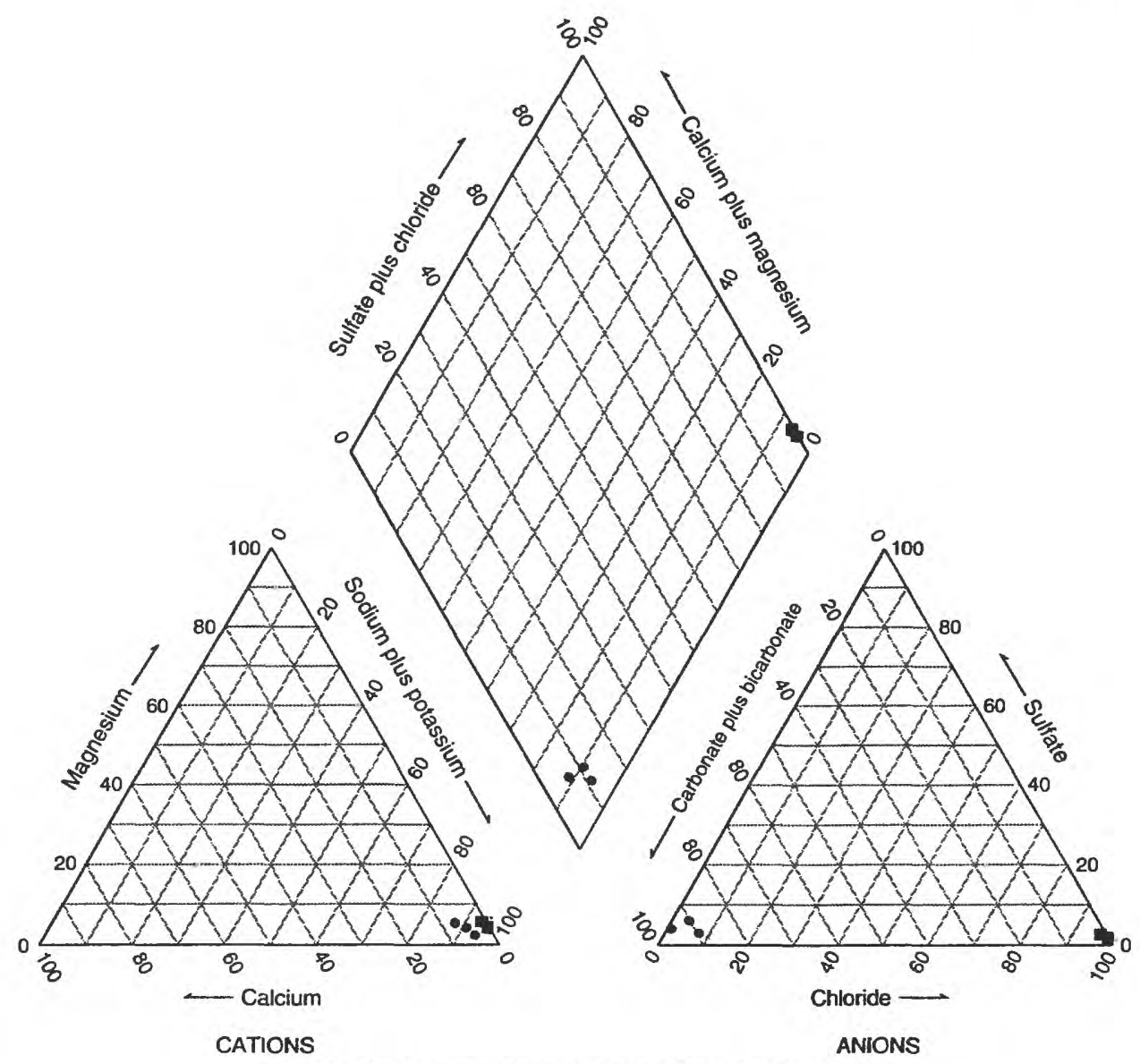

PERCENTAGE REACTING VALUES

Figure 54.--Change in water chemistry from subarea to subarea in the lower Wilcox aquifer, based on three representative samples.

\section{RELATION OF GROUND-WATER CHEMISTRY TO CHEMICAL AND PHYSICAL PROCESSES}

The major chemical processes and mechanisms postulated for chemically distinct subarea $I$ of the lower Wilcox aquifer are based on the results of factor analysis in conjunction with constituent concentrations, a trilinear diagram, ground-water movement, and information on water-rock interaction and probable minerals in the deposits. The major processes postulated in chemically distinct subarea 1 of the lower Wilcox aquifer are (1) alteration of albite (factor I), and (2) leaching of soluble salts from the soil zone (factor II). The postulated alteration of albite (factor I) accounts for about 17 percent more of the variability in concentration of chemical constituents than does the leaching of soluble salts from the unsaturated zone (factor II). The loading of dissolved solids on factor I is very high and significant, and on factor II it is low and nonsignificant, thus indicating that the alteration of albite accounts for most of the variation in concentration of dissolved solids in subarea 1 of the lower Wilcox aquifer. 
TABLE 25.--Factor loading and percent communalities for water chemistry in subarea 1 of the lower Wilcox

aquifer

[Bold type indicates significant factor value]

\begin{tabular}{lrcr}
\hline \multirow{2}{*}{$\begin{array}{c}\text { Constituent or } \\
\text { property }\end{array}$} & $\begin{array}{c}\text { Factor } \\
\text { II }\end{array}$ & $\begin{array}{c}\text { Factor } \\
\text { II }\end{array}$ & $\begin{array}{c}\text { Percent } \\
\text { commun- } \\
\text { ality }\end{array}$ \\
\cline { 2 - 4 } Dissolved solids & $\mathbf{0 . 9 8}$ & 0.14 & 99.9 \\
Calcium & -.08 & .91 & 83.4 \\
Magnesium & -.09 & .92 & 85.4 \\
Potassium & -.08 & .47 & 22.7 \\
& & & \\
Sodium & .96 & -.19 & 95.8 \\
Chloride & .73 & -.01 & 53.3 \\
Sulfate & .08 & .47 & 22.7 \\
Bicarbonate & .89 & .03 & 79.3 \\
Iron & -.03 & .43 & 18.5 \\
& & & \\
Manganese &. .11 & .21 & 5.6 \\
Silica & .07 & .31 & 10.1 \\
pH & .69 & -.20 & 51.6 \\
Sampling depth. & .34 & -.45 & 31.8 \\
Percent variability & & & \\
accounted for by & & & \\
the respective & & & \\
number of factors & $45.9+28.9=74.8$ \\
\hline
\end{tabular}

Hydrologic, geologic, and related information that supports the two processes postulated above for chemically distinct subarea 1 are discussed briefly in the context of the water chemistry and results of factor analysis of the chemical data. The alteration of albite (eq. 1) is supported by (1) the presence of feldspar as fine particles or rock fragments in sedimentary deposits of the coastal plain provinces (Plummer, 1932), (2) aquifer outcrop areas through which carbon dioxide enters the ground water (fig. 53), (3) significant positive loading of sodium and bicarbonate on factor I, and (4) the much larger concentration of sodium compared to chloride. Carbon dioxide from both the atmosphere and the soil acidifies precipitation (eq. 5) prior to recharge of the aquifer through the outcrop areas. The acidified ground water reacts with albite and produces kaolinite and sodium and bicarbonate ions. It is postulated that with the dissolution of albite, cementing materials holding mineral fragments together would also be dissolved by the acidified water, thus releasing residual sodium chloride. This process would explain the loading of chloride on factor I and the low concentration of this ion in the ground water of subarea 1 (table 24).

The leaching of soluble salts from the soil zone by water from precipitation (eq. 15) is supported by (1) the large amount of outcrop in this subarea, and (2) the small concentrations observed of ions of calcium, magnesium, potassium, and sulfate (table 24). Also, the decrease in the effect of leaching with depth occurs because as water moves downward in the aquifer it moves further from the area of leaching and the source of soluble salts. Vertical leakage downward from the overlying middle Wilcox aquifer was simulated to most of subarea 1 of the lower Wilcox aquifer (fig. 45). Vertical leakage does not appear to have a major effect on the ground-water chemistry in subarea 1. 


\section{SUMMARY AND CONCLUSIONS}

The ground-water chemistry of the six aquifers and five permeable zones composing the gulf coast aquifer systems, a 290,000- $\mathrm{mi}^{2}$ area in south-central United States, was studied using chemical data from both the fresh and saltwater part of these units. These aquifer systems are composed of sediments of both marine and nonmarine origin that were deposited during Tertiary and Quaternary time, creating vast layers of sand and clay. These sand and clay layers are composed of an assemblage of minerals that react with moving ground water to produce considerable variation in the chemistry of the water. Based on the study, the ground-water chemistry is characterized, and the geochemical and hydrologic processes responsible for the observed water composition are postulated for each aquifer and permeable zone.

The chemistry of the ground water in each of the aquifers and permeable zones is characterized by mapping the median concentration of dissolved solids and the primary (the most frequently occurring) water type in each 100square-mile area. Also mapped is the direction of horizontal and vertical ground-water flow. A summary of the results of mapping median dissolved-solids concentration and primary water type are presented in the following paragraphs. The median concentration of dissolved solids generally is less than $500 \mathrm{mg} / \mathrm{L}$ in water from the outcrop and subcrop areas of the aquifers and permeable zones in the gulf coast aquifer systems. Also, areas with water having median concentrations of dissolved solids less than $1,000 \mathrm{mg} / \mathrm{L}$ are in bands parallel to the outcrop and extend downdip for several miles, as in permeable zone E (lower Miocene-upper Oligocene deposits) or for several hundred miles as in the middle Wilcox aquifer. Other areas that have water with median concentrations of dissolved solids less than 1,000 $\mathrm{mg} / \mathrm{L}$ are in the northeastern part of the study area and extend from southern Illinois southward on either side of the Mississippi River to as far as northeastern Louisiana. These areas are present only in the upper Claiborne aquifer, the middle Claiborne aquifer, the lower Claiborne-upper Wilcox aquifer, the middle Wilcox aquifer, and the lower Wilcox aquifer.

There is a pronounced increase in the concentration of dissolved solids, based on the median values of all samples in each 100-square-mile area, in aquifers and permeable zones in an area extending from western Mississippi westward to Louisiana and Arkansas. This area is largely a regional ground-water discharge area. The aquifers and permeable zones showing the most pronounced effect from ground-water discharge are the lower Claiborne-upper Wilcox aquifer, the middle Wilcox aquifer, and the lower Wilcox aquifer. Those aquifers and permeable zones showing some effect are permeable zone D (middle Miocene deposits), the upper Claiborne aquifer, and the middle Claiborne aquifer. The median concentration of dissolved solids in the aquifers and permeable zones increases by $1,000 \mathrm{mg} / \mathrm{L}$ or more over a distance of several miles in the downdip direction in some places, for example in permeable zone $\mathrm{E}$ across central Louisiana. These areas of rapid increases in median concentration are considered transition zones where the ground water changes from fresh to slightly saline or from slightly saline to brine. Downdip from the transition zone to the downdip limit of the aquifers or permeable zones, the concentration of dissolved solids in the ground water increases in a downdip direction to as much as $150,000 \mathrm{mg} / \mathrm{L}$ or more.

The median concentration of dissolved solids in water from permeable zone A (Holocene-upper Pleistocene deposits), which is the uppermost unit, generally is less than $500 \mathrm{mg} / \mathrm{L}$ at the updip limit, and increases to about 3,000 $\mathrm{mg} / \mathrm{L}$ onshore near the coast, and to $70,000 \mathrm{mg} / \mathrm{L}$ on the Texas and Louisiana Continental Shelf. The Mississippi River Valley alluvial aquifer, which is the uppermost aquifer in much of the northern part of the study area, is a freshwater aquifer that has median concentrations of dissolved solids generally in the range of 50 to $500 \mathrm{mg} / \mathrm{L}$ and as much as $3,000 \mathrm{mg} / \mathrm{L}$ in a few isolated areas.

The primary water types observed across the study area are related to the median concentration of dissolved solids, and the median concentration of dissolved solids is in turn related to the major chemical processes active in the area. The following is a summary describing the primary water type in each of the States and the water types as they relate to median dissolved-solids concentrations.

Calcium bicarbonate is the primary water type in most of the aquifers and permeable zones in Arkansas, Missouri, Tennessee, and eastern Texas where the median concentration of dissolved solids generally is less than $500 \mathrm{mg} / \mathrm{L}$. Sodium bicarbonate is the primary water type in most of the aquifers and permeable zones in Louisiana, Mississippi, 
eastern Texas, and southern Arkansas where the median concentration of dissolved solids is more than $500 \mathrm{mg} / \mathrm{L}$ but less than $1,000 \mathrm{mg} / \mathrm{L}$. The primary water type is a mixture of calcium, sodium, and bicarbonate ions in water from most of the aquifers and permeable zones in central and southwest Texas, Alabama, Florida, Kentucky, Tennessee, and parts of eastern Texas where the median concentration of dissolved solids is more than $1,000 \mathrm{mg} / \mathrm{L} \mathrm{but} \mathrm{less} \mathrm{than}$ $3,000 \mathrm{mg} / \mathrm{L}$.

Sodium chloride is the primary water type in most of the aquifers and permeable zones in Texas, Louisiana, Mississippi, and Alabama where the median concentration of dissolved solids is greater than $3,000 \mathrm{mg} / \mathrm{L}$. It is also the primary water type in the Continental Shelf area. The primary water type in the outcrop and subcrop areas varies from calcium bicarbonate to sodium bicarbonate and may be a mixture of the two types. Also, some sulfate-type water occurs in Texas in updip areas where the median concentration of dissolved solids is less than $3,000 \mathrm{mg} / \mathrm{L}$.

The major processes active in the aquifers and permeable zones of the gulf coast aquifer systems were determined by first dividing each of the aquifers and permeable zones into chemically distinct subareas. The subareas were tested by linear discriminant function analysis to determine if the subarea contained water of similar chemistry. The chemical and physical data in each subarea were then subjected to factor analysis to determine the degree of correlation between constituents and properties of water. Based on the degree of correlation, the probable geochemical processes and mechanisms that contribute to the observed water chemistry were postulated. The following paragraphs describe the processes postulated as active in each subarea for each of the aquifers or permeable zones.

The major processes postulated in subarea 1 in all units below the alluvial aquifer and permeable zone $\mathrm{A}$ are the alteration of silicates such as albite and plagioclase followed by leaching of soluble salts from the soil and unsaturated zone, whereas in the alluvial aquifer and permeable zone $\mathrm{A}$ the major processes are dissolution of carbonate minerals followed by leaching of the unsaturated zone. Other processes postulated as occurring in this subarea are dissolution of gypsum, cation exchange, and dissolution of residual sodium chloride crystals. Subarea 1 begins at the updip limit of most units and extends downdip and contains most of the outcrop areas.

The major processes postulated in subarea 2 are upward leakage and alteration of silicates such as albite. Other processes postulated as occurring in this subarea are leaching, cation exchange, oxidation of pyrite, and dissolution of gypsum. Subarea 2 is commonly adjacent to and generally downdip of subarea 1 , above middip, and contains some outcrop areas especially in southern Texas.

The major processes postulated in subarea 3 are upward leakage coupled with dissolution of halite in permeable zone $\mathrm{A}$ and alteration of albite feldspar in permeable zone B and the upper and middle Claiborne aquifers. Other processes postulated as occurring in this subarea are dissolution of minerals such as celestite, gypsum, and caliche; alteration of secondary minerals, cation exchange, and precipitation of carbonate minerals. Subarea 3 generally is gulfward of subarea 2 and may include some outcrop areas, commonly in southern Texas.

The major processes postulated in subareas 4 and 5 are dissolution of minerals in evaporite sediments of salt domes and caprock and some upward leakage. The predominant mineral in the evaporite sediments is halite. Other minerals present in amounts ranging from small to traces include sylvite, anhydrite, gypsum, and kieserite. Other processes postulated as occurring in subareas 4 and 5 are dissolution of kieserite, iron oxide, and hydrous manganese; cation exchange; sulfate reduction; chloritization; illitization; genesis of clays; and precipitation of secondary and carbonate minerals. Outcrop areas are not present in subareas 4 and 5 except in permeable zone A, which crops out or subcrops throughout its onshore areal extent.

It is concluded that areas where the median concentration of dissolved solids in ground water is less than 1,000 $\mathrm{mg} / \mathrm{L}$ are in the northeastern part of the study area and along or near the outcrop areas and may extend downdip as far as the midpoint of the respective aquifer or permeable zone. The primary water types in these areas range from calcium bicarbonate below $500 \mathrm{mg} / \mathrm{L}$ to sodium bicarbonate above $500 \mathrm{mg} / \mathrm{L}$ median dissolved-solids concentrations. The major chemical and physical processes controlling the water chemistry in these outcrop and updip areas are leaching of soluble salts from the unsaturated zone and alteration of silicates. In areas where the median concentration of dissolved solids ranges from $1,000 \mathrm{mg} / \mathrm{L}$ to $3,000 \mathrm{mg} / \mathrm{L}$, the primary water types are either sodium bicarbonate or a mixture of sodium bicarbonate and calcium bicarbonate. The major chemical and physical processes in these middip 
areas are upward leakage from underlying deposits or dissolution of residual evaporite crystals and alteration of silicates.

In areas where the median concentration of dissolved solids ranges from $3,000 \mathrm{mg} / \mathrm{L}$ to $10,000 \mathrm{mg} / \mathrm{L}$, the primary water types are either sodium bicarbonate, sodium chloride, or a mixture of the two. The major chemical and physical processes in these middip to downdip areas are upward leakage, dissolution of evaporites, and alteration of silicates. In areas where the concentration of dissolved solids exceeds $10,000 \mathrm{mg} / \mathrm{L}$, which are downdip areas, the primary water type is sodium chloride. The major processes in downdip areas are dissolution of evaporites in salt domes and caprock and upward leakage. Consequently, the ground water changes from a fresh sodium-calcium-bicarbonate type along the outcrop and updip areas to a slightly saline sodium-bicarbonate- chloride type at near middip to a brine sodiumchloride type in downdip areas. Other important processes that occur in the gulf coast aquifer systems and have a minor effect on the water chemistry are exchange reactions, oxidation-reduction reactions, precipitation of minerals, and alteration of secondary minerals.

\section{SELECTED REFERENCES}

Ackerman, D.J., 1996, Hydrology of the Mississippi River Valley alluvial aquifer, south-central United States: U.S. Geological Survey Professional Paper 1416-D, 56 p.

Back, William, 1961, Techniques for mapping hydrochemical facies, in Short papers in the geologic and hydrologic sciences: U.S. Geological Survey Professional Paper 424-D, p. D380-D382.

Baker, E.T., Jr., and Wall, J.R., 1976, Summary appraisals of the Nation's ground-water resources, TexasGulf Region: U.S. Geological Survey Professional Paper 813-F, 29 p.

Beckman, J.D., and Williamson, A.K., 1990, Salt-dome locations in the Gulf Coastal Plain, south-central United States: U.S. Geological Survey Water-Resources Investigations Report 90-4060, 44 p.

Bedinger, M.S., and Sniegocki, R.T., 1976, Summary appraisals of the Nation's ground-water resources, Arkansas-White-Red Region: U.S. Geological Survey Professional Paper 813-H, 31 p.

Bennett, G.D., 1979, Regional ground-water systems analysis: U.S. Army Corps of Engineers, Water Support Center, Fort Belvoir, Virginia, Water Spectrum, v. 11, no. 4, p. 36-42.

Boswell, E.H., 1976, The lower Wilcox aquifer in Mississippi: U.S. Geological Survey Water-Resources Investigations Report 75-60, 3 sheets.

Boswell, E.H., Cushing, E.M., and Hosman, R.L., 1968, Quaternary aquifers in the Mississippi embayment, with a discussion of Quality of the water, by H.G. Jeffery: U.S. Geological Survey Professional Paper 448-E, $15 \mathrm{p}$.

Boswell, E.H., Moore, G.K., and MacCary, L.M., and others, 1965, Cretaceous aquifers in the Mississippi embayment, with a discussion of Quality of the water, by H.G. Jeffery: U.S. Geological Survey Professional Paper 448-C, $37 \mathrm{p}$.

Cederstrom, D.J., Boswell, E.H., and Tarver, G.R., 1979, Summary appraisals of the Nation's ground-water resources, South Atlantic-Gulf Region: U.S. Geological Survey Professional Paper 813-O, 35 p.

Cushing, E.M., Boswell, E.H., Speer, P.R., and Hosman, R.L., and others, 1970, Availability of water in the Mississippi embayment: U.S. Geological Survey Professional Paper 448-A, 13 p.

Dalton, M.G., and Upchurch, S.B., 1978, Interpretation of hydrochemical facies by factor analysis: Ground Water, v. 16 , no. 4 , p. $228-233$.

Davis, J.C., 1986, Statistics and data analysis in geology (2d ed.): New York, John Wiley, 646 p.

Dickinson, George, 1953, Geological aspects of abnormal reservoir pressures in Gulf Coast Louisiana: American Association of Petroleum Geologists Bulletin, v. 37, no. 2, p. 410-432.

Drever, J.I., 1982, The geochemistry of natural waters: Englewood Cliffs, New Jersey, Prentice-Hall, Inc., $388 \mathrm{p}$.

Fenneman, N.M., 1938, Physiography of eastern United States: New York, McGraw-Hill, 714 p.

Fertl, W.H., 1976, Abnormal formation pressures--Implications to exploration, drilling, and production of oil and gas resources: Amsterdam, The Netherlands, Elsevier Scientific Publishing Company, 382 p.

Foster, M.D., 1949, Chemistry of ground water, in Meinzer, O.E., ed., Hydrology: New York, Dover Publications, Inc., 712 p.

Freeze, R.A., and Cherry, J.A., 1979, Groundwater: Englewood Cliffs, New Jersey, Prentice-Hall Inc., 604 p. 
GandI, L.A., 1982, Characterization of aquifers designated as potential drinking water sources in Mississippi: U.S. Geological Survey Open-File Report 81-550, 90 p.

Grim, R.E., 1968, Clay mineralogy (2d ed.): New York, McGraw-Hill, 596 p.

Grubb, H.F., 1984, Planning report for the Gulf Coast Regional Aquifer-System Analysis in the Gulf of Mexico Coastal Plain, United States: U.S. Geological Survey Water-Resources Investigations Report 84-4219, 30 p.

1987, Overview of the Gulf Coast Regional Aquifer-System Analysis, south-central United States, in Vecchioli, John, and Johnson, A.I., eds., Regional aquifer systems of the United States, Aquifers of the Atlantic and Gulf Coastal Plain: American Water Resources Association Monograph Series, no. 9, p. 101-118.

Hair, J.F., Jr., Anderson, R.E., Tatham, R.L., and Grablowsky, B.J., 1979, Multivariate data analysis with readings: Tulsa, Oklahoma, Petroleum Publishing Company, $360 \mathrm{p}$.

Halbouty, M.T., 1979, Salt domes, Gulf Region, United States and Mexico (2d ed.): Houston, Texas, Gulf Publishing Company, $561 \mathrm{p}$.

Hem, J.D., 1985, Study and interpretation of the chemical characteristics of natural waters (3d ed.): U.S. Geological Survey Water-Supply Paper 2254, 263 p.

Hosman, R.L., 1988, Geohydrologic framework of the Gulf Coastal Plain: U.S. Geological Survey Hydrologic Investigations Atlas HA-695, 2 sheets, scale 1:2,500,000.

Hosman, R.L., Long, A.T., Lambert, J.W., and others, 1968, Tertiary aquifers in the Mississippi embayment, with discussion of Quality of water, by H.G. Jeffery: U.S. Geological Survey Professional Paper 448-D, $29 \mathrm{p}$.

Hosman, R.L. and Weiss, J.S., 1991, Geohydrologic units of the Mississippi embayment and Texas coastal uplands aquifer systems, south-central United States: U.S. Geological Survey Professional Paper $1416-\mathrm{B}, 19 \mathrm{p}$.

Hull, L.C., 1984, Geochemistry of ground water in the Sacramento Valley, California: U.S. Geological Survey Professional Paper 1401-B, 36 p.

Jones, P.H., 1969, Hydrodynamics of geopressure in the northern Gulf of Mexico basin: Journal of Petroleum Technology, v. 21, p. 803-810.

Jones, P.H., and Wallace, R.H., Jr., 1974, Hydrogeologic aspects of structural deformation in the northern Gulf of Mexico basin: U.S. Geological Survey Journal of Research, v. 2, no. 5, p. 511-517.

Joreskog, K.G., Klovan, J.E., and Reyment, R.A., 1976, Geological factor analysis: Amsterdam, The Netherlands, Elsevier Scientific Publishing Company, 178 p.

Jorgensen, D.G., 1975, Analog-model studies of ground-water hydrology in the Houston district, Texas: Texas Water Development Board Report 190, 84 p.

Klein, Howard, Baker, R.C., and Billingsley, G.A., 1950, Ground-water resources of Jefferson County, Arkansas: Fayetteville, University of Arkansas Institute of Science and Technology Research Series, no. 19, 44 p.

Krauskopf, K.B., 1979, Introduction to geochemistry (2d ed.): New York, McGraw-Hill, 617 p.

Lyon, L.T., Buckman, H.O., and Brady, N.C., 1953, The nature and properties of soils (5th ed.): New York, MacMillan, $591 \mathrm{p}$.

Mesko, T.O., Williams, T.A., Ackerman, D.J., and Williamson, A.K., 1990, Ground-water pumpage from the gulf coast aquifer systems, 1960-85, south-central United States: U.S. Geological Survey WaterResources Investigations Report 89-4180, $177 \mathrm{p}$.

Meyer, W.R., and Carr, J.E., 1979, A digital model for simulation of ground-water hydrology in the Houston area, Texas: Texas Department of Water Resources Report LP-103, [133] p.

Mississippi River Commission, 1974, Water quality and pollution: U.S. Army Corps of Engineers, Lower Mississippi Region Comprehensive Study, appendix L, 246 p.

Moore, G.K., and Brown, D.L., 1969, Stratigraphy of the Fort Pillow test well, Lauderdale County, Tennessee: Tennessee Department of Conservation, Division of Geology Report of Investigations 26,1 sheet.

Murray, C.R., and Reeves, E.B., 1977, Estimated use of water in the United States in 1975: U.S. Geological Survey Circular 765, $39 \mathrm{p}$.

Novak, S.A., and Eckstein, Yoram, 1988, Hydrochemical characterization of brines and identification of brine contamination in aquifers: Ground Water, v. 26, no. 3, p. 317-324. 
Parker, T.J., and McDowell, A.N., 1955, Model studies of salt-dome tectonics: American Association of Petroleum Geologists Bulletin, v. 39, no. 12, p. 2,384-2,470.

Payne, J.N., 1968, Hydrologic significance of the lithofacies of the Sparta Sand in Arkansas, Louisiana, Mississippi, and Texas: U.S. Geological Survey Professional Paper 569-A, 17 p.

1970, Geohydrologic significance of lithofacies of the Cockfield Formation of Louisiana and Mississippi and the Yegua Formation of Texas: U.S. Geological Survey Professional Paper 569$\mathrm{B}, 14 \mathrm{p}$.

1972, Hydrologic significance of lithofacies of the Cane River Formation or equivalents of Arkansas, Louisiana, Mississippi, and Texas: U.S. Geological Survey Professional Paper 569-C, 17 p.

1975, Geohydrologic significance of lithofacies of the Carrizo Sand of Arkansas, Louisiana, and Texas and the Meridian Sand of Mississippi: U.S. Geological Survey Professional Paper 569-D, 11 p.

Pettijohn, R.A., 1986, Processing water-chemistry data, gulf coast aquifer systems, south-central United States, with summary of dissolved-solids concentrations and water types: U.S. Geological Survey Water-Resources Investigations Report 86-4186, 42 p.

1988, Dissolved-solids concentrations and primary water types, gulf coast aquifer systems, southcentral United States: U.S. Geological Survey Hydrologic Investigations Atlas HA-706, 2 sheets, scale 1:5,000,000.

Pettijohn, R.A., Weiss, J.S., and Williamson, A.K., 1988, Distribution of dissolved-solids concentrations and temperature in ground water of the gulf coast aquifer systems, south-central United States: U.S. Geological Survey Water-Resources Investigations Report 88-4082, 5 sheets, scale 1:3,500,000.

Pettijohn, R.A., Busby, J.F., and Beckman, J.D., 1992, Properties and chemical constituents in ground water from the Mississippi River Valley alluvial aquifer and permeable zone A (Holocene-upper Pleistocene deposits), south-central United States: U.S. Geological Survey Water-Resources Investigations Report 91-4149, 5 sheets, scale 1:3,500,000.

1993a, Properties and chemical constituents in ground water from permeable zone D (middle Miocene deposits), coastal lowlands aquifer system, south-central United States: U.S. Geological Survey Water-Resources Investigations Report 92-4105, 5 sheets, scale 1:3,500,000.

1993b, Properties and chemical constituents in ground water from the middle Wilcox aquifer, gulf coast regional aquifer systems, south-central United States: U.S. Geological Survey Water-Resource Investigations Report 93-4070, 5 sheets, scale 1:3,500,000.

$1993 \mathrm{c}$, Properties and chemical constituents in ground water from the lower Wilcox aquifer, Mississippi embayment aquifer system, south-central United States: U.S. Geological Survey WaterResources Investigations Report 93-4071, 5 sheets, scale 1:3,500,000.

Pettijohn, R.A., Busby, J.F., and Cervantes, M.A., 1993a, Properties and chemical constituents in ground water from permeable zone C (lower Pliocene-upper Miocene deposits), coastal lowlands aquifer system, south-central United States: U.S. Geological Survey Water-Resources Investigations Report 91-4151, 5 sheets, scale 1:3,500,000.

1993b, Properties and chemical constituents in ground water from the middle Claiborne aquifer, gulf coast regional aquifer systems, south-central United States: U.S. Geological Survey WaterResources Investigations Report 92-4104, 5 sheets, scale 1:3,500,000.

$1993 \mathrm{c}$, Properties and chemical constituents in ground water from the lower Claiborne-upper Wilcox aquifer, gulf coast regional aquifer systems, south-central United States: U.S. Geological Survey Water-Resources Investigations Report 92-4102, 5 sheets, scale 1:3,500,000.

Pettijohn, R.A., Busby, J.F., and Layman, T.B., 1993a, Properties and chemical constituents in ground water from permeable zone B (lower Pleistocene-upper Pliocene deposits), coastal lowlands aquifer system, south-central United States: U.S. Geological Survey Water-Resources Investigations Report $91-4152,5$ sheets, scale 1:3,500,000.

1993b, Properties and chemical constituents in ground water from permeable zone E (lower Mioceneupper Oligocene deposits), coastal lowlands aquifer system, south-central United States: U.S. Geological Survey Water-Resources Investigations Report 92-4103, 5 sheets, scale 1:3,500,000.

$1993 \mathrm{c}$, Properties and chemical constituents in ground water from the upper Claiborne aquifer, gulf coast regional aquifer systems, south-central United States: U.S. Geological Survey Water-

Resources Investigations Report 91-4150, 5 sheets, scale 1:3,500,000.

Plummer, F.B., 1932, Cenozoic system in Texas, in The geology of Texas, v. 1, Stratigraphy: Austin, The 
University of Texas Bulletin 3232, p. 519-818. (Reprinted 1981, eighth printing.)

Prudic, D.E., 1991, Estimates of hydraulic conductivity from aquifer-tests analyses and specific-capacity data, gulf coast regional aquifer systems, south-central United States: U.S. Geological Survey Water-Resources Investigations Report 90-4121, 38 p.

P-STAT Inc., 1985, P-STAT users manual, version 8 (2d ed.): Princeton, New Jersey, 891 p.

Robertson Research (U.S.) Inc., 1980, Framework for oil and gas occurrence in the Gulf Coast Tertiary: Houston, Texas, Robertson Research (U.S.) Inc., v. 1, 241 p.

Sampson, R.J., 1978, Surface II graphics system (revised ed.): Lawrence, Kansas, Kansas Geological Survey, $240 \mathrm{p}$.

1988, Surface III graphics system users manual, version 3.0: Lawrence, Kansas, Kansas Geological Survey, $467 \mathrm{p}$.

Sniegocki, R.T., 1964, Hydrogeology of a part of the Grand Prairie region, Arkansas: U.S. Geological Survey Water-Supply Paper 1615-B, $72 \mathrm{p}$.

Solley, W.B., Chase, E.B., and Mann, W.B. IV, 1983, Estimated use of water in the United States in 1980: U.S. Geological Survey Circular 1001, $56 \mathrm{p}$.

Speiran, G.K., 1987, Relation of aqueous geochemistry to sediment depositional environment, Middendorf aquifer, South Carolina, in Vecchioli, John, and Johnson, A.I., eds., Regional aquifer systems of the United States, Aquifers of the Atlantic and Gulf Coastal Plain: American Water Resources Association Monograph Series, no. 9, p. 79-96.

Taylor, R.E., 1975, Chemical analyses of ground water for saline-water resources studies in Texas Coastal Plain stored in National Water Data Storage and Retrieval System: U.S. Geological Survey OpenFile Report 75-79, $669 \mathrm{p}$.

Terry, J.E., Hosman, R.L., and Bryant, C.T., 1979, Summary appraisals of the Nation's ground-water resources--Lower Mississippi Region: U.S. Geological Survey Professional Paper 813-N, 41 p.

Thorne, D.W., and Peterson, H.B., 1954, Irrigated soils--Their fertility and management, (2d ed): New York, The Blakiston Company, Inc., 392 p.

Torak, L.J., and Whiteman, C.D., Jr., 1982, Applications of digital modeling for evaluating the ground-water resources of the "2,000-foot" sand of the Baton Rouge area, Louisiana: Louisiana Department of Transportation and Development, Office of Public Works Water Resources Technical Report 27, 87 p.

U.S. Department of Agriculture, 1951, Soil Survey Manual: Washington, D.C., U.S. Government Printing Office, U.S. Department of Agriculture Handbook 18, 503 p. (Reprinted 1962.)

U.S. Environmental Protection Agency, 1986, Quality criteria for water, 1986: Washington, D.C., Government Printing Office, U.S. Environmental Protection Agency, Office of Water Regulations and Standards, EPA-440/5-86-001, [453] p.

Weiss, J.S., 1987, Determining dissolved-solids concentrations in mineralized ground water of the gulf coast aquifer systems using electric logs, in Vecchioli, John, and Johnson, A.I., eds., Regional aquifer systems of the United States, Aquifers of the Atlantic and Gulf Coastal Plain: American Water Resources Association Monograph Series, no. 9, p. 139-150.

1992, Geohydrologic units of the coastal lowlands aquifer system, south-central United States: U.S. Geological Survey Professional Paper 1416-C, 32 p.

Weiss, J.S., and Williamson, A.K., 1985, Subdivision of thick sedimentary units into layers for simulation of ground-water flow: Ground Water, v. 23, no. 6, p. 767-774.

Wesselman, J.B., 1983, Structure, temperature, pressure, and salinity of Cenozoic aquifers of south Texas: U.S. Geological Survey Hydrologic Investigations Atlas HA-654, 1 sheet.

Whitfield, M.S., Jr., 1975, Geohydrology of the Evangeline and Jasper aquifers of southwestern Louisiana: Louisiana Department of Conservation, Louisiana Geological Survey, and Louisiana Department of Public Works Water Resources Bulletin 20, 72 p.

Williams, T.A., and Williamson, A.K. 1989, Estimating water-table altitudes for regional ground-water flow modeling, U.S. Gulf Coast: Ground Water, v. 27, no. 3, p. 333-340.

Williamson, A.K., in press, Ground-water flow in the gulf coast aquifer systems, south-central United States: U.S. Geological Survey Professional Paper 1416-F.

Williamson, A.K., Grubb, H.F., and Weiss, J.S., 1990, Ground-water flow in the gulf coast aquifer systems, south-central United States--A preliminary analysis: U.S. Geological Survey Water-Resources 
Investigations Report 89-4071, $124 \mathrm{p}$.

Winslow, A.G., and Kister, L.R., 1956, Saline-water resources of Texas: U.S. Geological Survey WaterSupply Paper 1365, 105 p.

Zurawski, Ann, 1978, Summary appraisals of the Nation's ground-water resources--Tennessee Region: U.S. Geological Survey Professional Paper 813-L, 35 p. 


\section{TABLE 26}


Table 26. Analyses of water from each subarea of an aquifer or permeable zone in the gulf caast aquifer systems.

[Concentrations are in milligrams per liter, except iron and manganese, which are in micrograms per liter. Depth is in feet, pH is in units, and termperature is in degrees Celsius. Chemical symbols: $\mathrm{Ca}, \mathrm{Calcium}$; $\mathrm{Mg}$, magnesium; $\mathrm{Na}$, sodium; $\mathrm{K}$, potassium; $\mathrm{Fe}$, iron; $\mathrm{Mn}$, manganese; $\mathrm{HCO}_{3}$, bicarbonete; $\mathrm{SO}_{4}$, sulfate; $\mathrm{Cl}_{4}$ chloride; $\mathrm{SiO}$, silica. Water type is the most frequently occurring. <, less than, - , no data]

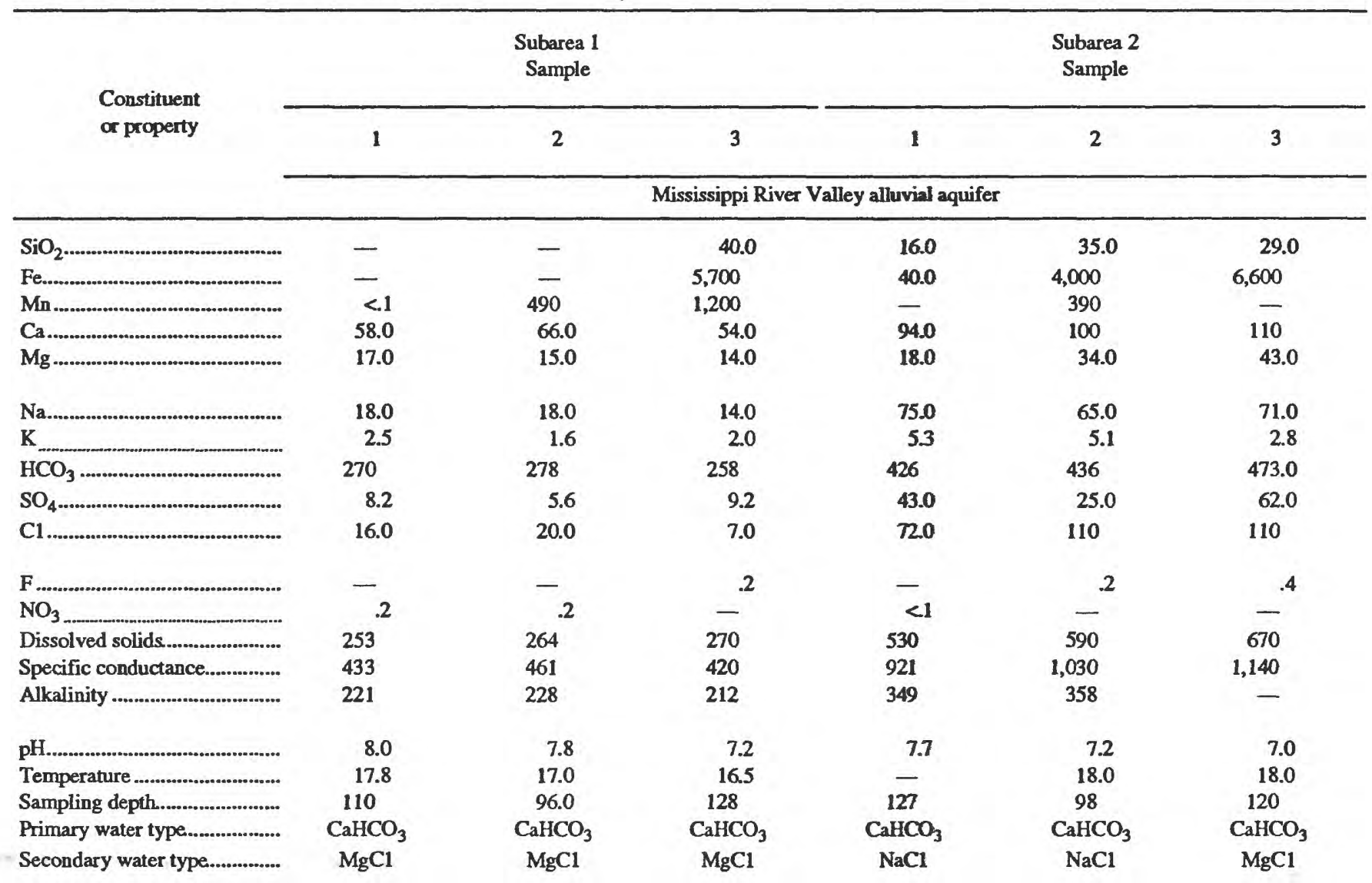




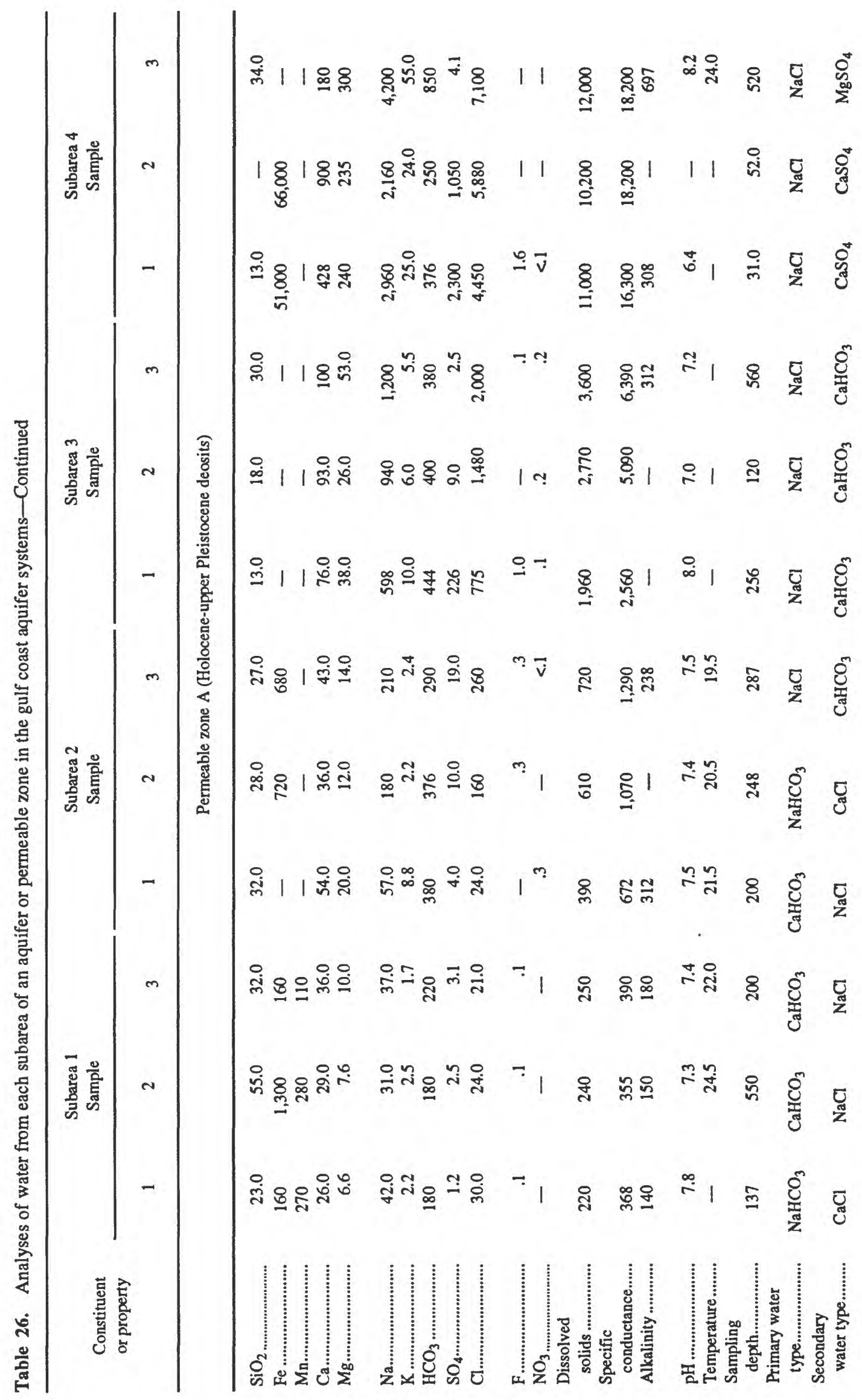




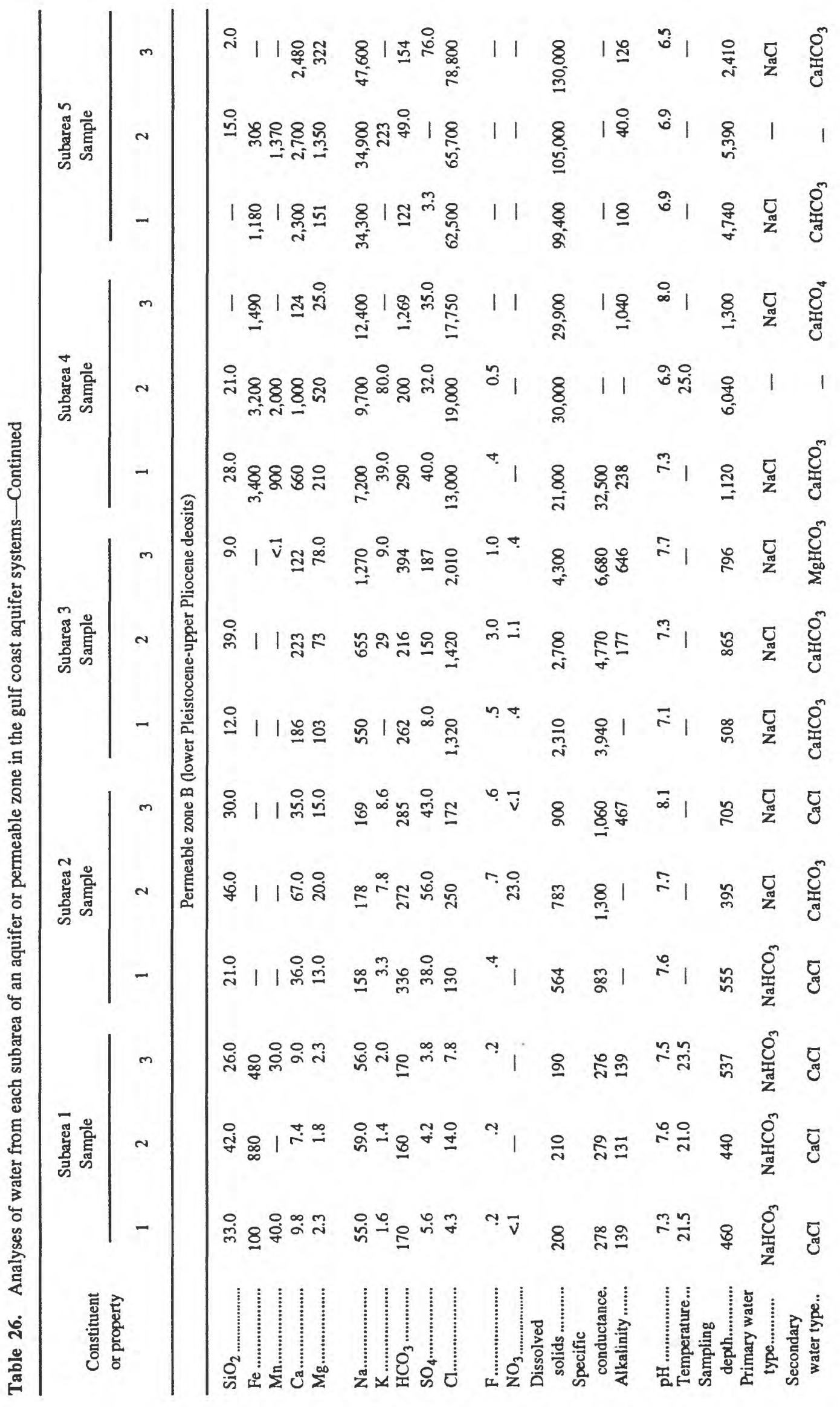




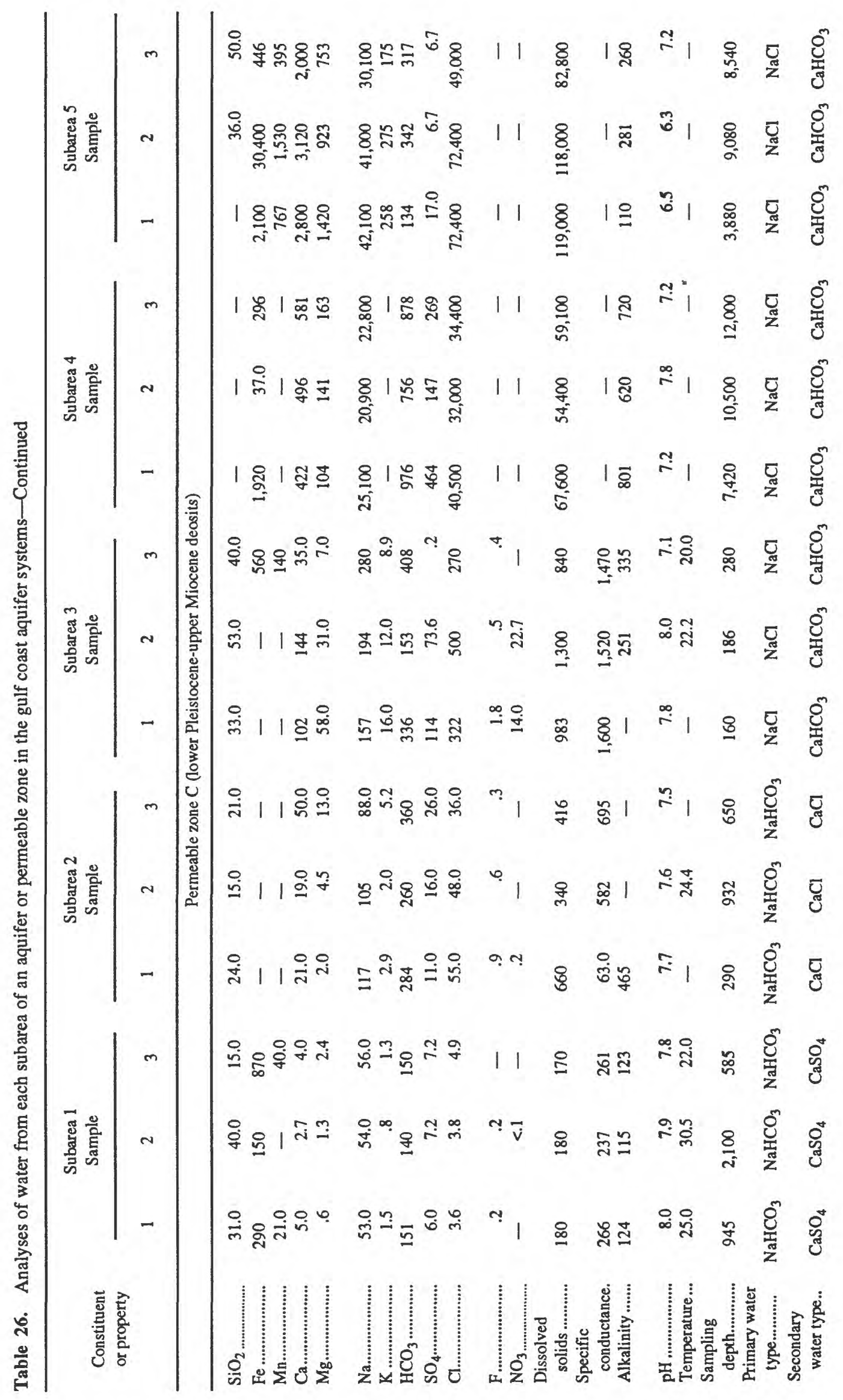




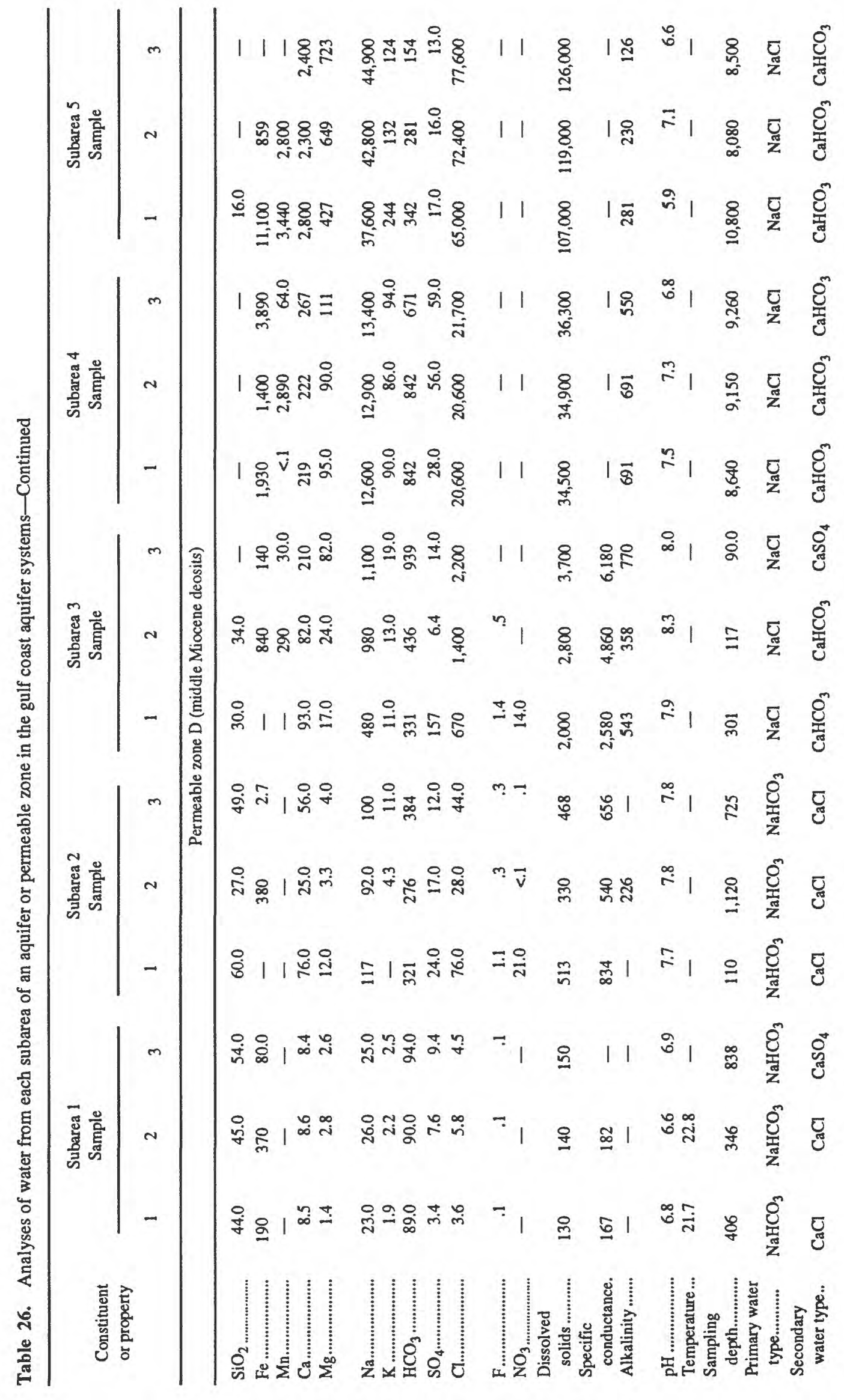




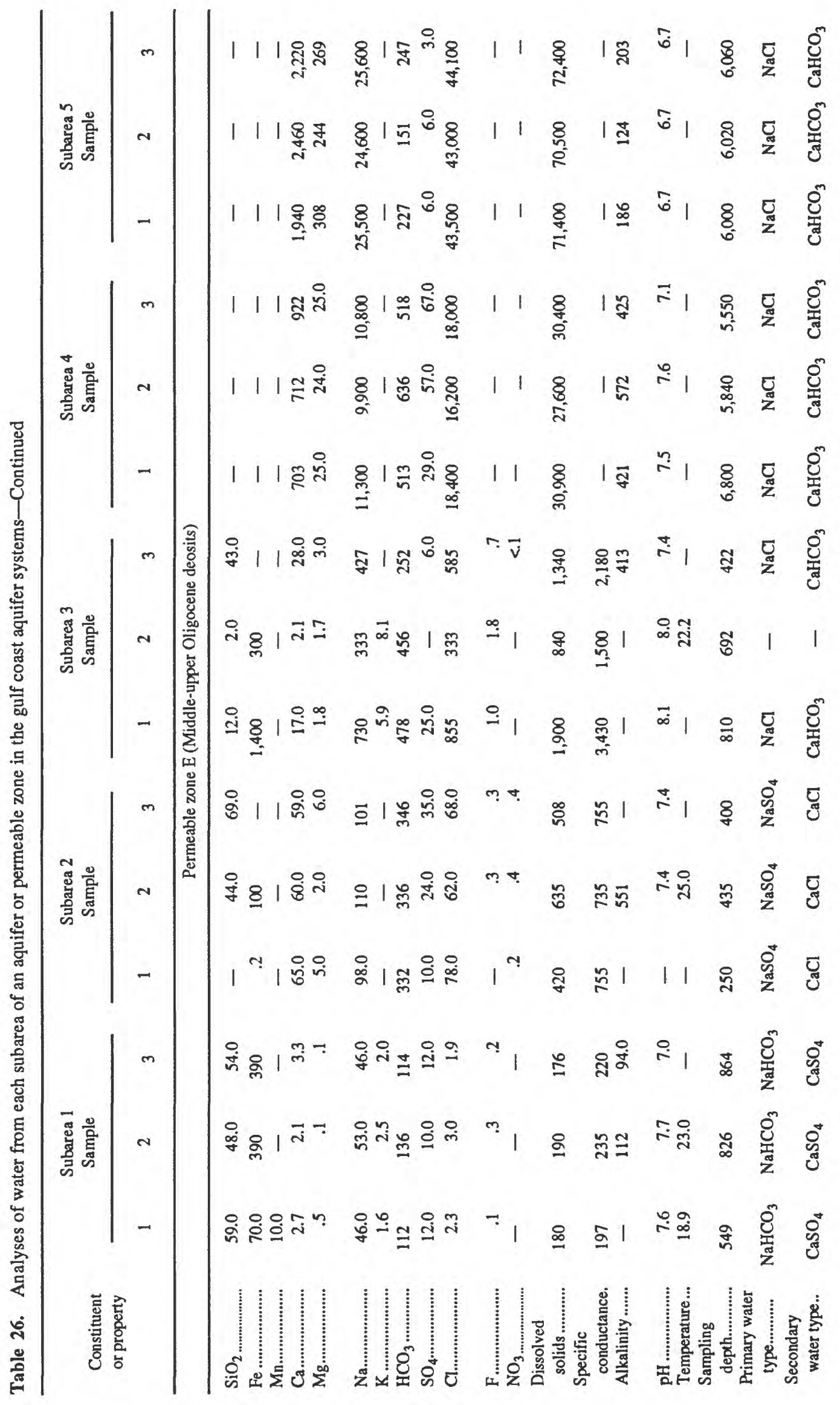




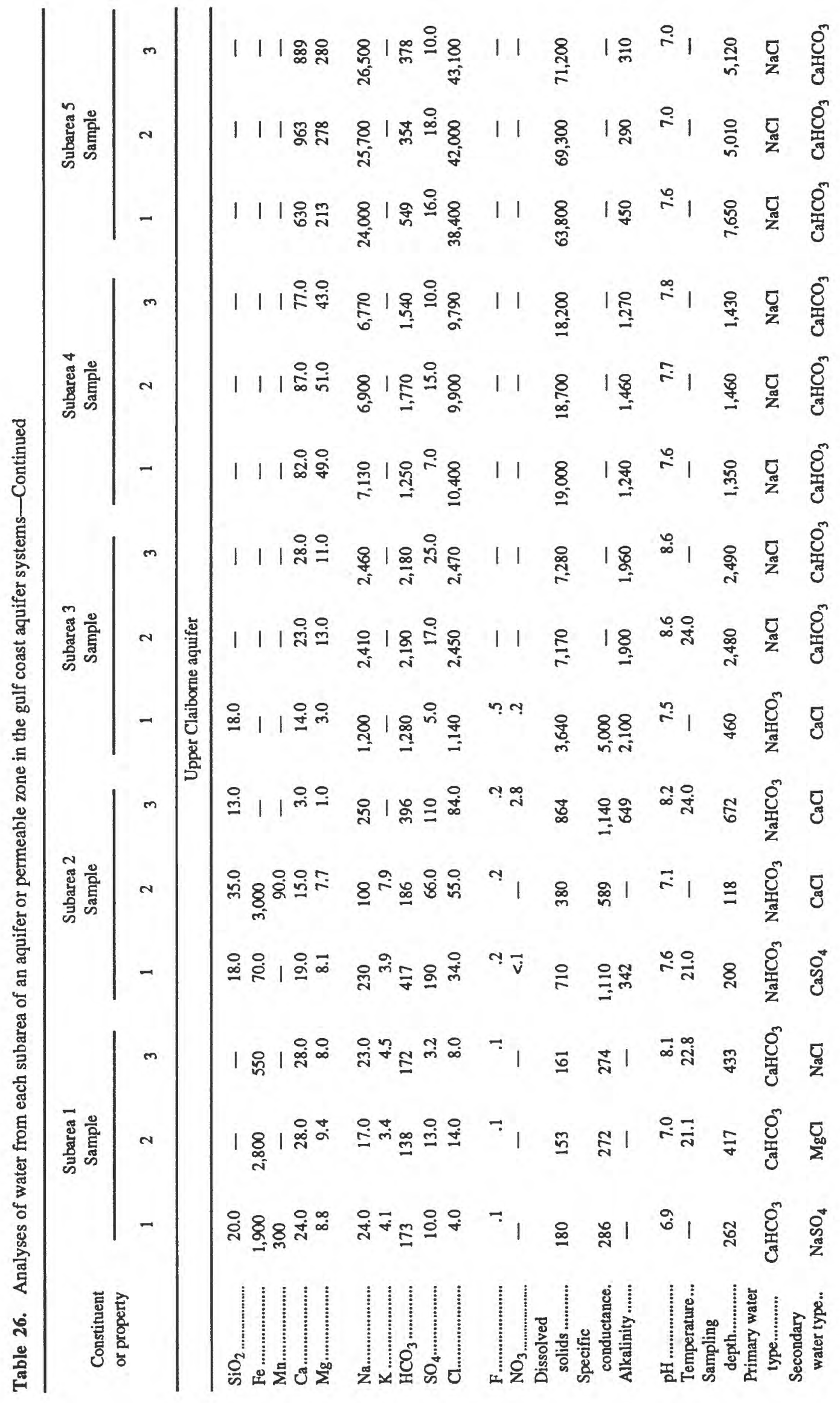




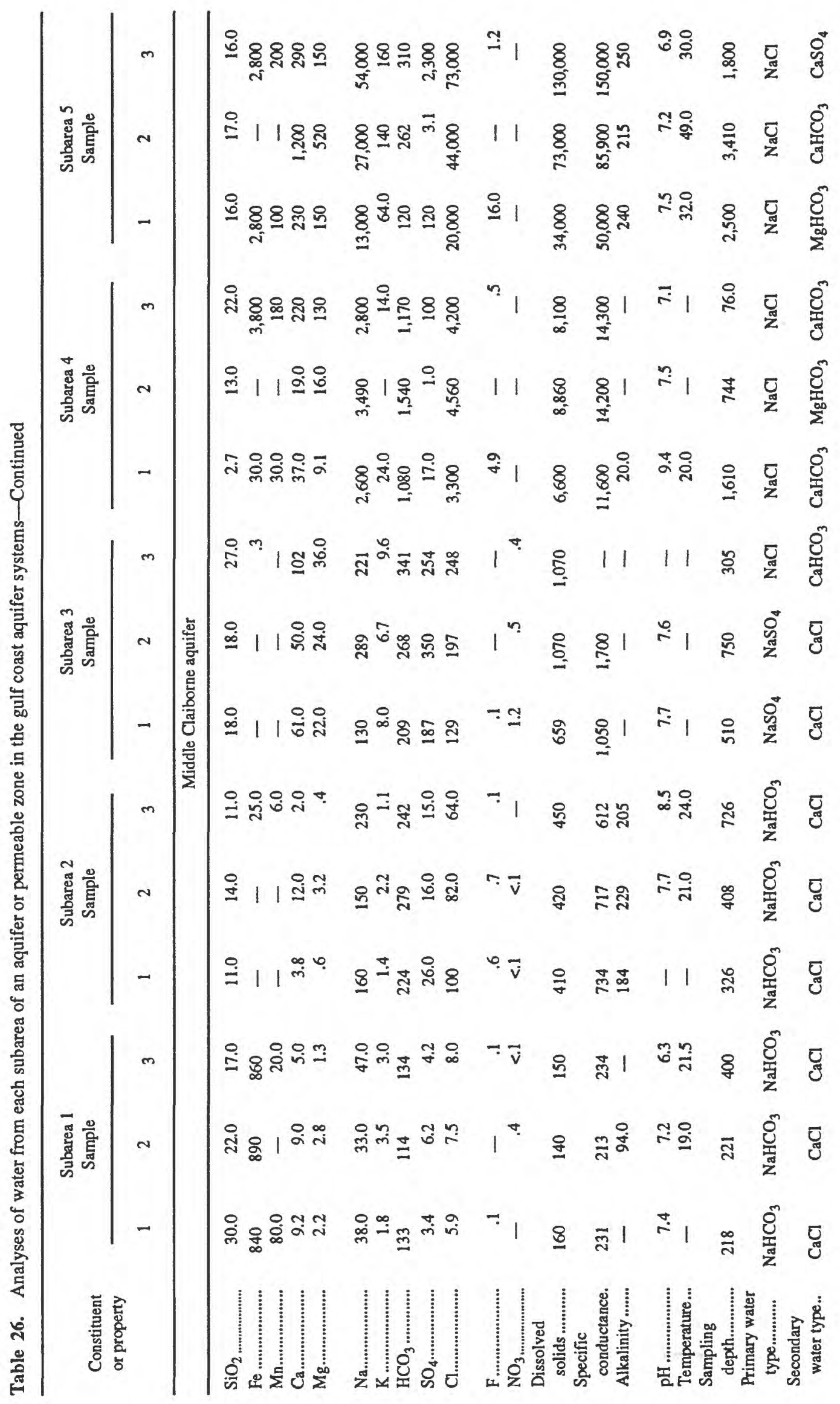




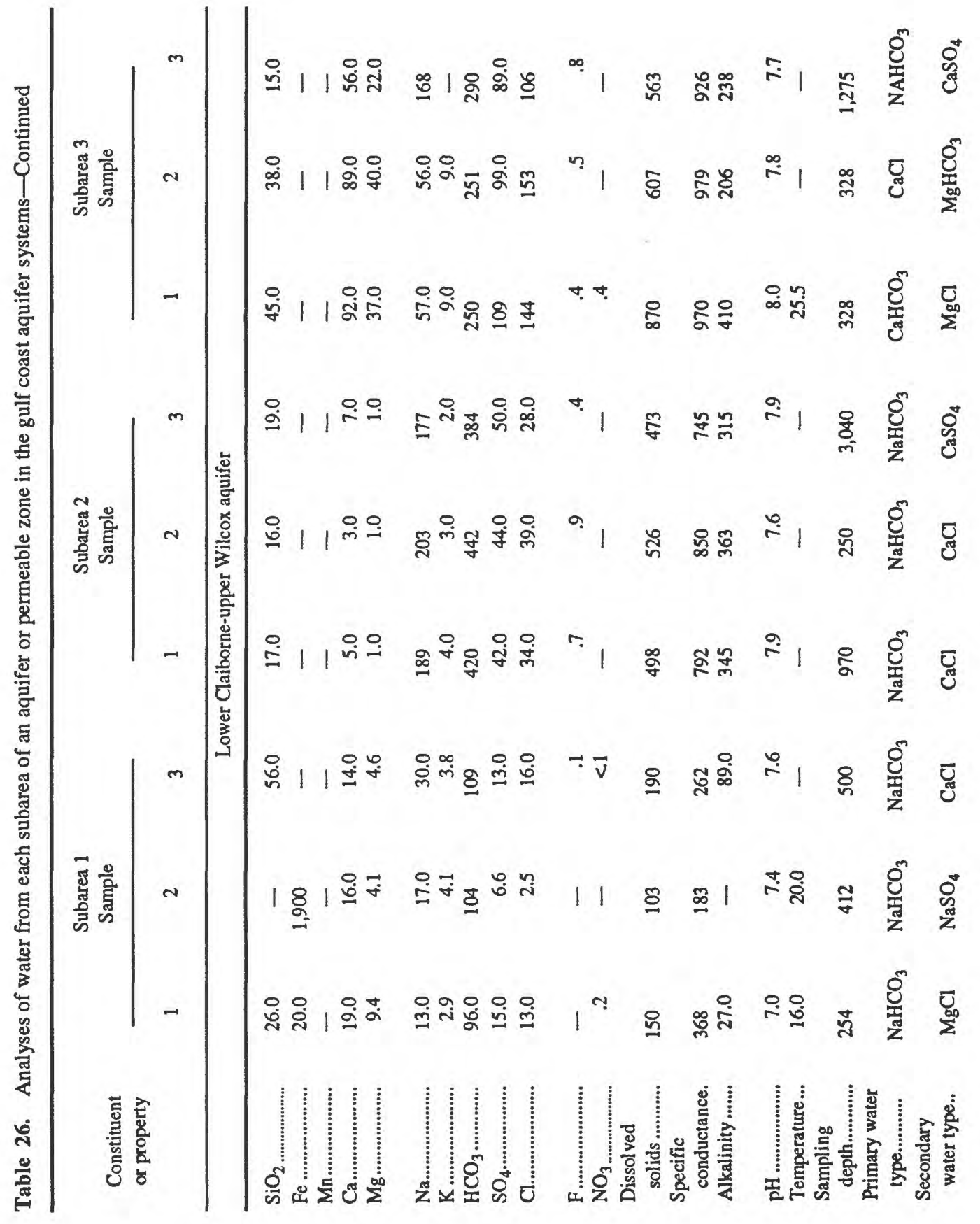




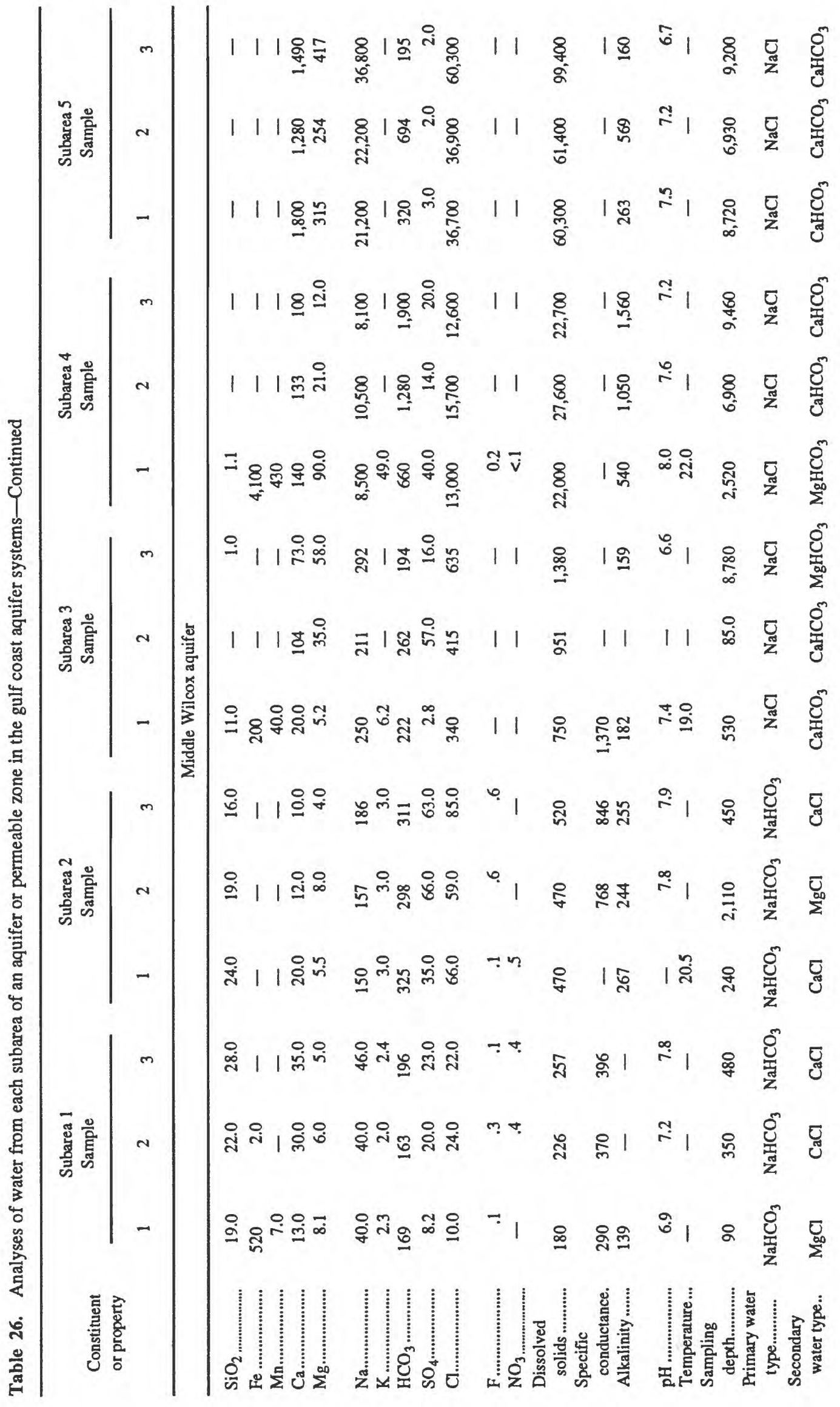


Table 26. Analyses of water from each subarea of an aquifer or permeable zone in the gulf coast aquifer systems-Continued

\begin{tabular}{|c|c|c|c|c|c|}
\hline \multirow{2}{*}{$\begin{array}{l}\text { Constituent } \\
\text { or property }\end{array}$} & \multicolumn{3}{|c|}{$\begin{array}{c}\text { Subarea } 1 \\
\text { Sample }\end{array}$} & \multicolumn{2}{|c|}{$\begin{array}{c}\text { Subarea } 2 \\
\text { Sample }\end{array}$} \\
\hline & 1 & 2 & 3 & 1 & 2 \\
\hline \multicolumn{6}{|c|}{ Lower Wilcox aquifer } \\
\hline $\mathrm{SiO}_{2} \ldots \ldots \ldots \ldots$ & 10.0 & 4.1 & 11.0 & 117 & 15.0 \\
\hline $\mathrm{Fe}$ & 250 & 230 & 110 & 148,000 & 18,000 \\
\hline Mn .................................. & - & - & - & - & 950 \\
\hline Ca & 3.3 & 2.3 & 2.6 & 1,040 & 1,500 \\
\hline 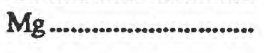 & 1.0 & .4 & .9 & 340 & 620 \\
\hline $\mathrm{Na}$ & 41.0 & 48.0 & 45.0 & 30,600 & 39,000 \\
\hline$K_{1}$ & 2.5 & 2.4 & 1.3 & 360 & 100 \\
\hline $\mathrm{HCO}_{3} \ldots \ldots \ldots \ldots$ & 120 & 127 & 122 & 155 & 190 \\
\hline $\mathrm{SO}_{4} \ldots \ldots$ & 3.3 & 2.8 & 5.5 & - & - \\
\hline $\mathrm{Cl}$ & 1.2 & 6.2 & 3.0 & 49,600 & 63,000 \\
\hline F & - & .1 & - & - & .3 \\
\hline $\mathrm{NO}_{3}$ & .3 & .2 & 1.6 & 一 & - \\
\hline Dissolved solids.......... & 120 & 130 & 140 & 82,000 & 104,000 \\
\hline Specific conductance. & 195 & 214 & 236 & 94,000 & 130,000 \\
\hline 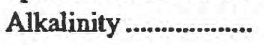 & 98.0 & 104 & 100 & 127 & 160 \\
\hline 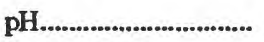 & 7.6 & 7.6 & 7.4 & 6.5 & 6.9 \\
\hline Temperature ................. & 24.5 & 23.0 & 24.5 & - & 47.0 \\
\hline Sampling depth........... & 1,500 & 1,030 & 1,510 & 4,680 & 4,230 \\
\hline Primary water type.... & $\mathrm{NaHCO}_{3}$ & $\mathrm{NaHCO}_{3}$ & $\mathrm{NaHCO}_{3}$ & - & - \\
\hline Secondary water type & $\mathrm{CaSO}_{4}$ & $\mathrm{CaCl}$ & $\mathrm{CaSO}_{4}$ & 一 & 一 \\
\hline
\end{tabular}

